PNL-4048

BHARC $-400 / 81 / 027$

UC-70

\title{
NUCLEAR POWER AND THE PUBLIC: \\ AN UPDATE OF COLLECTED SURVEY RESEARCH ON NUCLEAR POWER
}

William L. Rankin

Barbara D. Melber

Thomas D. Overcast

Stanley M. Nealey

DECEMBER 1981

Prepared for the Waste Management Systems Studies Program of the Pacific Northwest Laboratory of the U.S. Department of Energy under contract DE-AC06-76RLO-1830
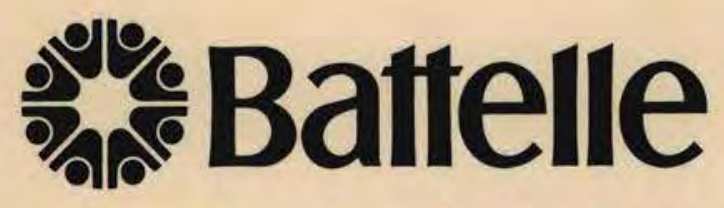

Human Affairs Research Centers

4000 N.E. 41st Street $\bullet$ Seattle, Washington 98105 


\title{
DISCLAIMER
}

This report was prepared as an account of work sponsored by an agency of the United States Government. Neither the United States Government nor any agency thereof, nor any of their employees, makes any warranty, express or implied, or assumes any legal liability or responsibility for the accuracy, completeness, or usefulness of any information, apparatus, product, or process disclosed, or represents that its use would not infringe privately owned rights. Reference herein to any specific commercial product, process, or service by trade name, trademark, manufacturer, or otherwise, does not necessarily constitute or imply its endorsement, recommendation, or favoring by the United States Government or any agency thereof. The views and opinions of authors expressed herein do not necessarily state or reflect those of the United States Government or any agency thereof.

\author{
PACIFIC NORTHWEST LABORATORY \\ operated by \\ BATTELLE \\ for the \\ UNITED STATES DEPARTMENT OF ENERGY \\ under Contract DE-AC06-76RLO 1830
}

\begin{tabular}{|c|c|}
\hline \multirow{2}{*}{\multicolumn{2}{|c|}{ Printed in the United States of America }} \\
\hline & \\
\hline \multicolumn{2}{|c|}{$\begin{array}{l}\text { Available from } \\
\text { National Technical Information Service }\end{array}$} \\
\hline \multicolumn{2}{|c|}{ United States Department of Commerce } \\
\hline \multicolumn{2}{|c|}{5285 Port Royal Road } \\
\hline \multicolumn{2}{|c|}{ Springfield, Virginia 22151} \\
\hline \multirow{2}{*}{\multicolumn{2}{|c|}{$\begin{array}{l}\text { NTIS Price Codes } \\
\text { Microfiche A01 }\end{array}$}} \\
\hline & \\
\hline \multicolumn{2}{|c|}{ Printed Copy } \\
\hline & Price \\
\hline Pages & Codes \\
\hline 001-025 & $\mathrm{A} 02$ \\
\hline $026-050$ & $\mathrm{~A} 03$ \\
\hline $051-075$ & A04 \\
\hline $076-100$ & A05 \\
\hline $101-125$ & A06 \\
\hline $126-150$ & A07 \\
\hline $151-175$ & $A 08$ \\
\hline $176-200$ & A09 \\
\hline $201-225$ & A010 \\
\hline $226-250$ & A011 \\
\hline $251-275$ & A012 \\
\hline $276-300$ & A013 \\
\hline
\end{tabular}


PNL -4048

BHARC $-400 / 81 / 027$

UC-70

NUCLEAR POWER AND THE PUBLIC: AN UPDATE OF COLLECTED SURVEY RESEARCH ON NUCLEAR POWER

Topical Report

William L. Rankin

Barbara D. Melber

Thomas D. Overcast

Stanley M. Nealey

December 1981

Prepared for the Waste Management Systems Studies Program

of the Pacific Northwest Laboratory

of the U.S. Department of Energy

under contract DE-ACO6-76RLO-1830

Battelle Memorial Institute

Human Affairs Research Centers

Social Change Study Center

Seattle, Washington 98105 
LIST OF TABLES • • • • • • • • • • • • • •

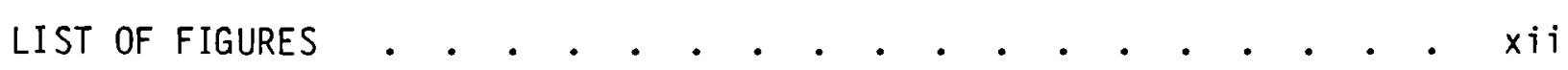

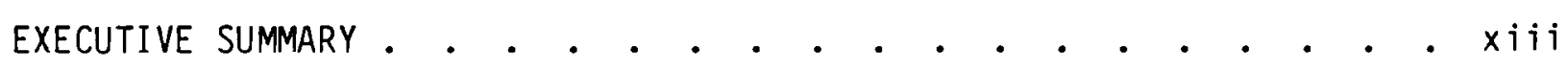

CHAPTER 1 INTRODUCTION

CHAPTER 2 PROCEDURE AND SURVEY VARIABILITY $\quad$ •

2.1 Types of Information Collected by Surveys . . . . 5

2.2 Procedure for Acquiring Survey Data . • • • • • 7

2.3 Description of Surveys . . . . . . . . . 8

2.4 Variation in Surveys . . . . . . . . . . . 10

2.4.1 Populations of Interest and
Sampling Procedures . . . . . . . . . . . . . $\quad$. $\quad 10$

2.4.2 Questionnaire Content . . . . . . . 16

2.4.3 Data Collection Methods . . . . . . 17

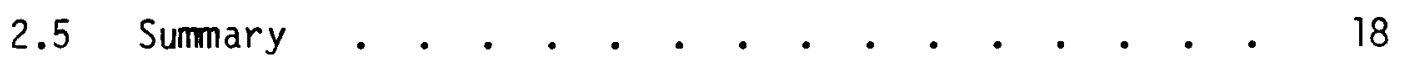

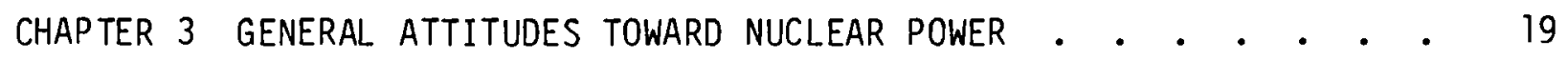

3.1 Introduction . . . . . . . . . . . . . . 19

3.2 General Attitudes Toward Nuclear Power . . . . . 20

3.2.1 Introduction . . . . . . . . . 20

3.2.2 Nuclear Power Plant Construction--General. . 20

3.2.3 Nuclear Power Plant Construction--Local • . 29

3.2.4 Continued Operation of Nuclear
Power Plants . . . . . . . . . . . . . . 35

3.2.5 Strength of Attitudes Toward Nuc lear
Power . . . . . . . . . . . . . . 42

3.3 The Relationship Between Attitudes Toward Nuclear
Power and Nuclear-Related State Initiatives • • 48

3.3.1 Introduction . . . . . . . . . . 48 
3.3.2 Maine . . . . . . . . . . . . 51

3.3.3 Massachusetts . . . . . . . . . 53

3.3.4 Missouri . . . . . . . . . . 57

3.3.5 Oregon . . . . . . . . . . . . . 59

3.3.6 South Dakota . . . . . . . . . 62

3.3.7 Summary . . . . . . . . . . . . 63

3.4 The Relationship Between Attitudes Toward Nuclear
Power and Respondent Demographic Characteristics . . 64

3.4.1 Sex Differences in Attitudes

Toward Nuclear Power . . . . . . . 65

3.4.2 Educational Differences in Attitudes
Toward Nuclear Power . . . . . . . 71

3.4.3 Income Differences in Attitudes
Toward Nuclear Power . . . . . . . 75

3.4.4 Occupational Differences in Attitudes
Toward Nuclear Power . . . . . . 80

3.4.5 Age Differences in Attitudes
Toward Nuclear Power . . . . . . . 82

3.4.6 Regional Variations in Attitudes
Toward Nuclear Power . . . . . . 84

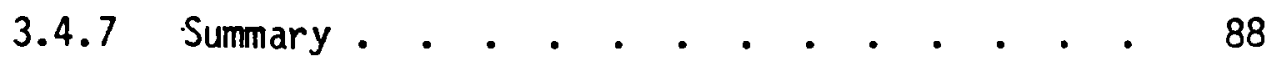

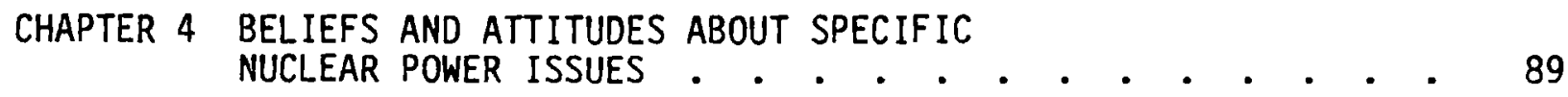

4.1 Introduction . . . . . . . . . . . . . 89

4.2 Volunteered Beliefs about Nuclear Power. . . . . 90

4.2.1 Introduction . . . . . . . . . . 90

4.2.2 Volunteered Reasons for Favoring or Opposing the Construction of More Nuc lear Power Plants . . . . . . . . 91

4.2.3 Volunteered Likely Benefits and Likely Harmful Consequences that Might Come from Building More Nuclear Power Plants . . . . 97 
4.2.4 Volunteered Advantages and Disadvantages of Nuc lear Power Plants . . . . . . . 101

4.2.5 Summary of Volunteered Responses . . . 103

4.3 Structured Assessments of Nuclear Power Issues . . 104

4.3.1 Introduction . . . . . . . . . . . 104

4.3.2 Direct Comparisons of Nuclear Power
Benefits . . . . . . . . . 105

4.3.3 Direct Comparisons of Nuclear Power Problems . . . . . . . . . 107

4.3.4 Direct Comparisons of Nuclear Power Issues . • • . . . . . . . • . . 109

4.3.5 Analys is of the Effects of Nuclear Beliefs on Nuc lear Attitude. . . . . . . . . 119

4.3.6 Surmary . . . . . . . . . . . . . 121

4.4 Reactor Safety . . . . . . . . . . . 122

4.4.1 Introduction . . . . . . . . . . 122

4.4.2 Belief in the Safety Record . . . . . 122

4.4.3 Responsibility for Nuclear Plant Safety . . 129

4.4.4 Summary . . . . . . . . . . . . 131

4.5 Three Mile Island . . . . . . . . . . 132

4.5.1 Introduction . . . . . . . . . . 132

4.5.2 Beliefs and Attitudes about the
Three Mile Island Accident . . . . . 132

4.5.3 Beliefs and Attitudes Toward Nuclear Power in Light of the Kemeny Commission Report . . 140

4.5 .4 Summary . . . . . . . . . . . . 143

4.6 Nuclear Waste Management . . . . . . . . . 144

4.6.1 Introduction . . . . . . . . . . . 144

4.6.2 The Problem of Nuclear Wastes Compared to Other Industrial Risks . . . . . . . 145 
4.6.3 Beliefs about the Ability to Solve

the Waste Disposal Problem

4.6.4 Effect of Waste Management Concerns

on Nuclear Reactor Operation

and Construction . . . . . . . . . 150

4.6.5 Attitudes about What Waste Management

Plan Might Be Acceptable . • . . . . 152

4.6.6 Summary . . . . . . . . . . . • . 159

4.7 The Supply of Uranium . . . . . . . . . . 161

4.7.1 Introduction . . . . . . . . . . 161

4.7.2 Beliefs and Attitudes about the
Supply of Uranium . . . . . . . 162

4.7 .3 Summary . • . . • . . . • . . . . 164

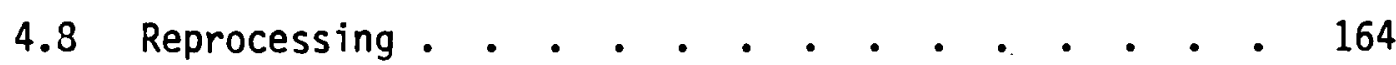

4.8.1 Introduction . . . . . . . . . . 164

4.8.2 Beliefs about Reprocessing . . . . . . 164

4.8.3 Attitudes about Reprocessing . . . . . 165

4.8 .4 Summary . • • • • • • • • • • • . 170

4.9 The Breeder Reactor . . . . . . . . . 170

4.9.1 Introduction . . . . . . . . . 170

4.9.2 Beliefs and Attitudes Regarding
the Breeder Reactor . . . . . . 170

4.9.3 The Future Role of the Breeder Reactor . 175

4.9.4 Summary . • • • • • • . • • • • 176

4.10 Proliferation in the Context of Reactor Sales

Abroad . • • • • • • • • • • • • 176

4.10 .1 Introduction . . . . . . . . . • 176

4.10.2 Concern over Proliferation . • • • • 177

4.11 The Process of Constructing a Nuclear

Power Plant . . . . . . . . . . . . . 184

4.11 .1 Introduction . . . . . . . . . . 184 
4.11.2 Beliefs and Attitudes about Constructing

a Nuclear Power Plant . . . . . . . 184

4.11 .3 Summary . . . . . . . . . . . . . 190

4.12 Summary . . . . . . . . . . . . . . . . 191

CHAPTER 5 NUCLEAR POWER ATTITUDES IN THE CONTEXT OF

PUBLIC PERSPECTIVES ON GENERAL ENERGY

ISSUES AND ENVIRONMENTAL ISSUES . . . . . . . . . . 198

5.1 Introduction . . . . . . . . . . . . . . 198

5.2 Attitudes Toward Alternative Energy Technologies . . 199

5.2.1 Introduction . . . . . . . . . . . 199

5.2.2 Comparison of General Attitudes toward Energy Alternatives . . . . . . . . 199

5.2.3 Public Preferences for Local Power Plants . . . . . . . . . . 208

5.2.4 Summary of Comparative Attitudes toward Energy Alternatives. . . . . . . . 211

5.3 Beliefs about Characteristics of Energy Sources . . 212

5.3.1 Introduction . . . . . . . . . . 212

5.3.2 Environmental Beliefs . . . . . . . 212

5.3.3 Comparative Health and Safety Beliefs . . . 218

5.3.4 Comparative Beliefs about Cost . . . . 221

5.3.5 Beliefs about Energy Source Availability . . 223

5.3.6 Summary of Comparative Beliefs about Energy Technologies . • . . . . . . 226

5.4 The Conservation Alternative . . . . . . . 227

5.4.1 Introduction . . . . . . . . . . . 227

5.4.2 Preferences for Conservation Policy . . . 227

5.4.3 Beliefs about Economic Impacts of Conservation . . . . . . . . . . 230

5.4.4 Reported Conservation Behavior . . . . 231

5.4.5 Summary of Conservation Belief Findings . . 233 
5.5 Supply Versus Demand Energy Orientations . • . . 234

5.5.1 Introduction . . . . . . . . . . . 234

5.5.2 Public Attitudes and Beliefs about

Consumption Versus Production

Energy Measures . . . . . . . . . 235

5.5.3 Energy Production Orientation and Nuc lear Power Attitudes . . . . . . 239

5.5.4 Summary . . . . . . . . . . . . . 241

5.6 Environmental Priorities . . . . . . . . . 243

5.6.1 Introduction . . . . . . . . . . . 243

5.6.2 General Trends in Environmental Concern . . 243

5.6.3 Conflicts between Environmental Protection and Economic Issues... . . . . . . . 245

5.6.4 Energy Supply Versus Environmental Trade-offs . . . . . . . . . . . . 249

5.6.5 Environmental Orientation and Nuclear Power Attitudes . . . . . . . . . 252

5.7 Beliefs about Growth and Scarcity . . . . . . 253

5.7.1 Introduction . . . . . . . . . . 253

5.7.2 Beliefs about Energy Shortages . . . . 255

5.7.3 Relationship between Belief about Energy Shortage and Nuclear Power Attitude - . . 258

5.7.4 Beliefs and Attitudes about Economic Growth . . . . . . . . . . . 259

5.7.5 Relationship between Attitude toward Economic Growth and Nuclear Power . . . 260

5.8 Sunmary . . . . . . . . . . . . . . 260

CHAPTER 6 SUMMARY AND CONCLUSIONS . . . . . . . . . . . . 264

REFERENCES • • . . . . . . . . . . . • . . . . . 278

APPENDIX A . . . . . . . . . . . . . . . . . 279

APPENDIX B . . . . . . . . . . . . . . . . . . . . 283

DISTRIBUTION . . . . . . . . . . . . . . . . . 285 


\section{LIST OF TABLES}

Page

2.1 Abbreviations Used in Report for the Survey Organizations . . 9

2.2 Recommended Allowance for Sampling Error (Plus or Minus)

at the $95 \%$ Confidence Level . . . . • . . • . . . . 13

2.3 Recommended Allowance for Statistically Significant

Difference Between Two Percentages at 95\% Confidence Level • . 15

3.1 Percentage of Support, Opposition, and Uncertainty to

Construction of a Nuclear Power Plant Within

Five Miles of Respondent's Community . . . . . . . . . 32

3.2 Percentage of Respondents Who Considered Moving as a

Function of the Distance that They Live from Three Mile

Is land

3.3 Percentage of Support, Uncertainty, and Opposition to the

Total and Permanent Closure of All Nuclear Power Plants . .

3.4 Percentage of Support, Opposition, and Uncertainty to

Cutting Back on Nuclear Power Plant Operation Until

the Implementation of Stricter Safety Regulations

3.5 Percentage of Support for Three Alternatives for

Nuc lear Power Plant Operation . . . . . . . . . . . .

3.6 Percentage of Respondents Who Differ on Strength of

Attitude toward Nuclear Power Plant Construction

3.7 National Data on Strength of Attitude toward the

Construction of More Nuclear Power Plants . . . . . . .

3.8 State Data on the Percentage of Strength of Attitude

toward the Construction of More Nuclear Power Plants

3.9 Percentage of Support for and Opposition to Construction

of a Second Nuclear Power Plant at Pilgrim Station.

3.10 Strength of Attitude toward Construction of a Second Nuc lear Power Plant at Pilgrim Station . . . . . . . . 56

3.11 Percentage of Approval and Disapproval of the Trojan Nuc lear Power Plant in Oregon . . . . . . . . . . 60

3.12 Attitudes toward Nuclear Power Plant Construction by Education and Year . . . . . . . . . . . . .

3.13 Attitudes toward Nuclear Power Plant Construction by Income and Year of Survey 
3.14 Attitude toward Local Construction of a Nuclear

Power Plant as a Function of Income . . . . . . . . . 78

3.15 Attitudes toward Nuclear Power Plant Construction

Pre- and Post-Three Mile Island by Income . . . . . . . . 79

3.16 Attitudes toward Nuclear Power Pre- and Post-Three Mile Island by Occupation. . . . . . . . . . . . . . .

3.17 Attitudes toward Nuclear Power Plant Construction by Age and Year . . . . . . . . . . . . . . . .

3.18 Attitudes toward Nuclear Plant Construction by Region and Survey Organization . . . . . . . . . 87

4.1 Volunteered Reasons for Favoring Nuclear Power . . . . . . 92

4.2 Volunteered Reasons for Opposing Nuclear Power . . . . . . 95

4.3 Percentage of Public Who Believe that Certain Benefits Are Likely to Come from Building More Nuclear Power Plants . . .

4.4 Percentage of Public Who Believe that Certain Harmful Consequences are Likely to Come from Building More Nuc lear Power Plants

4.5 Percentage of Public Who Volunteered Certain Advantages and Disadvantages of Nuc lear Power Plants . . . . . . . 102

4.6 Percentage of Public Who Believe in Certain Benefits of Nuc lear Power

4.7 Percentage of Public Who Expressed Worry about Spec if ic Nuc lear Power Problems . . . . . . . . . . . 108

4.8 Percentage of Public Who Believe that Specific Nuc lear Power Problems Are Major Problems . . . . . . . . 110

4.9 Percentage of Public Who Agree with Statements about Specific Nuclear Power Issues . . . . . . . . . . 112

4.10 Percentage of Public Who Believe in the Truthfulness of Statements about Specific Nuc lear Power Issues . . . . . 116

4.11 Percentage of Public Who Believe in Different Degrees of Nuc lear Power Plant Safety . . . . . . . . . . .

4.12 Percentage of Public Who Believe that Being Injured by an Accident is Less Likely than Being Hit by a Bolt of Lightning

4.13 Percentage of Public Who Believe that Nuclear Power Plants Can Explode 
4.14 Percentage of Public Who Believe that Various Groups

Could Best Guarantee Nuclear Power Plant Safety.

4.15 Percentage of the Public Who Rated Positively or Negatively the Handling of the Three Mile Island Accident by Four Different Groups . . . . . . . . . . 134

4.16 Percentage of the Public Who Believe in the Importance of Nuclear Power in Meeting Future Energy Needs

4.17 Percentage of Public and Leadership Groups Who Hold Certain Beliefs and Attitudes Toward Nuclear Power in Light of the Kemeny Commission Report . . . . . . . .

4.18 Percentage of Respondents Who Believe that a Given Type of Industrial Solid Waste Could Cause the Most Severe Problem . . . . . . . . . . . . . . 147

4.19 Percentage of the Public Who Favor or Oppose a Small-Scale Disposal Demonstration Project in Their State by Region of the Country .

4.20 Percentage of the Public Who Favor or Oppose Different Waste Storage Methods . . . . . . . . . 156

4.21 Percentage of the Public Who are More Likely or Less Likely to Support a Disposal Method if Certain Conditions are Met . . . . . . . . . . . . . 158

4.22 Percentage of the Public and Leadership Groups Who Hold Certain Beliefs about Reprocessing Spent Fuel • • • . 166

4.23 Percentage of Public and Leadership Groups Who Favor or Oppose Reprocessing Spent Fuel

4.24 Percentage of the Public and Leadership Groups Who Favor or Oppose Building Breeder Reactors. . .

4.25 Percentage of the Public Who Favor or Oppose the Sale of United States Reactors Abroad . . . . . . . . 178

4.26 Percentage of the Public and Leadership Groups Who Hold Certain Beliefs and Attitudes toward Export of United States Nuclear Technology . . . . . . . . .

4.27 Percentage of Public Who Selected a Certain Group as Best Qualified or Least Qualified to Settle Nuclear Power Plant Siting Decisions

4.28 Percentage of the Public and Leadership Groups Who Believe that the United States Is or Is Not Better Off as a Result of Protest Groups Delaying Nuclear Power Plant Construction 
5.1 Percentage of Public Who Favor Certain Measures to

Increase Energy Production . . . . . . . . . . . 201

5.2 Percentage of the Public Who Prefer Various Energy

Emphases for the Future . . . . . . . . . . . 207

5.3 Percentage of the Public who Favor and Oppose Various

Alternatives for Local Electric Power Plants . . . . . . 209

5.4 Beliefs of the Public about Pollution Characteristics

of Six Energy Sources . . . . . . . . . . . . 213

5.5 Beliefs of the Public that Energy Sources Raise

Few Health Hazards . . . . . . . . . . . . . 220

5.6 Beliefs of the Public Concerning Costs of Energy

Sources . . . . . . . . . . . . . . . 222

5.7 Beliefs of the Public about Electrical Energy

Supply Sources . . . . . . . . . . . . . 224

5.8 Percentage of the Public Who Reported Specific

Conservation Behaviors . . . . . . . . . . . . 232

5.9 Percentage of the Public Who Select a Supply Versus

Demand Energy Emphasis . . . . . . . . . . . . . 236

5.10 Energy Production Favorability by General Attitude toward Nuclear Power. . . . . . . . . . . . . 240

5.11 Support for Energy Sources by Attitude toward Local Nuclear Power Plant Construction . . . . . . . . 242

5.12 Assessment of Need for Change in Environmental Protection Regulations . . . . . . . . . . . . . 246

5.13 Economic Growth Versus Environmental Quality . . . . . . . 247

5.14 Nuclear Attitudes and Environmental Concerns . . . . . . 254 
Page

3.1 Construction of More Nuclear Plants . . . Trends Over Time . . 22

3.2 Construction of More Nuclear Plants ... Trends Over Time . . 24

3.3 Index of Acceptability of Building More Nuclear

Power Plants . . . . . . . . . . . . . . . . 27

3.4 Percentage of Support and Opposition to Local

Construction of a Nuc lear Power Plant . . . . . . . . 30

3.5 Sex Differences in Support and Opposition of

Nuclear Power Plant Construction - Cambridge . . . . . . 66

3.6 Sex Differences in Support and Opposition of

Nuc lear Power Plant Construction - Harris . . . . . . 67

3.7 Attitudes toward Local Nuclear Plant Construction by Sex, Year, and Survey Organization . . . . . . . . 70

3.8 Regional Divisions by Survey Organizations . . . . . . . 85

5.1 Public Attitudes Toward Alternative Energy

Production Approaches . . . . . . . . . . . . 200

5.2 Coal and Nuclear Power as Long-Term Reliable

Energy Sources . . . . . . . . . . . . . . 205

5.3 Power Plant Construction Versus Environmental Cost . . . . . 217

5.4 Construction Versus Conservation . . . . . . . . . . . 238

5.5 Trends in Public Concern about Air and Water Pollution . . . 244

5.6 Energy Versus Environment . . . . . . . . . . . 251

5.7 Seriousness of the Energy Shortage . . . . . . . . . 256 


\section{EXECUTIVE SUMMARY}

The purpose of this research was to collect, analyze, and summarize all of the nuclear power-related surveys conducted in the United States through June, 1981, that we could obtain. The surveys collected were national, statewide, and areawide in scope. Slightly over 100 surveys were collected for an earlier, similar effort carried out in 1977. About 130 new surveys were added to the earlier survey data. Thus, about 230 surveys were screened for inclusion in this report. Because of space limitations, national surveys were used most frequently in this report, followed distantly by state surveys. In drawing our conclusions about public beliefs and attitudes toward nuclear power, we placed most of our confidence in survey questions that were used by national polling firms at several points in time. A summary of the research findings follows, beginning with general attitudes toward nuclear power, followed by a summary of beliefs and attitudes about nuclear power issues, and ended by a surmary of beliefs and attitudes regarding more general energy issues.

Public acceptance of a nuclear power plant built near one's residence has declined steadily since the early 1970's, so that there is majority opposition to the concept. Despite this gradual change in attitude, public acceptance of the continued construction of nuclear power plants at a more general level (in the United States) remained positive and quite steady during the mid-and late 1970's until the Three Mile Island accident in April, 1979. Immediately following the TMI accident support decreased, uncertainty about taking a stand on nuclear 
power decreased, and opposition toward nuclear power increased. Although there has been some attitude rebound toward pre-TMI support and opposition levels, the return has not been complete. At this time, however, the percentage of the public who supports the continued building of nuclear power plants in the United States is, on average, $5 \%$ to $10 \%$ more than the percentage of the public who opposes such construction.

It is important to note that men's and women's attitudes toward nuclear power were differentially affected by the TMI accident. While the attitudes of both groups changed following the TMI accident, women's attitudes changed much more dramatically in the antinuclear direction than did men's. In addition, while men's attitudes returned almost to pre-TMI levels, women's attitudes have not returned to pre-TMI levels over the two years post-TMI. Thus, the plurality to majority support that continued nuclear power plant construction still enjoys is composed of strong majority support on the part of men and minority support (plurality to majority opposition) on the part of women.

While public support for nuclear power has decreased as a result of the TMI accident, the public is not favorable to foregoing the nuclear option. This has been demonstrated both by other attitudinal questions and by 1980 state initiative votes. A series of questions has been asked to determine exactly what measures the public would accept regarding nuclear power. While a slight majority of the public favors cutting back on operations until certain safety questions are answered, a majority of the public is against prohibiting the construction of any more plants, and a large majority of the public is against shutting down all nuclear plants forever. 
In addition, state initiatives that would greatly restrict nuclear power were generally turned down. Maine voted down an initiative that would have closed down Maine Yankee and prevented other nuclear power plants from being built. Missouri voters turned down an initiative that would have prohibited the operation of nuclear plants until a waste management facility was available--an initiative that would have prohibited the start-up of the Calloway plants. Finally, South Dakota turned down an initiative that would have severely restricted nuclear operations--uranium mining, plant construction and operation, and waste management. However, Oregon did pass an initiative that requires voter approval of new nuclear power plants and a moratorium on the construction of new plants until a Federal waste disposal facility is available. The outcomes of these state initiative votes were predictable on the bas is of survey data collected before the initiative votes.

Beliefs and attitudes about specific nuclear power issues were also analyzed. The first type of data analyzed was from volunteered responses to open-ended questions about nuclear power. When respondents were asked why they opposed nuclear power, what harmful consequences might come from building more power plants, and disadvantages of nuclear power, the majority of the responses dealt with safety-related issues. The safety-related issue volunteered most often dealt specifically with reactor accidents. Second highest mention was given to radiation hazards from normal reactor operations, and waste management concerns were voiced third.

When asked why they supported nuclear power, what benefits would come from building more plants, and advantages of nuclear power, the 
majority of the responses dealt with energy supply issues. The public believes that there is a large supply of uranium within the United States and that this can fuel the United States plants for a long period of time. The related belief that these advantages help to free us from dependence upon other nations for our energy needs, especially for crude oil, is also believed to be a significant benefit of nuclear power. Finally, a minority of the public volunteered that nuclear power is cheaper than other types of energy.

When respondents volunteer concerns about nuclear power, reactor safety issues predominate the volunteered responses. However, when respondents are asked to make importance judgments regarding a list of nuclear issues, respondents show slightly more concern about nuclear waste management issues than reactor safety issues. Which is the most important issue? Regression analys is conducted on one of the national surveys found that reactor safety concerns were three to four times more important than nuclear waste concerns in affecting a respondent's attitude about building a nuclear power plant with in five miles of the respondent. Almost as strong a determinant of attitude as the safety belief was a respondent's belief about whether nuclear power is necessary to free us from Arab oil. Beliefs about government support of safety research and the regulation of safe operations also influenced local plant acceptance.

Numerous questions specifically about reactor safety have been asked by survey organizations. In general, the public is somewhat evenly split in its belief that reactors are safe or unsafe. However, the percentage of the public who were previously undecided about the reactor safety 
issue decreased in the late 1970 's, while the percentage who believe that reactors are unsafe has increased. These changes were evident before TMI. A plurality to majority of the public still believes that a nuclear power plant can explode like an atomic bomb. Finally, the public believes that the government should help to ensure nuclear power plant safety.

Numerous survey questions were asked about the TMI accident, which was the largest nuclear safety-related accident ever to have occurred. Almost the total United States public was aware of the accident, and a majority were distrubed by the accident. The cause was believed to be mostly due to human error. A plurality of the public was satisfied with the way the accident was handled. A majority of the public believes that more such accidents are likely to happen. Despite concerns raised by the accident and by the ensuing Kemeny Commission report, a majority of the public believed that nuclear power plants are necessary and that operating plants should not be shut down, because these options would incur economic costs and increased risk.

Nuclear waste management has been an important issue to survey researchers, so a large amount of survey data exist on this issue area. Public concern about nuclear waste management has increased during the late 1970's. On a general level, a large majority of the public now says that it is concerned about waste management issues. On a comparative basis, however, the public believes that the disposal of toxic industrial chemicals is a more severe problem than the disposal of nuclear wastes. However, nuclear wastes are believed to be qualitatively different, and more risky, than typical industrial risks. 
The public is about evenly divided in its belief as to whether an acceptable waste management disposal concept is or is not already available. However, a majority of the public believes that an acceptable solution will be found by the scientific and technical community. Public opposition to siting a high-level repository in one's state is much greater than public acceptance, although there is slight majority support for siting a small-scale demonstration facility in one's state. When asked to choose among different waste disposal techniques that have been certified as safe, the public showed greatest acceptance of above-ground storage at remote locations, followed closely by disposal in granite or in salt. United States leadership groups showed most favorability to granite disposal and salt disposal. Seabed disposal was uniformly the least popular disposal technique.

Other nuclear power issues have not received as much attention as rector safety and nuclear waste management. Some data exist, however, regarding beliefs and/or attitudes about the uranium supply, reprocessing, the breeder reactor, the sale of reactors abroad and related proliferation considerations, and about the fairness and length of the process that utilities go through to plan, construct, and operate a nuclear facility.

As discussed earlier, nuclear fuel supply considerations are believed to be a major advantage of nuclear power. Before 1977, the public was uncertain about how large the United States uranium supply was. However, probably because of former President Carter's stand on proliferation and his remarks about the large United States uranium supply and on supplying nations with United States uranium to forego the 
need for reprocessing, by 1978 the public believed that an adequate supply of uranium existed for the near term. The public did not support the sale of United States uranium abroad, even to control proliferation.

A slight majority of the United States public favors reprocessing nuclear fuel rather than disposing of it, while a much larger majority of United States leadership groups favor reprocessing, except for environmental leaders who oppose reprocessing. The main reasons found for supporting reprocessing are that it reduces the amount of nuclear wastes that need to be disposed and that it is economically attractive. Sabotage and terrorism concerns seem small enough so as not greatly to influence public attitudes toward reprocessing.

The public, at least through 1979, was largely unaware of the breeder reactor concept. There has been plurality public support for the concept, but there is a large amount of uncertainty about the breeder reactor. Many of the United States leadership groups support the breeder reactor--politicians, business leaders, regulators, labor leaders, and utility company leaders--while media leaders and environmental leaders strongly oppose the breeder concept.

The United States public generally does not favor the sale of United States reactors abroad, unless the foreign country is going to purchase a reactor from elsewhere regardless of the United States position. About one-fifth of the public opposes reactor sales abroad because of specific concerns about nuclear weapons proliferation.

Planning and constructing a nuclear power plant in the United States has become a complex process. A majority of the public believes that the government should have some say as to the type of power plants that 
utilities build and where the plant can be sited. In the case of a siting conflict, the public believes that a specialized group of scientists and engineers is best qualified to settle the siting issue. A majority of the public believes that the United States is better off because of protest groups delaying nuclear power plant construction, and a plurality of the public believes that decisions to build nuclear power plants are done at about the right speed. However, a majority of the public greatly underestimates how long it takes to build a nuclear power plant and how much a delay eventually costs the consumer. When told that it takes over ten years to build a plant, a plurality of the public favored speeding up the process. However, the public was evenly divided as to whether the government should limit public participation to speed up the process or whether full public participation should be allowed. This report also analyzed public beliefs and attitudes about nuclear power within the contexts of public beliefs and attitudes about non-nuclear energy sources and of environment and growth issues. The public strongly supports the development of solar power. It is believed to be the safest and least environmentally damaging of the energy sources and is believed to be cheaper than nuclear power. However, public expectations regarding solar power are much more optimistic than are expert predictions. The public supports drilling for offshore oil more than it supports nuclear power plant construction. However, increased oil production is seen only as a short-term solution, while nuclear power is seen as a much better long-term energy supply.

Support for nuclear power has declined through the late 1970's relative to support for other energy options. Nuclear power is seen as a 
good long-term source that is relatively non-polluting, but compared to other energy sources, it is believed to be expensive and more risky. Support for coal, which was lower than support for nuclear power through most of the 1970 's, is now equal to nuclear power in terms of general attitudes and is greater than support for nuclear power in terms of attitudes toward local power plant acceptance. Coal is seen as very polluting, but available and fairly inexpensive. However, the public does not believe that coal will play a long-term role in the United States energy future.

The public is strongly behind energy conservation, in principle, as a means of reducing energy demand. However, the public does not strongly support energy conservation in practice. The public typically supports voluntary rather than involuntary conservation programs. However, compared to higher prices, the public would rather decrease energy use through regulations or even rationing.

There is majority favorability toward increasing energy production, which is especially manifested during periods of energy shortages. However, there has been a shift from a majority belief in unlimited growth in energy production and consumption in the early 1970's to the present belief in reducing unnecessary energy production, especially for environmental reasons.

The public is generally concerned with maintaining and improving environmental quality. While support for environmental protection has remained somewhat stable over the past few years, there is some evidence that the public is more willing, as of late, to relax environmental controls to improve energy availability. While there is majority support 
for economic growth in the United States, there is general ambivalence over the priority that economic growth should receive when it conflicts with environmental protection.

A number of these broad energy issues are related to one's attitude toward nuclear power. Those who indicate more concern about environmental issues and who emphasize conservation approaches over energy production approaches tend to be against nuclear power. Those who are less concerned about environmental issues and who believe in increasing the energy supply tend to favor nuclear power. Beliefs about the general energy shortage (as opposed to specific shortages caused by foreign energy suppliers) and attitudes toward economic growth, however, appear not to be related to attitudes toward nuclear power.

Several conclusions can be drawn from these data. Obviously, a major nuclear-related event, such as the TMI accident, can have a long-lasting effect on public attitudes. Thus, we conclude that similar types of events, if they occur, can further change nuclear attitudes in the future. Safety beliefs are most strongly related to nuclear attitude, so safety-related events are most likely to change nuclear attitudes. Other safety-related events, like the TMI accident, have the potential for quickly and negatively affecting attitude. Lack of such accidents, continued reactor safety research, and strict regulation have the potential for changing nuclear attitude in a positive direction, but over a longer period of time.

A second major determinant of nuclear power attitude has to do with the belief about the ability of nuclear power to free the United States from foreign energy dependence. Thus, energy-related events, such as 
another oil embargo or large increases in the price of oil, have the potential for quickly changing attitudes toward nuclear power in a positive direction. Such events regarding domestic energy sources, such as a coal shortage due to a miners' strike, would probably not affect public attitudes toward nuclear power.

Despite the fact that the public has lowered its support for nuclear power over the past several years, we conclude that the public does not wish to forego the nuclear option at this point nor will it do so in the 1980's. The public believes that an energy shortage exists today and that a worse shortage is likely in the future. Given these beliefs, plus the fact that nuclear power is available today, that the public believes that a large United States uranium supply exists, and that other future energy sources, such as solar electricity, are not yet available in large quantities, the public wishes to keep nuclear power as an energy option.

Attitudes toward nuclear power are also formed relative to attitudes toward other energy sources. Thus, major events associated with other energy sources, such as technological breakthroughs or lack of such breakthroughs, could indirectly impact attitudes toward nuclear power. If solar-generated electricity became cost-competitive with nuclear power, for instance, there is little question that its use would be greatly favored by the public. If the promise of solar is not realized in the 1980's, however, acceptability of nuclear power could increase. Presently, however, nuclear power plants and coal power plants are the two main possibilities for electrical generation, so the nuclear-coal comparison is of most importance to the public. Over the past several years, local coal plant public acceptability has increased to be greater 
than local nuclear plant acceptability. Thus, technological breakthroughs or regulatory changes that positively affect coal's relative position to nuclear power could further increase coal's acceptability relative to nuclear's acceptability. 
CHAPTER 1

INTRODUCTION

Public interest in energy issues, such as energy supplies, energy costs, and energy technologies, increased during the decade of the 1970's, largely as the result of disruption in OPEC oil supplies and the ensuing price rises. Thus, the public has become more aware of the social and political consequences of various energy alternatives. One particular energy technology, nuclear power, has become an important social issue, as indicated by widespread media coverage of nuclear power issues, nuclear initiatives that were voted on in 1976 and 1980 , the formation of social groups to oppose or to support nuclear power, and numerous public conferences held on the nuclear fuel cycle, especially with regard to nuclear waste management. The April, 1979, accident at the Three Mile Island (TMI) power plant focused worldwide attention on nuclear power, and the full impact of this accident on public attitudes is not known.

Public discussion regarding nuclear power has often been rancorous and has prompted some to label the discussions as a debate or a conflict. Individuals on ail sides of the issue often claim that they are speaking for "the public." They often support their claims with anecdotal material or newspaper clippings. Survey data are rarely provided.

In order to determine what "the public" really thought about nuclear power, in 1977 we prepared a comprehensive review and analys is of nuclear power survey data, usually collected by national survey research firms. This study, Nuclear Power and the Public: Analysis of Collected Survey Research, examined over one hundred national, state, and local surveys. 
Since 1977, the salience of nuclear power as a social issue has increased, especially following the TMI accident in 1979. The need for a follow-up to the original study is evident in order to look at the long-term trends in beliefs and attitudes toward nuclear power and in order to assess the impact of TMI on these beliefs and attitudes. Thus, the objectives of this report are to analyze long-term trends in nuclear-related beliefs and attitudes and to analyze the specific effects of TMI.

As was the case for the earlier report, it is our goal to provide a comparative analysis of a large number of surveys collected over a long period of time. Although we draw our own conclusions from these data in this report, the data are provided in enough detail so that the reader can decide for himself/herself whether our conclusions are warranted or whether some other conclusion is just as likely.

The remainder of this report is divided into six major chapters: research methodology (Chapter 2); general nuclear power attitudes (Chapter 3), including the relationship of general attitudes to state initiative votes and to respondent demographic characteristics; beliefs and attitudes regarding specific nuclear power issues (Chapter 4); beliefs and attitudes regarding broad energy, environment, and economic growth issues (Chapter 5); and a summary and conclusions chapter (Chapter 6).

The chapter on research methodology describes our method of data acquisition. It also briefly defines our usage of the terms belief and attitude. In addition, a short discussion on determining the statistical significance of differences in survey results is presented. Finally, the 
chapter describes the method by which we refer to surveys throughout the rest of the report.

Chapter 3, the analys is of general nuclear power attitudes, examines in great detail the numerous and varied questions used by survey organizations to assess general attitudes to nuclear power. Thus, it provides information on general levels of support for or opposition to nuclear power and does so over an approximately 10-year time span. Special attention is given to the effects of variations in question wording on assessments of nuclear power attitude and to the impact of TMI on these attitudes. This chapter also examines the relationship of general nuclear power attitudes to state nuclear initiative votes. Finally, the relationship between respondent demographic characteristics and nuclear power attitude is examined. The demographic characteristics of most interest are sex, age, education, occupation, income, and geographic region of the country. The stability over time of the relationship between demographic characteristics and nuclear power attitude is examined, and the relative importance of the demographic characteristics in determining nuclear power attitude is analyzed.

Chapter 4 examines public beliefs and attitudes regarding specific nuclear power issues, including reactor safety, waste management, uranium supply, reprocessing, the breeder reactor, proliferation, and the regulatory process. Specific beliefs regarding these issues are discussed and the relative importance of these beliefs in determining nuclear power attitude is assessed. Changes in beliefs and attitudes over time, and especially as a result of TMI, are discussed. 
Chapter 5 evaluates the nuclear power option within the broad context of energy, environment, and economic growth issues. Thus, this chapter presents a comparative analys is of nuclear power and other energy-producing technologies. Public attitudes on increasing the energy supply versus curbing energy demand are evaluated. In addition, the differences and similarities between pronuclear and antinuclear respondents on a broad range of energy and environment issues is presented. Finally, changes over time in general energy beliefs and attitudes are discussed.

Chapter 6 highlights the major substantive findings in the report, including findings regarding nuclear-related beliefs and attitudes and regarding changes in these beliefs and attitudes over time. Conclusions are then drawn regarding the future of nuclear power in the U.S. 
CHAPTER 2

PROCEDURE AND SURVEY VARIABILITY

Survey data for this assessment of public beliefs and attitudes toward nuclear power were provided by a variety of sponsors and survey organizations. Most of the data presented are from the late 1970 's and early 1980's. Surveys dealing with nuclear power conducted outside of the United States were beyond the scope of this effort. This chapter briefly describes the types of information that were analyzed, the procedures that we used to collect relevant survey data, how these surveys are identified in the remainder of this report, and how these surveys differed in the type of sample used, in questionnaire content and design, and in method of data acquisition.

\subsection{Types of Information Collected by Surveys}

Surveys are used to collect four general types of information from respondents: beliefs, attitudes, demographics, and behaviors. The definitions of these terms are presented below so that the terms can be used consistently and meaningfully throughout the remainder of this report.

Attitudes describe whether people feel positively or negatively about something, e.g., the continued construction of nuclear power plants. Thus, an attitude is evaluative in nature. Attitude questions used to elicit the direction of one's feeling often use words such as good versus bad, should versus should not, and favor versus oppose. Examples of attitude questions of interest to this report are: "Do you 
agree or disagree that the U.S. should continue to build nuclear power plants?" and "Do you favor or oppose the reprocessing of spent nuclear fuel?"

Beliefs are assessments about what is true and what is false about attributes of an attitude object. For example, with regard to nuclear power plants, survey researchers are often interested in determining respondent beliefs about reactor safety, nuclear waste management, power plant costs, fuel availability, and proliferation. Beliefs about nuclear power attributes are important because they are assumed to be the reason why a respondent holds a specific attitude toward nuclear power. Examples of belief questions of interest to this report are: "Do you think that nuclear power plants are safe or unsafe?" and "Do you think that enough nuclear fuel exists for the next 50 years of reactor operation?"

Demographic characteristics are attributes of respondents. Demographics of interest to this report include the respondent's sex, age, education, income, occupation, and geographic region of the country. These types of data are most often collected so that belief and attitude data can be reported as a function of a given demographic variable.

Behaviors are what people have done or what people say that they will do (behavioral intention). Behaviors are not of great importance to this study, although some data regarding what people say that they have done regarding conservation are reported. 


\subsection{Procedure for Acquiring Survey Data}

This effort was totally dependent on survey data that had been collected by other survey research organizations. No new data were collected solely for inclusion in this report. Our first major attempt to acquire such data began in the fall of 1976 following nuclear safeguard initiative campaigns that were held in six states. At that time, both pro- and anti-initiative organizations were contacted in the six initiative states for information regarding surveys sponsored during the course of the campaigns. A substantial number of utility companies and business or industrial groups involved with nuclear power were also contacted with regard to any surveys that they had commissioned dealing with public attitudes toward nuclear power. Academic groups and national survey research firms were also directly contacted to determine whether they had conducted surveys relevant to our task. Finally, the Gallup Opinion Index, Current Opinion, and Public Opinion Quarterly were used to identify additional sources of survey data.

In order to update this information about public attitudes toward nuclear power, we began collecting post-1976 surveys in the fall of 1978 and again in the summer of 1981. Many of the same organizations were recontacted, although our focus was more on national survey data at this point. The survey data acquired for the update were collected by survey research organizations through June, 1981.

Across all data collection efforts, our procedure for acquiring survey data resulted in the procurement of 228 surveys that in some way dealt with nuclear power. Of the 228 surveys, 130 were national public surveys, 55 were state surveys, and the remaining 43 sampled from a more 
restricted geographical area (e.g., a utility district, a city, or a region around a nuclear power plant).

Data cited in specific survey reports from surveys conducted earlier were also included, even though complete reports of these surveys were not available to us. For example, survey reports done by Lou is Harris and Associates, Inc. in 1975 and 1976 included data from surveys conducted in 1973 and 1974. These data were included where useful. Finally, we should note that data from all of these surveys are not included in this report for the sake of brevity. This report focuses most on the national survey data and includes state and local data only when it supplements the national survey findings.

\subsection{Description of Surveys}

In order to refer to the surveys in a consistent manner throughout this report, the following system was developed. Each national survey was assigned a code name consisting of the abbreviated name (see Table 2.1) of the researcher(s) or organization that conducted the survey, followed in parentheses by the year and the month that the data were collected. For example, Harris $(78 / 10)$ indicates that Louis Harris and Associates, Inc., collected survey data on a national sample of respondents in October, 1978. When the survey sample was not national in scope, the location of the survey population is given preceding the date. For example, FH (MO 79/3) indicates that Fleishman-Hillard, Inc. collected survey data in March, 1979, using respondents from the State of Missouri. In a few cases, the month of the data collection is not known. In these cases, the abbreviations "unk." in the text and "u" in 
TABLE 2.1

ABBREVIATIONS USED IN REPORT

FOR THE SURVEY ORGANIZATIONS

Survey Organization

Abbreviation

Associates for Research in Behavior, Inc.

ARB

Bardsley \& Haslacher

$\mathrm{BH}$

Becker Research Corp.

Becker

Cambridge Reports, Inc.

Cambridge

CBS News/New York Times

CBS

Field Institute

Field

Fleishman-Hillard, Inc.

$\mathrm{FH}$

Gallup Opinion Index; Gallup Poll

Gallup

Louis Harris \& Associates, Inc.; ABC-Harris Survey

Harris

Mounta in West Research

TMI

National Science Foundation

NSF

NBC News/Associated Press

NBC

Newsweek Poll

Newsweek

Opinion Research Corp.

ORC

Potomac Institute

Potomac

Public Affairs Research Center,

PARC

Clark University

Response Analysis Corp.

RAC

Resources for the Future

RFF

Roger Seasonwe in Associates

Seasonwein

Roper Organization, Inc.

Roper

Solar Energy Research Institute

SERI

Survey Research Laboratory,

SRL University of Illinois

University of Main Social Science Research Institute

University of Michigan, Institute for Social Research

Washington Public Interest Research Group

WASHPIRG

The Weekly (Maine newspaper)

Weekly

Wiscons in Survey Research Laboratory

WSRL

Worcester Polytechnic Institute

WPI

Yankelovich, Skelly, and White, Inc.

YS\&M 
the tables will be used to signify that the month is "unknown" [e.g., YS\&W (78/unk.)]. A complete listing of survey data is provided in Appendix A. This Appendix identifies each survey by identification code, survey organization, sample size, and response mode. Surveys are listed separately according to whether they are national, state, or regional in scope.

\subsection{Variation in Surveys}

There is considerable variation in the surveys summarized in this report. This variation results from differences in the populations surveyed and the way in which samples of respondents are drawn from the populations, the types of questions asked in the survey, and the means by which the data are collected. These differences are discussed in more detail below.

\subsubsection{Populations of Interest and Sampling Procedures}

Survey populations of interest varied widely. Collected for possible use in this report were surveys designed to assess opinions of the population of the United States, of specific geographic regions or states, of utility company customers, of residents near a specific nuclear site, and of specific groups of interest (e.g., environmentalists, business leaders, and media leaders).

National samples were generally selected to be representative of the civilian population ( 18 years or older) residing within private households in the continental United States. Representative national samples selected by survey organizations usually included $1,000-1,500$ respondents. The methods used to select these representative samples 
involved some procedure to ensure that demographic groups that comprise a small percentage of the population are given accurate representation. The selection of particular respondents for interviewing in these national or state samples is a complex process involving several steps, each of which includes a random selection component and proceeds from the selection of geographical sampling areas, to the selection of households within these areas, and finally to the selection of specific individuals within the households. The number of geographical sampling areas chosen usually ranges from 100 [e.g., $\operatorname{RAC}(78 / 8)]$ to 300 [e.g., Gallup (77/2)]. Deviations from the theoretical sampling plan may occur in several ways, e.g., potential respondents may not be home when the interviewer calls or may refuse to be interviewed. In addition, quotas may often be imposed to avoid overrepresentation of women or older citizens, who are more often at home when the interviewer calls.

The sampling procedure for some of the other studies is often less complex. Some of the samples in these studies are randomly drawn from phone books or voter lists. Compared to the procedures described above, sampling from a phone book produces a less representative sample of the household population, because the phone book is not completely up to date and some people have unlisted numbers. However, if a random digit dialing procedure is used, a very representative sample can be gotten using telephone surveys. Random digit dialing is now commonly used by many survey organizations [e.g., CBS (79/4) and WASHPIRG (WA 78/12)]. Sampling from voter lists means that the sample is representative of those who voted and not, for instance, all adults over 18 years of age in a geographic area. 
Although sampling techniques are employed to minimize sampling error, results obtained from surveying a sample of individuals will differ somewhat from those that would have been obtained if the entire population had been surveyed. The difference between what was found for the sample compared to what would have been found for the entire population is called sampling error. The possible size of the sampling error is a function of population size, sample size, and the percentage of respondents within a given response category.

Table 2.2 shows how much allowance should be made for sampling error as a function of sample size and percentage of respondents selecting a specific response. This table assumes that the population size is infinite, and this assumption is reasonable if the population size is at least 10,000 . A $95 \%$ confidence interval is the interval in which the true population parameter (as opposed to what was found for the sample) is expected to be with .95 probability. For example, assume that in a sample of 1500 respondents $20 \%$ selected response " $A$ " and the remaining $80 \%$ selected response "not A." Table 2.2 then tells us that if the whole population had been surveyed (as opposed to just a 1500-person sample), we would expect with .95 probability that $20 \% \pm 2 \%$ (i.e., from $18 \%$ to $22 \%)$ of the population would also have selected response "A," or conversely, that $80 \% \pm 2 \%$ would have selected "not A."

Note that as the sample size becomes smaller the confidence interval becomes larger. Thus, in a sample of only 250 people, where $20 \%$ responded "A" and $80 \%$ responded "not $A$," the $95 \%$ confidence interval for the whole population is $20 \% \pm 5 \%$ (i.e., $15 \%$ to $25 \%$ ) for an "A" response. Note also that the confidence interval becomes larger as the percentage 
TABLE 2.2

RECOMMENDED ALLOWANCE FOR SAMPLING ERROR

(PLUS OR MINUS) AT THE 95\% CONFIDENCE LEVEL

\begin{tabular}{llllll}
\hline & \multicolumn{5}{c}{ Sample size } \\
\cline { 2 - 6 } $\begin{array}{c}\text { Response } \\
(\%)\end{array}$ & $\begin{array}{c}1,500 \\
(\%)\end{array}$ & $\begin{array}{c}1,000 \\
(\%)\end{array}$ & $\begin{array}{c}750 \\
(\%)\end{array}$ & $\begin{array}{c}500 \\
(\%)\end{array}$ & $\begin{array}{c}550 \\
(\%)\end{array}$ \\
\hline $10(90)$ & 2 & 2 & 2 & 3 & 4 \\
$20(80)$ & 2 & 3 & 3 & 4 & 5 \\
$30(70)$ & 3 & 3 & 4 & 4 & 6 \\
$40(60)$ & 3 & 3 & 4 & 5 & 7 \\
$50(50)$ & 3 & 4 & 4 & 5 & 7 \\
\hline
\end{tabular}


of respondents who chose " $A$ " and the percentage of respondents who chose "not A" becomes more even. Thus, for a 1500-person sample where $40 \%$ of the respondents choose "A" and 60\% choose "not $A$," the $95 \%$ confidence interval for the population is $40 \% \pm 3 \%$ for an "A" response and $60 \% \pm 3 \%$ for a "not A" choice.

Table 2.3 shows how large differences in percentages must be between two samples of respondents for the difference to be statistically significant. Statistical significance at the $95 \%$ confidence level means that 95 times out of 100 the difference found between the samples was a real difference and not due to random error. For example, assume that two samples of respondents have both been asked the same question, that one sample had 500 respondents and the other sample had 1000 respondents, and that around $50 \%$ of the respondents in both samples selected response "A." Table 2.3 indicates that the percentage of respondents in the two samples who selected "A" would have to differ by $6 \%$ or more for the samples to have responded statistically significantly differently.

of course, the difference between statistical significance and substantive significance should also be kept in mind while reading the report. While a difference of two or three percentage points between samples on a response to a given survey item may mean that the samples answered the question statistically significantly differently, the difference may seem too small to be of substantive significance. However, while the difference between two samples can easily be tested for statistical significance using accepted statistical techniques, "substantive" significance is more of a judgment on the part of the data analyst. Thus, in this report, a significant difference refers to a 
TABLE 2.3

RECOMMENDED ALLOWANCE FOR STATISTICALLY SIGNIFICANT DIFFERENCE BETWEEN TWO PERCENTAGES AT 95\% CONFIDENCE LEVEL

\begin{tabular}{cccccc}
\hline $\begin{array}{l}\text { 1st Sample Size/ } \\
\text { 2nd Sample Size }\end{array}$ & $\begin{array}{c}1,500 \\
(\%)\end{array}$ & $\begin{array}{c}1,000 \\
(\%)\end{array}$ & $\begin{array}{c}750 \\
(\%)\end{array}$ & $\begin{array}{c}500 \\
(\%)\end{array}$ & $\begin{array}{c}250 \\
(\%)\end{array}$ \\
\hline$\%$ Near 50 & & & & & \\
\hline 1,500 & 4 & 4 & 5 & 5 & 7 \\
1,000 & - & 5 & 5 & 6 & 7 \\
750 & - & - & 5 & 6 & 8 \\
500 & - & - & - & 7 & 8 \\
250 & - & - & - & - & 9 \\
Near 200 0 80 & & & & & \\
\hline 1,500 & 3 & 4 & 4 & 4 & 6 \\
1,000 & - & 4 & 4 & 5 & 6 \\
750 & - & - & 4 & 5 & 6 \\
500 & - & - & - & 5 & 7 \\
250 & - & - & - & - & 7 \\
\hline
\end{tabular}


statistically significant difference. Judgments about substantively significant differences are left to the reader.

\subsubsection{Questionnaire Content}

There is considerable variation in the purposes of the surveys included in this report and thus in questionnaire content and in the depth of focus on nuclear issues. It is possible that the range of issues addressed in a particular survey and the order in which the questions are asked may influence the responses that were obtained. For example, in the surveys provided by $C$ ambridge Reports, Inc., questions assessing attitudes toward the construction of nuclear power plants are asked in the context of questions pertaining to a large number of energy issues, while in several of the early surveys provided by Louis Harris and Associates, Inc., the questionnaires focused solely on nuclear power issues. The possible influences of these factors in the determination of responses is very hard to ascertain and is not attempted in this report.

Data collected during and immediately after the TMI incident were largely special surveys designed to assess beliefs about the incident and to evaluate its influence on future nuclear power development. The timing of these surveys is important to the interpretation of the response obtained. There is considerable variation in the data obtained by the different survey organizations as well as variation in responses each week during and immediately after the incident. Therefore, it is particularly important to note the date of data collection when assessing change in attitudes following the incident.

Additional factors that influence the responses to questions assessing nuclear energy attitudes are the phrasing of the question and 
the number of response categories provided. Questions including qualifiers, such as references to danger or safety, can produce different results than questions not including such qualifiers. Also, whether the responses included an undecided category can influence the results. For example, the questions assessing nuclear power attitudes, as well as attitudes toward other energy issues, most often provided only two response categories--agree or disagree. Respondents were encouraged to respond either agree or disagree and an undecided response was only accepted if it was volunteered by the respondent. When an additional undecided response category is provided to the respondents, the agree and disagree choices are selected less often, and the distribution of responses is changed. Thus, question wording and response options are important considerations when evaluating public opinion and will be discussed in the context of the substantive issues.

\subsubsection{Data Collection Methods}

Data collection methods used for the surveys in this report included personal interviews, telephone interviews, and mail questionnaires. Surveys conducted by personal interview can obtain more comprehensive, in-depth coverage of topics than telephone and mail surveys. However, each of the three methods have their advantages and disadvantages, which are covered in depth in other publications (see Dillman, 1978). Most of the survey data that are discussed in this report were collected using personal interviews. There has been a tendency more recently toward the use of telephone surveys. 


\subsection{Summary}

Numerous surveys were conducted from 1975 to 1981 to collect information on public beliefs and attitudes regarding nuclear power. As much of this survey data as possible was sought by us for possible inclusion in this report. The surveys that were obtained for the report varied in a number of ways, including: respondent population of interest (national, state, or a more restricted geographical area), respondent sampling procedure, questionnaire content, and data collection method (personal interview, telephone interview, or mail survey).

In the following assessment of the stability and change in nuclear power beliefs and attitudes over time, it is important to determine whether observed differences across time are "real" differences and not due to artifacts of sampling design or question wording. We placed our greatest confidence and emphasis in findings from national surveys, which were based on representative samples and conducted by established survey research organizations. When findings were consistent across survey organizations, our confidence in the validity of the results was greatly enhanced. In this report, particular attention is given to the same question asked by the same survey organization at different points in time in order to assess changes over time with the most confidence. 
CHAPTER 3

GENERAL ATTITUDES TOWARD NUCLEAR POWER

\subsection{Introduction}

This chapter discusses public attitudes toward nuclear power from 1971 through 1981. First, particular attention is directed toward long-term trends in support for and opposition to nuclear power, including the impact of the TMI accident on public attitudes. The relationship between attitudes toward nuclear power and the outcomes of recent nuclear-related state initiatives will then be discussed. Finally, the relationships between nuclear power attitude and respondent demographic characteristics--including sex, age, education, income, occupation, and geographic region--and general attitudes toward nuclear power are examined.

As discussed in Chapter 2, there is considerable variability in the survey data collected to assess attitudes toward nuclear power. In addition, public attitudes toward nuclear power may be influenced by other factors such as short-term changes in the state of the economy, major changes in the political climate (i.e., changing party control of the apparatus of government at either the state or federal level), or a highly publicized incident involving nuclear power, such as the TMI accident. Thus, it is important to remember that the level of general support for or opposition to nuclear power is subject to a number of different influences that may cause either short-term changes in attitude toward nuclear power or long-term, durable changes in attitudes. To assess whether there is attitude change that is not due to an artifact of 
the sampling strategy, timing of the survey, or a change in question wording requires a very careful analysis of the survey data and a degree of caution in interpreting the results of that analysis.

In examining changes in attitudes over long periods of time it is also important to remember that the data come from different individuals responding to the same or similar questions at successive points in time. The data do not represent the attitudes of the same individuals measured repeatedly across time. Thus, changes in attitudes refer to changes in the percentage of respondents who favor or oppose nuclear power. The survey data presented here do not address the question of how the attitudes of any given individual may have changed across time.

\subsection{General Attitudes Toward Nuclear Power}

\subsubsection{Introduction}

The numerous surveys that have addressed the issue of general attitudes toward nuclear power have employed many different question formats and methods of assessing attitudes. The material in this section will focus on survey questions that have addressed three types of attitudes, including attitudes toward:

1. the construction of nuclear power plants in general;

2. the construction of nuclear power plants in the respondents' locality; and

3. the continued operation of existing nuclear power plants.

\subsubsection{Nuclear Power Plant Construction--General}

Survey data assessing nationwide attitudes toward the construction of nuclear power plants have been obtained by Cambridge and Harris since 
1974 (see Tables 1 and 2 in Appendix B for raw data and IA scores for Cambridge and Harris). These data are important for two reasons. First, they allow the assessment of long-term attitude change (nearly seven years); and second, they allow an assessment of the impact of major events, such as the TMI accident, on attitudes toward nuclear power.

From 1975 through early 1979, Cambridge (see Figure 3.1) found only minor fluctuations in level of support for or opposition to the construction of additional nuclear power plants. Levels of support ranged from $45 \%$ to $58 \%(\bar{X}=51.28$, S.D. $=3.91)$, and opposition from $26 \%$ to $35 \%(\bar{X}=29.83$, S.D. $=2.53)$. Levels of uncertainty toward construction of nuclear power plants were similarly stable, ranging from $14 \%$ to $23 \%(\bar{X}=19.17$, S.D. $=2.28)$. Following the accident at TMI in Apri1, 1979, however, the relative stability of attitudes toward nuclear power plant construction was disrupted. Immediately before TMI, Cambridge (79/3) found support and opposition at $50 \%$ and $32 \%$, respectively. Two months after the accident, Cambridge (79/6) found that this situation had changed significantly: $39 \%$ were in favor of and $44 \%$ were opposed to nuclear power plant construction. For the same time period, uncertainty regarding nuclear power attitude had changed nonsignificantly from $18 \%$ to $16 \%$. Three months after the accident, Cambridge (79/6) found that the levels of support (46\%) and opposition (38\%) more closely approximated those found prior to April, 1979. However, since TMI the levels of support have never been as high and levels of opposition have never been as low as they were immediately prior to the accident. From a post-TMI high (49\%) in September, 1980, successive surveys through June, 1981, have shown declining levels of 


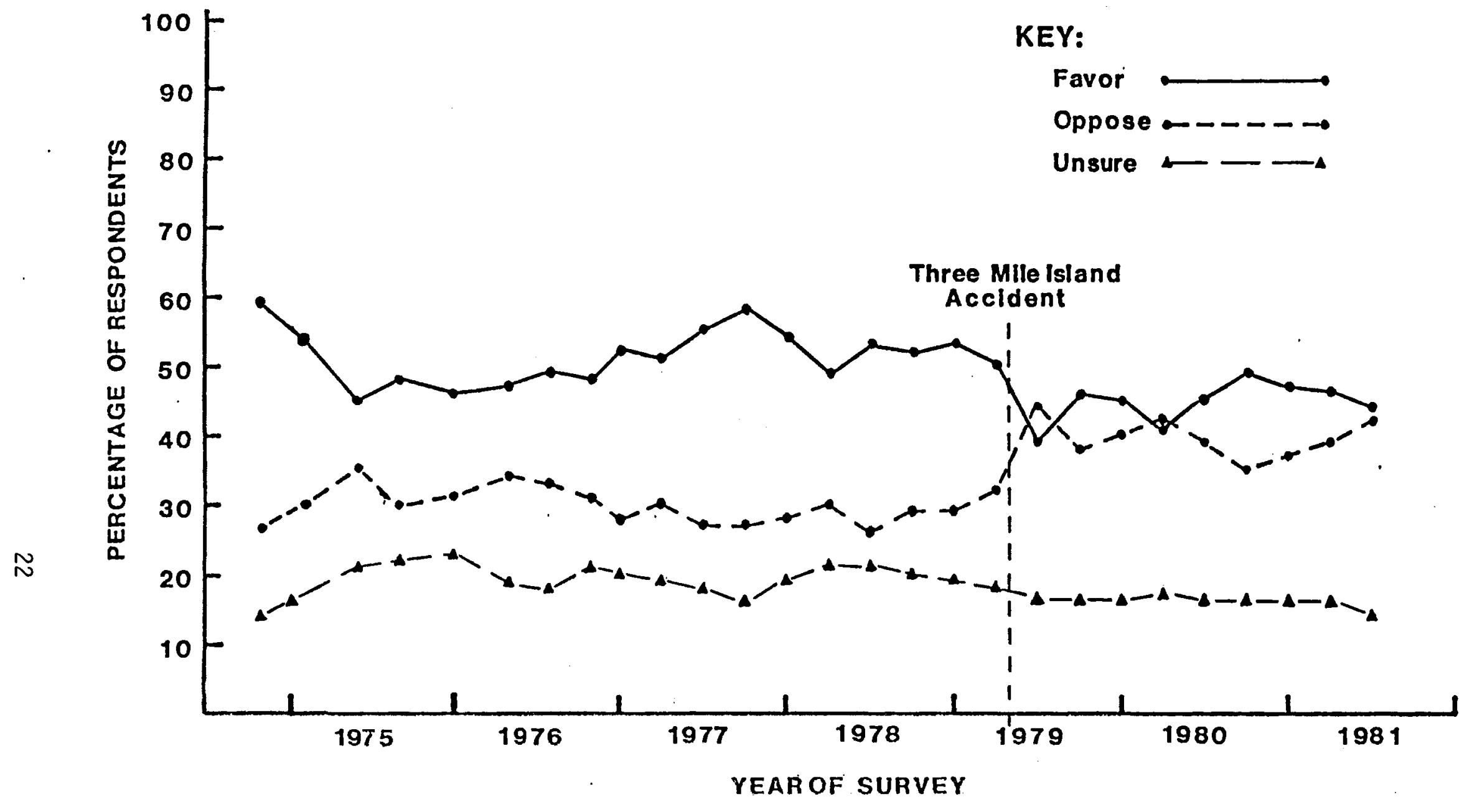

FIGURE 3.1 Construction of More Nuclear Plants . ... Trends Over Time

NOTE: "Do you favor or oppose the construction of more nuclear power plants?" (Cambridge) 
support and increasing levels of opposition to the construction of nuclear power plants. For the period following TMI levels of support averaged $44.67 \%($ S.D. $=3.04)$, opposition averaged $39.56 \%($ S.D. $=2.79)$, and uncertainty averaged $15.89 \%(S . D .=0.78)$.

The differences in average levels of support, opposition, and uncertainty between the pre- and post-TMI periods are all statistically significant. After TMI there was a significant decrease in support $(6.61 \%, p<.001)$, increase in opposition $(9.73 \%, p<.001)$, and decrease in uncertainty $(3.28 \%, p<.001)$ regarding the construction of more nuclear power plants.

Similar patterns are shown by the Harris data (see Figure 3.2) for the same time period before TMI. With the exception of the data for Apri1, 1976, levels of support, opposition and uncertainty were relatively stable. Schulman (1979) has suggested that the Apri1, 1976, data are due to several events associated with nuclear power that occurred during that time, "( $t)$ hree engineers from General Electric's reactor division quit their jobs to work for a California movement to halt nuclear power, followed in quick order by the close-down of the Vermont Yankee power plant because of a safety systems flaw and the resignation of a Nuclear Regulatory Commission safety engineer at Indian Point, New York, who charged that all reactors were unsafe." This does not, however, explain why a similar effect was not apparent in the Cambridge (76/4) survey for the same time period. The Harris (76/4) data may simply represent a sampling anomaly of no real significance.

For the period before TMI, the Harris data showed average levels of support $(X=56.50 \%$, S.D. $=6.75)$, opposition $(X=26.17 \%$, S.D. $=5.88)$, 


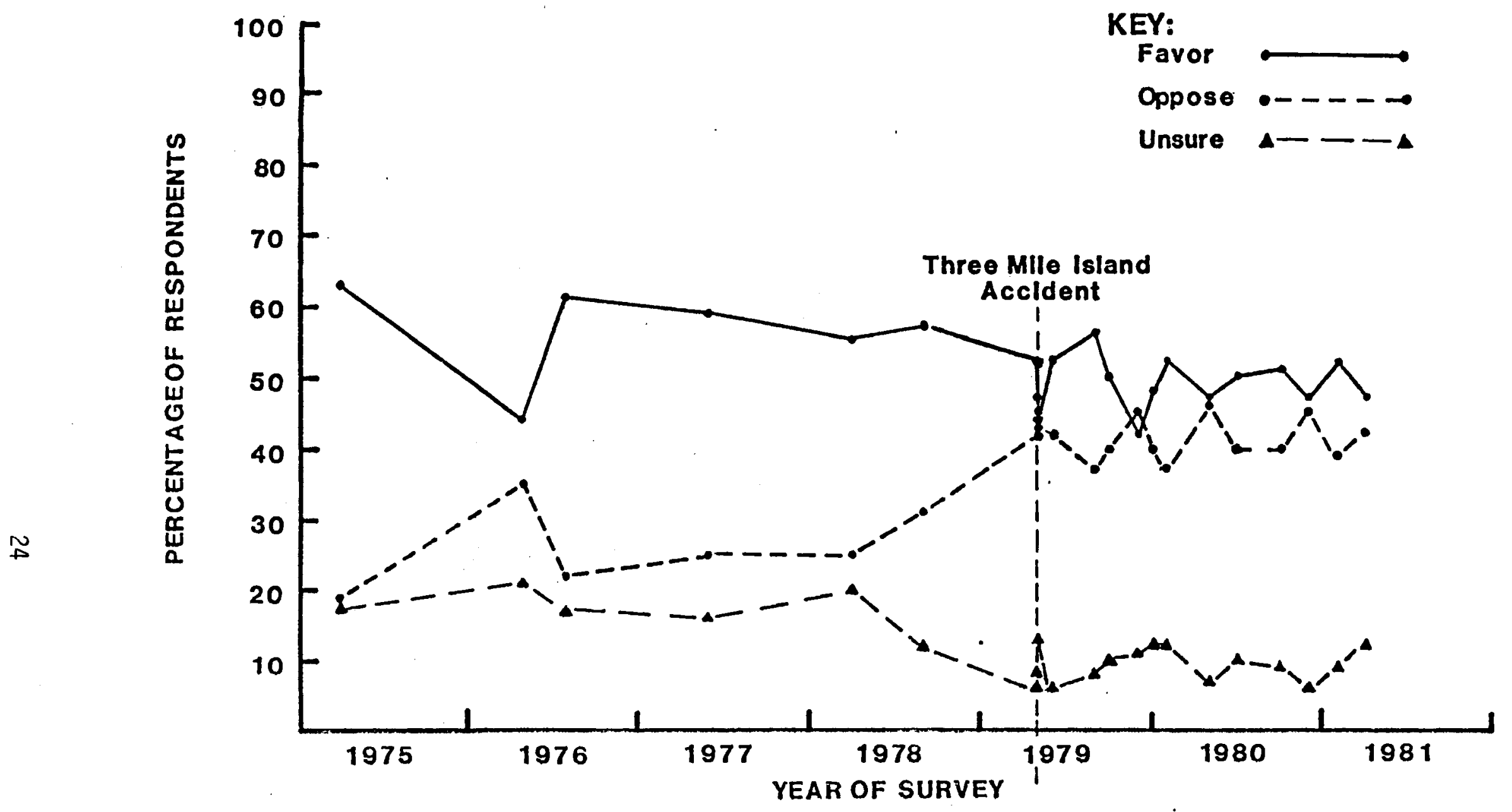

FIGURE 3.2 Construction of More Nuclear Plants ......Trends Over Time

NOTE: "In general, do you favor or oppose the building of more nuclear power plants in the United States?" (Harris) 
and uncertainty $(X=17.33 \%, S . D .=3.20)$ comparable to those found by Cambridge. After TMI, the Harris data show that support had decreased to an average of $49.07 \%($ S.D. $=3.56)$, opposition had increased to an average of $41.80 \%(S . D .=3.28)$, and uncertainty decreased to an average of $9.27 \%$ (S.D. $=2.40)$.

As was the case with the Cambridge data, all of the changes in the Harris data in the time period following TMI were statistically significant. Following TMI, average levels of support declined by $7.43 \%$ $(p<.005)$, average levels of opposition increased by $15.63 \%(p<.001)$, and uncertainty decreased by $8.06 \%(p<.001)$.

Another way to look at both the Cambridge and Harris data is to directly compare levels of support and opposition, ignoring the percentage of uncertainty or those who respond that they "don't know." An advantage of this approach is that it permits the incorporation of both favorability and opposition into the same metric and allows a direct comparison of one to the other. An obvious disadvantage is that it does ignore that undecided or noncommitted group of people who, depending upon the survey, may comprise up to $20 \%$ of the survey sample.

One way of making direct comparisons is through the use of what we shall call the Index of Acceptability (IA), which we define as the ratio of the percentage of favorability to the sum of favorability plus unfavorability times 100:

$$
I A=\frac{\% \text { favor }}{\% \text { favor }+\% \text { oppose }} \times 100
$$

Among those individuals who have made up their minds, the IA indicates the proportion of respondents who favor the statement posed in the attitude item. Note that the IA will equal 50 when favorability and 
opposition are equal, 67 when there is a 2 to 1 margin in favor, and 33 when there is a 2 to 1 margin opposed.

Figure 3.3 graphically shows the fluctuations in IA scores for the Cambridge and Harris data from 1974 through mid-1981 regarding general attitudes toward the construction of more nuclear power plants. Data from both surveys show considerable fluctuation across the years. It is apparent, however, that there has been a decrease in acceptability of additional nuclear power plant construction since the TMI accident in 1979.

In the four years prior to the TMI accident, IA scores averaged 68.67 (S.D. $=7.76)$ and 63.06 (S.D. $=3.76$ ) for Harris and Cambridge surveys, respectively. There was a sharp decline in acceptability after TMI and, although there has been considerable variation in IA scores in the two and one-half years since, there does not appear to be a trend for IA scores to return to their previous levels. For the years after TMI, the IA scores for the Cambridge and Harris data averaged, respectively, $53.00($ S.D. $=3.46)$ and $54.07(S . D .=3.47)$. The differences in average IA scores pre- and post-TMI for both the Cambridge and Harris data are statistically significant. The Cambridge data show a decline of 10.06 $(p<.001)$ in acceptability, and the Harris data show a decline of 14.60 $(p<.001)$.

An alternative explanation for the changes in levels of support, opposition, and uncertainty following TMI is that, rather than occurring in response to TMI, they reflected ongoing changes that would have occurred even in the absence of TMI. Neither the Cambridge nor the Harris data support this explanation. For both sets of data, regression 


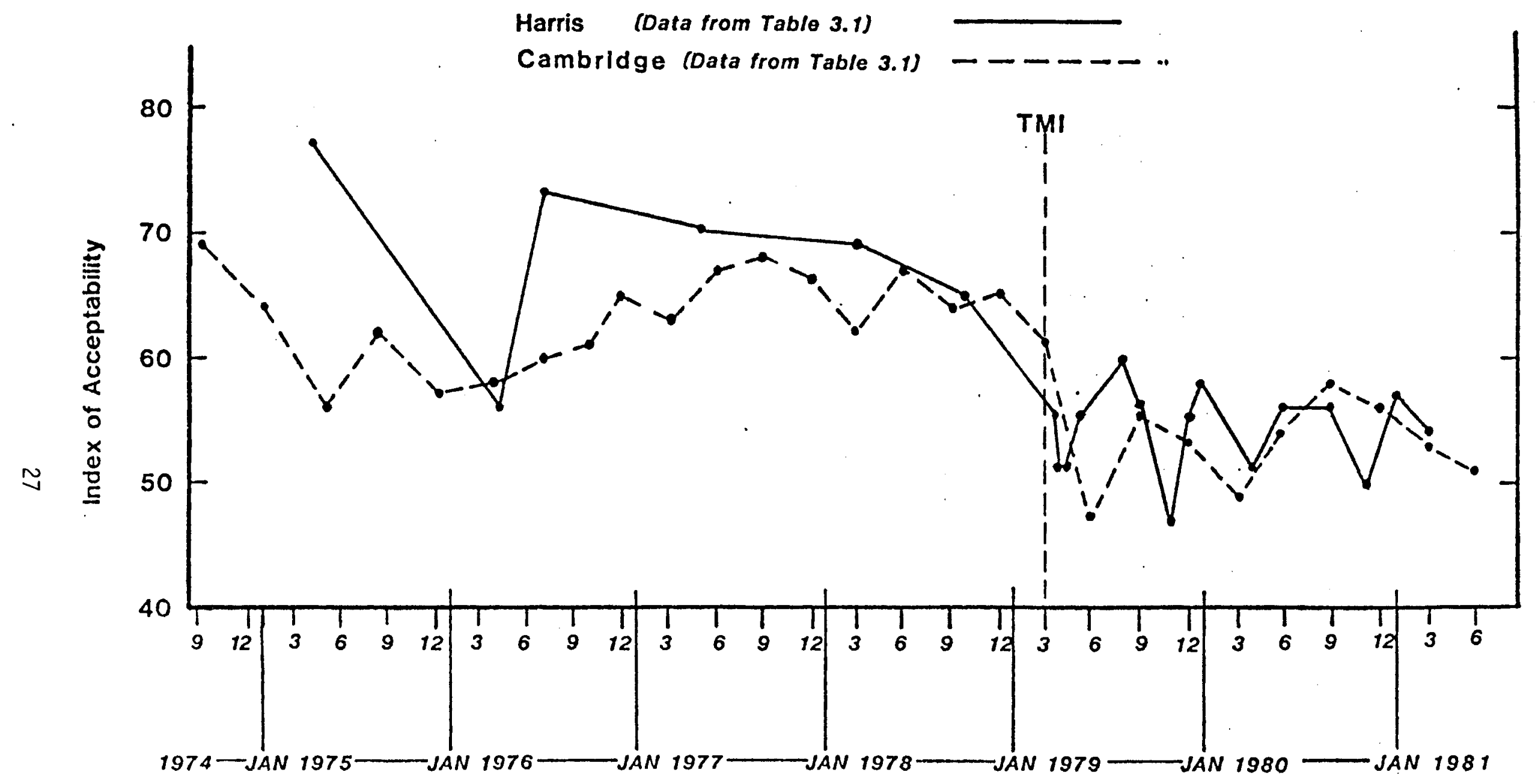

FIGURE 3.3 Index of Acceptability ${ }^{a}$ of Building More Nuclear Power Plants

a index of Acceptability $=\frac{\text { favor }}{\text { favor }+ \text { oppose }} \times 100$ 
analyses resulted in the same findings--prior to TMI there were fluctuations in levels of acceptability as measured by IA scores, but the slope of the line shown on Figure 3.3 was not significantly different ( $p>.32$ for the Cambridge data and $p>.59$ for the Harris data) from the horizontal. In other words, there was no trend toward increasing or decreasing levels of acceptability in the years prior to TMI.

As noted above, for the years following TMI, the average level of acceptability in both the Cambridge and Harris data significantly declined. The regression analyses for the same time period do not show any significant trend for levels of acceptability to increase to their pre-TMI levels or to decline further than they already have.

In summary, the accident at TMI and the incumbent attention paid to nuclear power in specific and to energy issues in general has had a significant effect on public attitudes toward the construction of additional nuclear power plants. On the question of support or opposition to continued nuclear power plant construction, about $54 \%$ of the American public favored such construction in the years preceding TMI. This base of support dropped to about $42 \%$ in the spring of 1979 , immediately after TMI. However, by summer 1979 support for cont inued nuclear plant construction had rebounded to about $47 \%$, still seven points lower than before the accident.

Surprisingly, TMI seemed to have a greater effect in increasing opposition than it did in decreasing support. The key may be in the percentage of the American public who were undecided about nuclear plant construction. This figure stood at about $18 \%$ before the accident, but has remained at about $12 \%$ since. Even before TMI about $28 \%$ of the 
American public opposed further nuclear plant construction. This figure rose to $44 \%$ during the accident period, but has averaged about $42 \%$ from the summer of 1979 to mid-1981. This suggests that opposition increased by $16 \%$ at the time of the accident but dropped off $3 \%$ since then for a net increase in opposition of 13\% comparing the pre- and post-Three Mile Island periods. While these changes cannot be attributed solely to the TMI accident, the accident does appear to be an important causal factor. Time and events will determine the nature, direction and extent of further changes in attitudes toward the construction of more nuclear power plants.

\subsubsection{Nuclear Power Plant Construction--Local}

The questions used by Cambridge and Harris to assess general attitudes toward construction of nuclear power plants were broadly worded, referring simply to "the construction of more nuclear power plants" (Cambridge) and to the "building of more nuclear power plants in the United States" (Harris). Other surveys, however, have phrased the question in terms of construction of a "local" nuclear power plant, using the respondent's own community as a referent. Figure 3.4 shows the percentage of individuals expressing favor or opposition to local construction of nuclear power plants and illustrates the significant turnaround that has occurred in the last nine years in the relative degrees of support and opposition for the local construction of nuclear power plants. The eight data points in Figure 3.4 were collected by three different research firms working for the same sponsor and using the same question. The 1971 and 1973 surveys were reported by Becker (73/6); the next four surveys were completed by $\operatorname{RAC}(75 / 8 ; 76 / 8 ; 77 / 8 ; 78 / 8)$; the 


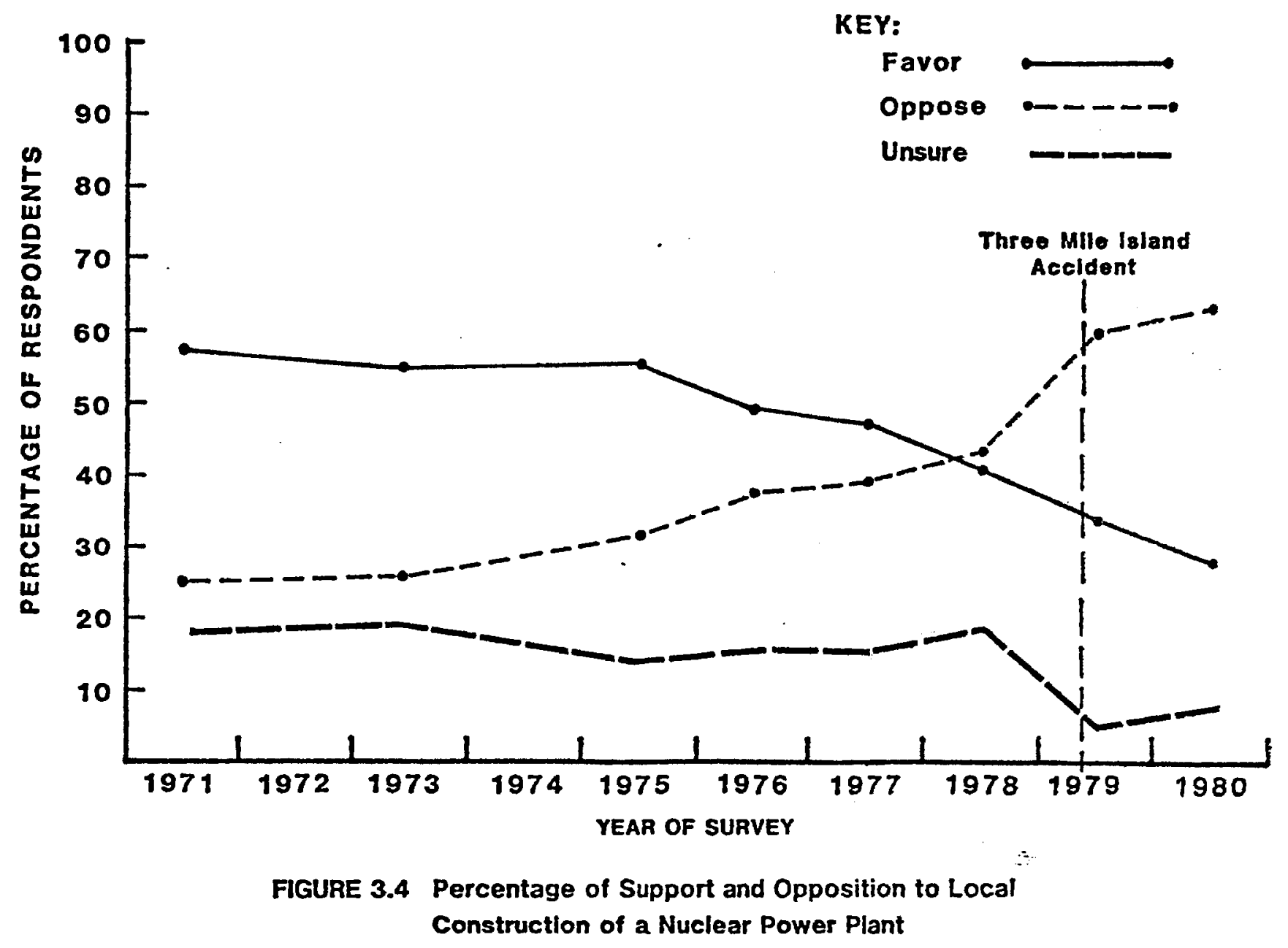

NOTE: "Suppose a new power plant had to be built in this area. For each of these ways of producing electricity, please tell me whether it would be all right with you if this method were used in this area, or whether you would be against it in this area. First take nuclear power. Would a new plant in this area that used nuclear power be all right with you or would you be against it? [ARB (80/6)]. Question presented in different format through 1977. A11 data points cited are in ARB $(80 / 60)$. 
final two surveys were completed by ARB $(79 / 7 ; 80 / 6)$. From 1971 through 1980 the percentage of those favoring local construction declined steadily from $57 \%$ to $28 \%$, while the percentage of those opposing rose from $25 \%$ to $63 \%$. Data from $\operatorname{RAC}(75 / 8 ; 76 / 8 ; 77 / 8 ; 78 / 8)$ also show a continuous decline in support for local nuclear power plant construction, from 55\% in favor in 1975 to $43 \%$ in favor in 1978. A similar increase in opposition--from 32\% to $41 \%$ between 1975 and $1978--$ is seen in the RAC data.

Questions in the Gallup $(76 / 6 ; 79 / 4)$ and Harris $(78 / 10 ; 80 / 1)$ surveys specified construction "within five miles". of the respondent's community or location. Table 3.1 shows the percentage of people who favor, oppose, or are uncertain about construction of nuclear power plants within five miles. Since 1976 there has been a consistent plurality opposed to such construction, with the highest expressions of opposition (60\%) and lowest support (33\%) measured by Harris (79/4) shortly after the TMI accident.

UMaine (ME 79/1) phrased the question in a different manner, referring to construction within ten miles. When phrased in this manner $60 \%$ expressed opposition, $33 \%$ were in favor, and $6 \%$ were unsure or undecided. The factor of distance was approached by TMI (Harrisburg 79/7) in a survey of Harrisburg, Pennsylvania, residents four months after TMI. The survey asked respondents at various distances from the TMI plant whether they had considered moving out of the area as a result of the accident. The results are shown in Table 3.2. Not surprisingly, as the distance from TMI increased, the percentage of those who thought about moving dropped very quickly. For those located within five miles 
TABLE 3.1

PERCENTAGE OF SUPPORT, OPPOSITION, AND UNCERTAINTY TO

CONSTRUCTION OF A NUCLEAR POWER PLANT WITHIN

FIVE MILES OF RESPONDENT'S COMMUNITY

\begin{tabular}{lccc}
\hline & Favor & Oppose & Uncertain \\
\hline Gallup $(76 / 6)^{\mathrm{a}}$ & 42 & 45 & 13 \\
Harris $(78 / 10)^{\mathrm{b}}$ & 36 & 55 & 7 \\
Gallup $(79 / 4)^{\mathrm{a}}$ & 33 & 60 & 7 \\
Harris $(80 / 1)^{\mathrm{b}}$ & 42 & 56 & 9 \\
\hline
\end{tabular}

a"As of today, how do you feel about the construction of a nuclear power plant in this area--that is, within five miles of here? Would you be against the construction of such a plant in your area, or not?" [Gallup $(76 / 6 ; 79 / 4)]$

b"Do you favor or oppose having a nuclear power plant within five miles of your community?" [Harris $(78 / 10 ; 80 / 1)]$ 
TABLE 3.2

PERCENTAGE OF RESPONDENTS WHO CONSIDERED MOVING AS A FUNCTION OF THE DISTANCE THAT THEY LIVE FROM THREE MILE ISLAND

\begin{tabular}{ll}
\hline Distance & $\%$ \\
\hline $0-5$ Miles & 30 \\
$5-10$ & 19 \\
$10-15$ & 17 \\
$15-25$ & 7 \\
$25-40$ & 5 \\
$40+$ & 3 \\
\hline
\end{tabular}

NOTE: "Has anyone in your household considered moving because of the accident?" [TMI (Harrisburg 79/7)] 
of the site, $30 \%$ thought about moving from the area because of the accident.

Taken together, these results suggest that there is a high degree of opposition to local construction of nuclear power plants, and this opposition has grown consistently in the last six years. The reported degree of opposition increases when the term "local" is anchored to a specified distance, e.g., "within five miles." Once constructed, however, and even in the face of an accident of uncertain proportions, relatively few people indicate a sufficient degree of concern to have considered moving.

A word of caution is necessary regarding these questions about specific distances. In the form in which they were asked it is difficult to interpret what respondents' attitudes in fact are toward local nuclear power plant construction. A negative response to such an item may reflect opposition to nuclear power, but an equally plausible alternative hypothesis is that the respondent is opposed to any industrial development "within five miles" of his or her home. Thus, similar results might be obtained if individuals were asked whether they favored or opposed the construction of an aluminum smelter or a steel fabricating mill within five miles of their home.

To more accurately assess attitudes toward nuclear power, such questions might be phrased to compare the desirability of different forms of industry. For instance, if an industry was to be established within five miles of a respondent's home, would he or she prefer it to be an aluminum smelter or a nuclear power plant/a nuclear power plant or a steel fabricating mill, etc. 
It should also be pointed out that it has been found (Melber, Nealey, Hammersla, \& Rankin, 1977) that those who actually live close to a nuclear power plant ("nuclear neighbors") are more supportive of nuclear power in general than is the general public. Thus, it may be that the actual experience of living near a nuclear power plant serves to moderate and minimize negative stereotypes about nuclear power which are reflected in responses to questionnaire items.

\subsubsection{Continued Operation of Nuclear Power Plants}

The most recent data in the previous sections showed that slightly more people favor the construction of more nuclear power plants in general than oppose such construction, but that a majority oppose the construction of nuclear power plants near their own communities. The material in this section will examine the question of the public's attitude toward the continued operation of existing nuclear power plants and their attitude regarding plants currently under construction. This analysis provides an opportunity for a more detailed examination of the components of attitudinal support and opposition to nuclear power plants.

The survey items that have addressed these issues can be categorized into three groups, including questions that refer to: (1) the permanent closure of all nuclear power plants; (2) the cutting back on the operation of nuclear power plants until more strict regulations can be developed and implemented; and (3) the continued operation of existing plants and the completion of those under construction, but with the implication that no new construction be started. Each group will be examined separately in the material below. 
Permanent closure. Items in this group generally asked whether respondents agreed or disagreed with such statements as "we should stop building nuclear plants including those under construction and shut down the existing ones as soon as possible" [RFF (80/1)], and "all nuclear power plants should be shut down permanently and no more should be allowed to be built" [Harris $(80 / 12)]$. Table 3.3 shows the percentage of support, opposition, and uncertainty expressed by respondents to such questions. Gallup (79/4) found that support for complete and permanent closure of nuclear plants peaked at $25 \%$ immediately following the TMI accident. Since then support for complete closure has remained relatively stable, averaging approximately $17 \%$.

In a similar fashion, Gallup (79/4) found that opposition to permanent disavowal of the nuclear alternative was lowest (64\%) immediately following the accident. Since TMI, opposition to permanently closing all plants has averaged about $75 \%$, i.e., nearly three-quarters of ' the respondents in these surveys oppose the total and permanent closure of all nuclear power plants.

Cut back--more strict regulations. Because the total and permanent closure of all nuclear power plants represents the most drastic alternative, we would expect it to receive relatively less support than more moderate positions. The second group of survey items represents such a position, asking respondents whether "nuclear power plants operating today are safe enough with the present safety regulations," or whether "their operations should be cut back until more strict regulations can be put into practice?" Table 3.4 shows the percentage of respondents who believe that nuclear power plants either are safe enough 
TABLE 3.3

PERCENTAGE OF SUPPORT, UNCERTAINTY, AND OPPOSITION TO

THE TOTAL AND PERMANENT CLOSURE OF ALL

NUCLEAR POWER PLANTS

\begin{tabular}{cccc}
\hline & Favor & Oppose & Uncertain \\
\hline Galiup $(79 / 4)^{\mathrm{a}}$ & 25 & 64 & 11 \\
Harris $(79 / 4)^{\mathrm{b}}$ & 15 & 79 & 6 \\
RFF $(80 / 1)^{\mathrm{c}}$ & 20 & 69 & 11 \\
UM $(80 / 1)^{\mathrm{d}}$ & 15 & 77 & 8 \\
UM $(80 / 4)^{\mathrm{d}}$ & 17 & 74 & 9 \\
UM $(80 / 6)^{\mathrm{d}}$ & 14 & 77 & 9 \\
UM $(80 / 9)^{\mathrm{d}}$ & 13 & 78 & 9 \\
UM $(80 / 11)^{\mathrm{d}}$ & 16 & 74 & 5 \\
Harris $(80 / 12)^{\mathrm{b}}$ & 17 & 78 & \\
\hline
\end{tabular}

a"Would you favor or oppose shutting down all nuclear plants at this time?" [Gallup (79/4)]

b"Do you approve or disapprove of the following policies for handling nuclear power in this country?--All nuclear power plants should be shut down permanently and no more be allowed to be built." [Harris $(79 / 4 ; 80 / 12)]$

C"We should stop building nuclear plants including those under construction and shut down the existing ones as soon as possible." [RFF $(80 / 1)]$ $80 / 11)]$

d"Close down all nuclear plants." [UM $(80 / 1 ; 80 / 4 ; 80 / 6 ; 80 / 9$; 
TABLE 3.4

PERCENTAGE OF SUPPORT, OPPOSITION, AND UNCERTAINTY TO CUTTING

BACK ON NUCLEAR POWER PLANT OPERATION UNTIL THE

IMPLEMENTATION OF STRICTER SAFETY REGULATIONS

\begin{tabular}{lccc}
\hline & Safe Enough & Cut Back & No Opinion \\
\hline Gallup $(76 / 6)^{a}$ & 34 & 40 & 26 \\
NBC $(79 / 4)^{b}$ & 51 & 43 & 6 \\
Gallup $(79 / 4)^{a}$ & 24 & 66 & 10 \\
Harris $(79 / 4)^{c}$ & 57 & 40 & 3 \\
Harris $(79 / 5)^{c}$ & 54 & 43 & 3 \\
Gallup $(79 / 6)^{a}$ & 34 & 40 & 26 \\
Gallup $(80 / 1)^{a}$ & 30 & 55 & 15 \\
Harris $(80 / 12)^{c}$ & 51 & 45 & 4 \\
\hline
\end{tabular}

a"Do you feel that nuclear power plants operating today are safe enough with the present safety regulations, or do you feel that their operations should be cut back until more strict regulations can be put into practice?" [Gallup (76/6;79/4;79/6;80/1)]

b"Should all nuclear power plants be closed down until questions about safety are answered?" [NBC (79/4)]

C"Do you approve or disapprove of the following policies for handling nuclear power in this country?--A11 nuclear power plants in the country should be closed down until the federal government knows more about the safety risks involved in them." [Harris $(79 / 4 ; 79 / 5 ; 80 / 12)$ ] 
to continue operations or should be cut back until questions regarding safety are answered.

Table 3.4 also illustrates an important point about differences in question wording that often arises whenever one attempts to compare data from different survey organizations. For the moment ignore differences in survey organizations in Table 3.4. Across all years and all organizations, it appears that a plurality of respondents do not feel that nuclear power plants are safe enough and agree that their operations should be cut back until the implementation of stricter safety procedures. On the average $47 \%$ feel they should be cut back, $42 \%$ feel they are safe enough, and $12 \%$ expressed no opinion. Note, however, the different percentages between the Harris and Gallup surveys, and the different question wordings. The Gallup data show that $31 \%$ feel that nuclear power is safe enough, $50 \%$ feel it should be cut back, and $19 \%$ expressed no opinion. Harris, on the other hand, found $54 \%$ who felt it to be safe enough, $43 \%$ who thought it should be cut back, and only $3 \%$ who expressed no opinion.

In terms of question wording, Gallup asked respondents whether nuclear power plant operations should be "cut back," while Harris asked whether such plants should be "shut down." As was pointed out above, a less drastic alternative is likely to receive a higher level of support. In this case, cutting back on operations is probably perceived as a less severe alternative than "shutting down" operations, and this perception is reflected in respondents' answers to the different questions. "Cutting back" operations of a nuclear power plant implies a reduced (and presumably safer) level of electrical production, which some may believe 
is not needed anyway, rather than a total cessation of activity with the resulting total loss of electrical production from nuclear power plant operation.

Thus, if people are asked whether nuclear power plant operations are safe enough or should be cut back (Gallup), approximately 50\% agree that they should be cut back. However, if people are asked whether nuclear power plants are safe enough or whether they should be shut down (Harris), then approximately $54 \%$ indicate that they are safe enough and should not be shut down. The implication of these data is that while the public is not convinced that nuclear power plants are safe, the public is not willing to forego completely the benefits of nuclear power (i.e., increased electrical generating capacity) until stricter safety regulations can be developed and implemented.

Only operate those already built. Another alternative to cutting back, closing down, or expanding nuclear power plant operation is to continue to operate only those plants that are already built. Table 3.5 shows the percentage of people favoring or opposing each alternative. A clear plurality (average across all surveys of $45 \%$ ) favor the continued operation of only those nuclear power plants that are currently operating, while approximately one-third (average of 30\%) favor building more nuclear power plants. A smaller minority (average of 16\%) favor closing down all existing nuclear power plants. It is important to note, however, that a majority of the respondents are opposed to the construction of more nuclear power plants--a result inconsistent with those regarding general attitudes toward nuclear power. 
TABLE 3.5

PERCENTAGE OF SUPPORT FOR THREE ALTERNATIVES FOR

NUCLEAR POWER PLANT OPERATION

\begin{tabular}{lcccccc}
\hline & RFF & UMb \\
\hline & $(80 / 1)$ & $(80 / 1)$ & $(80 / 4)$ & $(80 / 6)$ & $(80 / 9)$ & $(80 / 11)$ \\
\hline Build more & 23 & 32 & 31 & 31 & 30 & 32 \\
Operate only current & 47 & 45 & 43 & 46 & 48 & 42 \\
Close down & 20 & 15 & 17 & 14 & 13 & 16 \\
Don't know/no answer & 11 & 8 & 9 & 9 & 9 & 9 \\
& & & & & & \\
\hline
\end{tabular}

a"With which statement about the use of nuclear power in the United States do you most agree?" [RFF (80/1)]

bespondents to select alternative which most reflects their attitude. [UM $(80 / 1 ; 80 / 4 ; 80 / 6 ; 80 / 9 ; 80 / 11)]$ 
In summary, there is support for the cont inued operation of those nuclear power plants that are already on line. This support is weakened somewhat by the $50 \%$ (Gallup) who support cutting back on their operation until more strict safety regulations can be implemented, but strengthened by the 54\% (Harris) who oppose shutting them down pending such regulations. In addition to the support for continued operation of existing plants, there is strong (averaging about $75 \%$ ) opposition to the permanent closure of all nuclear power plants.

\subsubsection{Strength of Attitudes Toward Nuclear Power}

The material in the previous sections has dealt with the general levels of support and opposition to nuclear power, and data were presented using three response categories--favor/oppose/uncommitted. The material in this section will focus on the strength of attitudes toward nuclear power. Strength of attitude is an important concept because changes in attitudes occur gradually over time or in response to specific events such as the TMI accident. Compared to weak attitudes, strongly held attitudes are more likely to predict actual behavior toward the attitude object and are also more likely to be resistant to change (Insko, 1967).

Cambridge $(75 / 5 ; 78 / 5)$ collected data assessing the strength of attitudes toward the construction of more nuclear power plants using a seven-point scale (see Table 3.6). The 1975 data show that two-thirds of the respondents chose the extreme positions (23\% strongly favor and $27 \%$ strongly oppose) or the middle position (16\%). By 1978 those strongly in favor had remained relatively stable at $21 \%$, while those strongly opposed had decreased from $27 \%$ to $17 \%$. Those in the neutral category had 
TABLE 3.6

PERCENTAGE OF RESPONDENTS WHO DIFFER ON STRENGTH OF

ATTITUDE TOWARD NUCLEAR POWER PLANT CONSTRUCTION

\begin{tabular}{ccccccccc}
\hline $\begin{array}{c}\text { Strongly } \\
\text { Favor (\%) }\end{array}$ & 1 & 2 & 3 & 4 & 5 & 6 & 7 & $\begin{array}{c}\text { Strongly } \\
\text { Oppose }(\%)\end{array}$ \\
\hline Cambridge $(75 / 5)$ & 23 & 12 & 9 & 16 & 6 & 8 & 27 & \\
Cambridge $(78 / 5)$ & 21 & 11 & 13 & 22 & 9 & 8 & 17 & \\
\hline
\end{tabular}

NOTE: "On a scale from ' 1 ' to ' 7 ' where ' 1 ' means 'strongly favor' and 17 'means 'strongly oppose,' where would you place yourself on the scale with regard to the construction of more nuclear power plants?" [Cambridge $(75 / 5 ; 78 / 5)$ ] 
increased from $16 \%$ in 1975 to $22 \%$ in 1978. Combining across categories, in $197544 \%$ favored, $41 \%$ opposed, and $16 \%$ were neutral about the construction of more nuclear power plants. In 1978 the respective percentages were $45 \%, 34 \%$, and $22 \%$. These results are consistent with those discussed earlier regarding general support for and opposition to nuclear power during that period of time. Thus, from 1975 to 1978 attitudes toward nuclear power became slightly less polarized, but the extreme positions and the neutral position were still the three most chosen responses on the seven-point scale.

Other data from national samples exist where strength of attitude toward the construction of more nuclear power plants is measured using a four-point or five-point scale (see Table 3.7). Several interesting patterns are apparent in these data. First, through 1978 a plurality of the respondents were fairly favorable toward nuclear power. Those who were strongly favorable formed the second largest group, which was typically $10 \%$ to $20 \%$ larger than either of the unfavorable categories. Second, just before TMI, ORC (79/3) found that a $48 \%$ plurality of respondents strongly favored nuclear power. Note, however, that the $O R C(79 / 3)$ question was asked in the context of suggestions to improve the energy situation, which generally has been shown to increase levels of favorability to nuclear power (Melber et al., 1977). Third, through 1978, the percentage of those who were strongly unfavorable was usually slightly lower than the percentage of those who were fairly unfavorable. Fourth, immediately after TMI, Gallup (79/4) still found majority support for nuclear power, but the percentage of those who strongly favored (30\%) or who fairly favored (33\%) nuclear power was about equal. Because of 
TABLE 3.7

NATIONAL DATA ON STRENGTH OF ATTITUDE TOWARD THE CONSTRUCTION OF MORE NUCLEAR POWER PLANTS

\begin{tabular}{lccccc}
\hline & $\begin{array}{l}\text { Strongly } \\
\text { Favorable }\end{array}$ & $\begin{array}{l}\text { Fairly } \\
\text { Favorable }\end{array}$ & $\begin{array}{l}\text { Fairly } \\
\text { Unfavorable }\end{array}$ & $\begin{array}{l}\text { Strongly } \\
\text { Unfavorable }\end{array}$ & Unsure \\
\hline Becker $(73 / 6)^{a}$ & 28 & 33 & 9 & 4 & 26 \\
Becker $(74 / 6)^{a}$ & 26 & 38 & 12 & 5 & 19 \\
ORC $(74 / 11)^{b}$ & 29 & 40 & 11 & 9 & 11 \\
ORC $(75 / 2)^{b}$ & 31 & 33 & 8 & 14 & 14 \\
ORC $(75 / 4)^{b}$ & 26 & 29 & 10 & 11 & 24 \\
RAC $(75 / 8)^{a}$ & 28 & 47 & 10 & 7 & 8 \\
Gal (up $(76 / 7)^{c}$ & 34 & 37 & 10 & 13 & 7 \\
RFF $(78 / 8)^{b}$ & 23 & 42 & 16 & 10 & 5 \\
ORC $(79 / 3)^{d}$ & 48 & 26 & 11 & & \\
\hline
\end{tabular}

Three Mile Island

\begin{tabular}{llllll}
\hline Gallup $(79 / 4) \mathrm{c}$ & 30 & 33 & 13 & 17 & 7 \\
\hline
\end{tabular}

a"What is your general opinion of nuclear power? Would you say that it is strongly favorable, somewhat favorable, somewhat unfavorable, or strongly unfavorable?" [Becker $(73 / 6 ; 74 / 6)$ and RAC $(75 / 8)]$

b"Taking into account all you have heard or read, how do you feel toward nuclear power plants in general? Are you: very favorable; fairly favorable; fairly unfavorable; very unfavorable?" $[\operatorname{ORC}(74 / 11 ; 75 / 2 ; 75 / 4)$ and RFF $(78 / 8)]$

C"In order to meet the future needs of the nation, how important do you feel it is to have more nuclear power plants--extremely important, somewhat important, not too important, or not at all important?" [Gallup (76/7; 79/4)]

d"please tell me whether you strongly favor, mildly favor, mildly oppose, or strongly oppose this suggestion to improve our energy situation: more nuclear power plants should be built to generate electricity?" [ORC $(79 / 3)]$ 
the difference in question wording between ORC (79/3) and Gallup (79/4), it is very hard to speculate on the impact of the TMI accident on strength of attitude. However, it is clear that the polarization of attitudes found using the seven-point scale is not found using the four-point scale. This may be due to a scaling problem whereby those respondents who would have selected the 2 or 3 rating on the Cambridge $(75 / 5 ; 78 / 5)$ question selected the fairly favorable category on the questions presented in Table 3.7. The same sort of logic would hold for the 5 and 6 responses becoming fairly unfavorable responses.

Finally, data from state samples on the strength of attitudes toward the construction of additional nuclear power plants are available (see Table 3.8) where four-point scales were also used. The available data represent only five states (California, Massachusetts, Pennsylvania, Rhode Island, and Wisconsin) and thus limit the degree to which generalizations can be made. For present purposes, however, the data can be compared to the data derived from national samples in order to see if similar patterns and trends emerge.

The picture that emerges from the state data, although not as clear as that shown by the national surveys, is somewhat similar. Through 1978, the percentage of those who were fairly favorable toward nuclear power was about the same or higher than the percentage of those who were strongly favorable, and, except in California, the levels of unfavorability were approximately the same. However, in Massachusetts just prior to TMI, polarized attitudes were already apparent. Following TMI, the plurality of respondents in state surveys have usually been strongly unfavorable toward nuclear power. Among those who are favorable 
TABLE 3.8

STATE DATA ON THE PERCENTAGE OF STRENGTH OF ATTITUDE TOWARD THE CONSTRUCTION OF MORE NUCLEAR POWER PLANTS

\begin{tabular}{|c|c|c|c|c|c|}
\hline & $\begin{array}{l}\text { Strongly } \\
\text { Favorable }\end{array}$ & $\begin{array}{l}\text { Fairly } \\
\text { Favorable }\end{array}$ & $\begin{array}{l}\text { Fairly } \\
\text { Unfavorable }\end{array}$ & $\begin{array}{l}\text { Strongly } \\
\text { Unfavorable }\end{array}$ & Unsure \\
\hline $\begin{array}{l}\text { Becker (Plymouth 74/6)a } \\
\text { Becker (P y ymouth 77/u)a } \\
\text { Becker (RI 78/6)a } \\
\text { RAC (PA 78/8) } \\
\text { Field (CA 78/8)c } \\
\text { PARC (MA 79/2)d } \\
\text { PARC (MA 79/2)e } \\
\text { WPI (MA 79/u)f }\end{array}$ & $\begin{array}{l}37 \\
24 \\
27 \\
18 \\
26 \\
33 \\
24 \\
36\end{array}$ & $\begin{array}{l}38 \\
30 \\
33 \\
35 \\
25 \\
21 \\
18 \\
22\end{array}$ & $\begin{array}{l}11 \\
15 \\
15 \\
15 \\
15 \\
14 \\
17 \\
16\end{array}$ & $\begin{array}{r}2 \\
7 \\
16 \\
17 \\
29 \\
24 \\
41 \\
26\end{array}$ & $\begin{array}{r}10 \\
14 \\
9 \\
15 \\
5 \\
8 \\
5 \\
-\end{array}$ \\
\hline \multicolumn{6}{|c|}{ Three Mile Island } \\
\hline $\begin{array}{l}\text { WSRL (WI 79/5)g } \\
\text { PARC (MA 79/5)d } \\
\text { PARC (MA 79/5) e } \\
\text { Becker (P1ymouth 79/6) a } \\
\text { WPI (MA 80/3) f } \\
\text { Becker (MA 80/4) } \\
\text { Becker (MA 80/12) } \\
\text { Becker (MA 81/2) }\end{array}$ & $\begin{array}{l}15 \\
18 \\
12 \\
18 \\
19 \\
12 \\
21 \\
21\end{array}$ & $\begin{array}{l}37 \\
17 \\
14 \\
26 \\
17 \\
29 \\
27 \\
29\end{array}$ & $\begin{array}{l}22 \\
18 \\
10 \\
20 \\
19 \\
18 \\
13 \\
16\end{array}$ & $\begin{array}{l}15 \\
34 \\
57 \\
26 \\
46 \\
35 \\
32 \\
29\end{array}$ & $\begin{array}{r}11 \\
13 \\
7 \\
10 \\
- \\
6 \\
7 \\
5\end{array}$ \\
\hline
\end{tabular}

a"What is your general opinion of producing electric power by nuclear energy? Would you say that your opinion is strongly favorable, somewhat favorable, somewhat unfavorable, or strongly unfavorable?" [Becker (Plymouth 74/6; 77/u; $79 / 6) ;($ RI 78/6); and (MA 80/4;80/12;81/2)]

b" What is your general opinion of nuclear power? Would you say that it is strongly favorable, somewhat favorable, somewhat unfavorable, or strongly unfavorable?" [RAC (PA 78/8)]

C"There are several different ways that California might take care of its future energy needs. I'm going to read you some of these and I would like you to tell me whether you approve or disapprove of each one--allow the building of more nuclear power plants in California... Do you (approve) (disapprove) strongly or somewhat?" [Field (CA 78/8)]

d"Do you favor or oppose the building of more nuclear power plants in the United States (stronaly favor, mildly favor, mildly oppose, strongly oppose)?" [PARC (MA 79/2;79/5)]

e"Would you favor or oppose the building of a nuclear power plant in your community (strongly favor, mildly favor, mildly oppose, strongly oppose)?" [PARC (MA $79 / 2 ; 79 / 5)]$

f"Attitudes toward nuclear power: strongly oppose, mildly oppose, mildly favor, strongly favor." [WPI (MA 79/u; 80/3)]

g"In general, how do you feel about nuclear power plants (very favorable, fairly favorable, fairly unfavorable, very unfavorable)?" [WSRL (WI 79/5)] 
toward nuclear power, a higher percentage are usually fairly rather than strongly favorable.

Keeping in mind the limitations of the data, and the fact that changes in survey data can almost never be attributed to the impact of a single event (i.e., we cannot say that the events surrounding the TMI accident "caused" the changes in people's attitudes), we can describe the changes that occurred in these five states. Overall support for the construction of more nuclear power plants declined, composed of a significant decrease in the percentage of strong supporters and a smaller decrease in the percentage of those fairly favorable. Opposition increased significantly, composed of a large increase in those strongly opposed and a smaller increase in those fairly unfavorable.

It is tempting to speculate about the influence of TMI on the attitudes of individual respondents. For example, it is tempting to suggest that respondents who were fairly unfavorable prior to the TMI accident became strongly unfavorable after, or that those strongly favorable became fairly favorable. In spite of its intuitive appeal, the description of such a detailed process cannot be made from these data. We do not have the longitudinal data--measurements from the same individuals before and after some event--that would illuminate the specific anatomy of changes in attitudes toward the construction of more nuclear power plants.

\subsection{The Relationship Between Attitudes Toward Nuclear Power and Nuclear-Related State Initiatives}

\subsubsection{Introduction}

In 1976 and in 1980 a number of states have had initiative questions placed on election ballots dealing with issues related to nuclear power. 
The material in this section will discuss the relationship between the outcomes of some of the 1980 intiatives and attitude data that are relevant to these initiatives. Specifically, this section discusses attitude data and nuclear-related initiatives that occurred in five states in 1980, including Maine, Massachusetts, Missouri, Oregon, and South Dakota. In some cases there are data for the periods both before and after the intiatives, in others only for the period before or after.

A number of important points should be kept in mind regarding the relationship between attitudes and electoral behavior. Survey techniques and data interpretation are not exact sciences. For any given survey or electoral issue, one never knows the precise relationship between an individual's response to a survey item and his or her behavior in an election booth and the resulting decision on a ballot issue. Voting behavior is a quintessentially private behavior that culminates in the aggregation of many such private responses. When trying to predict how an individual will vote on an issue we must rely on his or her verbal report and the probability that the report will be followed with a consistent behavior in the voting booth. As pollsters are often aware, there are many sources of error in the equation. Nevertheless, when surveys are conducted shortly before elections, they often accurately predict voting behavior. It should be remembered, however, that in the case of the present data the surveys were often taken weeks or months before the ballot question came before the public, providing an interval during which many different events could have occurred and interacted to affect the outcome of an election. 
Similarly, in trying to find out how an individual voted on an issue, we must rely on his or her verbal report of past behavior in the voting booth. Again, there may be innumerable internal and external factors that affect the accuracy of this kind of postdiction. For example, an individual may support an apparently unpopular or minority view and behave consistently with those convictions in the voting booth, but be unwilling to take a public and open stand on the same position. Finally, when comparing survey data to voting behavior we are in a quandry over the framework for such an analysis. We can assume, with some intuitive sense of confidence, that survey-determined proponents and opponents of a measure behave consistentiy in the voting booth. What is the standard of comparison, however, for those who report that they are neutral, don't know, or are undecided on a survey item? Do these people not vote at all or not vote on the specific issue? If so, they are not the only ones who do not exercise their voting right. On the survey data the percentage of undecided respondents ranges from $2 \%$ to $15 \%$, yet up to $45 \%$ or more of the eligible voting population fail to make it to the polling place in most elections and not all of them vote on a given issue. Where then do the rest of the non-voters come from? We do not know what proportion of attitudinal opponents and proponents actualiy vote on an issue. Bearing these cautions in mind, the analys is presented in this section will allow a more detailed look at public attitudes about nuclear issues in several states, and how these may have interacted with the outcomes of nuclear-related in itiatives. 


\subsubsection{Maine}

On September 23, 1980, a special election was held in Maine on the question, "Shall an act to prohibit the generation of electric power by means of nuclear fission become law?" Of the $57.4 \%$ of the registered voters who voted in the special election, $41 \%$ voted yes $(161,181)$ and $59 \%$ voted no $(233,198)$. Although broadly worded, the effect of passage of the referendum would have been to shut down an operating nuclear power. plant--the Maine Yankee plant--and to prevent construction of other plants within the state.

Two surveys from the state of Maine, UMaine (ME 79/1) and Weekly (ME 80/5), both taken before the September election were available. UMaine (ME 79/1) found a plurality opposed to the construction of a second nuclear power plant (49.5\% opposed, $40.5 \%$ in favor, and $10 \%$ opposed), and a majority opposed to the construction of such a plant within ten miles of their own home (60.3\% opposed, $33.3 \%$ in favor, and $6.3 \%$ undecided). These results represented a significant change in attitude from 1976 [reported in Weekly (ME 80/5)] when approximately a 2 to 1 ratio favored the construction of a second nuclear power plant in Maine.

Although the state residents were generally opposed to the construction of a second nuclear power plant, UMaine (ME 79/1) found that a clear majority (64.7\%) of the Maine respondents were in favor of the continued operation of the existing plant. This conflict may have been a key factor in the defeat of the Maine referendum. Three groups of individuals were identified in the survey: (1) $37.5 \%$ who favored both the continued operation of Maine Yankee and the construction of a second 
nuclear power plant; (2) $27.7 \%$ who opposed both the continued operation of Maine Yankee and the construction of a new plant; and (3) $34.8 \%$ who were opposed to construction of a new plant within ten miles of the ir home, but favored the continued operation of Maine Yankee. Thus, in order to pass, proponents of the referendum would have had to convince the third group that Maine Yankee represented such a potential for immediate disaster that it should be closed regardless of the economic consequences. Evidently, this did not occur.

Weekly (ME 80/5) conducted a small (60 respondents) telephone survey four months before the special election in September. Respondents were read a list of five alternatives concerning nuclear energy in Maine and asked to choose the one that they favored. The results of the survey were similar to UMaine (ME 79/1) even though they were carried out over one year apart. A plurality (36.5\%) preferred to continue operating Maine Yankee, but with the added protection of more stringent safety standards. A second group (23.8\%) favored the continued operation of Maine Yankee, but also favored a ban on the construction of any new nuclear power plants in Maine. A third group (20.1\%) favored the closure of Maine Yankee. Only a very small number of respondents (4.8\%) favored both the continued operation of Maine Yankee and the construction of additional plants in Maine, compared to $37.5 \%$ for the same group in UMaine (ME 79/1).

In summary, the result of the Maine referendum was apparent from the survey data available prior to the vote. Although the results showed a plurality opposed the construction of a second nuclear power plant, the benefits of the continued operation of Maine Yankee apparently outweighed 
these concerns, resulting in a majority "no" vote on a referendum to close the plant and prohibit additional plants.

\subsubsection{Massachusetts}

Although Massachusetts had no formal initiatives or referenda, they did have what are called "public policy" questions on the ballots in individual areas of the state. Each district used its own question to measure public attitudes on nuclear power issues. The results of the voting held on November 4, 1980 had no weight other than to influence elected officials.

The district representing the communities of Plymouth and Kingston had a public policy question on the ballot regarding the construction of a second nuclear power plant at Pilgrim Station. The results of the district election were $8,282(44 \%)$ in favor of construction, $8,811(47 \%)$ opposed, and $1,815(9 \%)$ blank ballots. The same question (although in slightly different form) has been on the ballot periodically in Plymouth since 1974, and there are detailed survey data by Becker (Plymouth $79 / 6 ; 80 / 8$ ) on respondents from Plymouth and the surrounding areas.

Two surveys taken only months before the election illustrate the quickly changing nature of public attitudes. Becker (Plymouth 80/4) found that $51 \%$ would vote for and $42 \%$ would vote against construction of a second plant. Four months later Becker (Plymouth $80 / 8$ ) found that $43 \%$ would vote for and $52 \%$ would vote against construction. Three months later the actual vote was $44 \%$ in favor and $47 \%$ opposed, which is quite close to the final Becker (Plymouth 80/8) data.

Table 3.9 shows the percentage of support for and opposition to construction of a second nuclear power plant at Pilgrim Station since 1974, including the November, 1980, vote on the question. The data show a 
TABLE 3.9

PERCENTAGE OF SUPPORT FOR AND OPPOSITION TO CONSTRUCTION OF A SECOND NUCLEAR POWER PLANT AT PILGRIM STATION

\begin{tabular}{cccc}
\hline & For Construction & Against Construction & Don't Know \\
\hline Becker (Plymouth) & & & \\
$74 / 6^{\mathrm{a}}$ & 62 & 19 & 19 \\
$76 / 3^{\mathrm{b}}$ & 56 & 31 & 13 \\
$79 / 6 \mathrm{C}$ & 45 & 47 & 8 \\
$80 / 4 \mathrm{C}$ & 51 & 42 & 5 \\
80/8C & 43 & 52 & 9 \\
\hline
\end{tabular}

a"Would building these two additional nuclear units be all right with you or would you oppose it?" [Becker (Plymouth 74/6)]

b"The following question will be on the Plymouth town election ballot of April 24. 'Shall a second nuclear power station be constructed within the town of Plymouth?' If the election were being held today, would you vote in favor of constructing another nuclear power station in Plymouth, or would you vote aqainst it?" [Becker (Plymouth 76/3)]

C"If an election were held on the question of building Pilarim 2, that is, a second nuclear power station at $P l y$ mouth, would you vote in favor of this or would you vote against it?" [Becker (Plymouth 79/6; $80 / 4 ; 80 / 8)]$ 
decrease in support for and an increase in opposition to construction of the second plant. Table 3.10 shows the strength of attitudes toward construction. The data show a significant change in levels of support from a 3 to 1 ratio in favor in 1974 to a majority in opposition to construction in 1980. In addition, by 1980 support and opposition had polarized with the largest percentages falling in the strongly committed categories.

What is the relationship between the surveys and the election results in November, 1980? Based on the latest survey data available, one would have predicted a vote of $43 \%$ in favor of and $52 \%$ opposed to construction of the second plant, accurately predicting the outcome of the election but overestimating the strength of those opposed. Here the prediction is directly available from the survey data, as opposed to the situation in Maine, which was more complex. The explanation for the difference in outcome between the two votes most likely lies in the nature of the question presented to survey respondents and to the voters. In Plymouth individuals were only presented with the question of construction of a second plant. They were not, as in Maine, confronted with the problem of deciding on the fate of an operating plant. Thus, the Plymouth residents were not faced with as difficult or as restrictive a choice as the voters in Maine were.

What if the Plymouth residents were faced with such a choice? Although the issue did not arise, there is evidence to suggest that they would have rejected a proposition to ban the generation of electricity by the use of nuclear power, as did the voters in Maine, if that entailed the closure of a plant currently operating. Becker (Plymouth $80 / 8$ ) found that although the majority (56\%) of Plymouth residents did not feel that their electric bills were lower as a result of the operation of Pilgrim 1, 53\% agreed that it 
TABLE 3.10

STRENGTH OF ATTITUDE TOWARD CONSTRUCTION OF A SECOND NUCLEAR POWER PLANT AT PILGRIM STATION

\begin{tabular}{cccccc}
\hline & $\begin{array}{l}\text { Strongly } \\
\text { Favorable }\end{array}$ & $\begin{array}{l}\text { Somewhat } \\
\text { Favorable }\end{array}$ & $\begin{array}{l}\text { Somewhat } \\
\text { Oppose }\end{array}$ & $\begin{array}{l}\text { Strongly } \\
\text { Oppose }\end{array}$ & Undecided \\
\hline Becker $(P 1$ ymouth) & & & & & \\
$74 / 6$ & 37 & 37 & 11 & 2 & 12 \\
$79 / 6$ & 18 & 26 & 20 & 26 & 10 \\
$80 / 8$ & 27 & 12 & 11 & 41 & 5 \\
\hline
\end{tabular}

a"Now that you've had a chance to think about some of the arguments in favor of and against construction of a nuclear power plant in Plymouth, would you vote in favor of construction or would you oppose it?" [Becker (Plymouth $74 / 6 ; 79 / 6 ; 80 / 8)]$ 
provided a solid tax base for the community. Fifty-three percent also agreed that the plant had not adversely affected the community and that the entire area was better off as a result of having Pilgrim 1.

Thus, even though they opposed construction of an additional plant, Plymouth residents thought that the existence and operation of Pilgrim 1 had a continuing beneficial impact on the community. It is unlikely that they would have voted to close down an existing plant in order to prohibit construction of additional ones.

\subsubsection{Missouri}

On November 4, 1980, Proposition 11 appeared on the ballot in the state of Missouri, asking voters whether or not to prohibit "the operation of electrical power generating facilities utilizing nuclear fission unless: federally approved sites exist for permanent storage of spent fuel and other radioactive material. . ." The proposition failed with $61 \%$ voting against and $39 \%$ voting for. It is important to note that this proposition is somewhat less drastic than those offered in Maine or Massachusetts, which called for the permanent closure of existing plants and the prohibition of construction of additional plants. Missouri voters were asked whether or not to prohibit the operation of nuclear plants until approved waste disposal sites were developed. At the time there were no operating plants in Missouri, although Calloway 1 and 2 were in the construction stage near Fulton and could have been affected by the outcome of the vote.

A number of statewide surveys were taken in the years preceding the election, all of which suggested that there was a high degree of support for nuclear power among the residents of the state. FH (MO 79/3) 
surveyed attitudes toward using nuclear power to generate electricity and found $53 \%$ in favor and $17 \%$ opposed. There was also an uncharacteristically high (30\%) percentage of people who were undecided. A majority of the residents also favored the construction of a nuclear power plant at Fulton, Missouri (54\% favor, 17\% oppose, and $29 \%$ undecided). Even following the TMI accident, FH (MO 79/8) found that nearly one-half of the Missouri residents approved using nuclear power to generate electricity ( $49 \%$ favor, $31 \%$ oppose, $19 \%$ undecided), although there had been a significant increase in opposition and a decrease in those who were undecided. In addition, a majority (54\%) still approved of the construction of the plant at Fulton. Again, there was a large increase in opposition (from $17 \%$ to $30 \%$ ) and a decrease in those undecided (from $29 \%$ to $16 \%$ ). These results suggest that the TMI accident had the effect of increasing the opposition to nuclear power without changing the degree of support. FH (MO 79/8) found that TMI had affected citizens' attitudes toward nuclear power not at all (48\%) or only a little (15\%). Only 12\% were somewhat or greatly (16\%) affected.

The residents in the immediate area of the Fulton plant were not greatly affected by its presence. FH (Callaway 79/11) found that the plurality of county residents (38\%) had no particular reaction to living relatively close to an operating nuclear power plant--25\% of the county residents were generally favorable and $18 \%$ were generally unfavorable.

Thus, the available survey data show that there was a climate of acceptability surrounding nuclear power in Missouri in the time leading up to the vote on Proposition 11. In the absence of survey data obtained closer to November, 1980, and barring unusual circumstances that would 
have significantly changed public attitudes, we would have predicted that Proposition 11 would have gone down in defeat as it, in fact, did.

\subsubsection{Oregon}

On November 4, 1980, residents of Oregon passed (52.8\% to $47.2 \%$ ) State Ballot Measure 7 requiring voter approval for licensing for nuclear power plants and a moratorium on further construction until the development of a nuclear waste disposal facility. BH (Trojan 79/4), conducted a year before the election, addressed the issues of general attitudes toward nuclear power and toward the construction of additional nuclear power plants and also investigated the impact of the accident at TMI .

Following TMI the Oregon Assembly considered a one- or two-year moratorium on approval of the construction of nuclear power plants. Statewide, $81 \%$ of the population agreed that the legislature should impose a one-year moratorium, $17 \%$ were opposed to the delay, and $2 \%$ were undecided. In addition, $88 \%$ believed that TMI would increase present and future safety precautions in both the construction and operation of nuclear power plants.

BH (Trojan 79/4) also found that for the first time a plurality of the population disapproved of the existing Trojan nuclear power plant. Table 3.11 shows the degree of support for and opposition to the Trojan plant. The data show considerable fluctuation in the percentage of approval from a high of $66 \%$ in 1975 to a low of $43 \%$ in both 1970 and 1979. Levels of disapproval gradually increased in relatively steady increments, and there was a relatively steady decrease in the percentage of those who were undecided. 
TABLE 3.11

PERCENTAGE OF APPROVAL AND DISAPPROVAL OF THE TROJAN NUCLEAR POWER PLANT IN OREGON

\begin{tabular}{lccccc}
\hline & $(70 / u)$ & $(72 / u)$ & $(75 / u)$ & $(78 / u)$ & $(79 / 4)$ \\
\hline Approve & 43 & 57 & 66 & 47 & 43 \\
Disapprove & 22 & 16 & 23 & 35 & 47 \\
Undecided & 35 & 27 & 11 & 18 & 10 \\
\hline
\end{tabular}

NOTE: Exact question wording and survey dates unavailable in published report. Reported in BH $[\operatorname{Trojan}(79 / 4)]$. 
In addition to the plurality opposition to the existing nuclear power plant, BH (Trojan 79/4) showed that the clear majority of Oregon residents also disapproved of the possibility of constructing a second plant (60\% disapprove, $32 \%$ approve, $8 \%$ undecided). This finding was almost the opposite of the results found in 1972 (61\% approve, $17 \%$ disapprove, and 22\% undecided) and in 1975 (58\% approve, $29 \%$ disapprove, 13\% undecided). Eighty percent of the respondents refuted the premise that more nuclear power plants were the only way to assure that there would not be a shortage of power in Oregon; $61 \%$ disputed the claim that more such plants were needed to meet the future energy needs of the nation; and a total of $70 \%$ of the respondents opted for postponing (41\%) or banning (29\%) construction of nuclear power plants in Oregon.

As was the case in the other states reported above, although there was a high degree of opposition to an existing plant and to proposals to build an additional plant, the clear majority of Oregon residents opposed shutting down all of the nuclear power plants in the United States (59\% opposed, 32\% favor, and 9\% undecided).

Given the existing $\mathrm{climate}$ of opposition that was apparent in Oregon in the years preceding the November, 1980, election, it is no surprise that Ballot Measure 7 passed. Based on the data from BH (Trojan 79/4), however, it is surprising that the margin of passage (52.8\% to $47.2 \%$ ) was as narrow as it was. The measure did not call for the closure of already operating nuclear power plants nor for a permanent ban on additional construction in the state. Rather, the measure conditioned operating licenses on the existence of a nuclear waste disposal facility and voter approval. This final condition can, however, be seen as a significant 
deterrent to the investment of capital necessary to construct a nuclear power plant when an operating license is then left to a popular vote. Nonetheless, the general attitudes of the respondents in Oregon toward nuclear power do not appear to be significantly different from those of individuals in the other states reviewed in this section.

\subsubsection{South Dakota}

The voters in South Dakota were presented with the opportunity to vote on a very complicated act (which failed $51.1 \%$ to $48.9 \%$ ) that would have regulated uranium mining, the construction of nuclear power plants, and the disposal of nuclear waste (Initiative Measure 2). Although never legally interpreted by the South Dakota Attorney General, the measure apparently would have severely restricted nuclear-related activities in the state.

Cambridge (SD 80/6) conducted a survey five months before In it iative Measure 2 appeared on the ballot. The survey asked about the construction of nuclear power plants in general. The results showed that $52 \%$ opposed, $28 \%$ favored, $17 \%$ were neutral, and $8 \%$ didn't know about nuclear power plant construction. However, $46 \%$ said they would oppose a law that would prohibit construction of more nuclear power plants within the state, while $43 \%$ favored and $11 \%$ didn't know about such a law. Similarly, $50 \%$ would oppose a law prohibiting uranium or milling operations, while' $34 \%$ favored, and 15\% didn't know. Finally, South Dakota residents were asked if they would favor or oppose a law that would require the approval of a majority of the voters in a special statewide election in order to construct any nuclear power plants or waste disposal facilities or to begin any uranium mining or milling 
operations in South Dakota. The results showed that a clear $77 \%$ majority would favor such a law, while only $16 \%$ would oppose it.

In spite of the $52 \%$ opposition to construction of plants and $77 \%$ support of a law giving voter approval for more nuclear activities in the state, Initiative Measure 2 was voted down by a margin of $51.1 \%$ to 48.9\%. The root of the voters' decision on the measure is found in those pluralities ( $46 \%$ to $50 \%$ ) opposing prohibitory legislation and in such

attitudes as those expressed by a large $86 \%$ majority of the residents who agreed that individual property owners have a right to decide about the use of their land for uranium mining or milling.

\subsubsection{Summary}

Although there are widely divergent trends within and between the states covered in this section, there are several important lessons that seem to emerge from the data. First, there appears to be a plurality of opposition (and in some cases, a majority) to the construction of more nuclear power plants in these states. In addition, there is substantial opposition toward nuclear power in general. In spite of these attitudes, however, people in the states are not willing to forego the benefits of an existing nuclear power plant--there is a plurality of opposition to survey items or initiative measures that call for the closure of existing plants, either within a state or in the context of a nationwide ban. Finally, there is considerable support for the idea of allowing voters in the state to approve or disapprove proposals for nuclear-related activities.

The outcomes of the initiatives reflect the interactions of the attitudes expressed in the surveys. Thus, although there is opposition 
to construction of additional plants, measures that would "prohibit the generation of electric power by means of nuclear fission" (Maine) or prohibit the "operation of electrical power-generating facilities utilizing nuclear fission" (Missouri) fail at the polls, presumably because they would result in the shut-down of currently operating or soon-to-be completed plants. Yet when the measure calls for a moratorium on construction (Massachusetts) or for voter approval for licensure (Oregon), it may pass. It should also be pointed out, however, that all of these factors may be mediated in some fashion by an overriding climate of support (e.g., Missouri) or opposition (e.g., Oregon) toward nuclear power.

\subsection{The Relationship Between Attitudes Toward Nuclear} Power and Respondent Demograph ic Characteristics

The material in the previous section showed that there are considerable fluctuations in general attitudes toward nuclear power that have occurred gradually over time, and rather large changes that have occurred following the accident at TMI. This section will examine the influence of general demographic variations in attitudes toward nuclear power, focusing on sex, age, socioeconomic status (including education, income, and occupation), and geographic region.

The analyses presented here are based on data gathered in national samples by major survey organizations. Results from other national and local surveys will also be included where appropriate. Data from 1975 to the present will be presented focusing on two question types: (1) those which assess general attitudes toward the construction of more nuclear power plants, and (2) those which assess attitudes toward the 
construction of nuclear power plants in respondents' own local commun ities.

\subsubsection{Sex Differences in Attitudes Toward Nuclear Power}

National data show that males continue to be more supportive and less uncertain toward nuclear power than females. These findings are consistent for attitudes toward nuclear power plant construction in general and for local nuclear power plant construction.

Cambridge data assessing the attitudes of respondents toward nuclear power plant construction in the united States show that men are more likely to support and less likely to oppose nuclear power plant construction than are women (see Figure 3.5). Support for nuclear power plant construction from 1975 to 1978 by males ranges from $57 \%$ to $65 \%$, and by women ranges from $34 \%$ to $53 \%$. Opposition for the same time period ranges from $22 \%$ to $29 \%$ for men and $28 \%$ to $42 \%$ for women.

These data show that there are fluctuations in the levels of support and opposition toward nuclear power plant construction for both males and females. There is, however, a larger degree of fluctuation among women than men. Further, the Cambridge data show a decline in support and rise in opposition following TMI for both men and women, although there is some tendency in the Cambridge $(80 / 11)$ data for levels to return to their pre-TMI levels.

The Harris data are similar to those from Cambridge; men are more likely to support nuclear power plant construction (63\% to $70 \%$ ) than are women (50\% to $54 \%$ ), and men are less likely than women to oppose such construction (see Figure 3.6). The Harris data are different, however, in 


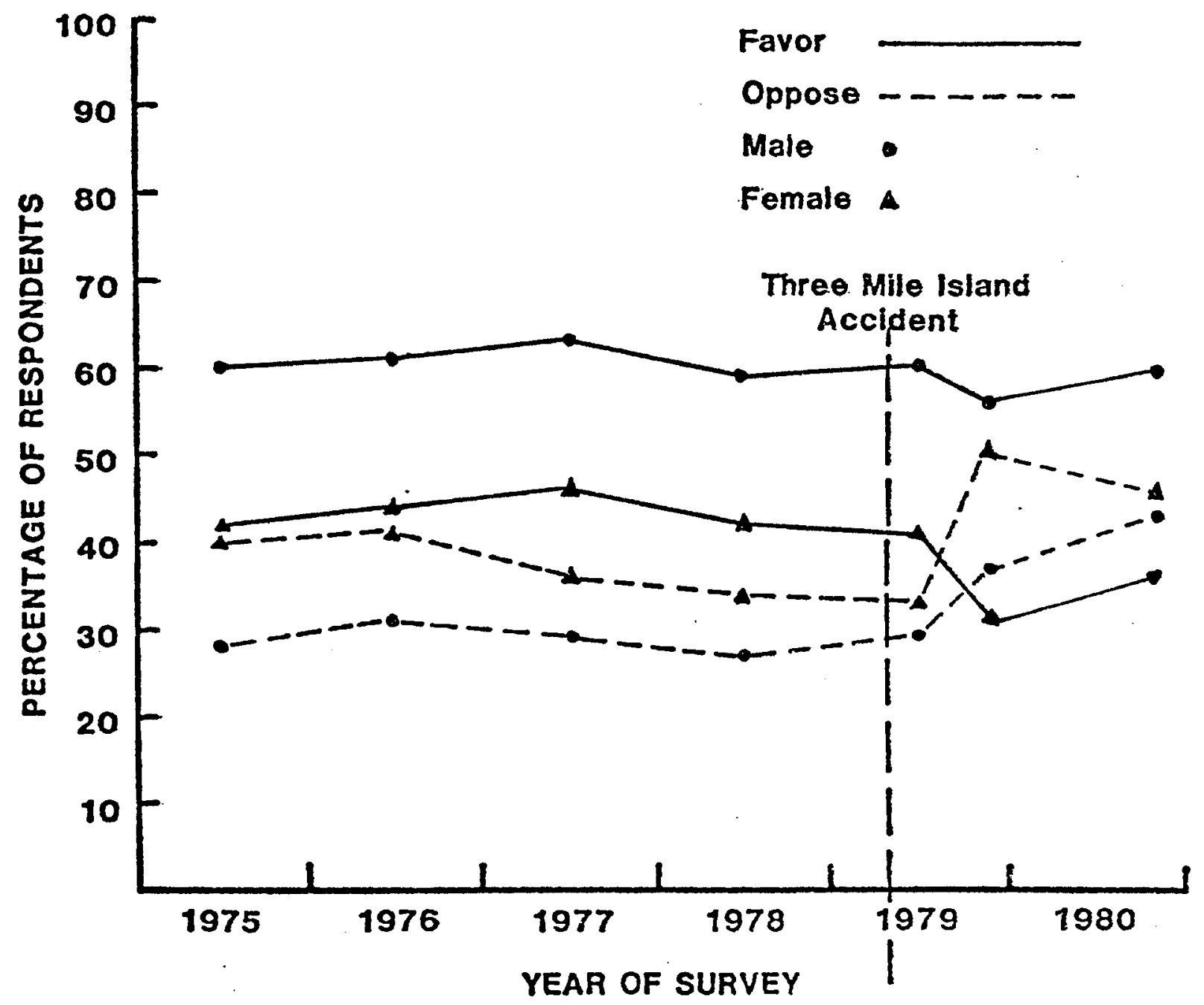

FIGURE 3.5 Sex Differences in Support and Opposition of Nuclear Power Plant Construction - Cambridge

NOTE: "Do you favor or oppose the construction of more nuclear power plants?" (Cambridge) 


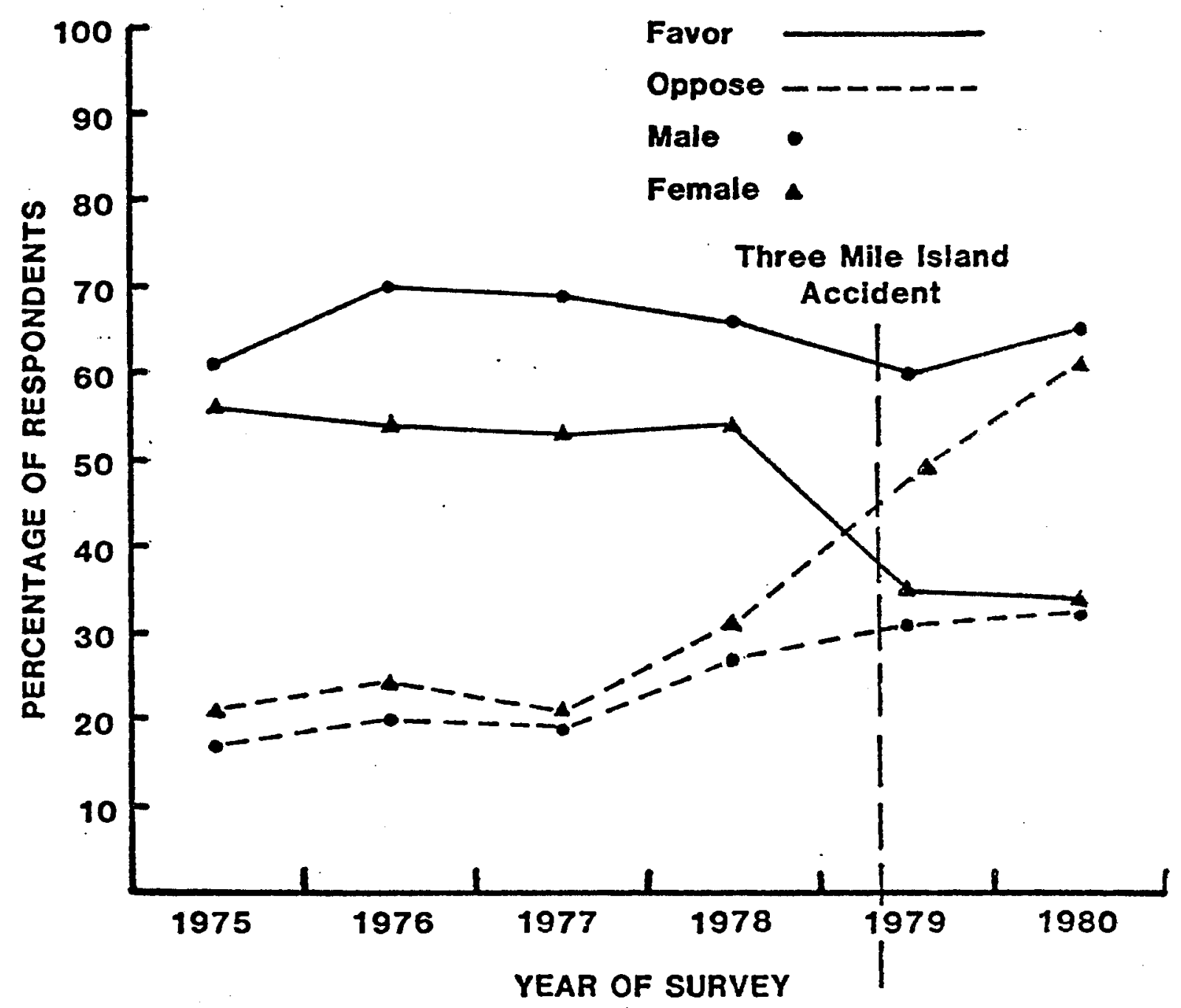

FIGURE 3.6 Sex Differences in Support and Opposition of Nuclear Power Plant Construction - Harris

NOTE: "In general, do you favor or oppose the building of more nuclear power plants in the United States?" (Harris) 
that they show a trend to increasing levels of opposition for both men and women from 1975 through 1979.

Sex differences in attitudes toward nuclear power plant construction following TMI are seen in both the Cambridge and Harris data. The Harris data show a decline in support and a rise in opposition to nuclear power plant construction following TMI; however, the changes are more pronounced for women than for men. Following TMI there was a tendency for levels of support and opposition to return to their pre-TMI levels, but the Harris $(80 / 11)$ data still show decreases in support for both men and women, and increases in opposition for men and women over the levels measured immediately after TMI in Harris $(79 / 6)$.

While the Harris data show rather large differences between the sexes following TMI, the differences shown in the Cambridge data are not so large. In addition to the dissimilarity between Harris and Cambridge on this point, as was discussed earlier in this chapter, there are differences in the general levels of support and opposition measured by the two organizations. The overall levels of support are higher in the Harris data than in the Cambridge data, although there is some indication that these differences are disappearing.

These differences have been recognized previously, and may be due to factors such as question wording, the order and context in which questions are asked, or differences in interviewer techniques. However, both data sets show that men are more supportive of nuclear power plant construction than women.

The data from three survey organizations show that men are more likely than women to support local construction of nuclear power plants (see 
Figure 3.7 ). The data from all three indicate that there has been an ongoing increase in opposition and decrease in support for local nuclear power plant construction, with the differences between males and females remaining relatively constant. Given the results discussed earlier regarding general attitudes toward local construction, the sex differences are not unexpected.

Summary. There is a consistent finding that men show greater levels of support, less opposition, and less uncertainty than women in their attitudes toward nuclear power plant construction, either generally or in reference to an individual's local community. As mentioned earlier, it is difficult to interpret the meaning of opposition to local construction because so few individuals live in a community close to where a nuclear power plant is to be built. Nonetheless, the expression of opposition can be taken to indicate a negative response toward nuclear power in general.

What is absent from the data, however, is an explanation for why males and females should differ in their attitudes. Such differences may lie in value differences between men and women (Rokeach, 1973; Rank in and Nealey, 1978) regarding health and safety concerns, attitudes toward risk, technological and economic growth, and conservation. Women may be more concerned than men with health and safety issues and with risks associated with nuclear power development. Attitudes toward safety and risk assessment may be important predictors of nuclear power attitudes and thus may partially explain the lower percentage of support among females. However, attitudes toward specific nuclear issues are interrelated with general attitudes toward nuclear power and should not be assumed to be causal 

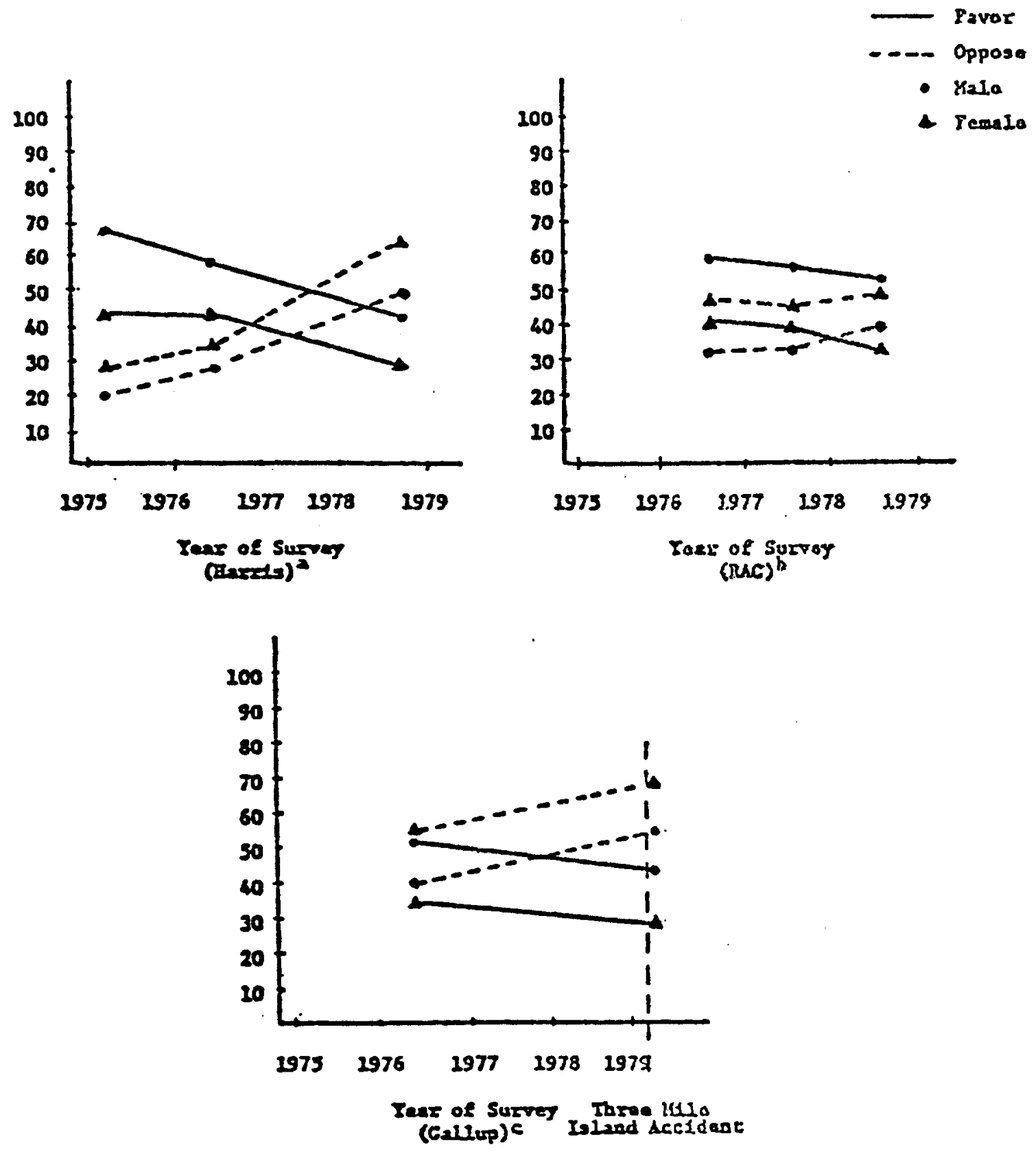

FIGURE 3.7 ATTITUDES TOWARD LOCAL NUCLEAR PLANT CONSTRUCTION BY SEX, YEAR, AND SURVEY ORGANIZATION

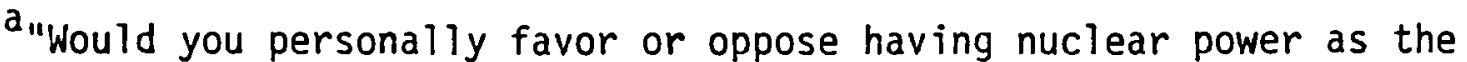
main source of energy for the electric power you use in your community?" [Harris $(75 / 4 ; 76 / 77)$ ]. "Do you favor or oppose having a nuclear power plant within five miles of your community?" [Harris (78/10)]

b"Suppose your local electric company said it wanted to build a nuclear power plant in this area. Would building such a plant be all right with you, or would you be against it?" $[R A C(76 / 6 ; 77 / 6 ; 78 / 6)]$

"As of today, how do you feel about the construction of a nuclear power plant in this area--that is, within five miles of here? Would you be against the construction of such a plant in this area or not?" [Gallup $(76 / 6 ; 79 / 4)]$ 
factors. In addition, Melber et al. (1977) have shown that women are also less likely than men both to think that continued economic growth is essential and to support the development of power generation facilities based on non-nuclear energy sources. These findings suggest that women may not be opposed specifically to nuclear power development, but may be generally reluctant to support economic growth and development.

Explanations for the greater uncertainty among females toward nuclear power are equally elusive. Although males may be more knowledgeable than females about specific nuclear power issues, no relationship between such knowledge and corresponding attitudes has been documented (Nealey and Rankin, 1978). The sources of uncertainty among females may be rooted in the traditional sex role socialization of males and females, with the stereotypical reluctance of females to enter into issues in the public arena or to take strong stands toward controversial issues.

\subsubsection{Educational Differences in Attitudes Toward Nuclear Power}

In general, the data show that differences in attitude toward nuclear power as a function of education are not as consistent as those differences associated with sex. As reported by Melber et al. (1977), national data through 1976 indicated that there were greater levels of support among the better educated, but little relationship between education and levels of opposition to nuclear power. Examination of the data through 1980 indicates even less differentiation among educational categories than was suggested in the 1977 analysis.

Cambridge Reports provides the most detailed analysis of attitudes toward nuclear power as a function of educational attainment. Although there is a great deal of variation in levels of support for nuclear power 
plant construction within each educational category across the years, the data suggest that support for nuclear power plant construction does not consistently increase with additional years of schooling (see Table 3.12). Although the level of support generally increases with educational level through 1976, the relationship does not appear to be as strong in the years following. However, the differences in attitudes toward nuclear power plant construction between the lowest and highest educational categories do remain predictable. Those with graduate training are more likely to support nuclear power plant construction than are those with a grade school education. Even though there is some variation in levels of support for nuclear power plant construction among educational categories, the Cambridge data show little variation among the same categories for opposition to such construction.

The Cambridge data also show changes in the levels of support and opposition following TMI. For all educational categories, there were decreases in the levels of support and increases in the level of opposition that are not accounted for solely by changes in the level of uncertainty. In addition, there is an apparent relationship between level of education and the degree of change in attitudes toward nuclear power plant construction before and after TMI. Immediately after TMI there was a larger increase in opposition among those with less education than among those with more education. By 1980 there was an apparent trend for levels of support and opposition in all educational categories to return to their pre-TMI levels, although other data from 1981 reported in Section 3.2 .2 suggest that these percentages have not returned to their 1978 levels. 
TABLE 3.12

ATTITUDES TOWARO NUCLEAR POWER PLANT CONSTRUCTION BY EDUCATION AND YEAR

\begin{tabular}{|c|c|c|c|c|c|c|c|c|c|c|c|c|c|c|c|c|c|c|c|c|c|}
\hline \multirow{2}{*}{ Education } & \multicolumn{7}{|c|}{ Favor (\%) } & \multicolumn{6}{|c|}{ 0ppose $(\Varangle)$} & \multicolumn{8}{|c|}{ Unsure $(\%)$} \\
\hline & 1975 & 1976 & 1977 & 1978 & 1979 & 1980 & $\begin{array}{l}\text { Mean } \\
\text { All } \\
\text { Years }\end{array}$ & 1975 & 1976 & 1977 & 1978 & 1979 & 1980 & $\begin{array}{l}\text { Mean } \\
\text { All } \\
\text { Years }\end{array}$ & 1975 & 1976 & 1977 & 1978 & 1979 & 1980 & $\begin{array}{l}\text { Mean } \\
\text { All } \\
\text { Years }\end{array}$ \\
\hline Grade school & 44 & 39 & 50 & 43 & 31 & 45 & 42.0 & 25 & 29 & 24 & 26 & 41 & 34 & 29.8 & 31 & 32 & 26 & 32 & 28 & 21 & 28.3 \\
\hline Some high school & 42 & 46 & 50 & 48 & 34 & 45 & 44.2 & 31 & 28 & 28 & 26 & 46 & 37 & 32.7 & 27 & 26 & 22 & 27 & 20 & 18 & 23.3 \\
\hline $\begin{array}{l}\text { High school } \\
\text { graduate }\end{array}$ & 49 & 47 & 54 & 50 & 37 & 42 & 46.5 & 32 & 33 & 28 & 30 & 49 & 38 & 35.0 & 19 & 20 & 19 & 20 & 13 & 19 & 18.3 \\
\hline $\begin{array}{l}\text { Technical/ } \\
\text { vocational }\end{array}$ & 57 & 52 & 60 & 56 & 43 & 55 & 53.8 & 28 & 34 & 26 & 28 & 39 & 33 & 31.3 & 15 & 14 & 14 & 17 & 18 & 11 & 14.8 \\
\hline Some college & 54 & 54 & 55 & 56 & 43 & 51 & 52.2 & 33 & 32 & 30 & 30 & 41 & 37 & 33.8 & 13 & 14 & 15 & 14 & 16 & 12 & 14.0 \\
\hline College graduate & 59 & 55 & 61 & 55 & 44 & 46 & 53.3 & 31 & 33 & 28 & 26 & 44 & 42 & 34.0 & 10 & 12 & 11 & 19 & 11 & 12 & 12.5 \\
\hline Graduate school & 57 & 58 & 58 & 59 & 49 & 60 & 56.8 & 33 & 30 & 33 & 29 & 37 & 31 & 32.2 & 10 & 12 & 9 & 12 & 14 & 9 & 11.0 \\
\hline
\end{tabular}

NOTE: "Do you favor or oppose the construction of more nuclear power plants?" [Cambridge $(75 / 1 ; 75 / 5 ; 75 / 8 ; 76 / 4 ; 76 / 7 ; 76 / 10 ; 76 / 12 ; 77 / 3 ;$ $77 / 6 ; 77 / 9 ; 77 / 11 ; 78 / 3 ; 78 / 6 ; 78 / 9 ; 79 / 6)]$. Mean percentages for year calculated from quarterly surveys 1975-1978. Data for 1979 are froin (79/6). Data for 1980 are from $(80 / 11)$. 
The relationship between educational attainment and uncertainty toward nuclear power plant construction is much more consistent. It is clear that, across all the years of the Cambridge surveys, those with less education are more uncertain about nuclear power plant construction than are those with more education.

Summary. The data show that in general there is greater support and less uncertainty about nuclear power plant construction by the more highly educated. There does not appear to be a corresponding relationship between educational attainment and levels of opposition. The data also suggest that the attitudes of those in the lower educational categories were more affected by the accident at TMI than were those of individuals with higher levels of education.

There are several possible explanations that may account for the greater degree of change observed among respondents in the lower educational categories as a result of TMI. First, it is possible that those in the higher educational categories (who are more supportive) are less likely to be influenced by negative information because their attitudes are more strongly held and are thus less likely to change their attitude as a result of a perceived crisis. In addition, it may be that those individuals who are uncertain about an issue (in this case the highest degree of uncertainty is found among those in the lower educational categories) are more susceptible to the influence of negative information and thus more likely to change their attitude as a result of that information. At least some support for this latter interpretation is found in the analys is of sex differences in attitudes before and after TMI. There it was found that 
women (who are less likely to support and more likely to be uncertain about construction of nuclear power plants than are men) were more likely to be affected by the accident at TMI than were men. Because we lack the appropriate data to test these hypotheses, however, they must only be considered as plausible alternatives.

\subsubsection{Income Differences in Attitudes Toward Nuclear Power}

In general, the data show that attitudes toward nuclear power plant construction are related to level of income--as level of income increases support for construction of nuclear power plants increases and uncertainty decreases. As was the case with the analysis for educational attainment, however, opposition to nuclear power plant construction does not seem to be related to income level in any systematic fashion.

The Cambridge data show that as income level rises, levels of support increase and levels of uncertainty decrease (see Table 3.13). For the years up to 1977 there is little apparent fluctuation within income levels, and the level of support increases steadily as income increases. The 1978 data show some changes in support in the lower income categories, but a consistent increase in support for nuclear power plant construction in the higher categories. Following TMI there is not as clear a relationship between income level and support for nuclear power plant construction. The data show that the majority earning over $\$ 35,000$ are likely to support nuclear power plant construction, but the data do not show consistent differences in attitudes toward nuclear power plant construction by other income categories.

Similar patterns are apparent in the data regarding attitudes toward construction of nuclear power plants in respondents' local communities (see 
TABLE 3.13

ATTITUDES TOWARD NUCLEAR POWER PLANT CONSTRUCTION BY INCOME AND YEAR OF SURVEY

\begin{tabular}{|c|c|c|c|c|c|c|c|c|c|c|}
\hline $\begin{array}{l}\text { Year of } \\
\text { Survey }\end{array}$ & $\begin{array}{l}\$ 0- \\
\$ 3,999\end{array}$ & & $\begin{array}{l}\$ 4,000 \\
\$ 6,999\end{array}$ & $\begin{array}{l}\$ 7,000- \\
\$ 9,999\end{array}$ & $\begin{array}{l}\$ 10,000- \\
\$ 12,999\end{array}$ & $\begin{array}{l}\$ 13,000- \\
\$ 14,999\end{array}$ & $\begin{array}{l}\$ 15,000- \\
\$ 19,999\end{array}$ & $\begin{array}{l}\$ 20,000- \\
\$ 24,999\end{array}$ & $\begin{array}{c}\text { Over } \\
\$ 25,000\end{array}$ & $\begin{array}{c}\text { Over } \\
\$ 35,000\end{array}$ \\
\hline \multicolumn{11}{|l|}{ Favor (\%) } \\
\hline $\begin{array}{l}1975 \\
1976 \\
1977 \\
1978 \\
79 / 3 \\
79 / 6 \\
80 / 11\end{array}$ & $\begin{array}{l}41 \\
33 \\
42 \\
48 \\
\end{array}$ & $\begin{array}{l} \\
36^{a} \\
33^{a} \\
41^{a}\end{array}$ & $\begin{array}{l}44 \\
43 \\
48 \\
42\end{array}$ & $\begin{array}{l}46 \\
44 \\
52 \\
55 \\
49 \\
38 \\
38 \\
\end{array}$ & $\begin{array}{l}51 \\
52 \\
54 \\
49 \\
50 \\
32 \\
50 \\
\end{array}$ & $\begin{array}{l}55 \\
49 \\
56 \\
50 \\
49 \\
38 \\
47 \\
\end{array}$ & $\begin{array}{l}56 \\
55 \\
61 \\
54 \\
53 \\
45 \\
48 \\
\end{array}$ & $\begin{array}{l}58 \\
57 \\
60 \\
57 \\
56 \\
43 \\
47 \\
\end{array}$ & $\begin{array}{l}58 \\
62 \\
64 \\
63 \\
67^{\mathrm{b}} \\
38^{\mathrm{b}} \\
52^{\mathrm{b}} \\
\end{array}$ & $\begin{array}{l}49 \\
58 \\
65 \\
\end{array}$ \\
\hline Mean & 37.7 & & 41.0 & 46.0 & 48.3 & 49.1 & 53.1 & 54.0 & 57.7 & 57.3 \\
\hline \multicolumn{11}{|l|}{ Unsure (\%) } \\
\hline $\begin{array}{l}1975 \\
1976 \\
1977 \\
1978 \\
79 / 3 \\
79 / 6 \\
80 / 11\end{array}$ & $\begin{array}{l}28 \\
37 \\
26 \\
24 \\
\end{array}$ & $\begin{array}{l}26^{a} \\
18^{a} \\
20^{a}\end{array}$ & $\begin{array}{l}23 \\
24 \\
23 \\
30\end{array}$ & $\begin{array}{l}21 \\
19 \\
19 \\
24 \\
23 \\
21 \\
20 \\
\end{array}$ & $\begin{array}{l}17 \\
18 \\
16 \\
26 \\
12 \\
13 \\
16 \\
\end{array}$ & $\begin{array}{l}14 \\
19 \\
16 \\
22 \\
19 \\
11 \\
12 \\
\end{array}$ & $\begin{array}{l}15 \\
14 \\
13 \\
21 \\
16 \\
14 \\
14 \\
\end{array}$ & $\begin{array}{l}12 \\
13 \\
12 \\
23 \\
14 \\
19 \\
17 \\
\end{array}$ & $\begin{array}{l}12 \\
10 \\
12 \\
16 \\
10^{\mathrm{b}} \\
14^{\mathrm{b}} \\
12^{\mathrm{b}} \\
\end{array}$ & $\begin{array}{r}21 \\
9 \\
4 \\
\end{array}$ \\
\hline & 25.6 & & 23.4 & 21.0 & 16.9 & 16.1 & 15.3 & 15.7 & 12.3 & 11.3 \\
\hline \multicolumn{11}{|l|}{ Oppose (\%) } \\
\hline $\begin{array}{l}1975 \\
1976 \\
1977 \\
1978 \\
79 / 3 \\
79 / 6 \\
80 / 11\end{array}$ & $\begin{array}{l}31 \\
30 \\
32 \\
23\end{array}$ & $\begin{array}{l}38^{a} \\
48^{a} \\
39^{a}\end{array}$ & $\begin{array}{l}33 \\
32 \\
28 \\
31\end{array}$ & $\begin{array}{l}33 \\
37 \\
29 \\
27 \\
29 \\
42 \\
41 \\
\end{array}$ & $\begin{array}{l}32 \\
31 \\
30 \\
31 \\
38 \\
54 \\
35 \\
\end{array}$ & $\begin{array}{l}31 \\
32 \\
28 \\
30 \\
32 \\
52 \\
41 \\
\end{array}$ & $\begin{array}{l}29 \\
31 \\
26 \\
33 \\
31 \\
41 \\
38 \\
\end{array}$ & $\begin{array}{l}30 \\
30 \\
29 \\
28 \\
30 \\
38 \\
36 \\
\end{array}$ & $\begin{array}{l}30 \\
28 \\
24 \\
28 \\
23^{b} \\
48^{b} \\
36^{b} \\
\end{array}$ & $\begin{array}{r}30 \\
33 \\
31 \\
\end{array}$ \\
\hline Mean & 34.4 & & 34.1 & 34.0 & 35.9 & 35.1 & 32.7 & 31.6 & 31 & 31.3 \\
\hline
\end{tabular}

a $\$ 0-\$ 6,999$.

b $\$ 25,000-\$ 34,000$.

NOTE: "Do you favor or oppose the construction of more nuclear power plants?" [Cambridge $175 / 1 ; 75 / 5 ; 75 / 8 ; 76 / 4 ; 76 / 7 ;$ $76 / 10 ; 76 / 12 ; 77 / 3 ; 77 / 6 ; 77 / 9 ; 77 / 11 ; 78 / 3 ; 78 / 6 ; 78 / 9 ; 79 / 3 ; 79 / 6)]$. Mean percentages calculated from quarterly surveys for each year. Data for 1980 are from $(80 / 11)$. 
Table 3.14). Those in the higher income brackets are more likely to support local construction than are those in the lower brackets. For example, during the TMI incident $37 \%$ of those earning over $\$ 20,000$ favored local construction of nuclear power plants, while $27 \%$ of those earning $\$ 7,000$ or less favored such construction.

The Gallup data also suggest only slight variations in the relationship between income level and opposition to local nuclear power plant construction. In addition, those with higher incomes are less likely to be undecided about local construction.

While no consistent differences in the degree of change in support or opposition to nuclear power plant construction as a function of income is seen before and after TMI, change in uncertainty toward nuclear power plant construction was related to income level. Greater changes are apparent in the lower income categories than in the higher categories. However, the difference in the degree of change by income level may be due to an initially higher percentage of undecided respondents within the lower income brackets and a much lower level of undecided respondents among those in the higher brackets.

Similar relationships can be seen in the Harris data (see Table 3.15). There is a relatively direct relationship between income level and support for the construction of nuclear power plants. Prior to 1979 those in the higher income brackets were more likely to support nuclear power plant construction than were those in the lower brackets. Following TMI, in May, 1979, there is a slight rebound in support in all income brackets, but by November, 1980, there was some erosion in support at all levels. 
TABLE 3.14

ATTITUDE TOWARD LOCAL CONSTRUCTION OF A NUCLEAR

POWER PLANT AS A FUNCTION OF INCOME

\begin{tabular}{lccccccccc}
\hline $\begin{array}{l}\text { Build More Nuclear } \\
\text { Plants Locally }\end{array}$ & \multicolumn{3}{c}{ Favor } & \multicolumn{3}{c}{ Oppose } & \multicolumn{2}{c}{ No Opinion } \\
\cline { 2 - 9 } & $(76 / 6)$ & $(79 / 4)$ & Change & $(76 / 6)$ & $(79 / 4)$ & Change & $(76 / 6)$ & $(79 / 4)$ & Change \\
\hline$\$ 0-2,999$ & 35 & 28 & -7 & 36 & 65 & +29 & 29 & 7 & -22 \\
$\$ 3,000-\$ 4,999$ & 37 & 27 & -10 & 39 & 63 & +24 & 24 & 10 & -14 \\
$\$ 5,000-\$ 6,999$ & 43 & 28 & -15 & 43 & 64 & +21 & 14 & 8 & -6 \\
$\$ 7,000-\$ 9,999$ & 39 & 32 & -7 & 47 & 59 & +11 & 14 & 9 & -5 \\
$\$ 10,000-\$ 14,999$ & 41 & 33 & -8 & 47 & 61 & +14 & 12 & 6 & -6 \\
$\$ 15,000-\$ 19,999$ & 43 & 32 & -11 & 51 & 62 & +11 & 6 & 6 & 0 \\
$\$ 20,000$ and over & 43 & 37 & -6 & 45 & 58 & +13 & 7 & 5 & -2
\end{tabular}

NOTE: "As of today, how do you feel about the construction of a nuclear plant in this area--that is, within five miles of here? Would you be against the construction of such a plant in this area, or not?" [Gallup $(76 / 6 ; 79 / 4)]$ 
TABLE 3.15

ATTITUDES TOWARD NUCLEAR POWER PLANT CONSTRUCTION

PRE - AND POST-THREE MILE ISLAND BY INCOME

\begin{tabular}{|c|c|c|c|}
\hline Income Level & Favor (\%) & Oppose (\%) & Unsure (\%) \\
\hline & $(76 / 6)$ & $\underline{(76 / 6)}$ & $(76 / 6)$ \\
\hline \multicolumn{4}{|l|}{ Pre-Three Mile Island } \\
\hline $\begin{array}{l}\$ 0-\$ 4,999 \\
\$ 5,000-\$ 9,999 \\
\$ 10,000-\$ 14,999 \\
\$ 15,000 \text { and over }\end{array}$ & $\begin{array}{l}53 \\
57 \\
63 \\
68\end{array}$ & $\begin{array}{l}22 \\
25 \\
24 \\
19\end{array}$ & $\begin{array}{l}25 \\
18 \\
13 \\
13\end{array}$ \\
\hline & $(79 / 4)(79 / 5)$ & $(79 / 4)(79 / 5)(80 / 11)$ & $(79 / 4)(79 / 5)(80 / 11)$ \\
\hline
\end{tabular}

Post-Three Mile Island

\begin{tabular}{|c|c|c|c|c|c|c|c|c|c|}
\hline Under $\$ 7,500$ & 30 & 45 & 39 & 55 & 48 & 51 & 15 & 7 & 10 \\
\hline$\$ 7,501-\$ 15,000$ & 42 & 49 & 42 & 44 & 45 & 51 & 14 & 5 & 7 \\
\hline$\$ 14,001-\$ 25,000$ & 48 & 53 & 47 & 40 & 42 & 52 & 13 & 4 & 1 \\
\hline$\$ 25,001$ and over & 42 & 62 & 56 & 38 & 34 & 40 & 10 & 4 & 4 \\
\hline
\end{tabular}

NOTE: "In general do you favor or oppose the building of more nuclear power plants in the United States?" [Harr is $(76 / 6 ; 79 / 4 ; 79 / 5 ; 80 / 11)]$ 
Summary. Similar to the findings observed in the analysis of educational levels, the relationsh ip between attitudes toward nuclear power plant construction and income level shows increasing support for and decreasing uncertainty toward construction as income levels increase. Additionally, there is no consistent relationship between opposition and income level. Unlike the findings observed following TMI for educational level, there is a similar degree of change in support and opposition to nuclear power plant construction following TMI for all income categories. Greater decreases in uncertainty are observed for the lower income brackets than for the higher income brackets (particularly. on the issue of local construction of nuclear power plants), although these differences in degree of change may be due to an initially higher degree of uncertainty among the lower income groups.

\subsubsection{Occupational Differences in Attitudes Toward Nuclear Power}

Gallup provided national data on the relationship between occupational group and attitudes toward the construction of local nuclear power plants (see Table 3.16). The data show that persons in professional or business occupations are more likely to support the construction of nuclear power plants in their own communities than are those in other occupational groups. Professional and business occupations are also less likely to be unsure about local nuclear power plant construction than are those in other occupational groups. As was the case with educational and income level, there is no consistent relationship between occupational group and opposition to local construction of nuclear power plants. 
TABLE 3.16

ATTITUDES TOWARD NUCLEAR POWER PRE- AND POST-THREE MILE ISLAND BY OCCUPATION

\begin{tabular}{|c|c|c|c|c|c|c|c|c|c|}
\hline \multirow[b]{2}{*}{ Occupation } & \multicolumn{3}{|c|}{ Favor (x) } & \multicolumn{3}{|c|}{ Oppose (x) } & \multicolumn{3}{|c|}{ Unsure $(x)$} \\
\hline & $\begin{array}{l}\text { Pre } \\
(76 / 6)\end{array}$ & $\begin{array}{c}\text { Post } \\
(79 / 4)\end{array}$ & Change & $\begin{array}{l}\text { Pre } \\
(76 / 6)\end{array}$ & $\begin{array}{c}\text { Post } \\
(79 / 4)\end{array}$ & Change & $\begin{array}{l}\text { Pre } \\
(76 / 6)\end{array}$ & $\begin{array}{c}\text { Post } \\
(79 / 4)\end{array}$ & Change \\
\hline
\end{tabular}

Nuclear Power to Meet

Future Energy Needsa

Professional and business

Clerical and sales

Non-labor forc

$\begin{array}{lll}80 & 71 & -9 \\ 76 & 70 & -6 \\ 73 & 63 & -10 \\ 63 & 54 & -9\end{array}$

$\begin{array}{ll}16 & 27 \\ 13 & 28 \\ 16 & 31 \\ 20 & 33\end{array}$

+11
+15
+15
+13

$\begin{array}{rrr}4 & 2 & -2 \\ 11 & 2 & -9\end{array}$

Build More Nuclear

Power PTants LocalTyb

Professional and business

Clerical and sales

Manual workers

$\begin{array}{llll}50 & 33 & -17 & 43 \\ 32 & 43 & +11 & 59 \\ 45 & 33 & -12 & 42 \\ 41 & 33 & -8 & 43\end{array}$

$\begin{array}{ll}63 & +20 \\ 55 & -4 \\ 59 & +17 \\ 60 & +17\end{array}$

$\begin{array}{rll}7 & 4 & -3 \\ 9 & 2 & -7 \\ 13 & 8 & -5 \\ 16 & 7 & -9\end{array}$

a"In order to meet the future needs of the nation, how important do you feel it is to have more nuclear power plants--extremely important somewhat important, not too important, or not at all important?" [Gallup $(76 / 6 ; 79 / 4)]$. Based on combined categories.

buAs of today, how do you feel about the construction of a nuclear power plant in this area-- that is, within five miles of here? Would you be against the construction of such a plant in this area or not?" [Gallup $(76 / 6 ; 79 / 4)]$ 


\subsubsection{Age Differences in Attitudes Toward Nuclear Power}

Cambridge data (see Table 3.17) on the relationship between age and attitudes toward nuclear power plant construction show little variation within age categories between 1975 and 1978. From 1976 to 1980, however, support for nuclear power plant construction is slightly higher in the 36-45 and 46-55 age categories than in the others. Further, opposition to nuclear power plant construction is highest within the youngest and oldest age categories. The greatest amount of uncertainty toward nuclear power plant construction is found in the $65+$ age category.

Similar findings are shown in the Harris data (see Table 3.17). The greatest amount of support for nuclear power plant construction is in the 30-49 category (53\% to 64\%) support, while the greatest opposition is in the $18-29$ category (22\% to $52 \%$ opposition). Decrease in support and opposition to nuclear power plant construction following TMI is shown in all age groups, and there is no apparent relationship between age and the tendency to show greater or lesser degrees of change after the TMI accident.

Sumary. The analysis of attitudes toward the construction of nuclear power plants as a function of age shows that the greatest amount of support lies in the middle (30-55) age groups, and the greatest opposition in the youngest (18-29) groups. The greatest amount of uncertainty toward nuclear power plant construction is found in the oldest age group.

A number of possible explanations are apparent for the findings about age and attitudes. For instance, it is possible that greater support among the middle age categories reflects greater concern with growth and development and a lessened concern with safety. The middle years reflect 
TABLE 3.17

ATTITUDES TOWARD NUCLEAR POWER PLANT CONSTRUCTION

BY AGE AND YEAR

\begin{tabular}{|c|c|c|c|c|c|c|c|c|c|c|c|c|c|c|c|c|c|c|c|c|c|}
\hline \multirow[b]{2}{*}{ Age } & \multicolumn{7}{|c|}{ Favor $(\%)$} & \multicolumn{6}{|c|}{ Oppose (\%) } & \multicolumn{8}{|c|}{ Unsure (\%) } \\
\hline & 1975 & 1976 & 1977 & 1978 & 1979 & 1980 & $\begin{array}{l}\text { Mean } \\
\text { All } \\
\text { Years }\end{array}$ & 1975 & 1976 & 1977 & 1978 & 1979 & 1980 & $\begin{array}{l}\text { Mean } \\
\text { All } \\
\text { Years }\end{array}$ & 1975 & 1976 & 1977 & 1978 & 1979 & 1980 & $\begin{array}{l}\text { Mean } \\
\text { All } \\
\text { Years }\end{array}$ \\
\hline \multicolumn{22}{|l|}{ Cambr idge $^{a}$} \\
\hline $\begin{array}{l}18-25 \\
26-35 \\
36-45 \\
46-55 \\
56-65 \\
65 \text { and over }\end{array}$ & $\begin{array}{l}46 \\
49 \\
51 \\
51 \\
54 \\
51\end{array}$ & $\begin{array}{l}46 \\
45 \\
52 \\
55 \\
50 \\
46\end{array}$ & $\begin{array}{l}51 \\
54 \\
58 \\
58 \\
52 \\
54\end{array}$ & $\begin{array}{l}49 \\
48 \\
54 \\
54 \\
52 \\
53\end{array}$ & $\begin{array}{l}35 \\
38 \\
42 \\
42 \\
39 \\
41\end{array}$ & $\begin{array}{l}37 \\
45 \\
47 \\
54 \\
56 \\
45\end{array}$ & $\begin{array}{l}44.0 \\
46.5 \\
50.6 \\
52.3 \\
50.5 \\
48.3\end{array}$ & $\begin{array}{l}39 \\
35 \\
30 \\
27 \\
25 \\
26\end{array}$ & $\begin{array}{l}39 \\
34 \\
29 \\
30 \\
29 \\
28\end{array}$ & $\begin{array}{l}34 \\
30 \\
26 \\
26 \\
27 \\
23\end{array}$ & $\begin{array}{l}31 \\
32 \\
27 \\
30 \\
25 \\
22\end{array}$ & $\begin{array}{l}53 \\
48 \\
42 \\
41 \\
44 \\
36\end{array}$ & $\begin{array}{l}47 \\
40 \\
35 \\
30 \\
28 \\
38\end{array}$ & $\begin{array}{l}40.5 \\
36.5 \\
31.5 \\
30.7 \\
29.7 \\
27.2\end{array}$ & $\begin{array}{l}15 \\
16 \\
19 \\
22 \\
19 \\
23\end{array}$ & $\begin{array}{l}16 \\
22 \\
20 \\
16 \\
22 \\
26\end{array}$ & $\begin{array}{l}15 \\
17 \\
16 \\
17 \\
21 \\
22\end{array}$ & $\begin{array}{l}20 \\
20 \\
19 \\
16 \\
23 \\
26\end{array}$ & $\begin{array}{l}12 \\
14 \\
16 \\
18 \\
17 \\
23\end{array}$ & $\begin{array}{l}16 \\
15 \\
18 \\
15 \\
16 \\
16\end{array}$ & $\begin{array}{l}15.7 \\
17.3 \\
18.0 \\
17.3 \\
19.7 \\
22.7\end{array}$ \\
\hline \multicolumn{22}{|l|}{ Harr is ${ }^{b}$} \\
\hline $\begin{array}{l}18-29 \\
30-49 \\
50-64 \\
65 \text { and over }\end{array}$ & $\begin{array}{l}64 \\
64 \\
63 \\
--\end{array}$ & $\begin{array}{l}57 \\
60 \\
63 \\
--\end{array}$ & $\begin{array}{l}52 \\
63 \\
61 \\
--\end{array}$ & $\begin{array}{l}52 \\
60 \\
58 \\
--\end{array}$ & $\begin{array}{l}40 \\
53 \\
51 \\
44\end{array}$ & $\begin{array}{l}39 \\
48 \\
58 \\
46\end{array}$ & $\begin{array}{l}50.7 \\
58.0 \\
59.0 \\
46.0\end{array}$ & $\begin{array}{l}22 \\
20 \\
15 \\
--\end{array}$ & $\begin{array}{l}27 \\
24 \\
17 \\
--\end{array}$ & $\begin{array}{l}34 \\
23 \\
20 \\
--\end{array}$ & $\begin{array}{l}40 \\
29 \\
25 \\
--\end{array}$ & $\begin{array}{l}52 \\
41 \\
42 \\
47\end{array}$ & $\begin{array}{l}58 \\
48 \\
34 \\
43\end{array}$ & $\begin{array}{l}38.8 \\
30.8 \\
25.5 \\
45.0\end{array}$ & $\begin{array}{l}14 \\
16 \\
22 \\
--\end{array}$ & $\begin{array}{l}16 \\
16 \\
20 \\
--\end{array}$ & $\begin{array}{l}14 \\
14 \\
19 \\
--\end{array}$ & $\begin{array}{r}8 \\
10 \\
15 \\
--\end{array}$ & $\begin{array}{l}8 \\
7 \\
7 \\
9\end{array}$ & $\begin{array}{r}3 \\
4 \\
7 \\
11\end{array}$ & $\begin{array}{l}10.5 \\
11.2 \\
15.0 \\
10.0\end{array}$ \\
\hline
\end{tabular}

a"Do you favor or oppose the construction of more nuclear power plants?" [Cambridge $175 / 1 ; 75 / 5 ; 75 / 8 ; 76 / 4 ; 76 / 7 ; 76 / 10 ; 76 / 12 ; 77 / 3 ; 77 / 6 ;$ $77 / 9 ; 77 / 11 ; 78 / 3 ; 78 / 6 ; 78 / 9 ;)]$. Mean percentages calculated from quarterly surveys for each year 1975-1978; data for 1979 are post-Three Mile Island $(79 / 6) ; 1980$ data from $(80 / 11)$.

b"In general do you favor or oppose the building of more nuclear power plants in the United States? [Harris (75/4; 76/6; 77/5; 78/10; 79/4; $80 / 11){ }^{2}$ 
that time in which individuals have completed their educations and are seeking to advance careers and, consequently, growth and development is equated with greater occupational and financial opportunities. On the other hand, younger individuals, who normally face fewer financial responsibilities, may not be as concerned with economic growth and development, and may be more supportive of alternative energy sources and technologies.

\subsubsection{Regional Variations in Attitudes Toward Nuclear Power}

The analysis of attitudes toward nuclear power across different geographical regions of the country is useful for a number of reasons. First, it allows the identification of how individual regions differ from the national patterns of attitudes toward nuclear power. More specifically, it allows an examination of the impact of the TMI accident on attitudes toward nuclear power in different regions, particuarly in northeastern states relative to other regions of the country. Finally, it allows a rough estimation of the relationship between a region's dependency on nuclear power as an energy source and the attitudes of regional residents toward nuclear power. The material in this section will examine variations in such regional attitudes for survey questions addressing general attitudes toward construction of nuclear power plants.

Data on regional differences in attitudes toward nuclear power plant construction are available from both Cambridge and Harris surveys. Because the two organizations use different regional breakdowns, the results they obtain may be somewhat different and comparisons between the two survey organizations may be difficult. Figure 3.8 shows the regional breakdowns used by Cambridge and Harris. 


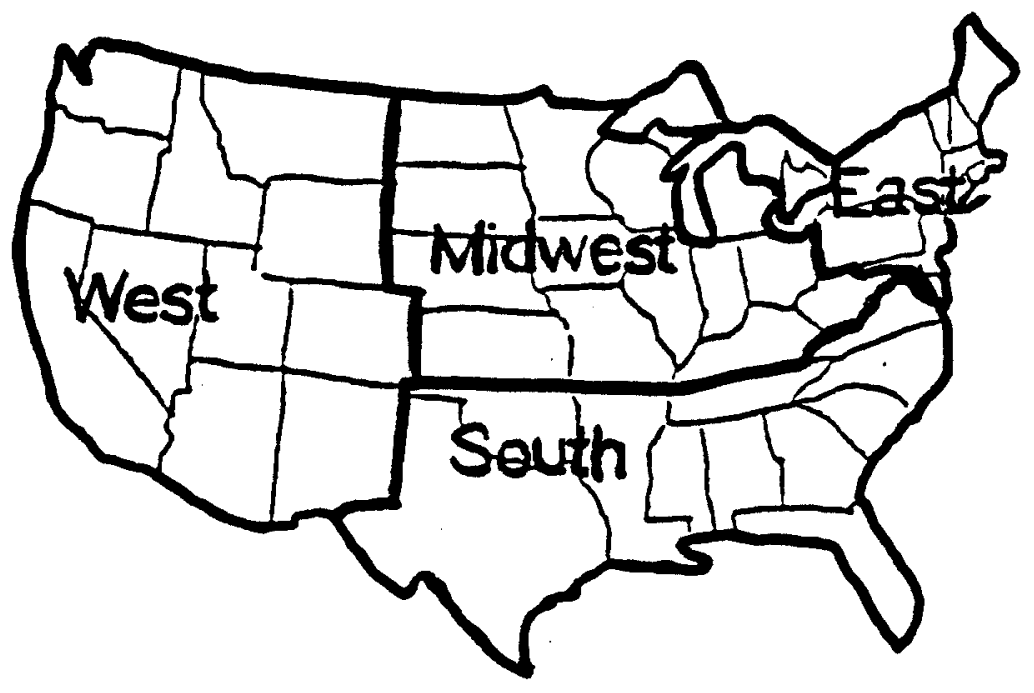

General divisions used by:

Gallup, Harris

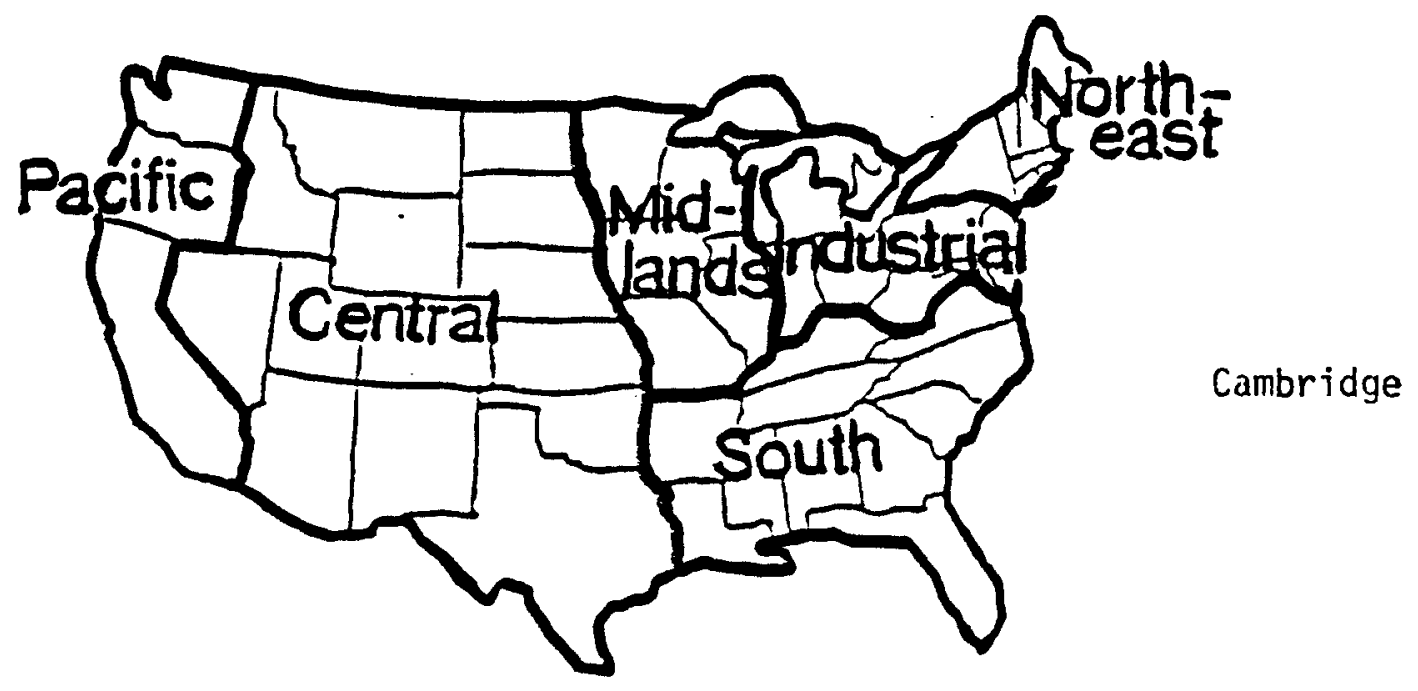

FIGURE 3.8 REGIONAL DIVISIONS BY SURVEY ORGANIZATIONS 
Data assessing regional differences in attitudes toward construction of nuclear power plants are available from both Cambridge and Harris surveys (see Table 3.18). From 1975 through the early months of 1979, the Cambridge data show that support for nuclear power plant construction was highest in the central states (Rocky Mountain, Plains, and Southwestern states), ranging from $56 \%$ to $59 \%$ and lowest in the Northeast, ranging from $44 \%$ to $47 \%$. Opposition to nuclear power plant construction prior to TMI was generally higher in the Northeast, Midlands, and Pacific regions. Immediately after the accident at TMI there were decreases in support, increases in opposition, and decreases in levels of uncertainty across all regions. Following TMI there has been a tendency for levels of support to return to their pre-TMI levels. Levels of opposition, however, seem to be staying at levels higher than they were prior to TMI. Support following TMI is highest in the South, Central, and Pacific regions (averaging about 52\%), while opposition is highest in the Northeast, Industrial, and Midlands regions (averaging about $42 \%$ ).

The Harris data appear to show less variation in support of nuclear power plant construction among regions than do the Cambridge data, and show similar trends. Prior to TMI, support was highest in the South and West. After TMI, support was highest in the South (about 51\%) and the Midwest (about 52\%). Support was lowest in the East. Opposition prior to TMI was highest in the East and West, and remained so after TMI.

Data from both the Cambridge and Harris surveys show a decrease in support of and increase in opposition to nuclear power plant construction by all regions after TMI. It is also clear that the level of opposition 
TABLE 3.18

ATTITUDES TOWARD NUCLEAR PLANT CONSTRUCTION

BY REGION AND SURVEY ORGANIZATION

\begin{tabular}{|c|c|c|c|c|c|c|c|c|c|c|c|c|c|c|c|c|c|c|c|c|c|c|c|c|}
\hline \multirow[b]{2}{*}{ Cambridge $^{a}$} & \multicolumn{8}{|c|}{ Favor $(\%)$} & \multicolumn{8}{|c|}{ Oppose $(\%)$} & \multicolumn{8}{|c|}{ Unsure $(q)$} \\
\hline & $\underset{5}{\stackrel{\text { sn }}{\sigma}}$ & $\begin{array}{l}\frac{0}{2} \\
\frac{1}{2}\end{array}$ & 会 & 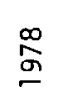 & $\frac{m}{n}$ & $\frac{0}{2}$ & $\stackrel{\nwarrow}{\frac{\pi}{\pi}}$ & $\overline{\bar{O}}$ & $\frac{\text { Ln }}{\frac{\pi}{\sigma}}$ & 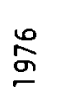 & مิ & $\stackrel{\infty}{\stackrel{\infty}{\sigma}}$ & $\frac{m}{n}$ & $\frac{\infty}{2}$ & $\frac{\sim}{\frac{N}{\pi}}$ & $\bar{\varnothing}$ & $\frac{\operatorname{m}}{\frac{\pi}{\sigma}}$ & $\stackrel{\circ}{\stackrel{\sigma}{\sigma}}$ & 음 & $\stackrel{\infty}{\stackrel{\infty}{\sigma}}$ & $\frac{m}{g}$ & $\frac{0}{\frac{\sigma}{N}}$ & $\stackrel{\cong}{\cong}$ & $\bar{\varnothing}$ \\
\hline \multirow[t]{2}{*}{$\begin{array}{l}\text { Northeast } \\
\text { Industrial } \\
\text { Midlands } \\
\text { South } \\
\text { Central } \\
\text { Pacific }\end{array}$} & $\begin{array}{l}43 \\
52 \\
44 \\
48 \\
58 \\
53\end{array}$ & $\begin{array}{l}47 \\
44 \\
49 \\
51 \\
56 \\
52\end{array}$ & $\begin{array}{l}56 \\
54 \\
48 \\
55 \\
58 \\
54\end{array}$ & $\begin{array}{l}44 \\
52 \\
49 \\
56 \\
59 \\
47\end{array}$ & $\begin{array}{l}47 \\
51 \\
39 \\
56 \\
58 \\
42\end{array}$ & $\begin{array}{l}32 \\
40 \\
33 \\
48 \\
46 \\
33\end{array}$ & $\begin{array}{l}37 \\
40 \\
44 \\
54 \\
39 \\
52\end{array}$ & $\begin{array}{l}38 \\
40 \\
46 \\
53 \\
53 \\
52\end{array}$ & $\begin{array}{l}33 \\
29 \\
37 \\
29 \\
28 \\
34\end{array}$ & $\begin{array}{l}34 \\
33 \\
36 \\
25 \\
26 \\
34\end{array}$ & $\begin{array}{l}28 \\
28 \\
34 \\
22 \\
27 \\
33\end{array}$ & $\begin{array}{l}36 \\
26 \\
34 \\
20 \\
23 \\
37\end{array}$ & $\begin{array}{l}36 \\
31 \\
38 \\
24 \\
25 \\
41\end{array}$ & $\begin{array}{l}56 \\
44 \\
48 \\
37 \\
38 \\
47\end{array}$ & $\begin{array}{l}49 \\
41 \\
39 \\
35 \\
45 \\
31\end{array}$ & $\begin{array}{l}42 \\
42 \\
41 \\
29 \\
35 \\
36\end{array}$ & $\begin{array}{l}21 \\
18 \\
19 \\
23 \\
14 \\
13\end{array}$ & $\begin{array}{l}19 \\
22 \\
16 \\
24 \\
18 \\
13\end{array}$ & $\begin{array}{l}16 \\
18 \\
18 \\
22 \\
15 \\
14\end{array}$ & $\begin{array}{l}20 \\
23 \\
17 \\
24 \\
18 \\
16\end{array}$ & $\begin{array}{l}17 \\
18 \\
23 \\
19 \\
17 \\
18\end{array}$ & $\begin{array}{l}12 \\
17 \\
19 \\
15 \\
16 \\
20\end{array}$ & $\begin{array}{l}13 \\
19 \\
16 \\
11 \\
15 \\
18\end{array}$ & $\begin{array}{l}20 \\
18 \\
14 \\
18 \\
12 \\
12\end{array}$ \\
\hline & \multicolumn{8}{|c|}{ TMI } & \multicolumn{8}{|c|}{ TMI } & \multicolumn{8}{|c|}{ TMI } \\
\hline \multirow[b]{2}{*}{ Harris } & \multicolumn{8}{|c|}{ Favor $(\%)$} & \multicolumn{8}{|c|}{ Oppose (\%) } & \multicolumn{8}{|c|}{ Unsure $(\%)$} \\
\hline & $\frac{0}{n}$ & $\frac{0}{0}$ & $\frac{\text { in }}{R}$ & $\frac{O}{\infty}$ & $\frac{\nabla}{D}$ & $\frac{n}{g}$ & $\bar{\varnothing}$ & & $\frac{\sigma}{n}$ & $\frac{0}{2}$ & $\frac{n}{r}$ & $\stackrel{\circ}{\frac{O}{\infty}}$ & $\frac{\nabla}{d}$ & $\frac{n}{n}$ & $\bar{\varnothing}$ & & $\frac{+}{i n}$ & $\frac{0}{2}$ & $\stackrel{n}{\approx}$ & $\frac{O}{\infty}$ & $\frac{\nabla}{d}$ & $\frac{n}{\sigma}$ & $\bar{\varnothing}$ & \\
\hline \multicolumn{25}{|l|}{ Total } \\
\hline \multirow[t]{2}{*}{$\begin{array}{l}\text { East } \\
\text { Midwest } \\
\text { South } \\
\text { West }\end{array}$} & $\begin{array}{l}58 \\
65 \\
64 \\
65\end{array}$ & $\begin{array}{l}54 \\
62 \\
65 \\
65\end{array}$ & $\begin{array}{l}58 \\
57 \\
62 \\
62\end{array}$ & $\begin{array}{l}55 \\
59 \\
58 \\
54\end{array}$ & $\begin{array}{l}35 \\
52 \\
42 \\
48\end{array}$ & $\begin{array}{l}45 \\
55 \\
56 \\
54\end{array}$ & $\begin{array}{l}42 \\
49 \\
55 \\
46\end{array}$ & & $\begin{array}{l}23 \\
18 \\
15 \\
18\end{array}$ & $\begin{array}{l}29 \\
19 \\
14 \\
25\end{array}$ & $\begin{array}{l}26 \\
25 \\
21 \\
27\end{array}$ & $\begin{array}{l}35 \\
28 \\
27 \\
34\end{array}$ & $\begin{array}{l}54 \\
34 \\
42 \\
40\end{array}$ & $\begin{array}{l}50 \\
41 \\
36 \\
42\end{array}$ & $\begin{array}{l}52 \\
46 \\
42 \\
48\end{array}$ & & $\begin{array}{l}19 \\
17 \\
21 \\
14\end{array}$ & $\begin{array}{l}17 \\
19 \\
12 \\
10\end{array}$ & $\begin{array}{l}16 \\
18 \\
17 \\
11\end{array}$ & $\begin{array}{r}9 \\
14 \\
15 \\
11\end{array}$ & $\begin{array}{l}11 \\
14 \\
16 \\
11\end{array}$ & $\begin{array}{l}5 \\
5 \\
8 \\
5\end{array}$ & $\begin{array}{l}6 \\
5 \\
6 \\
6\end{array}$ & \\
\hline & \multicolumn{8}{|c|}{ TMI } & \multicolumn{8}{|c|}{ TMI } & \multicolumn{8}{|c|}{ TMI } \\
\hline
\end{tabular}

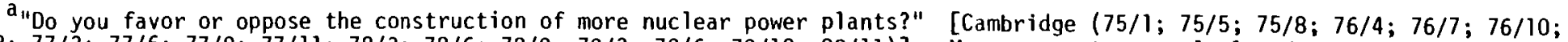
$76 / 12 ; 77 / 3 ; 77 / 6 ; 77 / 9 ; 77 / 11 ; 78 / 3 ; 78 / 6 ; 78 / 9 ; 79 / 3 ; 79 / 6 ; 79 / 12 ; 80 / 11)]$. Mean percentages calculated from quarterly surveys for each year 1975-1978; data since 1978 are not averaged so that the effects of TMI can be more closely analyzed.

b" In general, do you favor or oppose the building of more nuclear power plants in the United States?" [Harris (75/4; 76/6; $77 / 5 ; 78 / 10 ; 79 / 4 ; 79 / 5 ; 80 / 11)]$ 
to nuclear construction after TMI is highest in the Northeast (Cambridge) and East (Harris) even though these regions have the greatest dependence upon nuclear power as a source of energy.

\subsubsection{Surmary}

In general, both Cambridge and Harris show that there is greater support, less opposition, and less uncertainty among males than females regarding the construction of nuclear power plants. Females also showed greater changes in their support and opposition following TMI than did males. With regard to education, the surveys found that there is greater support and less uncertainty about nuclear power plant construction by the more highly educated. There does not appear to be a corresponding relationship between educational attainment and levels of opposition. Similar to the educational level findings, the relationship between attitudes toward nuclear power plant construction and income shows increasing support for and decreasing uncertainty toward construction as income increases. There is also no consistent relationship between opposition and income. Professional and business occupations are more likely to support and less likely to be uncertain about the construction of more nuclear power plants compared to other occupations. Attitudes toward nuclear power plant construction were also related to the ages of respondents. Support was highest in the middle age brackets and lowest in the younger and older age brackets. Finally, the analysis of the regional differences in attitudes showed that support was generally higher in the central states and lowest in the northeastern states. Following TMI there were declines in support in all of the regions, but by 1980 there was an apparent trend in all regions for levels of support to return to their pre-TMI levels. 


\section{BELIEFS AND ATTITUDES ABOUT SPECIFIC NUCLEAR POWER ISSUES}

\subsection{Introduction}

The preceding chapter has discussed general attitudes toward nuclear power and how these attitudes relate to various demographic groups in the population. This chapter analyzes the reasons for support for or opposition to nuclear power in terms of beliefs about specific nuclear power issues, including energy availability, energy independence, reactor safety, nuclear waste management, pollution, and economic considerations. Attitudes toward some aspects of the nuclear fuel cycle, including reactor operation, waste management, and reprocessing, are also covered.

Two different types of survey questions are of special importance to this chapter: (a) questions that require volunteered responses from a respondent, and (b) questions that have structured responses, which are determined by the survey organization, and from which the respondent is asked to select his/her answer. These two types of questions, known respectively as open-ended questions and structured questions, can provide different perspectives on the issue areas noted above and will therefore be discussed separately. In addition, a number of the survey organizations have asked a series of structured questions about various nuclear power issues. Since these sets of questions make it easy to compare public beliefs about the importance of various advantages of, disadvantages of, and concerns about nuclear power, these structured 
questions will be analyzed in a comparative fashion, keeping the sets of questions intact. Finally, individual structured questions are available that are relevant to specific nuclear fuel cycle issues.

Given the different types of data available, this chapter will use the following outline. First, we will analyze open-ended questions where respondents were asked to volunteer: reasons for favoring or opposing nuclear power plants; benefits and possible harmful consequences from building more nuclear power plants; and advantages and disadvantages of nuclear power plants. Then we will analyze the sets of structured questions where the importance of benefits and/or risks can be directly compared. Finally, we will analyze structured questions regarding various nuclear power issue areas, including reactor safety, the TMI accident, nuclear waste management, uranium supply, reprocessing, the breeder reactor, nuclear weapons proliferation, and the regulatory process.

\subsection{Volunteered Beliefs about Nuclear Power}

\subsubsection{Introduction}

Beliefs about nuclear power that are gathered using open-ended questions are important to the analys is of public beliefs and attitudes because they provide a different type of information than do responses to structured questions. For volunteered responses, a respondent has to recall information where cues for the information come only from the question itself (e.g., "Why do you favor nuclear power?"). For structured responses, a respondent has only to recognize the correct information where cues for the information come both from the question 
and from the structural responses (e.g., "Which of these three things concerns you most about nuclear power--a reactor accident, nuclear waste management, or economic costs?"). Thus, information that has to be recalled must be learned better than information that has only to be recognized. To this extent open-ended questions are best for determining what somebody has learned well while recognition tests are a more sensitive measure of learning.

Thus, when a respondent is asked to volunteer, for example, advantages of nuclear power, the best-learned responses are likely to be elicited. However, when a respondent is asked to compare the importance, say, of three specified disadvantages of nuclear power, information that is less well learned can be brought into the judgment process. We will now discuss volunteered general assessments of nuclear power.

\subsubsection{Volunteered Reasons for Favoring or Opposing the Construction of More Nuclear Power Plants}

In this series of quarterly surveys, Cambridge Reports, Inc. has, at various times, followed their general attitude question with an open-ended question asking the respondent why he or she favored (opposed) nuclear power. Data from eleven surveys conducted from 1975 through 1978 are available for analysis. The volunteered reasons for support will be discussed first, followed by the reasons for opposition. The volunteered reasons for supporting nuclear power are presented in Table 4.1 and can generally be divided into six different categories: energy source, economics, safety, pollution, keeping up technologically with the rest of the world, and other responses. As can be seen from the table, a majority of the respondents supported nuclear power for a reason relating 
TABLE 4.1

VOLUNTEERED REASONS FOR FAVORING NUCLEAR POWER

\begin{tabular}{|c|c|c|c|c|c|c|c|c|c|c|c|}
\hline \multirow[b]{2}{*}{ Reasons for Favoring } & \multicolumn{11}{|c|}{ Cambridge (\%) } \\
\hline & $(75 / 5)$ & $(75 / 8)$ & $(75 / 11)$ & $(76 / 4)$ & $(76 / 7)$ & $(76 / 10)$ & $(76 / 12)$ & $(77 / 11)$ & $(78 / 3)$ & $(78 / 5)$ & $(78 / 7)$ \\
\hline Total percentage favoring & 45 & 53 & 46 & 47 & 49 & 48 & 52 & -- & -- & -- & 45 \\
\hline \multicolumn{12}{|l|}{ Energy source } \\
\hline $\begin{array}{l}\text { Need the energy, need more power } \\
\text { plants, need the progress, } \\
\text { create energy for future gene- } \\
\text { rations, essential to have more } \\
\text { full, helps to solve energy } \\
\text { crisis }\end{array}$ & 16 & 21 & 25 & 23 & 22 & 29 & 33 & 29 & 25 & 36 & 36 \\
\hline $\begin{array}{l}\text { We have some, we will have some, } \\
\text { coming thing, they are } \\
\text { inevitable }\end{array}$ & -- & -- & -- & 6 & 4 & 5 & 8 & 6 & 8 & 4 & 4 \\
\hline $\begin{array}{l}\text { Good source of electricity, good } \\
\text { solution, good energy source }\end{array}$ & 20 & 15 & 8 & 7 & 9 & 7 & 5 & 9 & 8 & 6 & 3 \\
\hline $\begin{array}{l}\text { Only solution no alternative, no } \\
\text { other choice, only thing left, } \\
\text { other resources are depleted }\end{array}$ & 13 & $-\infty$ & -- & 7 & 5 & 2 & 4 & 5 & 4 & 6 & 3 \\
\hline $\begin{array}{l}\text { Will make us independent of other } \\
\text { nations }\end{array}$ & 5 & 4 & 4 & 4 & 6 & 3 & 2 & 2 & 5 & 2 & 4 \\
\hline $\begin{array}{l}\text { Good until solar is ready, it will } \\
\text { take longer to get solar ready, } \\
\text { only workable source in } \\
\text { immediate future }\end{array}$ & 3 & 1 & 1 & 1 & 1 & 1 & -- & 1 & 1 & 1 & 1 \\
\hline $\begin{array}{l}\text { Doesn't use up natural resources, } \\
\text { would conserve fossil fuels and } \\
\text { other natural resources }\end{array}$ & $=-$ & 9 & 5 & 4 & 4 & 6 & 1 & 1 & 3 & 2 & 2 \\
\hline Total percent mention & 57 & 50 & 43 & 52 & 51 & 54 & 53 & 58 & 58 & 64 & 61 \\
\hline
\end{tabular}


Table 4.1--Continued

\begin{tabular}{|c|c|c|c|c|c|c|c|c|c|c|c|}
\hline \multirow[b]{2}{*}{ Reasons for Favoring } & \multicolumn{11}{|c|}{ Cambridge (x) } \\
\hline & $(75 / 5)$ & $(75 / 8)$ & $(75 / 11)$ & $(76 / 4)$ & $(76 / 7)$ & $(76 / 10)$ & $(76 / 12)$ & $(77 / 11)$ & $(78 / 3)$ & $(78 / 5)$ & $(78 / 7)$ \\
\hline \multicolumn{12}{|l|}{ Economics } \\
\hline $\begin{array}{l}\text { Cheap, cheapest, cheaper than oil, } \\
\text { more efficient, keep prices down }\end{array}$ & 19 & 21 & 22 & 20 & 16 & 15 & 14 & 13 & 15 & 9 & 14 \\
\hline $\begin{array}{l}\text { Put people to work, provide jobs, } \\
\text { help economy }\end{array}$ & -- & -- & -- & 4 & 3 & -- & 3 & 1 & 2 & 6 & 2 \\
\hline Total percent mention & 19 & 21 & 22 & 24 & 19 & 15 & 17 & 14 & 17 & 15 & 16 \\
\hline \multicolumn{12}{|l|}{ Safety } \\
\hline $\begin{array}{l}\text { Safe enough, no mishaps yet, it's } \\
\text { well controlled }\end{array}$ & 7 & 4 & 4 & 9 & 4 & 6 & 8 & 8 & 6 & 3 & 6 \\
\hline $\begin{array}{l}\text { Good if can be made safe, need to } \\
\text { be careful of danger, good } \\
\text { with strict controls }\end{array}$ & -- & -- & -- & -- & 4 & 4 & 3 & 3 & 3 & 2 & 3 \\
\hline Total percent mention & 7 & 4 & 4 & 9 & 8 & 10 & 11 & 11 & 9 & 5 & 9 \\
\hline \multicolumn{12}{|l|}{ Other } \\
\hline Cleaner, less pollution, clean & -- & 8 & 14 & 6 & 7 & 5 & 3 & 3 & 7 & 1 & 2 \\
\hline $\begin{array}{l}\text { Have to stay ahead of the rest } \\
\text { of the world, keep up with the } \\
\text { Russians, other countries } \\
\text { have them }\end{array}$ & -- & -- & -- & -- & -- & 4 & 2 & 2 & - & 5 & 3 \\
\hline Other & -- & -- & -- & 6 & 10 & 11 & 9 & 9 & 6 & 7 & 8 \\
\hline Don't know & -- & -- & -- & 2 & 4 & 2 & 4 & 3 & 4 & 2 & 2 \\
\hline 0ther/don't know & 17 & 17 & 17 & -- & -- & -- & -- & -- & -- & -- & -- \\
\hline
\end{tabular}

NOTE: "Why do you favor nuclear power?" [Cambridge $(75 / 5 ; 75 / 8 ; 75 / 12 ; 76 / 4 ; 76 / 7 ; 76 / 10 ; 76 / 12 ; 77 / 11 ; 78 / 3 ; 78 / 5 ; 78 / 7)]$ 
to the need for nuclear power as an energy source. Within this category of responses, the need for energy was volunteered most often, followed by responses relating to the inevitability of nuclear power, the belief that it is a good source, the belief that there are no other alternatives, the belief that it can help in achieving energy independence, the belief that it can hold us over until solar can take over, and the belief that it conserves other resources. The percentage of those volunteering energy source reasons for supporting nuclear power increased from 1975 to 1978 from an approximate average of $50 \%$ to an approximate average of $60 \%$. This increase was mostly due to the increase in need the energy responses. These changing beliefs could be due to the fact that more people believe that there was or is going to be an energy shortage. Thus, events like the gasoline shortfall in the summer of 1979 could influence the belief in the need for nuclear power.

As a category, responses relating to the economics of nuclear power were volunteered by about $15 \%$ to $25 \%$ of those who favored nuclear power as the reason for holding this attitude. Responses relating to electricity cost made up about $80 \%$ of these responses, while the belief that it provides jobs were volunteered much less often. Economic benefit responses declined from about $21 \%$ in 1975 to about $16 \%$ in 1978 . The third most volunteered category of responses related to the belief that nuclear power is safe. This was closely followed by the belief that nuclear power is a clean, nonpolluting source of energy.

Respondents who opposed nuclear power plant construction in the Cambridge surveys were asked to volunteer the reason for holding that attitude. These volunteered responses are presented in Table 4.2 and can 
TABLE 4.2

VOL UNTEERED REASONS FOR OPPOSING NUCLEAR POWER

\begin{tabular}{|c|c|c|c|c|c|c|c|c|c|c|}
\hline \multirow[b]{2}{*}{ Reasons for 0pposing } & \multicolumn{10}{|c|}{ Cambridge $(\not)$} \\
\hline & $(75 / 5)$ & $(75 / 8)$ & $(76 / 4)$ & $(76 / 7)$ & $(76 / 10)$ & $(76 / 12)$ & $(77 / 11)$ & $(78 / 3)$ & $(78 / 5)$ & $(78 / 7)$ \\
\hline Total percent opposing & 35 & 29 & 34 & 33 & 21 & 28 & -- & - & -- & 38 \\
\hline \multicolumn{11}{|l|}{ Danger } \\
\hline $\begin{array}{l}\text { Too dangerous, unsafe, risky, high risk of } \\
\text { accident }\end{array}$ & 44 & 42 & 38 & 38 & 35 & 39 & 36 & $42^{\mathrm{a}}$ & 27 & 24 \\
\hline $\begin{array}{l}\text { Not safe yet, not safe enough, not enough } \\
\text { safeguards, too many problems }\end{array}$ & 11 & 11 & 14 & 10 & 5 & 11 & 4 & -- & 4 & 4 \\
\hline Waste is dangerous, poisonous, or deadly & 4 & 5 & 3 & 4 & 4 & 5 & 10 & 7 & 13 & 9 \\
\hline $\begin{array}{l}\text { Radiation or radioactivity danger, fallout } \\
\text { factor, danger of radiation leaks }\end{array}$ & 8 & 4 & 2 & 5 & 7 & 1 & 4 & 5 & 4 & 5 \\
\hline Danger of explosion, could blow up & 8 & 5 & 5 & -- & 3 & 3 & 2 & 3 & 4 & 3 \\
\hline $\begin{array}{l}\text { More chance of nuclear war, chance of } \\
\text { sabotage or terrorists stealing fuel }\end{array}$ & - & -- & 2 & 3 & 4 & 2 & 5 & 4 & 2 & 2 \\
\hline Sounds dangerous, scary & -- & -- & -- & -- & $=$ & -- & 3 & 3 & 3 & 1 \\
\hline Total percent mention & 75 & 67 & 64 & 60 & 58 & 61 & 64 & 64 & 57 & 48 \\
\hline \multicolumn{11}{|l|}{ other } \\
\hline $\begin{array}{l}\text { Have enough power plants and energy now, } \\
\text { don't need more plants, getting too } \\
\text { industrialized, too much development } \\
\text { now }\end{array}$ & 4 & $6^{a}$ & 10 & 6 & 7 & 7 & 7 & 7 & 6 & 13 \\
\hline $\begin{array}{l}\text { Costs too much, waste of money, too } \\
\text { expensive, raises price of electricity }\end{array}$ & 6 & $8^{a}$ & -- & 8 & 7 & 8 & 6 & 6 & 3 & 9 \\
\hline $\begin{array}{l}\text { Pollution, pollutes water, overheats } \\
\text { water, bad for environment }\end{array}$ & 6 & 7 & 3 & 4 & 8 & 4 & 6 & 6 & 3 & 6 \\
\hline Not enough study done, don't know enough yet & -- & -- & -- & 2 & 7 & 3 & 4 & 5 & 4 & 6 \\
\hline $\begin{array}{l}\text { Solar energy or other alternatives are } \\
\text { better }\end{array}$ & 2 & -- & 3 & 4 & 2 & 1 & 2 & 4 & 9 & 6 \\
\hline other & -- & -- & 14 & 10 & 6 & 11 & 8 & 5 & 13 & 8 \\
\hline Don't know & -- & -- & 5 & 5 & 5 & 5 & 3 & 4 & 5 & 3 \\
\hline other/don't know & 7 & $12^{a}$ & -- & -- & -- & -- & -- & -- & -- & -- \\
\hline
\end{tabular}

a"Too dangerous" and "not safe yet" category combined.

NOTE: "Why do you oppose nuclear power?" [Cambridge $(75 / 5 ; 75 / 8 ; 76 / 4 ; 76 / 7 ; 76 / 10 ; 76 / 12 ; 77 / 11 ; 78 / 3 ; 78 / 5 ; 78 / 7)]$ 
generally be divided into six categories: danger responses, including reactor accident-related responses, waste-related responses, and health-related responses; no need for more nuclear power plants; economic cost; pollution; insufficient technical knowledge; and the belief that other alternatives are better.

Danger-related responses were offered by $50 \%$ to $75 \%$ of those who opposed nuclear power as their reason for holding such an attitude. Many of the responses seemed to relate to reactor safety: the category regarding the danger of explosion seems clearly related to reactor safety; the category regarding too dangerous, unsafe, risky, and high risk of accidents also seems to refer to reactor safety, although the response was general enough to include other aspects of the fuel cycle; the radiation or radioactivity danger and the not safe yet categories were also general but most likely related to reactor safety. Waste-related dangers were also mentioned by $3 \%$ to $13 \%$ of the opposition, and sabotage, terrorism, and/or proliferation concerns were mentioned by $0 \%$ to $5 \%$.

As a category, danger responses had decreased from about $70 \%$ mention in 1975 to about $55 \%$ mention in 1978. This was mostly due to a decrease in the too dangerous and not safe yet responses. Waste management related responses, however, had increased in mention from about $5 \%$ in 1975 to about $10 \%$ in 1978. Thus, reactor safety concerns, although still the most-cited reasons for opposition, decreased from 1975 through 1978, while waste-related concerns increased.

Other reasons cited for opposing nuclear power were the beliefs that we don't need more plants for electricity production; that nuclear power 
is too expensive; that nuclear power pollutes, especially water; that we don't know enough yet; and that other alternatives are better. All of these responses have typically been volunteered by less than $10 \%$ of those who oppose nuclear power. The belief that other alternatives were better increased from about 1\% mention in 1975 to about $7 \%$ mention in 1978 .

\subsubsection{Volunteered Likely Benefits and Likely Harmful Consequences that Might Come from Building More Nuclear Power Plants}

NSF $(79 / 10)$ asked respondents to volunteer benefits and harmful consequences that are likely to come from building more nuclear power plants. However, the respondent was not asked these two questions unless he or she had ". . .ever heard or read about controversies over nuclear power plants." Only 9\% of the respondents said that they were unaware of such controversies. The remaining $91 \%$ of the respondents were asked, "Do you think that any benefits (harmful consequences) are likely to come from building more nuclear power plants?" The $63 \%$ who believed that some benefits are likely were asked, "What might be some of the benefits? What others?" The $78 \%$ who believed that some harmful consequences are likely were asked an analogous question. The likely benefits will be discussed first.

The benefits that were volunteered are presented in Table 4.3. They were volunteered only by the $63 \%$ of the respondents who believed that nuclear power plants had some likely benefit. By far, the likely benefit from building more nuclear power plants volunteered most often is that the new plants will help to increase the energy supply or will help solve our energy shortage. This benefit was mentioned first by $59 \%$ of the respondents and was mentioned second by $6 \%$ of the respondents. The 
TABLE 4.3

PERCENTAGE OF PUBLIC WHO BELIEVE THAT CERTAIN BENEFITS

ARE LIKELY TO COME FROM BUILDING MORE

NUCLEAR POWER PLANTS

Benefits

\begin{tabular}{cc} 
NSF & $(79 / 10)$ \\
\hline $\begin{array}{c}\text { First } \\
\text { Mention }\end{array}$ & $\begin{array}{r}\text { Second } \\
\text { Mention }\end{array}$
\end{tabular}

Increase the supply of energy; solve our power shortage

Produce cheaper energy; less expensive than other energy sources

Reduce importation of foreign oil; reduce balance of payment problem; reduce foreign dependence

Rely less on fossil fuels; conserve our fossil fuels

Improve economy; produce more jobs

Produce cleaner energy; no air pollution from burning coal or oil

Improve our standard of living; lead to technological progress

Learn more about nuclear power and learn how to improve safety

Would have military use; help in national defense

59

No second benefit mentioned

22

13

5

7

Other response

3

5

Don't know/No answer

2

2

2

6

1

1

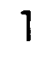

1

$0 \quad 49$

$-b \quad 2$

\section{$\longrightarrow$}

${ }^{a}$ Respondents ( $9 \%$ of all respondents) who had not ". . ever heard or read anything about controversies over nuclear power plants" were not asked this question.

\section{${ }^{b}$ Less than $0.5 \%$.}

NOTE: "Do you think that any benefits are likely to come from building more nuclear power plants? What might be some of the benefits? What others?" Only the respondents who answered "yes" to this question (63\%) volunteered the benefits listed above. [NSF (79/10)] 
response volunteered second most of ten (35\% total mention) was that the electricity from nuclear power would be cheaper than from other energy sources. A total of $12 \%$ of the respondents volunteered the response that more nuclear power plants would help lessen our dependence on foreign energy sources. The other likely benefits were volunteered less than $10 \%$ of the time, including conservation of fossil fuels ( $8 \%$ total mention), improve economy and produce jobs $(8 \%)$, and production of less polluting energy $(7 \%)$. Forty-nine percent of the respondents did not volunteer a second benefit.

The volunteered likely harmful consequences are presented in Table 4.4. They were volunteered only by the $78 \%$ of the respondents who believed that nuclear power plants had some likely harmful consequences. The likely harmful consequence mentioned most of ten was a reactor accident of some sort. A reactor accident was volunteered first by $36 \%$ of the respondents and was volunteered second by $9 \%$ of the respondents. Closely following a reactor accident as a likely harmful consequence was the consequence from low level radiation leaks to surrounding areas (42\% total mention). Although it is not clear from the response where these leaks are coming from, the likely referent is the radiation that is known to escape from nuclear power plants during normal operations.

Likely harmful consequences from nuclear waste management (24\% total mention) and health risks to present and future generations (23\% total mention) were volunteered equally often. Pollution concerns were volunteered fifth most of ten (11\% total mention). Other likely harmful consequences were mentioned less than $10 \%$ of the time, including a nonspecific unsafe response ( $9 \%$ total mention), increased energy 
TABLE 4.4

PERCENTAGE OF PUBLIC WHO BELIEVE THAT CERTAIN HARMFUL

CONSEQUENCES ARE LIKELY TO COME FROM BUILDING

MORE NUCLEAR POWER PLANTS

\begin{tabular}{llc}
\hline & \multicolumn{1}{c}{ NSF (79/10) } \\
\cline { 2 - 3 } Harmful Consequences & $\begin{array}{c}\text { First } \\
\text { Mention }\end{array}$ & $\begin{array}{c}\text { Second } \\
\text { Mention }\end{array}$ \\
\hline $\begin{array}{l}\text { Possibjlity of melt-down, nuclear explosion, } \\
\text { or other catastrophic accident (Three Mile } \\
\text { Island type situation); human error leading } \\
\text { to accident }\end{array}$ & 36 \\
$\begin{array}{l}\text { Low level radiation leaks to surrounding area } \\
\text { Problems in disposal and maintenance of used } \\
\text { nuclear materials }\end{array}$ & \\
Health risks to nonworkers, genetic risks, & 31 & 11 \\
danger to unborn children, cancer & 13 & 11 \\
Heat pollution or other environmental damage & 7 & 16 \\
$\begin{array}{l}\text { It's just unsafe (nonspecific) } \\
\text { Increased energy costs }\end{array}$ & 3 & 4 \\
$\begin{array}{l}\text { Susceptibility to terrorism or terrorists } \\
\text { Dangers to the health of nuclear workers }\end{array}$ & 5 & 2 \\
No second harmful consequence mentioned & 1 & 1 \\
Other response & 1 & 1 \\
Don't know/No answer & $-b$ & 35 \\
\hline
\end{tabular}

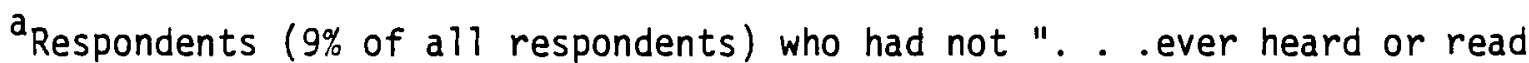
about controversies over nuclear power plants" were not asked this question.

$b_{\text {Less }}$ than $0.5 \%$.

NOTE: "Do you think that any harmful consequences are likely to come from building more nuclear power plants? What might be some of these consequences? What others?" Oniy the respondents who answered "yes" to this question (78\%) volunteered the consequences listed above. [NSF $(79 / 10)$ ] 
costs $(3 \%)$, and terrorism $(2 \%)$. Thirty-five percent of the respondents to this question did not volunteer a second likely harmful consequence. In summary, the likely benefits that were volunteered most of ten pertained to increasing the energy supply and producing cheaper energy. The likely harmful consequences that were mentioned most of ten pertained to reactor accidents, leakage of low level radiation, nuclear waste management, and health effects to present and future generations. There was more agreement as to the major likely benefit (increased energy supply) than to the major likely harmful consequence (reactor accident). A slightly higher percentage of respondents were able to volunteer two likely harmful consequences than were able to volunteer two likely benefits.

\subsubsection{Volunteered Advantages and Disadvantages of Nuclear Power Plants}

A final set of volunteered responses regarding nuclear power was collected by ARB $(79 / 7)$. All respondents, regardless of their attitude toward or awareness of nuclear power. issues, were asked what they saw as the major advantages and disadvantages of nuclear power. These data are presented in Table 4.5 .

The major advantage volunteered most of ten ( $26 \%$ total mention) was that nuclear power did not require a dependence on other countries, followed closely by the beliefs that it is cheaper than other sources (23\%) and that nuclear power is already available (19\%), and followed more distantly by the belief that nuclear power does not create air pollution (10\%). Forty-two percent of the respondents said that there were no major advantages, or that they did not know of any major advantages of nuclear power. 
TABLE 4.5

PERCENTAGE OF PUBLIC WHO VOLUNTEERED CERTAIN ADVANTAGES

AND DISADVANTAGES OF NUCLEAR POWER PLANTS

\begin{tabular}{lc}
\hline & ARB $(79 / 7)^{\mathrm{a}}$ \\
\hline Advantages & \\
No dependence on other countries & 26 \\
Cheaper & 23 \\
Available & 19 \\
No air pollution & 10 \\
Source of unlimited energy & 3 \\
More modern & 1 \\
Other & 3 \\
None/don't know & 42 \\
Disadvantages & \\
Possible accidents & 53 \\
Radiation hazards, under normal conditions & 52 \\
Problems of waste disposal & 38 \\
Water pollution by discharges & 26 \\
Too expensive & 3 \\
Not safe & 3 \\
Too much unknown about it & 3 \\
Public opinion against it & 2 \\
Other & 3 \\
None/don't know & 3 \\
\hline
\end{tabular}

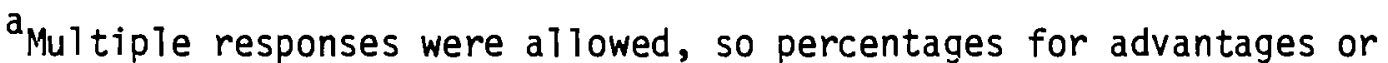
disadvantages do not sum to $100 \%$

NOTE: "How about nuclear plants--what do you see as their major advantages (disadvantages)?" [ARB (79/7)] 
The major disadvantages volunteered most often were possible accidents (53\%) and radiation hazards from normal operations (52\%). Problems of waste disposal (38\%) and water pollution (26\%) followed. Fourteen percent of the respondents said that there were no major disadvantages of nuclear power or that they did not know of any major disadvantages.

In summary, the major volunteered advantages of nuclear power were that it is an available, inexpensive supply of energy that is not dependent upon foreign energy sources. The major disadvantages dealt with reactor accidents, radiation discharges during normal operations, waste management, and water pollution. Fifty-eight percent of the respondents volunteered about 1.5 advantages apiece, while the remaining $42 \%$ volunteered no advantages. Eighty-six percent of the respondents volunteered about 2.1 disadvantages apiece, while the remaining $14 \%$ volunteered no disadvantages. Evidently, the disadvantages of nuclear power are easier for respondents to recall than are the advantages.

\subsubsection{Summary of Volunteered Responses}

Three types of volunteered responses were discussed: reasons why respondents favored or opposed nuclear power; benefits and harmful consequences likely to come from building more nuclear power plants; and advantages and disadvantages of nuclear power plants. Respondents who favored nuclear power generally did so because they believed that the energy is needed. Respondents who opposed nuclear power generally did so for safety-related reasons, pertaining mostly to reactor safety. When asked to volunteer the likely benefits that would come from building more nuclear power plants, a majority of the respondents said that needed 
energy would be produced followed by the benefit that nuclear power would be cheaper than other energy forms. The most often mentioned likely harmful consequences were the possibility of a reactor accident and the leakage of low-level radiation to surrounding areas. When asked to volunteer advantages of nuclear power, a plurality of the respondents said that nuclear power was not dependent upon other countries, followed closely by the beliefs that it is cheaper and available. However, more disadvantages were volunteered than were advantages. Over half of the respondents volunteered the disadvantages of possible accidents and of radiation hazards from normal operating conditions. In addition, disadvantages regarding waste disposal and water pollution were volunteered quite often.

\subsection{Structured Assessments of Nuclear Power Issues}

\subsubsection{Introduction}

Several survey research firms have asked respondents a set of structured questions in order to get comparative data on which benefits and/or risks of nuclear power are seen as most important. Sometimes only benefit comparisons are asked, sometimes only risk comparisons are asked, and sometimes various nuclear issues, which imply both benefits and risks, are asked at the same time. The structured sets of questions will be discussed in the following order: benefits only comparisons; risks on ly comparisons; and general issues comparisons. 


\subsubsection{Direct Comparisons of Nuclear Power Benefits}

Harris $(75 / 4 ; 76 / 7 ; 78 / 10 ; 79 / 4 c)$ has asked a set of structured questions regarding nuclear power benefits (see Table 4.6). Respondents were asked whether or not they believed eight statements about nuclear power, which were all phrased in a positive manner. About $75 \%$ of the general public believed that nuclear power made the United States less dependent on foreign sources, possibly because that proportion of the public thought that nuclear fuel could be obtained entirely within the United States. From $59 \%$ to $66 \%$ of the general public believed that nuclear power would be reliable in the long run. This belief was probably based on the fact that from $51 \%$ to $71 \%$ of the respondents believed that we would not run out of the supply anytime soon and on the fact that from $63 \%$ to $71 \%$ believed that nuclear fuel could be produced in almost unlimited quantities. Fewer respondents believed that nuclear power did not pollute the air so much (from $55 \%$ to $61 \%$ ); that nuclear power did not pollute the water so much (from $39 \%$ to $46 \%$ ); and that nuclear power raised few health hazards and dangers in using it (from $31 \%$ to $48 \%$ ). No questions were asked about the economics of nuclear power.

As was the case for the volunteered reasons for supporting nuclear power, these structured belief questions indicate that energy supply advantages are the most important perceived benefits of nuclear power followed more distantly by pollution advantages and health and safety advantages. The percentage of respondents who believed in the supply advantages of nuclear power increased slightly from 1975 to 1978, while beliefs about the advantages of nuclear power regarding pollution and health and safety have decreased a little. This was generally the case 
TABLE 4.6

PERCENTAGE OF PUBLIC WHO BELIEVE IN

CERTAIN BENEFITS OF NUCLEAR POWER

\begin{tabular}{|c|c|c|c|c|}
\hline & \multicolumn{4}{|c|}{ Harris $(\%)$} \\
\hline & $(75 / 4)$ & $(76 / 7)$ & $(78 / 10$ & $(79 / 4 c)$ \\
\hline Makes us less dependent on foreign sources & 76 & 73 & 76 & $-a$ \\
\hline Can be obtained almost entirely within U.S. & 73 & 73 & 78 & - \\
\hline $\begin{array}{l}\text { Is reliable form of energy for the U.S. to } \\
\text { depend upon in the long run }\end{array}$ & 66 & 63 & 59 & 63 \\
\hline $\begin{array}{l}\text { Will not run out of supply any time soon in } \\
\text { the future }\end{array}$ & 53 & 51 & 71 & - \\
\hline Can be produced in almost unlimited quantities & 65 & 63 & 69 & 71 \\
\hline $\begin{array}{l}\text { Is a clean source of energy and doesn't } \\
\text { pollute the air so much }\end{array}$ & 57 & 60 & 55 & 61 \\
\hline $\begin{array}{l}\text { Is a clean source of energy and doesn't } \\
\text { pollute the water so much }\end{array}$ & 44 & 46 & 39 & - \\
\hline $\begin{array}{l}\text { Raises few health hazards and dangers in } \\
\text { using it }\end{array}$ & 36 & 34 & 31 & 48 \\
\hline
\end{tabular}

aquestion not asked in that survey.

NOTE: "Do you think nuclear power. . .or not?" [Harris $(75 / 4 ; 76 / 7 ; 78 / 10)]$ 
for volunteered reasons for support, also. It is interesting to note that significantly more respondents believed, during the TMI accident, that nuclear power raises few health hazards and dangers in using it (48\%) than was the case from 1975 through 1978 (31\% to 36\%). It may be that the TMI accident made this belief more salient so that people who were undecided about the belief earlier were more willing to take a position.

\subsubsection{Direct Comparisons of Nuclear Power Problems}

YS\&W and Harris have both asked a series of questions to determine which nuclear power problems are believed by the public to be worrisome or problematical. YS\&W did not include radioactive waste issues in the ir list to choose from in 1976 and 1977. When it was included in 1978, however, $62 \%$ of the respondents said that they worried about radioactive waste disposal--the most worry shown for any of the problems (see Table 4.7). Averaging across the three years, the other worries, in order of importance, were: contamination of water (47\%), possibility of seepage causing health hazards (45\%), danger to workers (40\%), possibility of seepage causing death (32\%), danger of seepage from earthquakes (32\%), possibility of sabotage (31\%), atomic explosion (29\%), and theft of nuclear materials (29\%).

Unfortunately, economic considerations were not included. Also, the seepage problems were hard to interpret. They could have referred to liquid radioactive waste leaks, such as at Hanford in 1973, or seepage might refer to leaks from cooling water pipes and pumps. Actually, except for the waste disposal problem and atomic explosion (which likely refers to a reactor accident), the remainder of the problems could occur 
TABLE 4.7

PERCENTAGE OF PUBLIC WHO EXPRESSED WORRY

ABOUT SPECIFIC NUCLEAR POWER PROBLEMS

\begin{tabular}{llll}
\hline & \multicolumn{3}{c}{ YS\&W (\%) } \\
\cline { 2 - 5 } & $(76 / \mathrm{u})$ & $(77 / \mathrm{u})$ & $(78 / \mathrm{u})$ \\
\hline Problem of radioactive waste disposal & $--\mathrm{a}$ & -- & 62 \\
Contamination of water & 47 & 47 & 46 \\
Possibility of seepage causing health hazards & 45 & 44 & 46 \\
Danger to workers & 40 & 36 & 44 \\
Possibility of seepage causing death & 31 & 32 & 33 \\
Danger of seepage from earthquakes & 30 & 33 & 33 \\
Atomic explosion & 28 & 25 & 35 \\
Possibility of sabotage & 28 & 32 & 32 \\
Theft of nuclear materials & 27 & 32 & 29 \\
\hline
\end{tabular}

aNot included.

NOTE: "Some people say that we will be using more and more nuclear power plants to generate electricity, but this seems to worry some people. Which of the following, in any, worry you about nuc lear power plants?" [YS\&W (76/unk; 77/unk; 78/unk)] 
anywhere in the fuel cycle. Regardless, several things are clear. Radioactive waste disposal caused the most worry, and atomic explosions, sabotage, and theft of nuclear materials caused the least worry. There were few changes in the percentage of respondents who worried about a given problem from 1976 through 1978. However, there was more worry shown in 1978 compared to 1976 with regard to atomic explosions and possibility of sabotage.

Harris $(75 / 4 ; 76 / 7 ; 78 / 10 ; 79 / 4 b)$ asked respondents how much of a problem they believed certain nuclear power problems to be (see Table 4.8). The $(79 / 4 b)$ survey was conducted immediately following the TMI accident. As was the case above, nuclear waste disposal was believed to be the most serious problem. From $63 \%$ to $80 \%$ of the respondents believed it to be a "major problem," with a steady increase in such a belief from 1975 to 1978. Even following TMI, radioactive waste disposal was believed by more respondents $(80 \%)$ to be a major problem than the escape of radioactivity into the atmosphere (62\%), the chance that radioactive materials can adversely affect people's health (75\%), and the chance of an explosion in case of an accident (62\%). This was despite the fact that the last three problems were discussed frequently by the media during the accident. This indicates just how serious a problem nuclear waste disposal was perceived to be by the public. Thermal pollution, sabotage concerns, and plutonium concerns were believed to be the least serious nuclear power problems.

\subsubsection{Direct Comparisons of Nuclear Power Issues}

$A R B$ and Harris have both asked a series of structured questions about nuclear power issues--issues that are both positive and negative. The ARB data will be discussed first. 
TABLE 4.8

PERCENTAGE OF PUBLIC WHO BELIEVE THAT SPECIFIC

NUCLEAR POWER PROBLEMS ARE MAJOR PROBLEMS

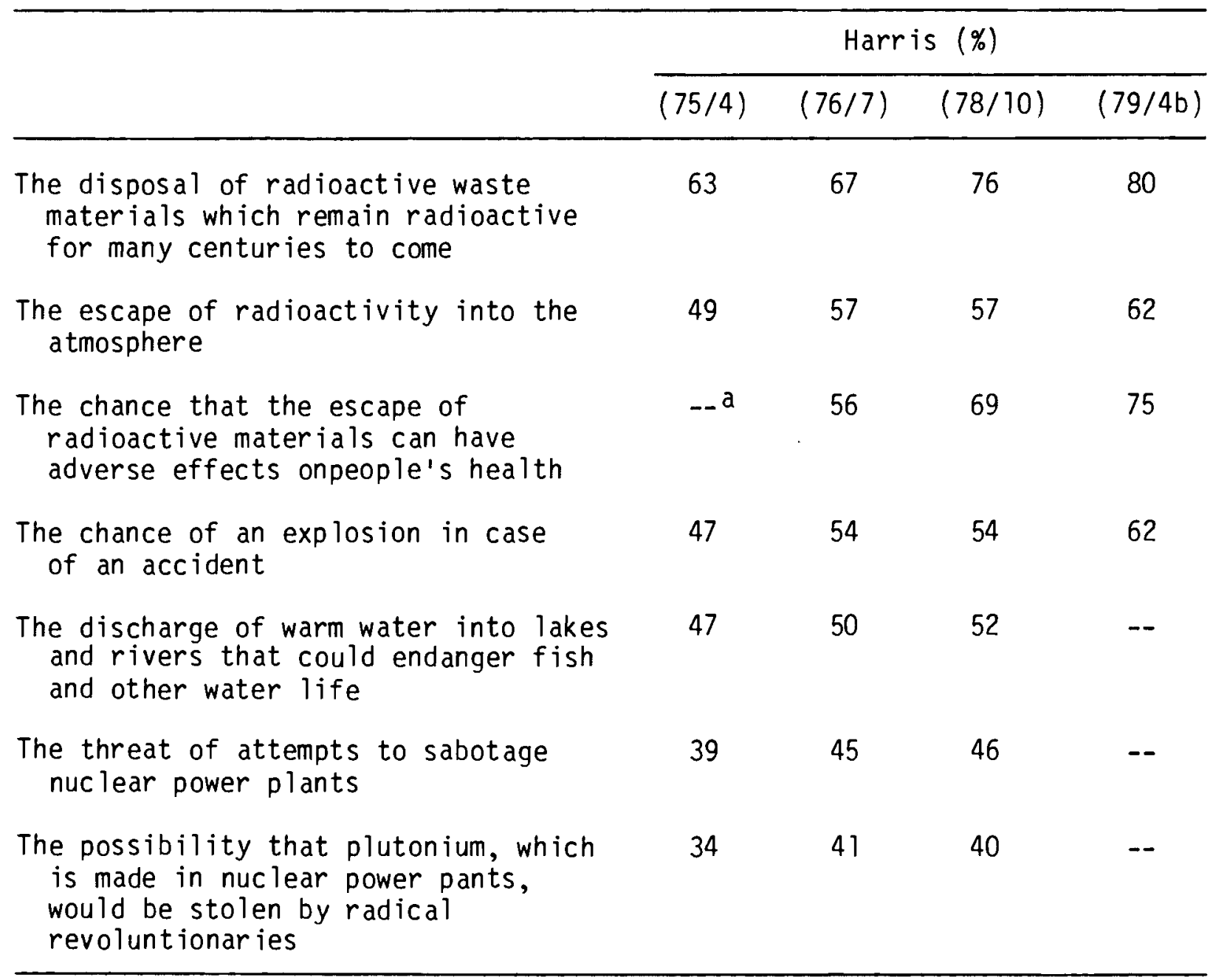

$a_{\text {Not included. }}$

NOTE: "Now let me ask you about some things that some people have said are problems associated with nuclear power being used as a source of energy for electric power. Do you think. . . is a major problem connected with nuclear power plants, a minor problem, or hardly a problem at all?" [Harris $(75 / 4 ; 76 / 7 ; 78 / 10 ; 79 / 4 b)$ ] 
ARB (77/unk.; 78/unk.; 79/7; 80/6) made a series of statements about nuclear power with which respondents agreed or disagreed (see Table 4.9). Only the percentage of respondents who agreed with the statement was reported. The statements are divided into safety issues, waste management issue, economic issues, and two general issue questions. Two of the surveys were conducted before the TMI accident, one was conducted about four months after TMI, and the fourth was conducted a year and several months after TMI.

Responses to the safety issue questions indicated public concern over reactor safety. In 1977 and 1978, 59\% and 70\%, respectively, of the respondents agreed that the thing that worried them most about nuclear power plants was the question of their safety. However, following TMI, ARB $(79 / 7)$ found that $86 \%$ were most concerned about power plant safety, and this decreased slightly to $83 \%$ in ARB $(80 / 6)$. Thus, TMI significantly raised respondents' concern about reactor safety.

Confidence in the engineers and scientists who design nuclear plants has declined from 64\% in 1977 to $54 \%$ in 1980, although the decline appears to have begun before the TMI accident. Following TMI, there has only been a minority belief ( $33 \%$ to $35 \%$ ) that the equipment made by nuclear engineering companies is well-designed and safe. Confidence in government regulation declined as a result of TMI. While about $56 \%$ of the respondents had confidence that the government would see to it that nuclear plants would be built safely before TMI, this confidence dropped to about $45 \%$ following TMI. In addition, since TMI, about $31 \%$ of the respondents believed that the government is doing a good job of checking on the safety of nuclear power plants. On another question, asked only 
TABLE 4.9

PERCENTAGE OF PUBLIC WHO AGREE WITH STATEMENTS

ABOUT SPECIFIC NUCLEAR POWER ISSUES ${ }^{a}$

ARB

$(77 / u)^{\mathrm{b}} \quad(78 / \mathrm{u})^{\mathrm{b}} \quad(79 / 7) \quad(80 / 6)$

Safety Issues

The thing that worries me the most about nuclear plants is the question of their safety

I have confidence that the engineers and scientists who design nuclear plants know what they are doing

The equipment made by nuclear engineering companies is well-designed and safe

I have confidence that government will see to it that nuclear plants are built safely

The government does a good job of checking on the safety of nuclear power plants

The electric companies do a good job of training the people who work in nuclear power plants

Waste Management Issue

The thing that worries me the most about nuclear plants is the question of radioactive waste disposal

Economic Issues

Electricity from a nuclear plant will cost less than electricity from a regular power plant

Nuclear power will assure jobs in the area because then there'11 be enough electricity

for industry and business

Nuclear plants are necessary to free America from relying on Arab oil 
TABLE 4.9--Continued

ARB

$\overline{(77 / u)^{b} \quad(78 / u)^{b} \quad(79 / 7) \quad(80 / 6)}$

General Issues

When it comes right down to it, I don't

55

57

60

51

feel I know enough about nuclear energy

to make an intelligent decision on

whether a nuclear plant should be built

around here

While there are arguments to both sides, most of the experis seem to be in favor of building nuclear power plants

apercentage of public who agreed "strongly" or agreed "somewhat" with the belief statement.

${ }^{b}$ Data provided in ARB $(80 / 6)$.

${ }^{\mathrm{C}}$ Question not asked in that survey.

NOTE: "The next questions have to do with nuclear energy. Please tell me how much you agree or disagree with each. This may not be easy, but do the best you can." Response choices included: strongly agree; somewhat agree; neither agree nor disagree; somewhat disagree; and strongly disagree. [ARB (77/unk; 78/unk; 79/7;80/6)] 
post-TMI, a $40 \%$ minority of the respondents felt that utility companies do a good job of training the people who work in nuclear power plants. Thus, respondents seemed concerned about nuclear safety issues, both because of actions on the part of the nuclear industry and because of perceived lack of adequate government regulation.

Respondents showed approximately equal amounts of concern regarding waste management issues. Before TMI, from $65 \%$ to $74 \%$ of the respondents said that waste management issues worried them most. This increased significantly to $84 \%$ following TMI. According to the ARB data, waste management was a slightly greater concern to respondents than reactor safety prior to TMI. Following TMI, both issues were of equal importance.

Beliefs about economic issues related to nuclear power seem to be equally positive and negative. From $34 \%$ to $46 \%$ of the respondents believe that electricity from nuclear plants costs less than electricity from other types of plants. This belief declined in 1980, but probably not as a result of the TMI accident, since the belief had not changed by July, 1979. From $49 \%$ to $54 \%$ of the respondents believed that nuclear power will help to assure jobs in the area. This belief seemed to be largely unaffected by TMI. From $48 \%$ to $58 \%$ of the respondents believed that nuclear plants are necessary to free the U.S. from relying on Arab 0i1. The percentage of respondents believing this increased in 1979 , probably as a result of the oil shortage in the summer of 1979. In 1980, however, the percentage believing this decreased to pre-1979 levels. Finally, $A R B$ asked respondents to agree or disagree with two statements about building plants. A $51 \%$ to $60 \%$ majority of the respondents agreed that they did not really know enough about nuclear 
power to make an intelligent decision as to whether a plant should be built somewhere near them. This belief seems to have been unaffected by TMI. In addition, a $53 \%$ to $64 \%$ majority believed that most of the experts seem to be in favor of building nuclear power plants. More respondents seemed to believe this somewhat immediately following TMI than before TMI or a year after TMI.

In summary, these data show about equal public concern regarding reactor safety and nuclear waste management issues. Both issues became more salient following TMI. Concerns regarding reactor safety seem to stem both from concerns about the nuclear industry and from concerns about federal regulators. The public is somewhat evenly split in its beliefs about economic issues. Finally, a slight majority of the respondents believe that they do not know enough to make decisions about nuclear power, and a slight majority believes that most experts are in favor of nuclear power.

Harris $(75 / 4 ; 78 / 9 ; 79 / 4 c)$ has asked respondents to judge the truthfulness of eight statements about nuclear power. They are divided into plant safety issues, waste management issues, economic issues, and pollution issues (see Table 4.10). With regard to plant safety, the TMI accident increased the percentage of respondents who believe that a major radiation leakage from a nuclear power plant can cause fallout that can kill large numbers of people. Before TMI, from $63 \%$ to $68 \%$ of the public believed the statement, while immediately following TMI, the percentage increased significantly to $84 \%$ of the public. In addition, while about $40 \%$ of the public believed that a power plant could undergo a massive nuclear explosion before TMI, this percentage increased significantly to 
TABLE 4.10

PERCENTAGE OF PUBLIC WHO BELIEVE IN THE TRUTHFULNESS

OF STATEMENTS ABOUT SPECIFIC NUCLEAR POWER ISSUES

\begin{tabular}{c}
\hline \multicolumn{1}{c}{ Harris } \\
\cline { 2 - 3 }$(75 / 4)(78 / 9)^{\mathrm{a}}(79 / 4 \mathrm{c})$ \\
\hline
\end{tabular}

Plant Safety Issues

A major radiation leakage from a nuclear power plant can cause fallout that can kill large numbers of people.

$$
\begin{aligned}
& \text { True } \\
& \text { Untrue } \\
& \text { Not sure }
\end{aligned}
$$

A nuclear power plant can fail and the nuclear materials can come together to cause a massive nuclear explosion.

True
Untrue
Not sure

Waste Management Issues

There is no satisfactory way of disposing of radioactive waste from nuclear power projects.

True

Untrue

Not sure

Waste from nuclear power plants can cause radioactivity exposure to too many people.

True

Untrue

Not sure -c $\quad 52$

- $\quad 19$

- 29

63

18

19

54

20

26

61

21

18

80

12

8

Economic Issues

Nuclear power plants can produce electric power more cheaply than oil-fired plants.

True

Untrue

Not sure
59

7

34
54

13

33
62

13

25 
TABLE 4.10--Continued

Harris

$\overline{(75 / 4) \quad(78 / 9)^{\mathrm{a}}(79 / 4 \mathrm{c})}$

Some communities have had nuclear power plants

for as long as 14 years and have had cheaper

electric power and no health problems.

True

Untrue

Not sure

$\begin{array}{rrr}41 & 51 & 56 \\ 6 & 10 & 13 \\ 53 & 39 & 31\end{array}$

If all electric power came from nuclear power plants, this country's dependence on foreign $0 i 1$ could be cut by one-third.

$\begin{array}{lrrr}\text { True } & 71 & 71 & 72 \\ \text { Untrue } & 5 & 7 & 10 \\ \text { Not sure } & 24 & 22 & 18\end{array}$

Pollution Issue

Nuclear power actually pollutes far less than electric power produced from oil or coal.

True

Untrue

Not sure

62

$9 \quad 16$

55

$\begin{array}{lll}29 & 25 & 21\end{array}$

${ }^{a}$ Data from Harris $(78 / 9)$ was reported in Harris $(79 / 4 c)$.

${ }^{b}$ For purposes of presentation, the responses completely true and partly true were combined in true, and completely untrue and partly untrue were combined in untrue.

${ }^{\mathrm{C}}$ Question not asked in that year. 
$66 \%$ immediately after TMI. The increased percentages for both beliefs resulted from decreases both in the percentage of those who believed that the statement was untrue and in the percentage of those who were not sure. The TMI accident also affected beliefs about waste management. In September, 1978, 52\% of the public believed in the truthfulness of the statement that there is no satisfactory way of disposing of nuclear wastes. This percentage increased significantly to $63 \%$ immediately following TMI. In addition, the percentage of the public who believed that nuclear wastes can cause radioactivity exposure to too many people increased significantly from $61 \%$ to $80 \%$ in the same time period.

The TMI accident had less of an effect on beliefs about economic issues. Following TMI, $62 \%$ of the public believed that nuclear-generated electricity was cheaper than oil-generated electricity, while 54\% believed this in 1978 and $59 \%$ believed this in 1975. Thus, the 1979 findings differed from the 1978 findings, but not from the 1975 results. Respondents were asked whether some communities have had nuclear plants for over 14 years with cheaper electricity and no health problems because of the plant. The percentage of the public who believed that the statement is true increased steadily from 1975 through 1978 to 1979 from $41 \%$ to $51 \%$ to $56 \%$. Because of the increase before TMI, the difference between the 1978 findings and the 1979 findings is probably not due to the TMI accident. Finally, there has been no change in the percentage of the public who believes that the U.S. could cut its dependence on foreign oil by one-third if all of this nation's electricity came from nuclear power. Approximately 70\% of the public has held this belief since 1975 . 
Finally, there has been a decrease in the percentage of the public who believes that nuclear power plants pollute less than oil-fired and coal-fired electric plants from $62 \%$ in 1975 to $59 \%$ in 1978 to $55 \%$ in 1979. It also appears that this change was not due to the TMI accident. In summary, the TMI accident did cause an increase in the percentage of the public who believe: that a radiation leak from a nuclear power plant can kill large numbers of people; that a nuclear power plant can fail and cause a massive nuclear explosion; that there is no satisfactory way of disposing of nuclear wastes; and that nuclear wastes can cause radioactivity exposure to too many people. Each belief is held by a majority of the public. In addition, beliefs about economic issues changed slightly from 1975 to 1979, in the direction favorable to nuclear power, but the changes do not seem to be a function of the TMI accident. A majority of the public believes that nuclear power actually pollutes far less than coal-fired or oil-fired power plants. The percentage of the public holding that belief declined from 1975 to 1979 , but probably not as a result of the TMI accident.

\subsubsection{Analysis of the Effects of Nuclear Beliefs on Nuclear Attitude}

The data tape containing the ARB $(80 / 6)$ data was made available to us for further statistical analysis. One question of interest to our research is which nuclear-related beliefs are the strongest determinants of nuclear attitude. We used multiple regression analysis to answer this question. Respondent's answers to the ARB (80/6) questions, which are listed in Table 4.9, were statistically related to the respondent's attitude toward nuclear power. The attitude question asked whether the respondent favored or opposed the construction of a nuclear power plant 
within five miles of the ir residence. Undecided responses were treated as missing data. The questions were allowed to enter the regression equation in order of importance as long as the beta weight for the question was significant $(p<.05)$.

The beta weight indicates the relative importance of the nuclear-related belief in determining the nuclear attitude. The belief questions are listed in order of importance with the absolute value of the beta weight given in parentheses: (1) the thing that worries me most about nuclear power plants is the question of their safety (.28); (2) nuclear power plants are necessary to free America from relying on Arab oil (.22); (3) government does a good job checking on the safety of nuclear power plants (.13); (4) confidence that the government will see to it that nuclear plants are built safely (.11); (5) electricity from a nuclear plant costs less than electricity from a regular power plant $(.10) ;(6)$ the equipment made by nuclear engineering companies is well-designed and safe $(.09) ;(7)$ the thing that worries me most about nuclear plants is the question of radioactive waste disposal (.08); (8) confidence that the engineers and scientists who design nuclear plants know what they are doing (.07); and (9) experts seem to be in favor of nuclear power $(.06)$.

This analysis indicates that the belief that most strongly determines one's attitude toward constructing a nuclear plant nearby is one's concern (belief) about nuclear power plant safety. Another strong determinant of nuclear attitude is one's belief about whether nuclear power plants are necessary to free America from relying on Arab oil. These beliefs are about twice as important as the next three (government 
does a good job of checking safety; confidence in government to see that plants are built safely; and nuclear electricity cheaper than other electricity) in determining nuclear power attitude. The two most important beliefs are about three to four times more important in determining attitude than are the remaining four beliefs (equipment is well designed and safe; biggest worry is waste disposal; confidence in scientists and engineers; and experts generally in favor of nuclear power).

These data seem to confirm the findings on volunteered reasons for supporting (opposing) nuclear power and the volunteered advantages (disadvantages) of nuclear power. The reason given most often for opposing nuclear power and the disadvantage volunteered most often dealt with concerns over reactor safety. The reasons for supporting nuclear power dealt with the need for energy, and the biggest advantage cited for nuclear power was that it required no dependence on other countries. Although concerns about nuclear waste management were given as much or more importance as reactor safety in the sets of structured questions, the volunteered responses showed reactor safety to be much more important, as did the regression analysis. However, the regression analysis, as opposed to the open-ended and structured questions, also suggest that the government plays an important part, in its role as regulator, in determining public attitudes toward the construction of nuclear power plants.

\subsubsection{Summary}

The public believes that the major benefits of nuclear power pertain to the amount and location of the uranium used in nuclear fuel. 
Three-quarters of the public believes that enough uranium can be found within the United States, which has the benefit of making the United States less dependent on foreign energy sources. About two-thirds of the public believes that nuclear power is reliable, can be produced in unlimited quantities, and that the uranium supply will not run out at any time soon. In a direct comparison of the importance of nuclear power problems, the public is most concerned about radioactive waste disposal issues followed by reactor safety issues, while the least concern is placed on pollution and sabotage/terrorism issues.

\subsection{Reactor Safety}

\subsubsection{Introduction}

As discussed earlier, nuclear power safety concerns constituted the largest set of reasons for opposing nuclear power. Safety considerations accompany each aspect of the nuclear fuel cycle from mining through waste disposal. Some people do not seem to differentiate between the different safety considerations. For instance, when asked to volunteer a disadvantage of nuclear power, some people simply say that it is dangerous. 0thers, however, will list specific dangers--for instance, regarding reactor operation, waste disposal, or sabotage and terrorism. The different aspects of safety will be discussed in individual sections of this chapter. Reactor safety, especially as it relates to reactor accidents, will be discussed in this section.

\subsubsection{Belief in the Safety Record}

Harris has asked a standard question from 1975 through 1979 regarding nuclear power plant safety. In addition, RFF (80/1) duplicated 
the Harris question in their survey. The Harris (79/4) and RFF (80/1) surveys were conducted after the TMI accident (see Table 4.11).

The Harris data will be discussed first. The most obvious change from 1975 through 1979 was the percentage of respondents who had not formed a belief regarding nuclear safety (i.e., were not sure). While $18 \%$ were not sure of their belief in 1975 , this had already dropped to $8 \%$ in 1978 and further dropped to 3\% following TMI. Most of those who formed a belief, went from no belief to a belief that nuclear power was not so safe or was dangerous. However, this change had already occurred prior to TMI. The major effect of TMI was to change some people's belief from the belief that nuclear power was very safe to the belief that it was somewhat safe.

Let us examine these changes in more detail. If the not so safe and dangerous responses are combined, the percentage of respondents who chose or volunteered the response went from $18 \%$ in 1975 to $23 \%$ in 1976 and 1977 ; $28 \%$ in 1978; and $30 \%$ following TMI. If the very safe and somewhat safe responses are combined, the percentage of respondents who chose the response stayed about the same- $-64 \%$ in $1975,63 \%$ in $1976,65 \%$ in 1977 , $64 \%$ in 1978 , and $67 \%$ in 1979 .

Thus, the Harris data seem to indicate that the TMI accident changed very few people's beliefs about reactor safety immediately following the accident. Those who previously believed that nuclear power was safe possibly looked at the accident, saw no apparent casualties, compared this to numerous deaths from such events as coal mining accidents and gasoline explosions, and therefore continued to believe in reactor safety. Those who previously believed that nuclear power was dangerous 
TABLE 4.11

PERCENTAGE OF PUBLIC WHO BELIEVE IN DIFFERENT

DEGREES OF NUCLEAR POWER PLANT SAFETY

\begin{tabular}{|c|c|c|c|c|c|c|}
\hline & \multicolumn{5}{|c|}{ Harris (\%) } & \multirow{2}{*}{$\frac{\operatorname{RFF}(\%)}{(80 / 1)}$} \\
\hline & $(75 / 4)$ & $(76 / 7)$ & $(77 / 4)$ & $(78 / 10)$ & $(79 / 4)$ & \\
\hline Very safe & 26 & 25 & 28 & 26 & 21 & 15 \\
\hline Somewhat safe & 38 & 38 & 37 & 38 & 46 & 40 \\
\hline Not so safe & 13 & 16 & 17 & 20 & 30 & 29 \\
\hline Dangerous ${ }^{\mathrm{a}}$ & 5 & 7 & 6 & 8 & $\ldots a$ & 9 \\
\hline Not sure & 18 & 14 & 12 & 8 & 3 & 7 \\
\hline
\end{tabular}

aThe dangerous response was not offered as a choice. However, in 1975, 1976, or 1978, if a respondent volunteered "dangerous" as a response, it was recorded as such. In 1979 the response was not allowed. Presumably, those who would have volunteered dangerous chose not so safe.

NOTE: "A11 in all, from what you have heard or read, how safe are nuclear power plants that produce electric power--very safe, somewhat safe, or not so safe?" [Harris $(75 / 4 ; 76 / 7 ; 77 / 4 ; 78 / 10$; 79/4) and $\operatorname{RFF}(80 / 1)]$ 
possibly looked at the accident, saw the potential for an even more serious accident and, therefore, continued to believe that reactors are unsafe.

However, the RFF $(80 / 1)$ data suggest that beliefs about reactor safety have changed. In this survey, $15 \%$ of the respondents believed that nuclear power is very safe, $40 \%$ believed that it is somewhat safe, $29 \%$ believed that it is not so safe, and $9 \%$ volunteered that it is dangerous. Compared to the Harris $(78 / 10)$ data, these data suggest that following TMI a lower percentage of the U.S. public believes that nuclear power is very safe and a higher percentage believes that it is not so safe. Unfortunately, Harris data for 1980 or 1981 do not exist for this question.

Two other safety issues that have been probed in several of the surveys have regarded the probability of being killed by a nuclear power plant accident and whether a nuclear explosion could occur at a power plant. Harris $(75 / 4 ; 79 / 4)$ asked respondents whether or not they believed that the probability of being injured or killed by a nuclear power plant accident was less than the probability of being hit by a bolt of lightning (see Table 4.12). As with the safety questions discussed above, the percentage of those who were not sure about their belief decreased significantly from 1975 to 1979 from $31 \%$ to $18 \%$. At the same time, the percentage of those who believed that the probability was greater than being hit by a bolt of lightning increased from $19 \%$ to $31 \%$, while the percentage of those who believed that the probability was less stayed the same at $50 \%$ and $51 \%$. 
TABLE 4.12

PERCENTAGE OF PUBLIC WHO BELIEVE THAT BEING INJURED

BY AN ACCIDENT IS LESS LIKELY THAN BEING HIT

BY A BOLT OF LIGHTNING

\begin{tabular}{lcc}
\hline & \multicolumn{2}{c}{ Harris $(\%)$} \\
\cline { 2 - 3 } & $(75 / 4)$ & $(79 / 4)$ \\
\hline Completely true & 26 & 23 \\
Partly true & 24 & 28 \\
Partly untrue & 11 & 16 \\
Completely untrue & 8 & 15 \\
Not sure & 31 & 18 \\
\hline
\end{tabular}

NOTE: "For each of the following statements about nuclear power plants, do you feel that it is true or untrue? The probability of being injured or killed by a nuclear power plant accident is less likely than being hit by a bolt of lightning." [Harris (75/4; 79/4)] 
Several survey organizations have asked respondents whether they bel ieve that nuclear power plants can explode (see Table 4.13) (see also Section 4.2). Harris (75/4) found that $39 \%$ of the public thought that nuclear power plants could have a massive nuclear explosion, $24 \%$ thought that it could not, and $37 \%$ were not sure. In 1979, after TMI, only $14 \%$ were not sure, those who believed that it could not explode still made up $24 \%$ of the public, but $66 \%$ thought that it could explode. However, CBS $(79 / 4)$ found that only $36 \%$ of the public believed that ". . .a nuclear power plant accident could cause an atomic explosion with a mushroom shaped cloud like the one at Hiroshima," $33 \%$ believed that it was not possible, and $31 \%$ had no opinion. RFF (80/1) asked a question quite similar to CBS (79/4). They found that a slight majority (52\%) of the public believed that a nuclear power plant could explode and cause a mushroom-shaped cloud.

The Harris $(79 / 4)$, CBS $(79 / 4)$, and RFF $(80 / 1)$ data are slightly discrepant. Harris (79/4) found the largest group of respondents (66\%) who believed that a power plant could have a massive nuclear explosion. However, this question did not specify an atomic bomb-like explosion with a mushroom shaped cloud, while the CBS (79/4) and RFF (80/1) questions did. Thus, the possible hydrogen explosion at TMI could have been interpreted by some to be a massive nuclear explosion but not a Hiroshima bomb-like explosion. The difference between the CBS (79/4) and the RFF $(80 / 1)$ data is harder to explain. Perhaps a real difference in beliefs did occur during the nine-month time period as a function of post-TMI media coverage. Regardless, it appears that a majority of the public believes that a nuclear power plant can have a massive nuclear explosion 
TABLE 4.13

PERCENTAGE OF PUBLIC WHO BELIEVE THAT

NUCLEAR POWER PLANTS CAN EXPLODE

\begin{tabular}{lllll}
\hline & \multicolumn{2}{c}{ Harris $^{2}$} & CBS $^{\text {b }}$ & RFFC \\
\cline { 2 - 5 } & $(75 / 4)$ & $(79 / 4)$ & $(79 / 4)$ & $(80 / 1)$ \\
\hline Can explode & 39 & 66 & 36 & 52 \\
Cannot explode & 24 & 20 & 33 & 31 \\
Not sure & 37 & 14 & 31 & 16 \\
\hline
\end{tabular}

a"For each of the following statements about nuclear power plants, do you feel that it is true or untrue? A nuclear power plant can fail, and nuclear materials can come together to cause a massive nuclear explosion." [Harris $(75 / 4 ; 79 / 4)$ ]

b"In the last few weeks, we've learned a lot about the dangers of nuclear power plants. From what you've heard or read, do you think a nuclear power plant accident could cause an atomic explosion with a mushroom shaped cloud like the one at Hiroshima?" [CBS (79/4)]

C"Do you think that it is possible for a nuclear power plant to explode and cause a mushroom-shaped cloud like the one at Hiroshima or don't you think that it is possible?" [RFF (80/1)] 
and that a plurality to slight majority of the public believes that a nuclear power plant can have an atomic fission explosion--an explosion that technically is not possible.

In summary, it appears that beliefs about reactor safety changed somewhat from 1975 through 1980. The percentage of the American public who believed that reactors are safe stayed about the same or declined slightly, those who believed that reactors are unsafe increased, and those who were unsure about their belief decreased. A large part of this change in beliefs seems to have occurred prior to TMI. TMI did seem to affect beliefs about nuclear power plants exploding--a plurality to majority of the public following TMI believed that nuclear power plants can explode like an atomic bomb.

\subsubsection{Responsibility for Nuc lear Plant Safety}

Because power plant safety is a major concern of the public, it is important to know who the public believes could best guarantee plant safety. Cambridge (77/5) asked such a question of the public (see Table 4.14$)$. The federal government (74\% total mention) was clearly the public's favorite institution for guaranteeing the safety of nuclear power plants. Second choice appeared to be state government (58\% total mention) or the United States military (55\% total mention).

However, the term safety here was probably interpreted to be more than safety from accidents so as to include safety from sabotage and terrorism. For instance, Cambridge (77/5) followed the above question with, "If the U.S. government protected each nuclear power plant with federal police forces, do you think the safety of the facilities would be increased?" A 54\% majority thought that safety would be increased, $25 \%$ 
TABLE 4.14

PERCENTAGE OF PUBLIC WHO BELIEVE THAT VARIOUS GROUPS

COULD BEST GUARANTEE NUCLEAR POWER PLANT SAFETY

\begin{tabular}{llllll}
\hline & & \multicolumn{3}{c}{ Choice (\%) } \\
\cline { 3 - 5 } & $\begin{array}{c}\text { Total } \\
\text { Mention }(\%)\end{array}$ & First & Second & Third \\
\hline The federal government & 74 & 30 & 28 & 16 \\
The United States military & 55 & 18 & 19 & 18 \\
$\begin{array}{l}\text { An international agency } \\
\begin{array}{l}\text { Electric utilities which own } \\
\text { and run the plants }\end{array}\end{array}$ & 40 & 17 & 11 & 12 \\
$\begin{array}{l}\text { State government } \\
\text { A private company }\end{array}$ & 58 & 14 & 12 & 15 \\
& 33 & 10 & 10 & 13 \\
\hline
\end{tabular}

NOTE: "Here's a list of groups or institutions which could possibly insure the safety of nuclear power plants. Tell me which you think would do the best job of guaranteeing the safety of the plants." [Cambridge (77/5)] 
thought that safety would not be increased, and $22 \%$ were not sure. Although a different type of safety was implicated, these results tend to further reinforce the finding that the United States public looks to the federal government for guaranteeing nuclear power plant safety.

Guaranteeing safety should probably not be equated with operating the plants, however. For instance, RAC (75/8) found that $53 \%$ of the general public believed that the federal government "would do a better job of ensuring the safety of nuclear power plants than would electric companies," while $37 \%$ believed that the electric companies would do a better job, and $10 \%$ did not know. However, if a nuclear power plant was to be built "around here," 50\% of the respondents would want a local electric company to own and operate it, compared to $39 \%$ for the federal government, and $11 \%$ with no opinion. This suggests that the respondents wanted the federal government to ensure nuclear safety through regulation, not operation and management. Finally, ARB $(79 / 7 ; 80 / 6)$ found that about $90 \%$ of the public believed that the government should have some or a lot of say about routine safety precautions in power plants.

\subsubsection{Summary}

From 1975 through 1980, the percentage of the public who believed that nuclear power plants are safe decreased slightly. At the same time, much of the undecided public decided that nuclear power plants are not so safe. Much of this change was evident prior to the TMI accident. There has also been an increase in the percentage of the public who believe that a nuclear power plant can explode, which may be due to the TMI accident. At this time a plurality to majority of the public believes 
that a nuclear power plant can explode like an atomic bomb. Finally, a plurality of the public thinks that the safety of nuclear power plants can best be guaranteed by the federal and state governments, and a large majority believe that the government should have some say about routine safety precautions in nuclear power plants.

\subsection{Three Mile Is land}

\subsubsection{Introduction}

The TMI accident has been called the worst accident in the history of nuclear power. Several surveys conducted during or immediately following the accident asked questions specifically about the accident and asked questions about the future of nuclear power as a result of the accident. These data are discussed in Section 4.5 .2 below. Immediately following the accident, the Kemeny Commission was formed to investigate the cause of the accident. Questions that probed general public and leadership group beliefs and attitudes following the release of the Kemeny Commission report are discussed in Section 4.5.3.

\subsubsection{Beliefs and Attitudes about the Three Mile Island Accident}

It was quite apparent that the United States public had heard about the TMI accident. Both Gallup (79/4a) and CBS (79/4) found that $96 \%$ of the public had heard or read about TMI. Harris (79/4b) found that $41 \%$ of the public was deeply disturbed by the incident, $41 \%$ were only somewhat disturbed, $17 \%$ were hardly disturbed at a 11 , and $1 \%$ were not sure. Gallup (79/4a) asked respondents, "How worried were you about your own or your family's safety. . .?" Twelve percent of the public were extremely worried, $16 \%$ were quite worried, $27 \%$ were not too worried, $44 \%$ were not 
at all worried, and $1 \%$ had no op inion. Amount of worry was related to geographic location--22\% of the Easterners were extremely worried compared to $7 \%$ to $10 \%$ of the public in the Midwest, South, and West.

Several surveys contained questions regarding beliefs about how the accident was handled. Gallup (79/4a) simply asked, "Do you think the situation was or was not handled as well as possible?" A slight plurality of $47 \%$ thought that it was handled as well as possible, while $41 \%$ thought that it was not, and $12 \%$ had no opinion.

Harris (79/4) asked specifically about Pennsylvania state officials, the Nuclear Regulatory Commission (NRC), the utility company that operated the plant, and the company that designed the plant (see Table 4.15). Pennsylvania state officials received $57 \%$ positive responses on their handling of the incident, followed by the NRC (44\%). Both groups received more positive than negative ratings. However, $52 \%$ of the respondents rated the electric utility negatively and $51 \%$ rated the power plant designer negatively.

CBS (79/4) asked a question about blame. It read, "Who or what do you think is most to blame for the accident--poor supervision by the government, careless operations by the power industry, or was it just human error?" Only $7 \%$ believed that the government was most to blame, $15 \%$ blamed the power company, 55\% blamed human error, $10 \%$ volunteered "more than one" as their response, and 13\% had no opinion. The pattern of responses was not different for pronuclear and antinuclear respondents. Thus a majority of the public believed that the accident was due to human error, and a plurality of the public was satisfied with the way that the accident was hand led. 
TABLE 4.15

PERCENTAGE OF THE PUBLIC WHO RATED POSITIVELY OR NEGATIVELY THE HANDLING OF THE THREE MILE ISLAND ACCIDENT BY FOUR DIFFERENT GROUPS

\begin{tabular}{lccc}
\hline & & Harris (79/4) (\%) \\
\cline { 2 - 4 } & Positive & Negative & Not Sure \\
\hline $\begin{array}{l}\text { Pennsylvania state officials } \\
\begin{array}{l}\text { The federal Nuclear Regulatory } \\
\text { Commission }\end{array}\end{array}$ & 57 & 34 & 9 \\
$\begin{array}{l}\text { The electric utility company } \\
\text { that operates the plant }\end{array}$ & 33 & 41 & 15 \\
$\begin{array}{l}\text { The company that designed the } \\
\text { plant }\end{array}$ & 30 & 51 & 19 \\
\hline
\end{tabular}

NOTE: "How would you rate the job done by. . . in handling the recent nuclear accident at the Three Mile Island plant-excellent, pretty good, only fair, or poor?" Excellent and pretty good were combined for a positive rating. Only fair and poor were combined for a negative rating." [Harris (79/4)] 
In addition to ascertaining publicly perceived blame for the accident, CBS (79/4) also asked about the perceived honesty of the public officials in apprising the public of the danger. Respondents were asked, "Do you think public officials have been honest in telling the public all they know about the danger from the accident, or was the danger greater, or less than they said?" Only $20 \%$ believed that the public officials were honest, while a $55 \%$ majority believed that the danger was actually greater, $8 \%$ believed that the danger was less, and $17 \%$ had no opinion. Antinuclear respondents were more likely than pronuclear respondents--69\% versus $44 \%--$ to believe that the danger was actually greater, while pronuclear respondents were more likely to believe that the danger was actually less $--14 \%$ versus $3 \%$.

CBS $(79 / 4)$ then followed with the question, "When public officials think there is a serious danger of some kind, do you think they should tell the public all they know about it, or do you think they should keep back information if they're afraid people will panic?" A 57\% majority believed that the officials should provide full information, while $38 \%$ believed that information should be withheld if it might cause panic, and $5 \%$ had no opinion.

CBS $(79 / 4)$ also asked respondents about media coverage of TMI. The question was, "Do you think that newspapers and television reported the accident fairly, or do you think they blew it out of proportion?" A 57\% majority believed that the media reported the accident fairly, $28 \%$ believed that the media blew it out of proportion, and $15 \%$ had no opinion. Pronuclear and antinuclear respondents answered the question differently, but not as much as might be expected. Of the pronuclear 
respondents, $52 \%$ believed that the media reported fairly, $37 \%$ believed that coverage was blown out of proportion, and $11 \%$ had no opinion. Of the antinuclear respondents, $64 \%$ believed that the media reported fairly, $22 \%$ believed that coverage was blown out of proportion, and $14 \%$ had no opinion.

A majority of the public generally believed that another such accident is likely. CBS (79/4) asked, "Do you think what happened at the Pennsylvania nuclear power plant was a freak accident, or do you think that more accidents like it are likely to occur?" Exactly $50 \%$ of the public believed that more accidents are likely, $37 \%$ believed that it was a freak accident, and $13 \%$ had no opinion. Even $35 \%$ of the pronuclear respondents believed that another accident was likely, although 52\% believed that it was a freak accident. Only $21 \%$ of the antinuclear respondents believed that it was a freak accident, while $69 \%$ believed that more accidents were likely. Harris (79/4) found an even stronger belief in future accidents. Respondents were asked, "Do you feel that what happened at the Pennsylvania nuclear plant could happen at any of the other nuclear power plants in the United States, or do you think an unusual series of things went wrong there that are extremely unlikely to happen in other nuclear plants?" On this question, $68 \%$ of the public believed that accidents could happen at other plants, $29 \%$ believed that the accident was unusual enough so that a similar accident was unlikely, and only $3 \%$ were not sure. In summary, a majority of the public thought that another accident is likely to happen.

Given that a majority of the public believed that government officials understated the dangers, and given that a majority of the 
public believed that another accident is likely, it is not surprising that CBS (79/4) found that a $60 \%$ majority of the public said that they would leave right away if such an accident happened near them. Only 30\% said that they would stay in the area, and $10 \%$ had no opinion. Pronuclear and antinuclear respondents answered this question quite differently, which is not surprising given that one's nuclear attitude is most closely related to one's belief about reactor safety. While $76 \%$ of the antinuclear respondents believed that they would leave right away, such was the case for only $48 \%$ of the pronuclear respondents. Conversely, $41 \%$ of the pronuclear respondents believed that they would stay in the area if an accident were to occur, while such was the case for only $18 \%$ of the antinuclear respondents. Six percent of the antinuclear respondents and $11 \%$ of the pronuclear respondents did not know what they would do in such a situation.

As discussed in Chapter 3, TMI did have an effect on general attitudes toward nuclear power and on willingness to have a nuclear power plant located in one's general area. However, Gallup (79/4a) found that the public did not advocate drastic measures because of the accident. When asked, "Would you favor or oppose shutting down all nuclear plants at this time?", only $25 \%$ of the public favored the idea, $65 \%$ opposed, and $10 \%$ had no opinion. This is not much different than the Becker $(73 / 6)$ findings that $19 \%$ of the public agreed with Ralph Nader "that nuclear power plants are unsafe and that all of them should be shut down immediately," $57 \%$ disagreed, and $24 \%$ had no opinion. This unwillingness to close down existing plants was probably based on the beliefs that 
shutting down plants poses a bigger risk from possible energy shortages than from the plants themselves on economic considerations.

Gallup (79/4b) asked respondents the following risk trade-off question. "Some people feel that nuclear power is essential to meet the energy needs of the nation in view of a dwindling supply of petroleum and the higher cost of this kind of fuel. Which do you think presents the greater risk to the nation--the presence of nuclear plants or the energy shortage that might result if these plants were eliminated?" A 56\% majority believed that the energy shortage that might result presented the bigger risk, while $31 \%$ believed that the nuclear plants presented the bigger risk, and $13 \%$ had no opinion. Also, the public was unwilling to reduce our nuclear dependency if it meant higher prices for electricity. Respondents were asked by Gallup (79/4b), "If the development of nuclear power were to be reduced in the immediate years ahead, we would have to rely on other sources of energy such as coal and oil, which in turn could increase the amount of money the consumer would have to pay for electricity. Would you, yourself, be willing to pay higher prices for electricity in order to reduce the nation's dependency on nuclear power, or not?" Exactly 50\% of the public was not willing, $41 \%$ were willing, and $9 \%$ had no opinion.

Thus, following TMI the general public still felt that nuclear power was important for meeting future energy needs (see Table 4.16). Sixty-three percent of the public still believed that nuclear power is important for meeting future energy needs, $31 \%$ believed that nuclear power is unimportant for meeting future energy needs, and $6 \%$ had no opinion. This is a significant decrease in perceived importance from 
TABLE 4.16

PERCENTAGE OF THE PUBLIC WHO BELIEVE IN THE IMPORTANCE OF NUCLEAR POWER IN MEETING FUTURE ENERGY NEEDS

\begin{tabular}{lcc}
\hline & \multicolumn{2}{c}{ Gallup $(\%)$} \\
\cline { 2 - 3 } & $(76 / 6)$ & $(79 / 4)$ \\
\hline Extremely important & 34 & 29 \\
Somewhat important & 37 & 34 \\
Not too important & 10 & 14 \\
Not at all important & 8 & 17 \\
No opinion & 11 & 6 \\
\hline
\end{tabular}

NOTE: "In order to meet the future needs of the nation, how important do you feel it is to have more nuclear power--extremely important, somewhat important, not too important, or not at all important?" "Gallup $(76 / 6 ; 79 / 4)]$ 
1976, where $72 \%$ of the public believed nuclear power was important for meeting future energy needs, $18 \%$ believed nuclear power unimportant, and $11 \%$ had no opinion. However, this decrease may have already occurred prior to TMI.

Although the general public, following the accident, did not favor shutting down all plants and still believed that nuclear power is important for meeting future energy needs, there was plurality sentiment for cutting back operations until more strict safety regulations could be put into effect. Gallup $(76 / 6 ; 79 / 4)$ asked, "Do you feel that nuclear power plants operating today are safe enough with the present safety regulations, or do you feel that their operations should be cut back until more strict regulations can be put into practice?" In 1976, there was plurality support (40\%) for continued operation and minority support (34\%) for cutting back operations. Following TMI, however, there was majority support (66\%) for cutting back operations and only a minority (24\%) favored continued operation under present safety regulations.

\subsubsection{Beliefs and Attitudes Toward Nuclear Power in Light of the Kemeny Commission Report}

Harris $(80 / 1)$ conducted a survey shortly after the Kemeny Commission Report was released. The U.S. public was sampled, as were four special groups: top corporate executives, investors/lenders, members of Congress, and federal regulators. Respondents were asked to agree or disagree with six statements (see Table 4.17) after they had been reminded of the duties of the Kemeny Commission and that the Kemeny Commission Report had raised some "fundamental issues concerning nuclear energy." However, it should not be assumed that all of the respondents, 
TABLE 4.17

PERCENTAGE OF PUBLIC AND LEADERSHIP GROUPS WHO HOLD CERTAIN

BELIEFS AND ATTITUDES TOWARD NUCLEAR POWER IN LIGHT OF

THE KEMENY COMMISSION REPORT

\begin{tabular}{|c|c|c|c|c|c|c|}
\hline Belief and Attitude Statements & (No. in group) & $\begin{array}{l}\text { General } \\
\text { Public } \\
(1,488)\end{array}$ & $\begin{array}{c}\text { Congress } \\
(47)\end{array}$ & $\begin{array}{c}\text { Federal } \\
\text { Regulators } \\
(47)\end{array}$ & $\begin{array}{c}\text { Investors/ } \\
\text { Lenders } \\
\text { (103) }\end{array}$ & $\begin{array}{c}\text { Top } \\
\text { Corporate } \\
\text { Executives } \\
(402)\end{array}$ \\
\hline
\end{tabular}

There is no guarantee against a catastrophic nuclear accident.

$\begin{array}{lrrrrr}\text { Agree } & 73 & 77 & 87 & 83 & 73 \\ \text { Disagree } & 22 & 21 & 11 & 15 & 24 \\ \text { Not sure } & 5 & 2 & 2 & 3 & 3\end{array}$

Fundamental regulatory changes are necessary if the risks of nuclear energy are to be kept within tolerable limits.

Agree
Disagree
Not sure

$\begin{array}{rrrrr}84 & 81 & 72 & 57 & 47 \\ 9 & 17 & 19 & 35 & 46 \\ 7 & 2 & 9 & 8 & 7\end{array}$

The disposal of nuclear waste is a problem that can be solved in an acceptable way.

Agree
Oisagree
Not sure

$\begin{array}{ll}62 & 68 \\ 26 & 2 \\ 12 & 1\end{array}$

68
21
11

$$
\begin{aligned}
& 66 \\
& 11 \\
& 23
\end{aligned}
$$

$\begin{array}{rr}85 & 90 \\ 1 & 2 \\ 14 & 8\end{array}$

There should be a temporary ban on licensing new nuclear power plants.

$\begin{array}{lrrrrr}\text { Agree } & 57 & 53 & 48 & 11 & 12 \\ \text { Disagree } & 37 & 45 & 52 & 88 & 87 \\ \text { Not sure } & 6 & 2 & 0 & 1 & 2\end{array}$

Nuclear power is too dangerous to permit its continued expansion.

$\begin{array}{lrrrrr}\text { Agree } & 34 & 30 & 17 & 0 & 2 \\ \text { Disagree } & 59 & 70 & 72 & 98 & 98 \\ \text { Mot sure } & 7 & 0 & 11 & 2 & 0\end{array}$

Nuclear energy involves inherent risks, but it is too important to abandon altogether at this time.

Agree
Oisagree
Not sure

77
19
4

$\begin{array}{rrrr}89 & 91 & 99 & 98 \\ 11 & 9 & 1 & 2 \\ 0 & 0 & 0 & 0\end{array}$

NOTE: For leadership groups: "The President's Commission to investigate the nuclear accident at Three Mile Island--the Kemeny Commission--recently released its final report. As you know, fundamental issues concerning nuclear energy were raised by this report. In light of this report, please tell me whether you tend to agree or disagree with the following statements."

For general public: "The President's Comission to investigate the nuclear accident at Three Mile Island recently released its final report which raised some fundamental issues concerning nuclear energy. In light of this report, please tell me whether you tend to agree or disagree with the following statements."

[Harris $(80 / 1)]$ 
especially members of the general public, knew about the Kemeny Commission or its findings, although the question was linked to the TMI accident and made it clear that there were negative findings by the Commission. In general, the data picture a public that is concerned about nuclear power but one that takes the attitude that despite the TMI accident and the Kemeny Commission findings the U.S. should take a "go slow, but go ahead" approach to nuclear power.

Respondents were first asked about the possibility of future accidents. A $70 \%$ to $90 \%$ majority of all the groups agreed that, "There is no guarantee against a catastrophic nuclear accident." In addition, except for top corporate executives, a majority of all groups agreed that, "Fundamental regulatory changes are necessary if the risks of nuclear energy are to be kept within tolerable limits." The general public (84\%) and members of Congress (77\%) were most likely to agree with this statement, while top corporate executives were evenly split $(47 \%$ agree, $46 \%$ disagree) in their belief. Respondents were also asked whether they believed that the nuclear waste problem could be solved in an acceptable way. A majority of all groups believed that it could, ranging from $62 \%$ of the general public to $90 \%$ of the top corporate executives.

After asking about respondent beliefs regarding three safety considerations, three questions were asked to probe respondent attitudes toward the continued use of nuclear power. The questions are discussed from most severe to least severe consequences to the nuclear power industry. The respondent groups were divided as to whether there should be a temporary ban on licensing new nuclear power plants (such a ban, in 
fact, occurred). A slight majority of the general public (57\%) and members of Congress (53\%) favored a temporary licensing ban. The ban was opposed by federal regulators (52\%), top corporate executives (87\%), and investors/lenders (88\%). A majority of all groups disagreed with the idea of stopping the expansion of nuclear power--from $50 \%$ of the general public to $98 \%$ of both the top corporate executives and the investors/lenders. Finally, there was strong majority sentiment that nuclear power could not be abandoned altogether at this time (implying shutting down existing plants as well as not licensing new plants), from $77 \%$ of the general public to $99 \%$ of the investors/lenders.

Thus, in light of the TMI accident and the Kemeny Commission findings, and despite the fact that a majority of the public and most leadership groups believe that there is no guarantee against a catastrophic nuclear accident and that fundamental regulatory changes are needed, a majority of the public and of the leadership groups still favor the continued use and expansion of the nuclear industry. There was, however, majority public and Congressional support for a temporary halt to power plant licensing.

\subsubsection{Summary}

Almost the total American population was aware of the TMI accident. A majority of the public was disturbed by the accident, and a minority of the public was worried about their safety or their family's safety during the accident. A plurality of the public was satisfied with the way the accident was handled, especially by NRC officials and Pennsylvania government officials. The cause of the accident was mainly believed to be human error, and a majority of the public believed that other 
accidents are likely. While the public believed that government officials minimized the danger, media coverage was believed to be fair. A majority of the public said that they would evacuate immediately if such an accident took place near them.

Despite the concern raised by the accident, a majority of the public believed that operating plants should not be shut down because of economic considerations and because greater risks would be incurred from subsequent energy shortages. A majority of the public still believed that nuclear power is important for meeting future energy needs.

The attitude of the public and of leadership groups about the future of nuclear power did not change as a function of the Kemeny Commission findings, which were released late in 1980. Despite the fact that a majority of the general public and most leadership groups believed that there is no guarantee against a catastrophic nuclear accident and that fundamental regulatory changes are necessary to keep risks within tolerable limits, a majority of the public and leadership groups favored the continued use and expansion of nuclear power. However, in light of the Kemeny Commission findings, a slight majority of the public and of Congress favored a temporary ban on licensing new plants.

\subsection{Nuc lear Waste Management}

\subsubsection{Introduction}

As discussed in Section 4.2, public concern regarding nuclear waste management increased from 1975 through 1979, so that nuclear waste management is believed to be one of the most important nuclear power problems. Prior to 1977 (see Melber et al., 1977), the public was 
somewhat evenly split as to whether they believed that a satisfactory waste management solution existed. About $40 \%$ believed that a technology for safe waste management did exist, about $40 \%$ believed that it did not exist, and about $20 \%$ were uncertain. At the same time, the public was somewhat optimistic that a technical solution could be found. About $50 \%$ believed that a technology would be found, about $25 \%$ did not, and the remaining $25 \%$ were unsure. More recent data are available to determine whether these beliefs have changed.

\subsubsection{The Problem of Nuclear Wastes Compared to Other Industrial Risks}

Cambridge $(78 / 10)$ distinguished among four nuclear waste-producing technologies--military, commercial, medicine, and industrial--and asked respondents which were the first and second most important technologies to our country today, and then asked which of the technologies produce the most waste. Combining first and second place importance mentions, nuclear medicine was seen as most important (66\%), followed by commercial nuclear power plants (49\%), military programs (47\%), and industrial uses $(35 \%)$. Fourteen percent of the respondents did not answer the question.

The above question was followed by, "When you think about nuclear waste in this country, which of these four applications of nuclear technology. . do you think produces the largest actual volume or physical amount of waste?" Despite the fact that the largest volume of waste is from the military program, a $31 \%$ plurality believed that the largest volume of waste comes from commercial plants, followed by military programs (24\%), industrial uses (21\%), a "combination" (volunteered by $13 \%$ ), and nuclear medicine (4\%). Eight percent did not know where most wastes come from. 
As a nuclear power problem, waste management is obviously important. However, survey findings indicate that it is not believed to be as serious as other industrial risks. YS\&W (78/unk.) asked general public respondents and key leadership respondents to compare the severity of four classes of industrial solid wastes--toxic industrial waste (mercury, cadmium, lead, etc.), radioactive wastes, industrial wastes such as slag mine tailings, and industrial packaging materials (see Table 4.18). There are several important findings regarding the perceived relative severity of the different types of waste. First, toxic industrial wastes were believed to be a much more severe problem than radioactive wastes both by the general public and by the key leaders. About $70 \%$ of the general public and $90 \%$ of the key leaders believed that toxic industrial wastes cause the most severe problem, compared to only about $50 \%$ and $70 \%$, respectively, for the public and key leaders' belief that radioactive wastes were the most severe problem. A second important finding was that the general public believed that radioactive wastes and industrial solid wastes such as slag mine tailings were of equal severity. However, such was not the case for the key leaders, who believed that radioactive wastes (about $68 \%$ ) were a more severe disposal problem than industrial wastes (about 38\%). Third, industrial packaging materials were believed to be the least severe problem by the general public (about $30 \%$ ) and by key leaders (about $8 \%$ ).

Although other waste problems are perceived to be more severe, nuclear waste disposal facilities still seem to present a special kind of risk. Cambridge $(78 / 10)$ asked the respondents the following question. "Some people argue that living near a nuclear waste storage site is 
TABLE 4.18

PERCENTAGE OF RESPONDENTS WHO BELIEVE THAT A GIVEN TYPE OF INDUSTRIAL SOLID WASTE COULD CAUSE THE MOST SEVERE PROBLEM

\begin{tabular}{|c|c|c|c|c|}
\hline \multirow{2}{*}{ Type of Industrial Solid Waste } & \multicolumn{2}{|c|}{ General Public (\%) } & \multicolumn{2}{|c|}{ Key Leadership (\%) } \\
\hline & $(77 / u)$ & $(78 / u)$ & $(77 / u)$ & $(78 / u)$ \\
\hline $\begin{array}{l}\text { Toxic industrial waste (mercury, } \\
\text { cadmium, lead, etc.) }\end{array}$ & 71 & 68 & 91 & 91 \\
\hline Radioactive wastes & 52 & 45 & 68 & 68 \\
\hline $\begin{array}{l}\text { Industrial wastes such as "slag" } \\
\text { mine tailings }\end{array}$ & 53 & 43 & 41 & 35 \\
\hline Industrial packaging materials & 30 & 29 & 12 & 6 \\
\hline
\end{tabular}

NOTE: "Now thinking about industrial waste disposal problems, what particular things do you feel cause the most severe industrial solid waste problems?" [YS\&W (77/unk; 78/unk)] 
really not that different from living near other industrial sites. That is, the people living in Detroit, for example, bear certain burdens by being in the city which produces cars for most Americans. And the residents of Pittsburgh bear certain burdens by being the city which produces steel which all Americans use. In a similar way, whichever people live near nuclear waste storage sites will bear certain burdens, but so do others in other ways. Do you think this line of argument is reasonable or do you feel that living near a nuclear waste material storage site is somehow different?" Fifty percent of the public believed that it was different, $30 \%$ believed that it was similar, and $20 \%$ were uncertain. Thus, nuclear wastes still have a mystique about them that elevates public concern compared to other industrial risks. There were some significant regional variations in responses to this question. Central state residents were about evenly split in their belief (39\% similar, $40 \%$ different, and $21 \%$ uncertain), while residents of Pacific states (27\% similar, 59\% different, and 14\% uncertain) and Northeast states (28\% similar, $57 \%$ different, and $20 \%$ uncertain) believed that nuclear waste storage sites provide a different type of risk than do other industrial facilities.

\subsubsection{Beliefs about the Ability to Solve the Waste Disposal Problem}

Before 1977 , state survey data indicated that the public was somewhat evenly split in believing that a satisfactory waste disposal technology did or did not exist (Melber, 1977). This seems to be the case at this time nationwide. Harris (78/10) asked a general public sample, "Do you believe the United States has the know-how today to 
isolate and store the radioactive waste for many years until the ir radioactivity has decayed to relatively harmless levels?"

Forty-one percent believed that the technology exists, $42 \%$ believed that it does not exist, $15 \%$ were not sure, and $2 \%$ did not answer. Southerners (45\%) were most likely to believe that the technology exists and Westerners (37\%) were least likely.

Then the $59 \%$ who believed that the technology does not exist, were not sure, or did not answer, were asked when they thought the technology would be developed. Twenty-seven percent believed that it would be developed within the next 10 years, $26 \%$ believed that it would be developed in the next 25 years, $9 \%$ believed that it would be developed in the next 50 years or more, $16 \%$ thought that it would never be developed, $18 \%$ were not sure, and $3 \%$ gave no answer. Midwesterners and Southerners were more optimistic about when the technology would be developed compared to Easterners and Westerners.

Using a different question, Cambridge (78/7) found that about $56 \%$ of the public believed that a waste technology exists while $26 \%$ do not. The following question was read: "Some people say that we can never really solve the problem of nuclear waste--that it will always be too dangerous to create it. Other people argue that we already have the technology for dealing with nuclear waste and all we have to do is decide to implement it. Which of these is closer to your feelings?" If respondents were undecided, they were asked, "We11, toward which point do you lean?" On this question $32 \%$ believed that we already have the technology, $24 \%$ leaned toward believing that we already have the technology, $14 \%$ believed 
that the waste problem can never really be solved, $12 \%$ leaned toward believing the waste problem can never be solved, and $17 \%$ were undecided.

A different question used by Harris $(78 / 10 ; 79 / 4)$ indicated less belief in the existence of a waste management solution. Respondents were asked the truthfulness of the statement, "There is no satisfactory way of disposing of radioactive waste from nuclear power plants." In 1978, 52\% believed that the statement was true, $29 \%$ believed that it was untrue, and 19\% were not sure. This is not the same split found with the other question wording. After TMI, 63\% of the respondents agreed with the statement, $19 \%$ disagreed, and 19\% were not sure. Thus, TMI seems to have had some impact on one's belief about whether a satisfactory waste disposal method already exists.

Finally, Harris $(80 / 1)$ conducted a survey immediately following the release of the Kemeny Commission findings (see Section 4.5 .3 and Table 4.17$)$. This survey found that $62 \%$ of the general public and from $66 \%$ to $90 \%$ of the leadership groups believed, "the disposal of nuclear waste is a problem that can be solved in an acceptable way."

Thus, the public is somewhat evenly divided in its belief as to whether the technology to manage nuclear wastes already exists. However, a majority of the public and of leadership groups believes that the nuclear waste problem will be solved in an acceptable manner.

\subsubsection{Effect of Waste Management Concerns on Nuclear Reactor Operation and Construction}

Concern over waste management could manifest itself in attitudes about the operation and construction of nuclear power plants. Harris $(78 / 10)$ asked respondents whether they believed, "We are best off 
forgetting about nuclear power today because we cannot predict with absolute certainty what might happen to spent fuel and wastes. . ." or whether "We should continue to use nuclear power. . . [and] plan to isolate the stored spent nuclear fuel and wastes based on what scientists believe today is safe. . ." A $64 \%$ majority believed that we should continue to use nuclear power, $28 \%$ believed that we should discontinue nuclear power because of waste management problems, and $9 \%$ were not sure. Cambridge $(78 / 7)$ asked respondents to agree or disagree with the statement, "Al1 nuclear power plants should be closed until some absolutely safe method of waste disposal is found." Thirty-two percent agreed with the statement (about the same percentage as those who opposed nuclear power in general in that survey), $52 \%$ disagreed with the statement, and $16 \%$ were undecided.

Then the $52 \%$ who disagreed with the statement were asked, "Do you think we should ban the construction of any new nuclear power plants in the future until some absolutely safe method of waste disposal is found or not?" Twenty-nine percent answered yes, $63 \%$ answered no, and $9 \%$ were not sure. If we assume that anyone who favors closing existing plants would also favor the less extreme measure of not building new ones, the results of the two questions can be combined to get the following. A total of $47 \%$ of the population would back the banning of new plants until a safe waste disposal method was found, $33 \%$ would oppose such a ban, and the remainder would be undecided. This indicates that concern over waste management does affect attitudes about power plant construction. Even about $25 \%$ of the population, who generally favored nuclear power plant 
construction, would forego building new plants until a waste disposal system has been demonstrated.

Nuclear waste problems also seemed to have had a direct effect in changing one's general nuclear power attitude. Cambridge $(78 / 5 ; 78 / 7)$ asked respondents if they had changed their position on nuclear power recently, and, if so, why. In Cambridge (78/5), $6 \%$ of the total had become less favorable and $14 \%$ of those (about $0.8 \%$ of the total sample) said they changed their attitude because of nuclear waste disposal. Learning more about the dangers (26\%) and having more information (22\%) were volunteered more often as reasons for change. In Cambridge (78/7), however, the most-volunteered reason for change had to do with waste disposal. Of the $5 \%$ who had become less favorable, $29 \%$ of those (about $1.5 \%$ of the total sample) volunteered waste disposal as the reason.

\subsubsection{Attitudes About What Waste Management Plan Might be Acceptable}

Several questions have been asked by survey researchers since 1976 that give some insight into public acceptance of a waste management plan. Cambridge $(78 / 5)$ asked respondents about the priority being placed on the government's waste management schedule. The question read: "The Federal government, under Federal law, has the responsibility for disposing of the radioactive waste. Recent reports say that the disposal facilities will not be built before 1988. Do you think the government's priority on radioactive waste disposal is too low, too high or about right?" Although a 1988 date would be very hard to make, $46 \%$ of the respondents believed that a 1988 date signaled too low a priority, only $23 \%$ believed that it was about right, $7 \%$ believed that it was too high a priority, and $24 \%$ did not know. These findings suggest that putting back 
the date for completing the first nuclear repository could be perceived in a negative fashion by the public.

But what kind of waste management plan might the public accept? Unfortunately, there are limited survey data regarding acceptance of a full-scale waste disposal facility in a given state. A telephone survey by WASHPIRG (WA 78/12) found little public acceptance for a waste repository in Washington. Respondents were first asked whether they had heard that Hanford was being considered as a permanent waste disposal site--61\% had and 39\% had not. Then respondents were asked, "Would you support, or are you opposed to burying the nation's nuclear waste at Hanford?" Nineteen percent of the Washington residents supported the idea, $44 \%$ opposed, and $38 \%$ were still uncertain. However, when it was suggested that foreign wastes might be buried at Hanford, the uncertainty disappeared--82\% opposed, on ly $5 \%$ supported, and on ly $13 \%$ were uncertain.

New York and Wisconsin residents were also opposed to a permanent radioactive waste repository in their state. Harris (NY 78/2) found that $16 \%$ of New York residents approved of such a facility, $66 \%$ opposed, and $18 \%$ were not sure. WSRL (WI 78/5) found that $13 \%$ of wisconsin residents approved of a permanent waste storage site, while $79 \%$ disapproved, and $9 \%$ were not sure.

There does seem to be public acceptance of the idea of a small-scale demonstration project, however. Cambridge (78/10) asked a question on acceptance of such a project (see Table 4.19 for exact question wording) and found that $52 \%$ of the public favored such a project in their state, $33 \%$ opposed such a project, and $16 \%$ were uncertain (this adds to $101 \%$ 


\section{TABLE 4.19}

PERCENTAGE OF THE PUBLIC WHO FAVOR OR OPPOSE

A SMALL-SCALE DISPOSAL DEMONSTRATION PROJECT

IN THEIR STATE BY REGION OF THE COUNTRY

\begin{tabular}{lccc}
\hline & Favor (\%) & Oppose (\%) & Unsure (\%) \\
\hline Total Public & 52 & 33 & 16 \\
\hline Region of the Country & & 38 & 17 \\
\hline Northeast (16)a & 45 & 31 & 18 \\
Industrial (26) & 51 & 32 & 8 \\
Midlands (13) & 60 & 30 & 82 \\
South (19) & 48 & 24 & 15 \\
Central (12) & 69 & 41 & \\
Pacific (14) & 45 & \\
\hline \\
apercentage of the total respondents who lived in that \\
region of the country.
\end{tabular}


because of rounding). Acceptance of such a facility was highest in the Central states and lowest in the Northeast and Pacific states. This suggests that the government's present plan to develop a waste test and evaluation facility may be viewed favorably by the public and that it may not be as hard to site as a full-scale waste repository.

Harris $(78 / 10)$ asked a series of questions of the American public and of seven leadership groups regarding storage of nuclear wastes in different types of hosts (granite, rock salt, seabed, and above-surface structures in isolated areas). The question read, "If the following was certified as one of the safest ways to store nuclear wastes, would you favor storing by that method?" The results are presented in Table 4.20. Even with "certification," only $53 \%$ of the total public endorsed the most-favored storage method, above-surface storage in isolated areas. Granite was favored by $44 \%$ of the general public and rock salt was favored by $43 \%$. Seabed disposal was the only method that was opposed (45\%) more than favored $(30 \%)$.

Favorability was different for the leadership groups, however. While the leadership groups differed in the amount of favorability shown to a given disposal method, the relative rankings were the same across groups. Stable granite and rock salt tied as the most-favored alternative followed by above-surface storage. A majority of all leadership groups, except business, opposed seabed disposal. A plurality of the business leaders favored seabed disposal. The environmental leaders opposed all four methods of storage more than they favored them. The least opposition (48\%) and most favor (36\%) was shown to stable granite. However, except for seabed disposal, the remaining leadership 
TABLE 4.20

PERCENTAGE OF THE PUBLIC WHO FAVOR OR OPPOSE DIFFERENT WASTE STORAGE METHODS

\begin{tabular}{|c|c|c|c|c|c|c|c|c|}
\hline \multirow[b]{2}{*}{ Storage Methods } & \multirow[b]{2}{*}{$\begin{array}{c}\text { Total } \\
\text { Public }(x) \\
(1,560)^{\mathrm{a}}\end{array}$} & \multicolumn{7}{|c|}{ Leadership Groups $(x)$} \\
\hline & & $\begin{array}{c}\text { Political } \\
(56)\end{array}$ & $\begin{array}{c}\text { Bus iness } \\
(53)\end{array}$ & $\begin{array}{l}\text { Regulator } \\
\text { (51) }\end{array}$ & $\begin{array}{c}\text { Environ- } \\
\text { mental } \\
(67)\end{array}$ & $\begin{array}{r}\text { Utility } \\
\text { Company } \\
(26)\end{array}$ & $\begin{array}{r}\text { Labor } \\
(30)\end{array}$ & $\begin{array}{r}\text { Media } \\
(41)\end{array}$ \\
\hline \multicolumn{9}{|c|}{ Specially designed and built } \\
\hline $\begin{array}{l}\text { structures in isolated } \\
\text { Favor } \\
\text { Oppose } \\
\text { Not sure } \\
\text { No answer }\end{array}$ & $\begin{array}{r}53 \\
24 \\
21 \\
3\end{array}$ & $\begin{array}{r}50 \\
41 \\
7 \\
2\end{array}$ & $\begin{array}{r}49 \\
36 \\
15 \\
0\end{array}$ & $\begin{array}{r}51 \\
39 \\
8 \\
2\end{array}$ & $\begin{array}{r}19 \\
66 \\
13 \\
1\end{array}$ & $\begin{array}{r}65 \\
31 \\
4 \\
0\end{array}$ & $\begin{array}{r}50 \\
37 \\
13 \\
0\end{array}$ & $\begin{array}{r}39 \\
46 \\
7 \\
7\end{array}$ \\
\hline \multicolumn{9}{|c|}{ Stable granite rock formations } \\
\hline $\begin{array}{l}\text { Favor } \\
\text { 0ppose } \\
\text { Not sure } \\
\text { No answer }\end{array}$ & $\begin{array}{r}44 \\
28 \\
25 \\
3\end{array}$ & $\begin{array}{r}79 \\
9 \\
9 \\
4\end{array}$ & $\begin{array}{r}66 \\
23 \\
11 \\
0\end{array}$ & $\begin{array}{r}75 \\
18 \\
4 \\
4\end{array}$ & $\begin{array}{r}36 \\
48 \\
15 \\
1\end{array}$ & $\begin{array}{r}92 \\
8 \\
0 \\
0\end{array}$ & $\begin{array}{r}50 \\
37 \\
10 \\
3\end{array}$ & $\begin{array}{r}61 \\
27 \\
5 \\
7\end{array}$ \\
\hline \multicolumn{9}{|c|}{$\frac{\text { Stable areas beneath Pacific }}{\text { seabed }}$} \\
\hline $\begin{array}{l}\text { Favor } \\
\text { 0ppose } \\
\text { Not sure } \\
\text { No answer }\end{array}$ & $\begin{array}{r}30 \\
45 \\
22 \\
3\end{array}$ & $\begin{array}{r}32 \\
57 \\
9 \\
2\end{array}$ & $\begin{array}{r}45 \\
42 \\
13 \\
0\end{array}$ & $\begin{array}{r}24 \\
65 \\
8 \\
4\end{array}$ & $\begin{array}{r}12 \\
78 \\
9 \\
1\end{array}$ & $\begin{array}{r}35 \\
65 \\
0 \\
0\end{array}$ & $\begin{array}{r}37 \\
53 \\
10 \\
0\end{array}$ & $\begin{array}{r}27 \\
61 \\
5 \\
7\end{array}$ \\
\hline
\end{tabular}

a Number of respondents.

NOTE: "If the following was certified as one of the safest ways to store nuclear wastes, would you favor storing by that method?" [Harris $(78 / 10)]$ 
groups favored each of the waste storage methods more than they opposed them.

Following the attitude questions about the four disposal methods, Harris $(78 / 10)$ asked respondents if they would be more likely or less likely to support that method if other conditions were met (see Table 4.21). Forty percent of the general public said that they would be more likely to support one of the storage methods if the alternative is on-site water basin storage (which is the case at time of writing). The leadership groups were even more affected by the alternative--even $52 \%$ of the environmental leaders said that they would be more likely to support one of the methods if on-site water basin storage was the alternative. Politicians were most influenced--89\% would be more likely to support a method given the alternative. This may have been due to the fact that there were nuclear power plants in their political district.

The "not in my backyard" philosophy was apparent in the next question--34\% of the general public said that they would be more likely to support one of the methods if the location selected for permanent disposal was not in their state. Politicians were most influenced by this condition--63\% were more likely to support one of the methods if it was not located in their state. Business leaders (51\%) were a distant second. Environmentalists were the least affected by the provision--60\% said that it did not make much difference.

In summary, a plurality of the general public thinks that the 1988 schedule for completing the first disposal facility does not indicate high enough priority on the part of the federal government to get the job done. As hard as this goal would be to meet anyway, the lack of majority 
TABLE 4.21

PERCENTAGE OF THE PUBLIC WHO ARE MORE LIKELY OR LESS LIKELY TO SUPPORT A OISPOSAL METHOD IF CERTAIN CONDITIONS ARE MET

\begin{tabular}{|c|c|c|c|c|c|c|c|c|c|c|c|c|}
\hline \multirow[b]{2}{*}{ Condition } & \multicolumn{5}{|c|}{ General Public (\%) } & \multicolumn{7}{|c|}{ Leadership Groups (\%) } \\
\hline & $\begin{array}{l}\text { Total }(\%) \\
(1,563)^{\mathrm{a}}\end{array}$ & $\begin{array}{l}\text { East } \\
(427)\end{array}$ & $\begin{array}{l}\text { Mid- } \\
\text { West } \\
(422)\end{array}$ & $\begin{array}{l}\text { South } \\
(438)\end{array}$ & $\begin{array}{l}\text { West } \\
(276)\end{array}$ & $\begin{array}{c}\text { Political } \\
(56)\end{array}$ & $\begin{array}{l}\text { Business } \\
\text { (53) }\end{array}$ & $\begin{array}{c}\text { Regulator } \\
\text { (51) }\end{array}$ & $\begin{array}{c}\text { Environ- } \\
\text { mental } \\
(67)\end{array}$ & $\begin{array}{l}\text { Utility } \\
\text { Company } \\
(26)\end{array}$ & $\begin{array}{r}\text { Labor } \\
(30)\end{array}$ & $\begin{array}{r}\text { Media } \\
(41)\end{array}$ \\
\hline \multicolumn{13}{|l|}{ The alternative would be } \\
\hline $\begin{array}{l}\text { continuing to store } \\
\text { spent nuclear fuel in } \\
\text { temporary facilities } \\
\text { near a nuclear gene- } \\
\text { rating plant }\end{array}$ & & & & & & & & & & & & \\
\hline $\begin{array}{l}\text { More Tikely } \\
\text { Less likely } \\
\text { Not much difference } \\
\text { Not sure } \\
\text { No answer }\end{array}$ & $\begin{array}{r}40 \\
21 \\
20 \\
17 \\
2\end{array}$ & $\begin{array}{l}35 \\
21 \\
24 \\
20 \\
--b\end{array}$ & $\begin{array}{l}45 \\
23 \\
20 \\
11 \\
1\end{array}$ & $\begin{array}{r}37 \\
18 \\
20 \\
21 \\
4\end{array}$ & $\begin{array}{r}43 \\
25 \\
17 \\
14 \\
2\end{array}$ & $\begin{array}{r}89 \\
2 \\
5 \\
2 \\
2\end{array}$ & $\begin{array}{r}77 \\
9 \\
8 \\
6 \\
0\end{array}$ & $\begin{array}{r}76 \\
8 \\
12 \\
2 \\
2\end{array}$ & $\begin{array}{r}52 \\
15 \\
25 \\
4 \\
3\end{array}$ & $\begin{array}{r}77 \\
12 \\
12 \\
0 \\
0\end{array}$ & $\begin{array}{r}63 \\
13 \\
17 \\
7 \\
0\end{array}$ & $\begin{array}{r}73 \\
7 \\
12 \\
2 \\
5\end{array}$ \\
\hline $\begin{array}{l}\text { The location selected for } \\
\text { permanent storage and } \\
\text { disposal was not in you } \\
\text { state }\end{array}$ & & & $\cdot$ & & & & & & & & & \\
\hline $\begin{array}{l}\text { More likely } \\
\text { Less likely } \\
\text { Not much difference } \\
\text { Not sure } \\
\text { No answer }\end{array}$ & $\begin{array}{r}34 \\
13 \\
36 \\
14 \\
2\end{array}$ & $\begin{array}{r}34 \\
14 \\
36 \\
16 \\
1\end{array}$ & $\begin{array}{l}42 \\
11 \\
36 \\
10 \\
1\end{array}$ & $\begin{array}{r}33 \\
13 \\
33 \\
17 \\
4\end{array}$ & $\begin{array}{r}27 \\
16 \\
42 \\
12 \\
2\end{array}$ & $\begin{array}{r}63 \\
0 \\
30 \\
5 \\
2\end{array}$ & $\begin{array}{r}51 \\
4 \\
38 \\
8 \\
0\end{array}$ & $\begin{array}{r}41 \\
8 \\
47 \\
4 \\
0 \\
4\end{array}$ & $\begin{array}{r}16 \\
16 \\
60 \\
1 \\
6\end{array}$ & $\begin{array}{r}46 \\
8 \\
46 \\
0 \\
0\end{array}$ & $\begin{array}{r}30 \\
10 \\
53 \\
3 \\
3\end{array}$ & $\begin{array}{r}29 \\
12 \\
46 \\
7 \\
5\end{array}$ \\
\hline
\end{tabular}

aNumber of respondents.

bless than $0.5 \%$.

NOTE: Previous question read, "If the following was certified as one of the safest ways to store nuclear wastes, would you favor storing by that method?" The above question, which followed, read, "How likely would you be to support that method if. . .?" [Harr is $(78 / 10)]$ 
acceptance by residents of the states makes the goal even harder to attain. Lack of acceptance seems partly due to the belief that waste management facilities pose qualitatively different risks compared to other industrial facilities. However, a slight majority of the general public would accept a small-scale demonstration nuclear waste storage site in their state. Evidently, the distinction between a small-scale demonstration site and a full-scale disposal site is a distinction that makes a difference with the public. The general public seemed most willing to accept above ground storage in remote locations, although storage in solid granite and rock salt received about the same acceptance. Seabed disposal was the least acceptable method of disposal. Leadership groups found solid granite and salt disposal most acceptable and seabed disposal least acceptable. The general public and members of the leadership groups all indicated a greater willingness to accept one of the disposal methods if the alternative was to continue to allow spent fuel to accumulate in water basin storage at the reactor site or if the site was not located in the ir state.

\subsubsection{Summary}

There appears to be increased public concern since 1976 regarding nuclear waste management problems. Since 1976 over twice as many people have said that they oppose nuclear power because of waste management problems than was previously the case. And, when respondents who had changed their attitude from support to opposition of nuclear power were asked why, the response volunteered most often was with regard to increased concern over nuclear waste management. There was increased concern regarding waste management after the TMI accident, indicating 
that probably any serious nuclear power problem will increase the salience of nuclear waste management. Finally, when nuclear power problems were directly compared, nuclear waste management was still believed to be a bigger problem than reactor safety, even after the TMI accident.

However, the general public believed that toxic industrial wastes were a more severe disposal problem than radioactive wastes. Further, the general public believed that the problems associated with disposing of radioactive wastes and of industrial wastes such as slag mine tailings were of equal severity. However, despite their beliefs about the severity of these disposal problems, the general public was less willing to live near a nuclear waste repository compared to other industrial facilities because radioactive wastes were believed to be qualitatively different.

The general public is somewhat evenly divided in their belief as to whether an acceptable waste management plan is already available, although a majority of the public believes that an acceptable solution will be found. A small minority of the public believed that an acceptable solution will never be found. Public opposition at the state level to a full-scale waste repository was much greater than public acceptance, although there is majority support for a small-scale, demonstration disposal facility. Given the public concern over nuclear wastes, and despite the lack of public acceptance of a full-scale waste repository in one's own state, the general public believed that the 1988 deadline for the first waste repository did not indicate high enough priority on the part of the federal government to solve the waste problem. 
When asked to choose among different waste disposal techniques that were certified as safe, the general public showed greatest acceptance of above ground storage at remote locations. Acceptance of storage in granite and salt closely followed, however. Choice of above surface storage may have reflected disbelief that other methods were available at the time. Leadership groups showed most favorability to disposal in granite and salt. The general public and all leadership groups showed least favorability to seabed disposal. All groups indicated a willingness toward greater acceptance of one of the disposal methods if on-site water basin storage was the alternative or if the waste disposal facility was not located in one's state. Politicians, especially, were willing to endorse a waste disposal method if the facility was not located in their state.

\subsection{The Supply of Uranium}

\subsubsection{Introduction}

In Sections 4.2 and 4.3 , we discussed the finding that the general public believed that a major benef it of nuclear power was the fact that it is a reliable long-term energy source. A large majority of the public believed that nuclear power could be obtained almost entirely within the United States and therefore believed that nuclear power makes us less dependent on foreign sources of energy. In this section, we will discuss specific questions that have been asked about how long the uranium supply is expected to last. Public beliefs about uranium supply are important to ascertain given the recent controversy over the need to reprocess spent nuclear fuel in order to extend the nuclear option. 


\subsubsection{Beliefs and Attitudes about the Supply of Uranium}

The general public seems to have had little knowledge about the uranium supply before 1978. When asked about how long the uranium supply would last, a plurality of the public was uncertain. Cambridge $(77 / 5 ; 77 / 11)$ asked several kinds of questions to ascertain uranium supply beliefs. First, respondents were asked, "Would you agree or disagree: There's plenty of uranium to be found in the world. We'll have enough to power all the nuclear power plants we can ever realistically build." While $25 \%$ of the public agreed and $28 \%$ disagreed with the statement, a $48 \%$ plurality was uncertain.

Less belief in a limitless uranium supply was shown when a reversed form of the above question was asked. Respondents were asked to agree or disagree with, "Uranium is a scarce resource just like oil and some day we will run out of it too." A $46 \%$ plurality agreed with this statement, while $17 \%$ disagreed, and $37 \%$ were uncertain.

In 1977, the public was also not sure about whether a 25-year uranium fuel supply existed. Cambridge $(77 / 5 ; 77 / 11)$ asked: "As you know, nuclear power plants use a form of uranium as their source of power. Given all the discussion recently about an energy crisis in America, do you think our country has enough uranium to fuel all the nuclear power plants we now have and the ones that will be built in the next 25 years?" Averaging across the two surveys, a 51\% majority was uncertain, while $31 \%$ believed that enough uranium existed, and $19 \%$ believed that uranium shortages would occur. When asked to estimate the number of years the uranium supply will last, $8 \%$ selected the $0-5$ year supply 
category, $12 \%$ selected $6-10$ years, $14 \%$ selected $11-20$ years, $14 \%$ selected over 20 years, and a $52 \%$ majority were unable to select a category.

There is less uncertainty, however, about using the United States uranium supply to stop proliferation. Cambridge (77/5) asked: "Due to fears of nuclear power proliferation, President Carter recently asked other nations to forego their reprocessing of used nuclear fuel. Since this would mean these nations would, as a result, give up a potential critical energy source, he offered to replace their lost energy by providing them with new uranium fuel from the United States. This will obviously reduce the uranium available for United States nuclear power plants. Do you think the United States should adopt this plan or not?" A $58 \%$ majority was against the plan, $14 \%$ supported the plan, and $28 \%$ were uncertain. Pronuclear and antinuclear respondents did not answer the question differently.

Harris $(75 / 4 ; 76 / 7 ; 78 / 10)$, however, found evidence that beliefs about the uranium supply changed in 1978. Harris asked respondents whether they believed that nuclear power "can be produced in almost unlimited quantities" and whether we "will not run out of supply anytime soon in the future." In 1975, 1976, and 1978, respectively, $65 \%, 63 \%$, and $69 \%$ of the public believed that nuclear power could be produced in unlimited quantities. These results are quite discrepant from the Cambridge findings, which suggested less optimism in the uranium supply and much more uncertainty. More important $1 y$, however, $71 \%$ of the public in 1978 believed that we would not run out of the uranium supply any time soon in the future compared to $51 \%$ in 1976 , and $53 \%$ in 1975 . It is 
possible, then, that former President Carter's statements on the uranium supply were accepted by the general public.

\subsubsection{Summary}

Through 1977 the public was generally uncertain about the uranium supply. However, by 1978 a majority of the public believed that an adequate uranium supply existed for the near term. The public was not in favor of selling United States uranium to other countries as a way to control proliferation, probably because of the perceived need for keeping the fuel for United States reactors.

\subsection{Reprocessing}

\subsubsection{Introduction}

As one of the questions in the preceding section indicated, uranium supply and reprocessing are related topics. During the political debate during the Carter administration regarding the uranium supply/reprocessing/proliferation relationships, survey organizations asked questions to ascertain public beliefs and attitudes regarding reprocessing.

\subsubsection{Beliefs about Reprocessing}

Harris $(78 / 10)$ found that $51 \%$ of the United States agreed ". . that much of the spent nuclear fuel can be recycled into fuel which can be used again." Twelve percent disagreed, $36 \%$ were not sure, and $2 \%$ did not answer. Men (60\%) more than women (43\%) agreed with the statement; women (45\%) more than men (26\%) were not sure. 
In order to examine the possible basis for reprocessing attitudes, Harris $(78 / 10)$ asked respondents three items about reprocessing spent fuel (see Table 4.22). First, there was a slight majority belief on the part of the general public and all the leadership groups, except the environmental group, that "it's cheaper to recycle spent fuel than it is to keep using new fuel." A plurality of environmentalists did not believe this to be true. Probably of most significance is the fact that a large percentage of respondents (from $8 \%$ to $29 \%$ ) were not sure about their belief on this item.

Second, respondents were asked whether they believed the statement, "Terrorists and saboteurs will somehow steal reprocessed fuel and threaten us with nuclear weapons even if safeguards are set up." A 46\% plurality of the general public did not believe this statement, while a $33 \%$ minority did. A majority of environmentalists did believe the statement, while a fairly large majority of all other leadership groups did not believe the statement.

The final belief question dealt with reprocessing and wastes: "[The] More spent fuel that we recycle, [the] less nuclear wastes we have to isolate and store." A 74\% majority of the total public believed this statement, while only a $6 \%$ minority did not, $16 \%$ were not sure, and $3 \%$ did not answer. A quite large majority (70\% to $90 \%$ ) of all leadership groups, except the environmental group, believed the statement. A $46 \%$ plurality of environmentalists believed the statement.

\subsubsection{Attitudes about Reprocessing}

The preceding section discussed the underlying beliefs as to why one might favor or oppose reprocessing. This section discusses attitudes 
TABLE 4.22

PERCENTAGE OF THE PUBLIC AND LEADERSHIP GROUPS

WHO HOLD CERTAIN BELIEFS ABOUT REPROCESSING SPENT FUEL

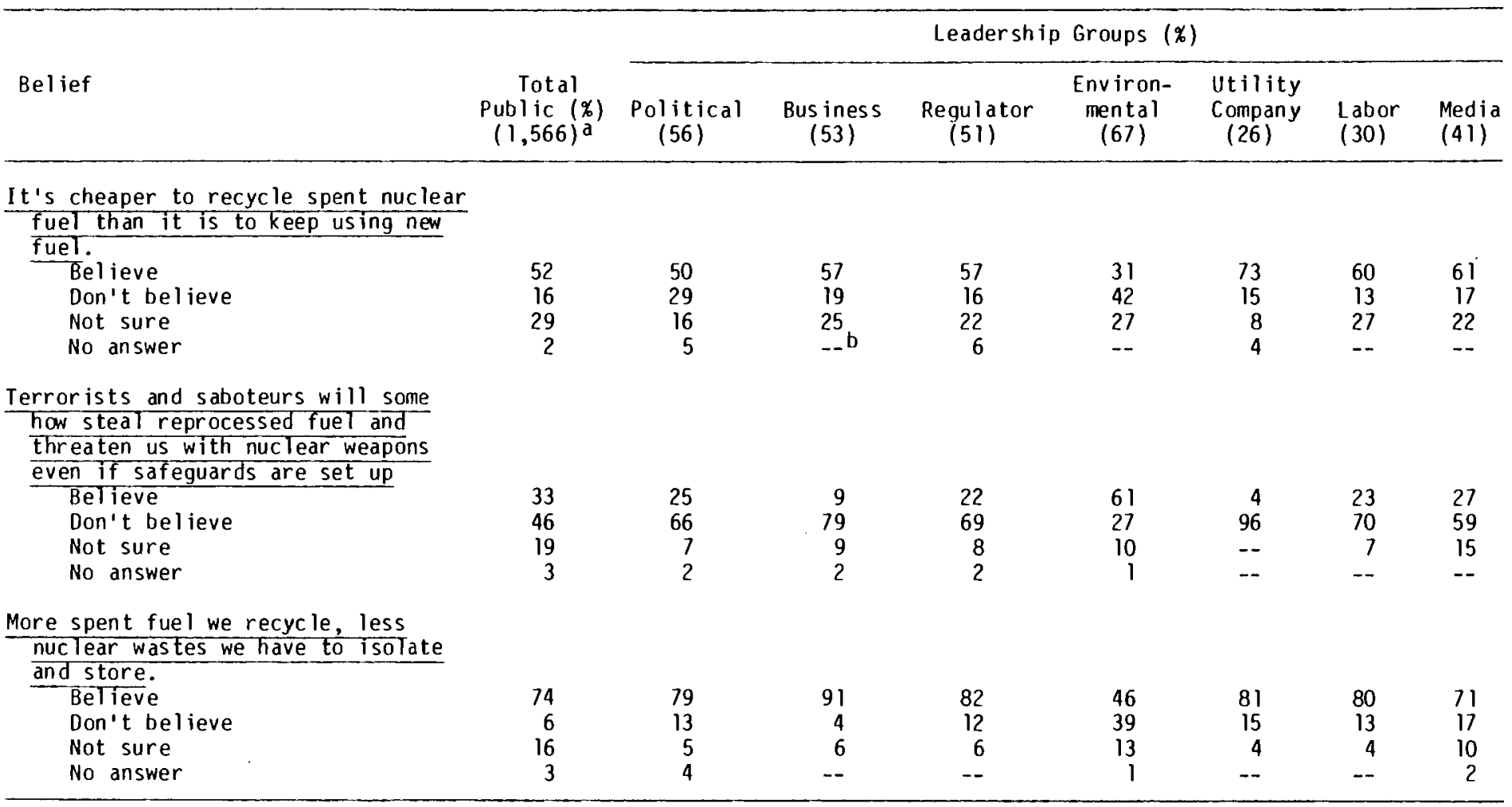

a Number of respondents.

bLess than $0.5 \%$.

NOTE: "Do you believe the following. . ? [Harris (78/10)] 
toward reprocessing--that is, support or opposition regarding whether reprocessing should actually be carried out.

Cambridge (77/5) asked a question of respondents regarding former President Carter's decision not to reprocess commercial spent fuel. The question read, "Can you tell me whether you favor or oppose stopping plans to reprocess and reuse the used uranium fuel from nuclear power plants?" Thirty-six percent opposed stopping the plans to reprocess, $28 \%$ favored stopping the plans, and a plurality of $37 \%$ were undecided. Thus, in 1977 the public was about evenly split as to whether they favored, opposed, or were uncertain about reprocessing.

Harris $(78 / 10)$, however, found clear majority support for reprocessing when respondents were asked, "Do you believe that spent nuclear fuel should be reprocessed or disposed of?" There was $64 \%$ majority support among the general public for reprocessing (see Table 4.23). Only $14 \%$ of the general public thought that the United States should dispose of the fuel rods without reprocessing. Except for the environmental leadership group, all leadership groups were very much in favor of reprocessing. Even $76 \%$ of the media group, a leadership group typically critical of nuclear power, supported reprocessing of spent fuel.

There may be several reasons why the Cambridge and Harris findings were so discrepant. Although actual attitude change may have occurred, the difference was probably mostly due to question wording. First, the Cambridge question may have caused a little confusion as to whether it was asking about favoring or opposing stopping plans to reprocess or favoring or opposing stopping Carter's plan not to reprocess. Second, 
TABLE 4.23

PERCENTAGE OF PUBL IC AND LEADERSHIP GROUPS WHO FAVOR OR OPPOSE REPROCESSING SPENT FUEL

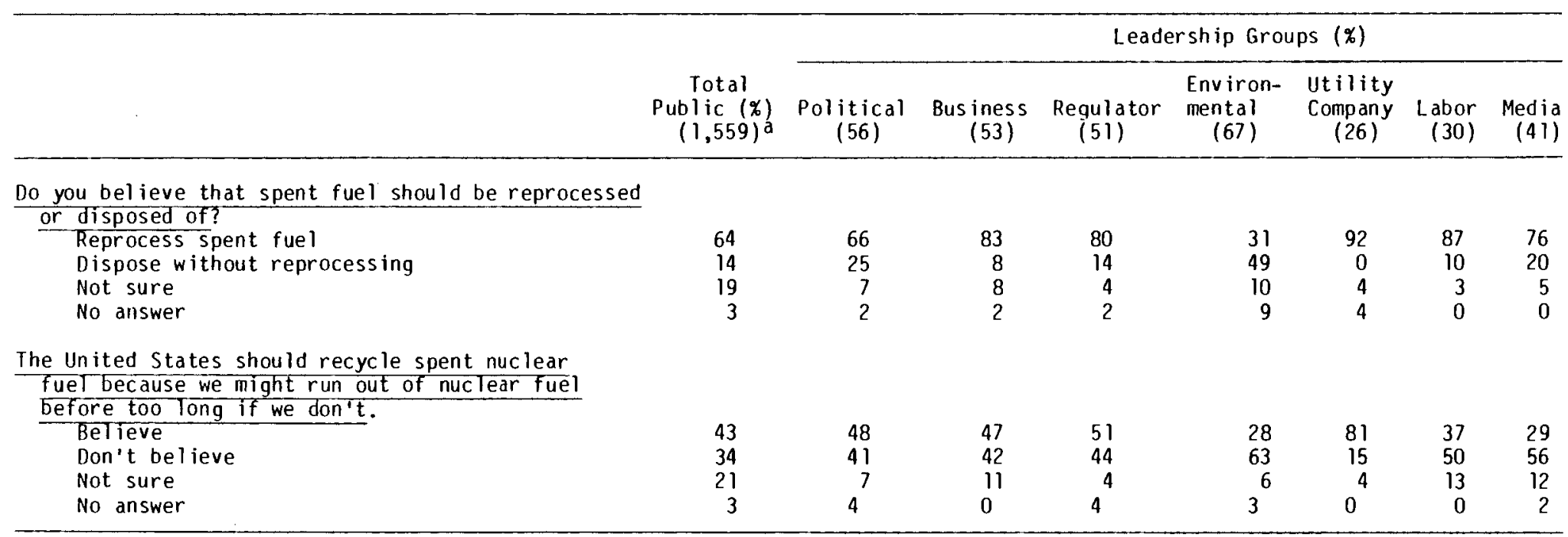

a Number of respondents.

NOTE: [Harris $(78 / 10)]$ 
the knowledge that it was the President's plan could have influenced some of the public to go along with the plan. Third, the Harris question posed the option of not reprocessing as disposal (instead of deferral through storage, for instance). In an age where concern over energy supply has become more salient along with a belief in the need to conserve sources of energy, a respondent may have felt social pressure to choose the reprocessing option in the presence of the interviewer. There is probably a slight majority of public support for reprocessing. It is very clear that most leadership groups favor reprocessing.

Although there was clear majority support for reprocessing by the public and all leadership groups, except environmentalists, this attitude did not seem to be held specifically because of the belief that "we might run out of nuclear fuel before too long if we don't" (see Table 4.23). Only a $43 \%$ plurality of the general public believed that we should reprocess because of an impending fuel shortage, compared to $64 \%$ who held the attitude that we should reprocess spent fuel rather than simply disposing of it. An $81 \%$ majority of utility company leaders favored reprocessing because of a possible fuel shortage. However, a $50 \%$ majority of labor leaders and a $56 \%$ majority of media leaders did not favor reprocessing because of a possible fuel shortage, although a large majority of these leaders favored reprocessing in general. A plurality to slight majority of political leaders, business leaders, and regulatory officials favored reprocessing because of possible fuel shortages. Environmentalists did not favor reprocessing despite possible fuel shortages. 


\subsubsection{Summary}

A slight majority of the general public favors reprocessing spent nuclear fuel, while a much larger majority of American leadership groups, except environmentalists, favors reprocessing. The main reason for support seems to be the belief that reprocessing reduces the amount of waste that needs to be disposed and, second, that reprocessing is economically attractive. Support seems to be based less on the belief that we need to reprocess because we are running out of uranium. Finally, sabotage and terrorism concerns seem small enough so as not to influence attitudes toward reprocessing.

\subsection{The Breeder Reactor}

\subsubsection{Introduction}

Following naturally from the discussion of fuel supply and reprocessing is the breeder reactor--the reactor that could stretch the uranium fuel supply 50 to 100 times. The breeder reactor--the $\mathrm{Cl}$ inch River Breeder Reactor, more specifically--has also become a salient public issue because of the political controversy it has generated. The survey findings regarding public beliefs and attitudes about the breeder reactor follow.

\subsubsection{Beliefs and Attitudes Regarding the Breeder Reactor}

Perhaps the most comprehensive questioning about the breeder reactor was conducted by Cambridge (77/11). After asking the respondents whether they believed that the uranium supply would be enough to fuel all the reactors that will be built in the next 25 years, respondents were asked: "There has been a lot of discussion recently about a new kind of 
nuclear power plant--called a breeder reactor. This is a plant that uses material like uranium to produce energy, but in addition, its waste material--or by-product--is itself a new kind of fuel for more nuclear power plants. In short, this breeder nuclear power plant produces more new fuel than it uses up. Are you familiar with this breeder nuclear power plant, only somewhat familiar, or not really familiar at all?" Oniy $9 \%$ of the public was familiar with the breeder reactor, $26 \%$ was somewhat familiar, 58\% was not really familiar, and $6 \%$ didn't know. High-income respondents, high-education respondents, and male respondents were most likely to be familiar with the breeder reactor concept.

A follow-up question was then asked: "Do you think that the U.S. should develop this new kind of nuclear power plant or not?" On this question, $46 \%$ said yes, $19 \%$ said no, and $35 \%$ were not sure. Demographic groups that were most familiar with the concept were also the most favorable toward development of the breeder reactor.

If a respondent opposed development of the breeder reactor, he or she was then asked: "If it were shown that the U.S. was running out of uranium to power its conventional nuclear plants, would you then favor or oppose building breeder reactors?" Of the 19\% who previously opposed breeder development, $36 \%$ would still oppose, $38 \%$ now did not know what their attitude would be, and $27 \%$ would change their minds to favor breeder development.

Finally, the breeder attitude question was asked in the context of presenting the chief argument against the (plutonium) breeder. The question read: "Now, those who oppose the breeder nuclear power plants do so because of their concern with the waste product such a plant 
produces--plutonium, which can be made into bombs. Others argue that they, too, are concerned about the plutonium problem, but that with proper safeguards this problem can be controlled. They argue that given our nation's serious energy crisis, we must go forward with all possible energy options for the future, even if some have unpleasant problems associated with them. How do you feel about this?" The results were almost exactly the same as for the first breeder development question--47\% felt that we should go forward with the breeder, $20 \%$ felt that we should stop the breeder, and $33 \%$ did not have an attitude. Thus, making the plutonium issue salient had little effect on responses.

This amount of support is higher than that found by a Cambridge $(77 / 5)$ survey conducted only six months earlier. Respondents were asked, "Can you tell me whether you favor or oppose stopping development of the U.S. breeder nuclear reactor demonstration project?" A plurality of $45 \%$ were uncertain, 32\% opposed stopping development (i.e., favored development), and $23 \%$ favored stopping development. As with the reprocessing question asked by Cambridge (77/5), however, the question may have been a little confusing. When it was made clear that breeder reactors produce more fuel than they consume, as Cambridge (77/11) did, there was more support. This was generally confirmed by the Harris $(78 / 10)$ data presented below.

Harris $(78 / 10)$ asked respondents whether they favored or opposed certain energy supply ideas, including, "Build breeder reactors which generate more fuel than they use." This question was asked of the general public and of the seven leadership groups (see Table 4.24). The Harris data, compared to the Cambridge data, found about the same amount 
TABLE 4.24

PERCENTAGE OF THE PUBL IC AND LEADERSHIP GROUPS

WHO FAVOR OR OPPOSE BUILDING BREEDER REACTORS

\begin{tabular}{|c|c|c|c|c|c|c|c|c|}
\hline & \multirow[b]{2}{*}{$\begin{array}{c}\text { Total } \\
\text { Public }(\%) \\
(1,566)^{\mathrm{a}}\end{array}$} & \multicolumn{7}{|c|}{ Leadership Groups (q) } \\
\hline & & $\begin{array}{l}\text { Political } \\
(56)\end{array}$ & $\begin{array}{l}\text { Bus iness } \\
(53)\end{array}$ & $\begin{array}{l}\text { Regulator } \\
(51)\end{array}$ & $\begin{array}{l}\text { Environ- } \\
\text { mental } \\
(67)\end{array}$ & $\begin{array}{l}\text { Utility } \\
\text { Company } \\
(26)\end{array}$ & $\begin{array}{l}\text { Labor } \\
(30)\end{array}$ & $\begin{array}{l}\text { Media } \\
\text { (41) }\end{array}$ \\
\hline Favor & 47 & 46 & 72 & 65 & 10 & 96 & 53 & 17 \\
\hline 0ppose & 28 & 43 & 15 & 27 & 85 & 4 & 37 & 71 \\
\hline Not sure & 22 & 7 & 11 & 6 & 3 & 0 & 10 & 12 \\
\hline No answer & 4 & 4 & 2 & 2 & 1 & 0 & 0 & 0 \\
\hline
\end{tabular}

aNumber of respondents.

NOTE: "Do you favor or oppose: Build breeder reactors which generate more fuel than they use." [Harris $(78 / 10)]$ 
of support, but more opposition and less uncertainty. Regarding general public respondents, $47 \%$ favored the breeder reactor, $28 \%$ opposed, $22 \%$ were not sure, and $4 \%$ did not answer the question. Regarding leadership groups, there was plurality support of the breeder reactor by the political leaders $(46 \%)$, and majority support by business leaders (72\%), regulatory officials (65\%), utility company officials (96\%), and labor leaders (53\%). There was majority opposition to breeder reactor development by environmental leaders (85\%) and by media officials (71\%).

The breeder reactor question was also asked by Harris (78/10) within the context of eight other options to increase the energy supply. For the total public, more support was given to the following concepts compared to the breeder reactor: speed up solar development (89\%), build coal gasification plants $(80 \%)$, speed up off-shore drilling for $0 i 1$ (74\%), recycle spent nuclear fuel to extend its use by $50 \%(70 \%)$, reduce the time required to get government approval for energy facility construction (70\%), and construct more nuclear power plants (57\%). Thus, to recycle spent nuclear fuel for present-day nuclear power plants seems to have more support than the breeder reactor. Two energy measures received much less support than the breeder reactor: importing more oil and 1 iquefied natural gas from overseas received $18 \%$ support ( $73 \%$ opposition), and federal takeover of exploration, production, and distribution of domestic energy received $28 \%$ support (59\% opposition). Harris $(78 / 10 ; 79 / 4)$ also asked respondents whether they believed that, "Through the use of breeder plants, plutonium which is used to produce nuclear power can be reused over and over again doing away with any possible new material shortage." Averaging across both surveys, $41 \%$ 
of the public believed that the statement was true, $18 \%$ did not believe the statement, and $41 \%$ were uncertain. Probably the most important group discussed above is the $41 \%$ of the public that is unsure about the breeder's ability to generate more fuel than it uses. These data, plus the findings regarding perceived knowledge about the breeder, indicate that the breeder reactor concept is not yet understood by many of the general public, at least through 1979.

Leadership groups surveyed by Harris $(78 / 10)$ tended to follow their typical patterns regarding beliefs and attitudes about nuclear energy. The following leadership groups had a majority belief that breeder reactors could prevent future fuel shortages: political (59\%), business $(62 \%)$, regulator $(52 \%)$, utility company (72\%), and labor (57\%). A majority of the environmental leadership group (55\%) and a plurality of the media leadership group (39\%) did not believe that breeder reactors could forestall future fuel shortages.

\subsubsection{The Future Role of the Breeder Reactor}

The general American public did not see much of a role for the breeder reactor in 1990, as shown by survey data collected by YS\&W (78/unk.). Respondents were asked, "By the year 1990, which of these technologies will play a major role in solving our energy problem?" The breeder reactor was quite low on the list: solar energy $(77 \%)$, better home insulation (53\%), more efficient automobiles (45\%), more nuclear plants (43\%), new developments in oil production (33\%), greater use of coal (33\%), electric automobiles (16\%), geothermal energy $(15 \%)$, shale $0 i 1(13 \%)$, alcohol $(12 \%)$, breeder reactors $(11 \%)$, and 
liquefied natural gas (10\%). Thus, the short-term role of the breeder reactor was not seen to be great by the American public.

\subsubsection{Summary}

The public is largely unaware of the breeder reactor concept and its potential for extending the uranium energy supply. When respondents were informed that breeder reactors produce more fuel than they use, about half the public supported the breeder reactor concept. Knowledge about the use of plutonium in breeder reactors did not seem to influence support or opposition to the concept.

\subsection{Proliferation in the Context of Reactor Sales Abroad}

\subsubsection{Introduction}

The final link in the uranium supply/reprocessing/breeder reactor chain is the concept driving the controversy--proliferation. The major nuclear power concern of the former Carter administration--proliferation-coupled with the belief in an adequate uranium supply, led the administration to oppose reprocessing and breeder reactors. But how concerned about proliferation are the public and the leadership groups?

Survey research findings on public concerns regarding proliferation are quite scanty. Presumably, since the United States already has nuclear weapons, nobody has opposed nuclear power in the United States because of proliferation concerns and nobody has volunteered proliferation as a major disadvantage of nuclear power (see Section 4.2). Since the United States' export of nuclear technology does have proliferation implications, survey questions relating to this issue do provide at least indirect evidence of proliferation concerns. 


\subsubsection{Concern over Proliferation}

Roper $(75 / 8 ; 76 / 11)$ asked respondents about their attitudes toward selling nuclear reactors abroad while keeping in mind proliferation considerations (see Table 4.25 for exact question wording). About $45 \%$ of the United States public held the attitude that the United States should not sell reactors abroad because of proliferation concerns, about $33 \%$ of the public approved of reactor sales abroad, and about 13\% of the respondents volunteered the response that the matter depended upon which country was the buyer.

Several interpretations of these findings are possible. One interpretation is that over half of the United States public was concerned enough about proliferation to oppose reactor sales abroad. This percentage was arrived at by combining the "should not sell" and the "depends on to whom sold" response categories. However, since many antinuclear respondents oppose anything nuclear, they would likely oppose any reactor sales abroad for any reason presented to them by the interviewer. Thus, a more conservative estimate of proliferation concern would be found by subtracting out the percentage of respondents opposed to nuclear power in the samples (approximately $30 \%$ both years). This would mean that about $25 \%$ of the American public was concerned about reactor sales abroad specifically for proliferation reasons. Thus, somewhere between approximately $25 \%$ to $60 \%$ of the American public was concerned enough over nuclear weapons to oppose United States reactor sales abroad.

A national survey conducted by Harris in 1977 (reported in Nuclear News) asked about export of nuclear technology to non-nuclear countries 
TABLE 4.25

PERCENTAGE OF THE PUBLIC WHO FAVOR OR OPPOSE

THE SALE OF UNITED STATES REACTORS ABROAD

\begin{tabular}{lcc}
\hline \multicolumn{1}{c}{ Response } & \multicolumn{2}{c}{ Roper (\%) } \\
\cline { 1 - 3 } & $(75 / 8)$ & $(76 / 11)$ \\
\hline U.S. should sell nuclear power plants & 35 & 31 \\
U.S. should not sell nuclear power plants & 45 & 42 \\
It depends on to whom sold (volunteered) & 10 & 15 \\
Don't know & 10 & 12 \\
\hline
\end{tabular}

NOTE: "The United States has been selling nuclear power plants for peaceful purposes to other countries. Some people say this is a mistake because it could give other nations a nuclear capability for warfare. Others say these nations can and will buy nuclear power plants from someone else if we don't sell them, and if we sell them we have more control over what they get and how they are used. How do you feel--that as a general policy the United States should or should not sell nuclear power plants to other countries?" [Roper $(75 / 8 ; 76 / 11)]$ 
and then asked about exports to specific countries. The general question was phrased as follows: "An increasing number of countries who do not have enough energy are turning to nuclear power as a major source of energy. However, only a few countries in the world have the technical know-how to build nuclear power plants. The new Carter Administration is worried that if too many countries have nuclear power plants they can convert that nuclear know-how to build nuclear weapons. Do you approve or disapprove the building of nuclear power plants in countries that don't have them now?" Of 1,466 United States adults, 65\% disapproved, $17 \%$ approved, and $18 \%$ had no opinion. These findings show more concern over proliferation than did the Roper findings. However, the question seems biased toward a disapprove response, since the question made it clear than an approve response contradicted the former President's desires.

More support is seen for sales abroad if the question implies that another country could supply the technology. For instance, if a non-nuclear country was going to buy a reactor, $53 \%$ of the respondents would rather have the country buy from the United States than from Russia. Otherwise, there was majority opposition to sales of United States reactors to eight specifically-named countries: Australia 58\% (opposition) to $24 \%$ (support); Japan, $68 \%$ to $15 \%$; Brazi1, $71 \%$ to $11 \%$; Argentina $72 \%$ to 10\%; Taiwan, $73 \%$ to $9 \%$; Pakistan, $73 \%$ to $8 \%$; Egypt, $74 \%$ to $8 \%$; and Iran, $74 \%$ to $7 \%$. In fact, $80 \%$ of the respondents agreed that widespread nuclear technology would eventually lead to nuclear war, while $11 \%$ disagreed, and $9 \%$ had no opinion. These findings suggest more widespread concern over proliferation than do the Roper findings, but, as 
noted above, the question wording was probably biased in the direction of expressing opposition to sales.

Of final importance is a Harris (78/10) survey. The general public was polled on nuclear attitudes along with seven leadership groups. A progression of questions was asked that ranged from asking respondents about simply selling United States reactors abroad to selling United States reactors only to countries that agreed to stringent safeguards provisions (see Table 4.26).

In agreement with the earlier Roper findings, only $32 \%$ of the total public favored the sale of reactors abroad (with no restrictions), while $54 \%$ opposed such a sale. When it was posited that the United States could help energy-short countries by selling them nuclear reactors, essentially the same percentage of respondents favored and opposed the sale. On both questions the business, regulator, utility company, and labor leadership groups supported reactor sales abroad, while environmental and media groups opposed. Only the political group answered the two questions differently. They strongly supported reactor sales abroad, but were somewhat evenly split as to whether we could help other nations solve their energy shortages by selling them reactors. Presumably, some politicians felt that we should help energy-short nations solve their energy problem in some other manner.

As was earlier the case, more support was seen for a United States reactor sale abroad when another vendor nation was involved. Respondents were asked whether it was better for the United States and its allies to make the sale rather than the Russians. There was strong majority agreement, except for the environmental group where there was plurality 
TABLE 4.26

PERCENTAGE OF THE PUBLIC AND LEADERSHIP GROUPS WHO HOLD CERTAIN

BELIEFS AND ATTITUDES TOWARD EXPORT OF UNITED STATES NUCLEAR TECHNOLOGY

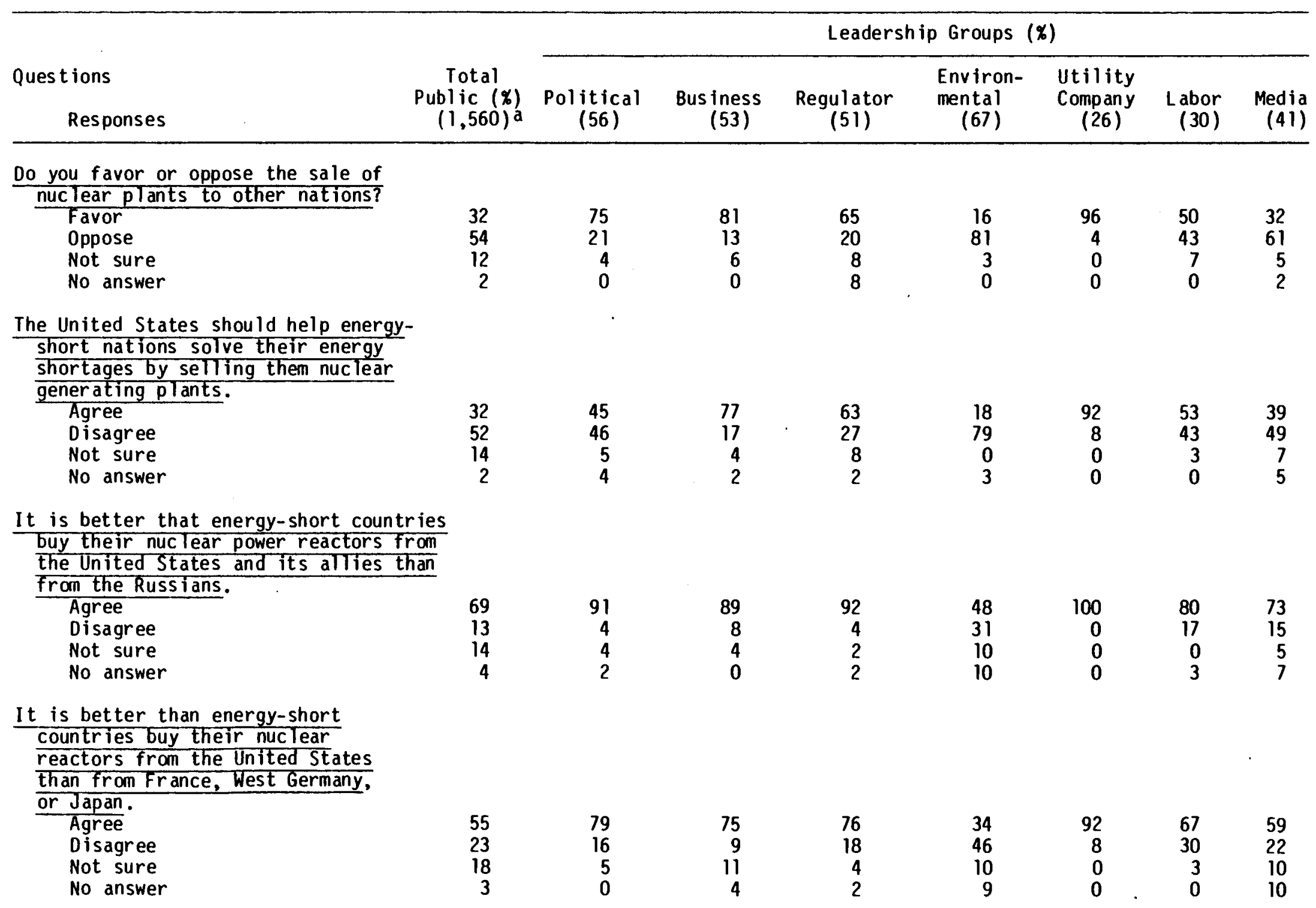


Table 4.26--continued

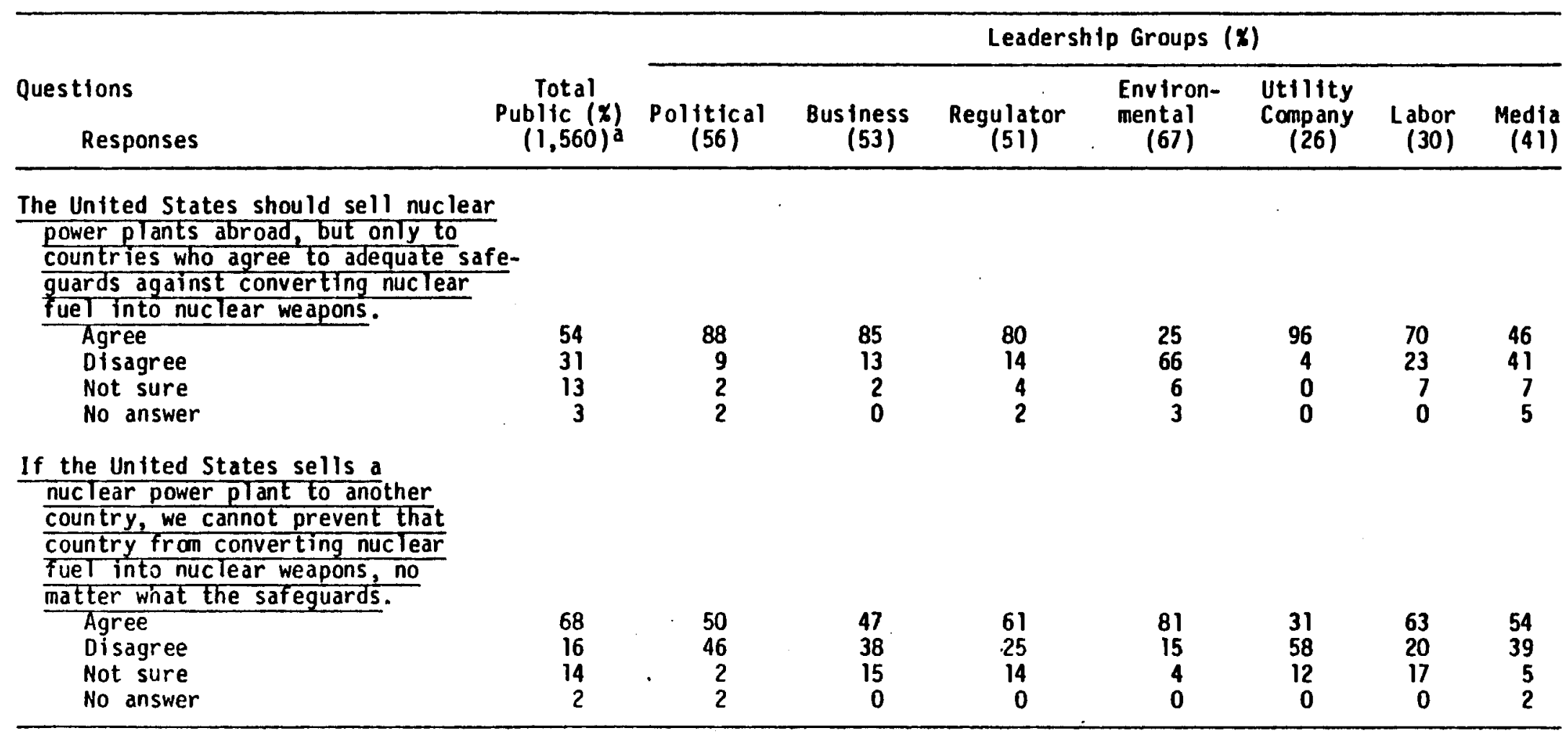

a Number of respondents.

Note: [Harris $(78 / 10)]$ 
agreement, that it was better for the United States and its allies to make the sale. When the same implication was made regarding a sale, but when the situation pitted the United States against Japan, West Germany, or France, a majority nod was given to the United States by all groups except the environmental group. A plurality of the environmentalists would rather that the United States not make the sale.

Provisions for stringent safeguards also seemed to increase acceptance of reactor sales abroad. If stringent safeguards were agreed to by a purchasing nation, a $54 \%$ majority of the general public would agree to a reactor sale. Five of the leadership groups gave strong majority support to this proposal, while the media group gave plurality support and the environmental group gave majority opposition.

Most publics did not believe that safeguards would be fully effective, however. Respondents were asked whether they believed that a purchasing nation would fabricate a nuclear weapon regardless of the safeguard provisions. Here, $68 \%$ of the general public felt that the safeguard provisions would not necessarily stop weapons production. A plurality to majority of all the leadership groups, except the utility company group, also felt that the safeguard provisions would not necessarily stop weapons construction. A majority of the utility company leaders believed that the safeguard provisions would prevent proliferation. Thus, there seemed to be acceptance of reactor sales abroad, if stringent safeguards were required, even when the safeguards might not be fully effective.

If the percentage of the general public who generally favored the sale of reactors abroad (32\%) is compared to the percentage who favor 
reactor sales to nations who agree to safeguards (54\%), there is a $22 \%$ difference. It is important to keep in mind, however, that $31 \%$ of the general public opposed reactor sales abroad, even with adequate safeguards. Thus, somewhat in agreement with the earlier Roper findings, it appears that about one-third of the United States public outright favors United States reactor sales abroad; about one-third of the general public outright opposed reactor sales abroad, possibly for proliferation reasons but more likely because of a general opposition to nuclear power; about one-fifth of the public was specifically concerned about the reactor sale/proliferation link to the extent that they did not favor United States reactor sales abroad without adequate safeguards provisions; and the remainder of the public had no opinion.

\subsection{The Process of Constructing a Nuclear Power Plant}

\subsubsection{Introduction}

The length of time that it takes from planning to build a nuclear power plant until it is constructed now ranges from 10 to 12 years. Because "time is money," this lengthy period has become a concern to the nuclear industry. However, as the survey will show, the public generally believes that the process should continue at about the same speed, partly because the public believes that nuclear power plants are constructed much more quickly than is the case.

\subsubsection{Beliefs and Attitudes about Constructing a Nuclear Power Plant}

Two survey organizations have asked questions regarding who should make the decision about whether or where a nuclear power plant should be 
built. ARB $(79 / 7 ; 80 / 6)$ asked respondents how much say they thought that the government should have over "the kind of power plants your electric company can build--oil, gas, coal, nuclear, or whatever" and "Deciding where to build a power plant." Respondents selected from the following responses--a lot of say, some say, and no say. In 1978, 1979, and 1980, respectively, $71 \%, 78 \%$, and $78 \%$ of the public believed that the government should have a lot or some say in the type of power plant that the electric companies can build, and $63 \%, 72 \%$, and $74 \%$ believed that the government should have a lot or some say in where the plant is to be built.

NSF $(79 / 10)$ asked respondents to suppose that a power plant was going to be built somewhere, but that its construction was opposed by a local citizens group. Assuming a conflict like this, respondents were asked which of eight groups was best qualified, second best qualified, and least qualified to decide the issue (see Table 4.27). The best qualified group was the specialized group of scientists and engineers, which $40 \%$ of the public believed was the best qualified group, $19 \%$ believed that it was the second best qualified group, and only $2 \%$ believed that it was the least qualified group. The group with the next highest mention was the citizens of the community voting in a referendum, which was selected by $32 \%$ of the public as best qualified, by $12 \%$ of the public as second best qualified, and by $16 \%$ of the public as least qualified. A Federal regulatory agency or commission was next, largely because $24 \%$ of the public selected it as second best qualified. The utility company received $20 \%$ best or second best mention and $29 \%$ least qualified mention. Local government officials, the governor and the 
TABLE 4.27

PERCENTAGE OF PUBLIC WHO SELECTED A CERTAIN GROUP AS BEST QUALIFIED OR LEAST QUALIFIED TO SETTLE NUCLEAR POWER PLANT SITING DECISIONS

\begin{tabular}{|c|c|c|c|}
\hline Group & $\begin{array}{l}\text { Best } \\
\text { Qualified } \\
\text { Group }\end{array}$ & $\begin{array}{l}\text { Second } \\
\text { Best } \\
\text { Qualified } \\
\text { Group }\end{array}$ & $\begin{array}{c}\text { Least } \\
\text { Qualifiec } \\
\text { Group }\end{array}$ \\
\hline $\begin{array}{l}\text { A specialized group of scientists and } \\
\text { engineers who specialize in this area }\end{array}$ & 40 & 19 & 2 \\
\hline $\begin{array}{l}\text { The citizens of the community voting in } \\
\text { a referendum }\end{array}$ & 32 & 12 & 16 \\
\hline A Federal regulatory agency or commission & 8 & 24 & 3 \\
\hline $\begin{array}{l}\text { The utility company that will operate the } \\
\text { plant }\end{array}$ & 5 & 15 & 29 \\
\hline Local government officials & 4 & 11 & 10 \\
\hline The governor and the state legislature & 3 & 6 & 4 \\
\hline The courts & 2 & 5 & 20 \\
\hline The President and Congress & 2 & 3 & 12 \\
\hline Don't know/no answer & 3 & 5 & 4 \\
\hline
\end{tabular}

NOTE: "Let's suppose that an electric utility company wants to build a nuclear power plant in a particular town or county, but a group of local citizens who live there are afraid that it might be dangerous and organize to stop its construction. In a case of a conflict like this, which one of the groups listed on this card would be best qualified to decide the issue? Which group would be second best qualified to decide it? And which group on the list do you think would be lease qualified to decide it?" [NSF (79/10)] 
state legislature, the courts, and the President and Congress were not believed to be highly qualified to make a decision on the siting issue. Twenty percent of the public believed that the courts were least qualified to make the siting decision.

Harris $(78 / 10)$ asked respondents whether they believed that the "public is better off as a result of protest groups delaying construction of nuclear power plants" (see Table 4.28). A $52 \%$ majority of the public believed that to be the case, while $34 \%$ of the public believed that we are worse off because of protest group delay, and $14 \%$ were not sure. A large majority (94\%) of the environmental leaders felt that the public was better off because of the actions of protest groups. A large $83 \%$ majority of the media leaders were also of this opinion, and so was a smaller 52\% majority of political leaders. A majority of the other leadership groups believed that the public was worse off because of protest groups--business (71\%), regulator (62\%), utility company (97\%), and labor $(56 \%)$.

Cambridge (78/5) asked a series of questions on the regulatory process in order to probe more deeply into the issue. First, respondents were asked, "Do you think most current decisions about whether or not to build a nuclear power plant are done carefully and thoughtfully, using the right amount of time, done too quickly and without enough thought, or done too slowly with too many delays?" A $34 \%$ plurality believed that the decisions were made carefully and thoughtfully, $24 \%$ believed that they were made too quickly, 19\% believed that they were done too slowly, and $23 \%$ did not know. 
TABLE 4.28

PERCENTAGE OF THE PUBL IC AND LEADERSHIP gROUPS WHO BELIEVE THAT THE

UNITED STATES IS OR IS NOT BETTER OFF AS A RESULT OF PROTEST

GROUPS DELAYING NUCLEAR POWER PLANT CONSTRUCTION

\begin{tabular}{|c|c|c|c|c|c|c|c|c|}
\hline & $\begin{array}{c}\text { Total } \\
\text { Public }(x) \\
\quad(1,555)^{\mathrm{a}}\end{array}$ & \multicolumn{7}{|c|}{ Leadership Groups $(x)$} \\
\hline $\begin{array}{l}\text { Much better off } \\
\text { Somewhat better off } \\
\text { Somewhat worse off } \\
\text { Much worse off } \\
\text { Not sure }\end{array}$ & $\begin{array}{l}17 \\
35 \\
22 \\
12 \\
14\end{array}$ & $\begin{array}{r}18 \\
34 \\
29 \\
14 \\
6\end{array}$ & $\begin{array}{r}4 \\
21 \\
42 \\
29 \\
4\end{array}$ & $\begin{array}{r}12 \\
18 \\
30 \\
32 \\
8\end{array}$ & $\begin{array}{r}51 \\
43 \\
3 \\
3 \\
0\end{array}$ & $\begin{array}{r}0 \\
4 \\
35 \\
62 \\
0\end{array}$ & $\begin{array}{r}17 \\
20 \\
33 \\
23 \\
7\end{array}$ & $\begin{array}{r}35 \\
48 \\
15 \\
3 \\
0\end{array}$ \\
\hline
\end{tabular}

aNumber of respondents.

NOTE: "Do you believe the public is better off as a result of protest groups delaying construction of nuclear power plants?" [Harris $(78 / 10)]$ 
However, responses to the question that followed made it obvious that the public underestimated how long it takes for a power plant to become fully operational. Twenty percent of the respondents believed that it only takes 5 years or less, $22 \%$ believed 6 to 8 years, 18\% believed 9 to 10 years, $7 \%$ believed 11 to 13 years, 5\% believed that it took 14 years or more, and $29 \%$ did not know. When respondents were informed of the actual length of time needed, a plurality favored speeding up the licensing process. Respondents were asked, "If you knew that the real average time from beginning to actual operation of a nuclear power plant is about 12 years would you then favor or oppose speeding up the regulatory process for licensing and approving a nuclear plant?" Given this information, a $44 \%$ plurality (made up largely of pronuclear respondents) favored speeding up the process, $34 \%$ opposed (made up largely of antinuclear respondents), and 22\% did not know.

Then respondents were told specifically about former President Carter's plan to speed the process: "One part of the National Energy Plan of President Carter proposes that we shorten the process of hearings and regulations that it takes before a nuclear power plant can be built. Would you favor or oppose shortening the process?" Responses were almost exactly the same as above--42\% favored, 38\% opposed, and 19\% did not know. When informed about the economic costs of delay, a plurality also favored shortening the process. The question read: "Each year's delay in building a nuclear power plant adds millions of dollars to the cost of the electricity it will eventually produce. If you knew that you would pay an extra $\$ 1.00$ per month on your electric bill for each year a nuclear power plant was delayed, would you be more favorable or less 
favorable to shortening the process?" A $40 \%$ plurality said that they would become more favorable, $36 \%$ said that it would make no difference, $15 \%$ said that they would become less favorable, and $9 \%$ did not know. A $60 \%$ majority of pronuclear respondents said that they would be more favorable, while a $48 \%$ plurality of ant inuclear respondents said that it would make no difference.

Since shortening the regulatory process impacts the amount of public participation, this trade-off was made clear in the final Cambridge (78/5) question. It read: "Almost everyone agrees that the public should participate in the decisions on whether nuclear power plants should be built, but these hearings frequently add several years to the length of time it takes to decide. Do you feel we should have full public participation even if it may allow a few people to delay a plan for the sake of delay or do you feel that the government should place reasonable limits to the length of time for public hearings?" The public was pretty evenly split regarding this attitude question-- $43 \%$ felt that the government should place reasonable limits $(59 \%$ of the pronuclear and $39 \%$ of the antinuclear respondents chose this answer), $40 \%$ felt that there should be full public participation (32\% of the pronuclear and $54 \%$ of the antinuclear respondents chose this answer), and $17 \%$ did not know (including a $9 \%$ plurality of those who were uncertain about the ir general nuc lear power attitude).

\subsubsection{Summary}

A majority of the public believes that the government should have some say in what kind of power plants utility companies build and in where the plants are built. In the case of a siting conflict, the public 
believes that a specialized group of scientists and engineers is best qualified to settle the conflict, followed by the citizens of the community voting in a referendum and by a federal regulatory agency or commission.

A majority of the public believed that the United States is better off because of protest groups delaying nuclear power plant construction and a plurality believed that the decisions to build a nuclear plant are done at about the right speed. However, a $60 \%$ majority of the public underestimated how long it takes and how much it costs the consumer, and, when provided this information, a plurality of the public favored speeding up the process. The public was eventy divided as to whether the government should place limits on public participation (in order to speed up the process) or whether full public participation should be allowed.

\subsection{Summary}

Three types of survey data were analyzed and reported in this chapter. First, volunteered responses to open-ended questions about nuclear power were discussed. Second, sets of questions that allow direct comparisons of the importance of nuclear power benefits and/or risks were discussed. Finally, responses to structured questions about aspects of the fuel cycle--e.g., reactor safety and waste management--and other nuclear issues--e.g., the TMI accident and regulatory issues--were presented.

Three types of information were collected using open-ended questions: volunteered reasons for favoring or opposing nuclear power plant construction; volunteered likely benefits and likely harmful 
consequences of further nuclear power plant construction; and volunteered advantages and disadvantages of nuclear power. Respondents who favored nuclear power generally did so because they believed that the energy is needed. Respondents who opposed nuclear power generally did so for safety-related reasons, pertaining more to reactor safety than to waste management. When asked to volunteer the likely benefits that would come from building more nuclear power plants, a majority of the respondents said that needed energy would be produced followed by the benefit that nuclear power would be cheaper than other energy forms. The most of ten mentioned likely harmful consequences were the possibility of a reactor accident and the leakage of low-level radiation to surrounding areas. When asked to volunteer advantages of nuclear power, a plurality of the respondents said that nuclear power was not dependent upon other countries, followed closely by the beliefs that it is cheaper and available. However, more disadvantages were volunteered than were advantages. Over half of the respondents volunteered the disadvantages of possible accidents and of radiation hazards from normal operating conditions. In addition, disadvantages regarding waste disposal and water pollution were volunteered quite of ten.

Data on direct comparisons of benefits and/or risks related to nuclear power were also analyzed. The public believes that the major benefits of nuclear power have to do with the large amount of uranium within the United States. This produces the added benefits of less dependence on foreign energy and an unlimited amount of energy for a long time. In a direct comparison of risks of nuclear power, the public is 
most concerned about waste management followed by reactor safety issues. Pollution and sabotage/terrorism are the least important issues.

A regression analysis was run on certain risks and benefit beliefs about nuclear power to determine which of the beliefs most strongly influence one's attitude toward building a nuclear plant nearby. The beliefs that had the most influence on attitude were the belief about nuclear power plant safety and the belief that nuclear power plants are necessary to free America from relying on Arab oil. These beliefs are about twice as important in determining attitude as the three next most important ones--whether the government does a good job of checking power plant safety, whether the government sees to it that plants are built safely, and whether nuclear-produced electricity is cheaper than other electricity.

From 1975 through 1980, the percentage of the public who believed that nuclear power plants are safe decreased slightly. At the same time, much of the undecided public decided that nuclear power plants were unsafe. Thus, the percentage who believed that nuclear power was unsafe increased during this time period. Much of this change was evident before the TMI accident. A plurality to majority of the public believes that a nuclear power plant can explode like an atomic bomb. A plurality of the public believes that the safety of nuclear power plants can best be insured by the federal and state governments, and a large majority of the public believes that the government should have some say about rout ine safety precautions at nuclear power plants.

Numerous survey questions were asked about the TMI accident. Almost the total American population was aware of the accident. A majority of 
the public was disturbed by the accident, and a minority of the public was worried about their safety or their family's safety during the accident. A plurality of the public was satisfied with the way the accident was handled, especially by Nuclear Regulatory Commission officials and Pennsylvania government officials. The cause of the accident was believed to be mainly human error, and a majority of the public believed that other accidents are likely. While the public believed that government officials minimized the danger, media coverage was believed to be fair. A majority of the public said that they would evacuate immediately if such an accident took place near them.

Despite the concern raised by the accident, a majority of the public believed that operating plants should not be shut down, because of economic considerations and because of the belief that greater risks would be incurred from subsequent energy shortages. A majority of the public still believed that nuclear power is important for meeting future energy needs. The United States public looks to the Federal government to ensure the safety of nuclear power plants.

There appears to be increased public concern since 1976 regarding nuclear waste management problems. Since 1976 over twice as many people have said that they oppose nuclear power because of waste management problems than was the case in the early 1970s. And, when respondents who had changed their attitude from support to opposition of nuclear power were asked why, the response volunteered most often referred to increased concern over nuclear waste management. There was increased concern regarding waste management after TMI, indicating that probably any serious nuclear power problem will increase the salience of nuclear waste 
management. Finally, when nuclear power problems were directly compared, nuclear waste management was still seen as a bigger problem than reactor safety, even after TMI.

However, the general public believed that toxic industrial wastes were a more severe disposal problem than radioactive wastes. Further, the general public believed that the problems associated with disposing of radioactive wastes and of industrial wastes such as slag mine tailings were of equal severity. However, despite their perceptions of the severity of these disposal problems, the general public was less willing to live near a nuclear waste repository compared to other industrial facilities because radioactive wastes were perceived as being quantitatively different.

As was the case before 1977, the general public was somewhat evenly divided in their belief as to whether an acceptable waste management plan is already available. A small minority of the public believed that an acceptable solution would never be found. Public opposition at the state level to a full-scale waste repository was greater than public acceptance, although there was slight majority support for a small-scale, demonstration disposal facility. Given the public concern over nuclear wastes, and despite the lack of public acceptance of a full-scale waste repository in one's own state, the general public believed that the 1988 deadline for the first waste repository did not indicate high enough priority on the part of the Federal government to solve the waste problem. When asked to choose among different waste disposal techniques that were certified as safe, the general public showed greatest acceptance of above ground storage at remote locations. Acceptance of storage in 
granite and salt closely followed, however. Choice of above surface storage may have reflected disbelief that other disposal methods were available at the time. United States leadership groups showed most favorability to disposal in granite and salt. The general public and all leadership groups showed least favorability to seabed disposal. All groups indicated a willingness toward greater acceptance of one of the disposal methods if on-site water basin storage was the alternative or if the waste disposal facility was not located in one's state. Politicians, especially, were willing to endorse a waste disposal method if the facility was not located in their state.

A slight majority of the general public favors reprocessing spent nuclear fuel, while a much larger majority of American leadership groups, except environmentalists, favors reprocessing. The main reason for support seems to be the belief that reprocessing reduces the amount of waste that needs to be disposed. A second reason for support is the belief that reprocessing is economically attractive. Support seems to be based very little on the belief that we need to reprocess because we are running out of uranium. Finally, sabotage and terrorism concerns seem small enough so as not to influence attitudes toward reprocessing. The public was largely unaware of the breeder reactor concept and its potential for extending the uranium energy supply. When respondents were informed that breeder reactors produce more fuel than they use, about half the public supported the breeder reactor concept. Knowledge about the use of plutonium in breeder reactors did not seem to influence support or opposition to the concept. 
About one-third of the United States public outright favored United States reactor sales abroad; and about one-third of the general public outright opposed reactor sales abroad, possibly for proliferation reasons but more likely because of a general opposition to nuclear power. About one-fifth of the public was specifically concerned about the reactor sale/proliferation link to the extent that they did not favor United States reactor sales abroad without adequate safeguards provisions. The remainder of the public had no opinion.

A majority of the public believed that the United States is better off because of protest groups delaying nuclear power plant construction, and a plurality believed that decision to build a nuclear plant are done at about the right speed. However, a majority of the public underestimated how long it takes and how much it costs the consumer. After being told how long the construction and licensing process really takes, a plurality of the public favored speeding up the process. However, the public was evenly divided as to whether the government should place limits on public participation (in order to speed up the process) or whether full public participation should be allowed. 
CHAPTER 5

NUCLEAR POWER ATTITUDES IN THE CONTEXT OF PUBLIC PERSPECTIVES ON GENERAL ENERGY ISSUES AND ENVIRONMENTAL ISSUES

\subsection{Introduction}

The purpose of analyzing public attitudes and beliefs concerning general energy and environmental issues is to place the discussion of nuclear energy attitudes in the context of the larger energy picture as it may be perceived by the public. The examination of public attitudes toward general energy issues can provide insight into understanding public attitudes toward nuclear energy in a number of ways. First, the comparison of public attitudes toward nuclear energy with attitudes toward alternative energy options provides a useful relative perspective. It is difficult to interpret the meaning of support and opposition levels toward nuclear power without knowing these levels for other energy options. In public policy matters, concern for the relative attractiveness of policy options may be as important as concern for the absolute desirability of any particular policy. For example, if all options for energy development are supported (or opposed) by a majority of the public, that has a different significance than if there is considerable variation in public acceptance across specific energy production sources. Second, the identification of underlying bases for nuclear power attitudes can be approached by examining the relationship of these attitudes to attitudes toward other policy issues among various sectors of the public. 
We hypothesize that the evaluation of nuclear energy is related to preferences and beliefs concerning specific energy sources, an emphasis on energy production in contrast to energy conservation as the better of two strategies to solve the energy problem, and orientations towards the broader issues of environmental quality and economic growth. We expect that attitudes toward nuclear power are influenced by both beliefs about objective relationships (e.g., the extent of environmental risk associated with specific energy options) and value positions (e.g., whether or not it is desirable to limit energy consumption). This chapter examines general trends in public attitudes toward energy and environmental policy issues and the extent to which attitudes toward these issues have been found to be related to pro and antinuclear attitudes.

\subsection{Attitudes Toward Alternative Energy Technologies}

\subsubsection{Introduction}

In this section we examine trends in attitudes of the general public concerning a broad range of energy strategies. We then look at beliefs about the specific characteristics of these alternative energy options.

\subsubsection{Comparison of General Attitudes Toward Energy Alternatives}

One comparative approach for identifying public attitudes toward energy technologies has been to assess favorability toward a series of possible approaches to increase energy availability. Figure 5.1 and Table 5.1 present trends over time in national survey findings of public support for several alternatives, including nuclear power, offshore oil drilling, coal, and solar energy. Solar energy has received the highest levels of public acceptance $(82 \%-89 \%)$ whenever it has been included in 

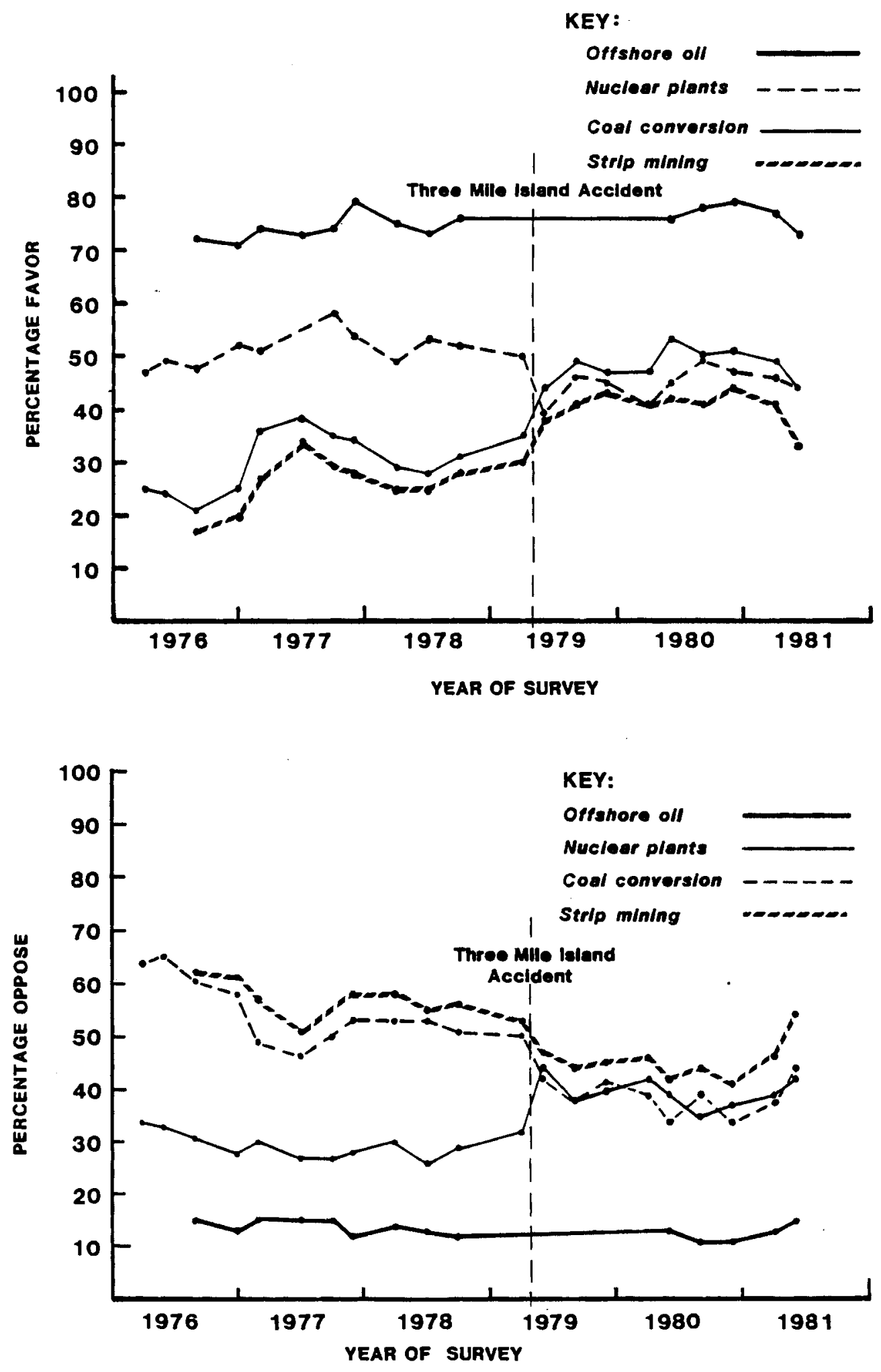

FIGURE 5.1 Public Attitudes Toward Alternative Energy Production Approaches

NOTE: "Do you favor or oppose each of the following measures? Expand offshore drilling for oil. Increase strip mining for coal even if it damages the environment. Conversion of electric utilities to coal even if it means dirtier air. Construction of more nuclear power plants." [Cambridge $(76 / 11 ; 77 / 11 ; 78 / 9 ; 79 / 3 ; 79 / 6)]$ 
TABLE 5.1

PERCENTAGE OF PUBLIC WHO FAVOR CERTAIN

MEASURES TO INCREASE ENERGY PRODUCTION

\begin{tabular}{lccccccc}
\hline & \multicolumn{7}{c}{ Year } \\
\cline { 2 - 7 } Production Source & $1973^{\mathrm{a}}$ & $1974^{\mathrm{a}}$ & $1975^{\mathrm{a}}$ & $1976^{\mathrm{a}}$ & $1978^{\mathrm{a}}$ & $1979^{\mathrm{b}}$ & $1981^{\mathrm{C}}$ \\
\hline Solar energy & -- & -- & -- & 82 & 89 & 88 & $\ldots$ \\
Off shore 0il drilling & -- & 67 & 66 & 64 & 74 & -- & 69 \\
Nuclear energy & 64 & 71 & 67 & 62 & 57 & 44 & -- \\
Strip mining coal & 42 & 48 & 49 & 49 & -- & -- & 48 \\
\hline
\end{tabular}

a"Do you favor or oppose each of these ideas? Speed up development of solar energy; speed up building of new nuclear power plants; speed up drilling for oil/natural gas off Atlantic, Pacific and Gulf coasts; allow more strip mining of coal?" [Harris $(73 / 9 ; 74 / 7 ; 74 / 11 ; 75 / 4 ; 76 / 7 ; 78 / 10)$ ]

b"I am going to name some of the different types of energy sources that might be used in the future. Please tell me if you approve or disapprove of each as an alternative? Solar energy? Nuclear energy?" [Gallup $(79 / 6)]$

C"A number of proposals are being considered by the federal government. For each tell me whether you would favor or oppose this. First, would you favor or oppose: easing restrictions on strip mining to provide more coal; enlarging the area of off-shore oil drilling on the East and West Coasts? [Newsweek $(81 / 6)$ ] 
the list of alternatives [Harris $(76 / 7 ; 78 / 10)$ and Gallup $(79 / 6)]$. There also has been majority public support for expanding offshore oil drilling over the past decade. Cambridge reports support levels of approximately 75\% from 1976 through 1981, and Harris reports levels of favorability between $64 \%$ to $74 \%$ from 1973 through 1978 .

Until the TMI accident, nuclear energy followed these two sources in level of public support for energy production measures, maintaining $51 \%$ to $57 \%$ favorability in 1978 [Cambridge (78/11) and Harris (78/10)] and $50 \%$ favorability in 1979 [Cambridge (79/3)]. The decrease in support for nuclear energy following TMI has been discussed in detail in Chapter 3 . The interest here is on the extent to which the accident appears to have had an effect on the public's evaluation of alternative energy sources.

There is no evidence of a significant effect of the accident on public favorability toward use of oil or natural gas. Support levels for taxing imported $0 i 1$ and deregulating natural gas prices have remained quite stable from 1977 through 1979, averaging $36 \%$ to $40 \%$ and $29 \%$ to $32 \%$, respectively. Support for taxing imported oil was 37\% in March, 1979, and $40 \%$ in June, 1979; and support for natural gas price deregulation was $30 \%$ in March, 1979, and 32\% in June, 1979 [Cambridge $(77 / 3 ; 77 / 6 ; 77 / 9$; $77 / 11 ; 78 / 3 ; 78 / 6 ; 78 / 9 ; 78 / 11 ; 79 / 3 ; 79 / 6)]$. In addition, in a direct trade-off question posed by Harr is $(79 / 5)$, the majority of the public (53\%) preferred building more nuclear power plants to the continued use of oil-fired electric plants (34\%) if the latter meant greater dependence on foreign oil. Public support for solar energy and offshore oil drilling also showed no change during the time of TMI. For example, solar energy received $89 \%$ favorability in 1978 and $88 \%$ support in 1979 
[Harris (78/10) and Gallup (79/6)], and offshore oil drilling averaged $76 \%$ support in 1978 compared to $78 \%$ support in 1980 [Cambridge (78/3; $78 / 6 ; 78 / 9 ; 80 / 5 ; 80 / 8 ; 80 / 11)]$.

Acceptability of coal, on the other hand, appears to have increased following the TMI accident. Coal had been one of the least preferred sources of energy throughout the 1970s. While the levels of support for the use of coal have differed across survey organizations, Cambridge and Harris consistently have found that coal received the lowest levels of public support and highest levels of opposition relative to other sources of energy (Figure 5.1 and Table 5.1). Favorability toward conversion of power plants to coal averaged $24 \%$ in $1976,36 \%$ in $1977,30 \%$ in 1978 , and $35 \%$ in 1979 prior to the accident; opposition levels averaged $62 \%$ in $1976,51 \%$ in $1977,53 \%$ in 1978 , and $50 \%$ in early 1979 [Cambridge (76/3; $76 / 5 ; 76 / 8 ; 76 / 12 ; 77 / 2 ; 77 / 6 ; 77 / 9 ; 77 / 11 ; 78 / 3 ; 78 / 6 ; 78 / 9 ; 79 / 3)]$. Thus, there was a decrease in public opposition in 1977 that leveled off and remained stable at about 50\% through early 1979. After TMI there was a further decrease in public opposition (from 50\% in March, 1979, to $42 \%$ in May, 1979) and an increase in public support (from 35\% to 44\%). Public support for coal conversion averaged $50 \%$ in 1980 and $47 \%$ in the first half of 1981; opposition averaged $37 \%$ in 1980 and $41 \%$ in the first half of 1981 [Cambridge $(79 / 3 ; 79 / 5 ; 80 / 3 ; 80 / 5 ; 80 / 8 ; 80 / 11 ; 81 / 3$; 81/5)]. Opposition to increased strip mining showed a similar pattern. Cambridge found greatest opposition in 1976 (averaging 62\%), a slight decrease in 1977 that remained stable through early 1979 (averaging 55\%), followed by a further decrease post-TMI that remained stable at approximately 44\% through early 1981. In June, 1981, however, public 
support for and opposition to strip mining returned to levels similar to the pre-TMI period of 33\% favorable and 54\% opposed. From spring 1979 through early 1981 support for coal conversion was similar to or greater than support for nuclear power plant construction, and support for increased strip mining was only slightly less than support for nuclear energy. Prior to that time, the difference in levels of support for nuclear energy compared to support for increased reliance on coal ranged from $17 \%$ to $31 \%$ greater favorability for nuclear power.

While the TMI accident appears to be related to enhanced public acceptability of coal, there is evidence that favorability toward coal as an energy alternative had increased in 1977 and 1978, particularly during the severe winter of 1977 (see Figure 5.1). In addition, trend data from Harris $(75 / 6 ; 76 / 7 ; 78 / 10 ; 79 / 4)$ indicate a substantial increase over time in the percentage of the public who considered coal "a reliable form of energy for the U.S. to depend on in the long run." In 1975 and 1976 about $40 \%$ of the public considered coal a reliable long-term source compared to $57 \%$ in 1978 and $64 \%$ in 1979 (see Figure 5.2). During this period, the percentage of the public who considered nuclear power a reliable, long-term energy source remained stable, ranging from $66 \%$ to 63\%, between June, 1975, through Apri1, 1979, immediately following the TMI accident.

The increase in support for coal must be regarded with caution. Since coal had been the energy source that received the lowest levels of public acceptability, the absolute level of favorability generally has not been high even though it has increased. Over $40 \%$ of the public 


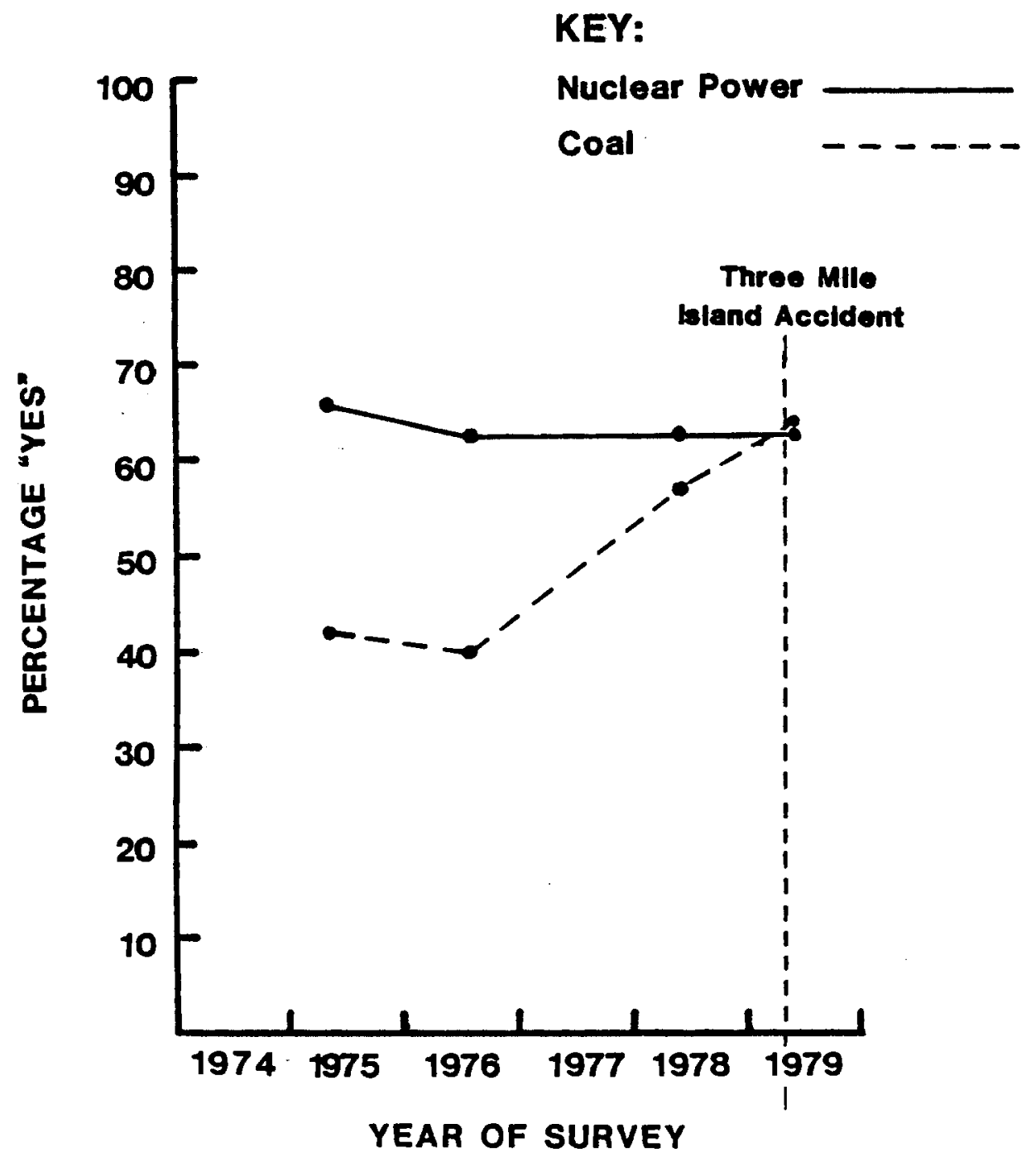

FIGURE 5.2 Coal And Nuclear Power As Long-Term Reliable Energy Sources

NOTE: "Do you think coal (nuclear power) is a reliable form of energy for the U.S. to depend upon in the long run?" [Harris (75/6; $76 / 7 ; 78 / 10 ; 79 / 4)]$ 
remained opposed to coal after TMI, similar to the level of opposition to nuclear power following the TMI accident [Cambridge (81/5)].

A different approach to assess public attitudes toward alternative energy technologies is to ask respondents to rank order their preferences for specific energy options. Results from this type of question are presented in Table 5.2. Data from Roper $(75 / 4 ; 77 / 3)$ indicate that solar energy ranked first and nuclear energy ranked second in the mid-1970s as the one or two best long-term sources of energy. Selection of solar energy increased from $50 \%$ to $67 \%$ while selection of nuclear power declined from $47 \%$ to $35 \%$ between 1975 and 1977 . Coal remained stable at $18 \%$ and offshore $0 i 1$ declined slightly from $18 \%$ to $12 \%$. In response to a similar question posed by NBC (79/4), during the TMI accident, nuclear energy declined to third place, following solar energy and coal. Fifty-two percent of the public thought that solar energy was the best energy source for the United States in the year 2000, $21 \%$ selected coal, $16 \%$ selected nuclear energy, and $4 \%$ selected $0 i 1$. In surveys by Seasonwein $(79 / 11)$ and SERI $(80 / 11)$, only $16 \%$ and $8 \%$, respectively, of the public selected nuclear energy as the first or second most preferred source. Solar energy continued to receive the highest percentage selection (38\% and $31 \%$, respectively), followed by coal (29\%) in the Seasonwein study and by conservation and 0 il/natural gas (both $14 \%$ ) in the SERI survey (see Table 5.2). Harris (79/12) reported similar results when respondents selected one option in a question that cited both an advantage and disadvantage of three alternatives--solar ("may not provide sufficient energy to support our current standard of living, but which 
TABLE 5.2

PERCENTAGE OF THE PUBLIC WHO PREFER VARIOUS ENERGY EMPHASES FOR THE FUTURE

\begin{tabular}{|c|c|c|c|c|c|c|c|c|c|}
\hline \multirow[b]{2}{*}{ Energy Source } & \multicolumn{2}{|c|}{$\begin{array}{l}\text { One Most } \\
\text { Preferred }\end{array}$} & \multicolumn{3}{|c|}{ Two Most Preferred } & \multicolumn{2}{|c|}{$\begin{array}{l}\text { Three Most } \\
\text { Preferred }\end{array}$} & \multicolumn{2}{|c|}{$\begin{array}{l}\text { One Least } \\
\text { Preferred }\end{array}$} \\
\hline & $(79 / 4)^{a}$ & $(80 / 11)^{b}$ & $(75 / 4)^{c}$ & $(77 / 3)^{c}$ & $(79 / 11)^{d}$ & $\overline{(80 / 1)^{e}}$ & $(80 / 11)^{b}$ & $(80 / 1)^{e}$ & $(80 / 11)^{b}$ \\
\hline Nuclear energy & 16 & 8 & 47 & 35 & 16 & 23 & 27 & 33 & 45 \\
\hline Coal & 21 & 12 & 18 & 18 & 29 & 36 & 36 & 9 & 13 \\
\hline $0 i 1$ and natural gas & 4 & 14 & - & - & 20 & 28 & 34 & 9 & 12 \\
\hline Water Power & - & 6 & 12 & - & - & 31 & 34 & 10 & 8 \\
\hline Solar energy & 52 & 31 & 50 & 67 & 38 & 61 & 66 & 6 & 3 \\
\hline Synfuels & - & 10 & - & - & 20 & 26 & 38 & 9 & 5 \\
\hline Conservation & - & 14 & - & - & 21 & 35 & 45 & 3 & 4 \\
\hline
\end{tabular}

"Looking ahead to the year 2000, which do you think would be the best source of energy for the United States: coal, oil, nuclear energy, or solar energy?" [NBC (79/4)]

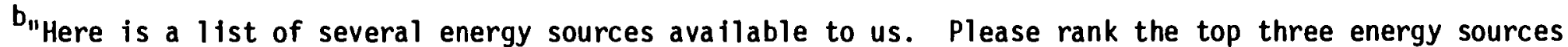
you would prefer to see developed to meet our future energy needs. Now, please indicate the source you least prefer." [SERI $(80 / 11)]$

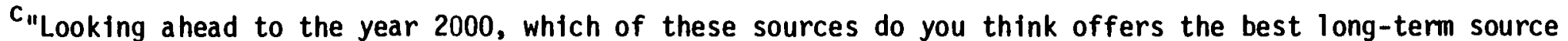
of energy--which one or two do you think we should spend the greatest effort on to develop?" [Roper (75/4; 77/3)]

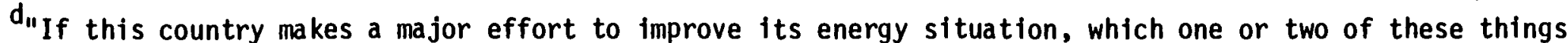
do you feel it should depend on most--0il and natural gas, or synthetic energy, or saving energy, or nuclear energy, or coal, or solar energy?" [Sea sonwein $(79 / 11)$ ]

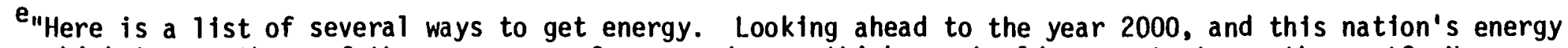
needs, which two or three of these sources of energy do you think we should concentrate on the most? Now, looking at the card again, which one of these sources of energy would you like to see us spend the least effort to develop?" [RFF (80/11)] 
causes little harm to the environment") received 53\% support; coal ("available in large quantities but increases air pollution") received $25 \%$, and nuclear energy ("has potential danger of radiation but can be produced in great quantity") received $17 \%$ selection.

Thus, the trend data for public attitudes toward various energy technologies for both general support and opposition and for direct choice questions are similar. Solar energy consistently received the highest level of support. While nuclear power had been preferred to coal by the general public before the TMI accident, nuclear energy has declined to a position of lesser support relative to coal since the TMI accident.

\subsubsection{Public Preferences for Local Power Plants}

Attitudes toward power plants in one's community are important to assess, since respondents of ten are more willing to approve construction of energy facilities "in general" or "within the United States," than they are willing to approve construction close to the ir own communities. Table 5.3 presents data on public attitudes regarding construction of six different types of electric power plants in the respondent's local community from $\operatorname{RAC}(77 / 8 ; 78 / 8)$ and $A R B(79 / 7 ; 80 / 6)$. Solar energy and hydroelectric plants received the highest levels of support, averaging $86 \%$ and $83 \%$ support, respectively. Construction of gas-fired plants has consistently received over $60 \%$ acceptability from the public. Attitudes toward coal, oil, and nuclear power plants have changed in the past few years. Public acceptance of coal increased from $41 \%$ in 1977 to $65 \%$ in 1978 (following a severe winter and acute natural gas shortages) to $71 \%$ in 1979 (post-TMI). In 1980, support decreased to $60 \%$. Favorability 
TABLE 5.3

PERCENTAGE OF THE PUBLIC WHO FAVOR AND OPPOSE VARIOUS

ALTERNATIVES FOR LOCAL ELECTRIC POWER PLANTS

\begin{tabular}{|c|c|c|c|c|c|c|c|c|}
\hline \multirow{2}{*}{$\begin{array}{l}\text { Type of } \\
\text { Power Plant }\end{array}$} & \multicolumn{4}{|c|}{ Approve } & \multicolumn{4}{|c|}{ Disapprove } \\
\hline & 1977 & 1978 & 1979 & 1980 & 1977 & 1978 & 1979 & 1980 \\
\hline Solar energy & - & 84 & 87 & 86 & - & 5 & 8 & 10 \\
\hline Hydroelectric power & - & 87 & 80 & 82 & - & 6 & 6 & 6 \\
\hline Natural gas & - & 69 & 68 & 64 & - & 24 & 26 & 28 \\
\hline Coal & 41 & 65 & 71 & 60 & 47 & 28 & 24 & 33 \\
\hline $0 i 1$ & - & 62 & 54 & 44 & - & 30 & 40 & 48 \\
\hline Nuclear energy & 47 & 41 & 34 & 28 & 39 & 43 & 60 & 63 \\
\hline
\end{tabular}

NOTE: "Here is a list of different ways of producing electrical power. Suppose a new power plant had to be built in this area. For each of these ways of producing electricity please tell me whether it would be all right with you if this method were used in this area, or whether you would be against using it in this area?" [RAC $(77 / 8 ; 78 / 8)$ and ARB $(79 / 7 ; 80 / 6)]$ 
towards oil-fired plants has shown a consistent decline from $62 \%$ approval in 1978 to $44 \%$ approval in 1980. Support for local nuclear power plants has also been in decline since the mid-1970's. Support decreased from $47 \%$ in 1977 to $28 \%$ in $1980[\operatorname{RAC}(77 / 8 ; 78 / 8)$ and $\operatorname{ARB}(79 / 7 ; 80 / 6)]$ (as discussed in detail in Chapter 3).

The data on the relative position of nuclear power versus coal-fired plants show some inconsistencies across different survey organizations. Data from Harris $(78 / 10)$ and Cambridge $(78 / 3 ; 78 / 7)$ conflict with the results from RAC (78/8), which showed $24 \%$ greater support for use of coal than for use of nuclear power in the respondent's local community (see Table 5.3). Harris $(78 / 10)$, on the other hand, found equal levels of favorability and opposition to coal and to nuclear power plants within five miles of the local community (37\% and $35 \%$ support, respectively, and $55 \%$ and $56 \%$ opposition, respectively). (The absolute support levels differ because of question wording: "in this area" by RAC and "within five miles" by Harris. The issue here, however, is the relative difference in acceptance of coal and nuclear power plants.) In two 1978 surveys Cambridge reported differences in preference for a coal versus a nuclear power plant in the community that ranged from a $4 \%$ greater preference for nuclear power [Cambridge (78/3)] to a $10 \%$ greater preference for coal [Cambridge (78/7)]. Neither Harris nor Cambridge found as great a difference in public acceptance of nuclear power and coal plants as RAC did in the 1978 surveys.

While these disparities in the levels of support for coal and nuclear power reported by different survey organizations are problemmatical, the weight of the evidence indicates a change from a 
clear-cut preference for a local nuclear power plant over a local coal-fired plant, which existed in earlier years. For example, Becker $(73 / 6 ; 74 / 5)$ found about $56 \%$ favorability to a local nuclear power plant and approximately $40 \%$ favorability to an oil or coal-burning plant in the early 1970's. While favorability toward local nuclear power plants has been declining steadily, acceptance of coal increased between 1977 and 1979 and then declined somewhat in 1980.

\subsubsection{Summary of Comparative Attitudes toward Energy Technologies}

Since 1976, the public has given more support to solar energy compared to all other energy sources; there is strong majority consensus that efforts should be made to develop this energy source. Solar energy is selected most often as the best source for the future by the general public.

Drilling for offshore oil receives substantial majority support as a short-term energy production measure. Public support for this measure has remained stable from 1973 through 1981. However, oil receives much less public support as a long-term energy source.

Public acceptance of nuclear energy declined at both the general and local community levels following the TMI accident. Decreased favorability toward nuclear power plant construction at the local level, however, had already been in evidence prior to TMI. In 1979 and 1980 a smaller percentage of the public selected nuclear energy as one of the best sources for the future than selected most other energy options.

There has been a definite increase in favorability toward coal. Coal plants are now as acceptable or are more acceptable than nuclear power plants. There is evidence of greater support for coal conversion 
and strip mining following the TMI accident. However, there has been a recent decrease in support for strip mining and for coal-burning power plants in some 1980 and 1981 surveys. There has been plurality to majority opposition to increased use of coal (e.g., 45-55\% disapproval of coal conversion and strip mining) when environmental risks are explicitly mentioned in the survey questions. While coal was not the first choice of most of the public for the future, it was selected as among the best two or three sources by a larger percentage of the public in 1977 and 1980 than during the mid-1970s.

\subsection{Beliefs about Characteristics of Energy Sources}

\subsubsection{Introduction}

The public's beliefs concerning the characteristics of specific energy sources are discussed in this section. Beliefs about environmental, health and safety, cost, and supply aspects of a number of energy options are presented. Information on public assessments of advantages and disadvantages of specific energy alternatives should aid in understanding the general levels of acceptance of these various sources.

\subsubsection{Environmental Beliefs}

Comparative beliefs regarding the impacts of various energy sources on environmental quality are presented in Table 5.4. Coal consistently has been considered the energy source most harmful to the environment, particularly in terms of air pollution. From 1975 through 1977, about $42 \%$ of the public selected coal as most harmful to the environment and about $24 \%$ of the public selected nuclear power as most harmful, relative 
TABLE 5.4

BELIEFS OF THE PUBLIC ABOUT POLLUTION CHARACTERISTICS OF SIX ENERGY SOURCES

\begin{tabular}{|c|c|c|c|c|c|c|}
\hline \multirow[b]{2}{*}{ Response by Date } & \multicolumn{6}{|c|}{ Energy Source } \\
\hline & $\begin{array}{c}\text { Nuclear } \\
\text { Power } \\
(\%)\end{array}$ & $\begin{array}{l}\text { Coal } \\
(\%)\end{array}$ & $\begin{array}{l}0 i 1 \\
(\%)\end{array}$ & $\begin{array}{l}\text { Natural } \\
\text { Gas } \\
(\%)\end{array}$ & $\begin{array}{l}\text { Hydro- } \\
\text { Electric } \\
\text { Plants } \\
(\%)\end{array}$ & $\begin{array}{l}\text { Solar } \\
\text { Energy } \\
(\%)\end{array}$ \\
\hline$\frac{\text { Most harmful to }}{\text { environmentd }}$ & & & & & & \\
\hline $\begin{array}{l}(75 / 8) \\
(76 / 8) \\
(77 / 8)\end{array}$ & $\begin{array}{l}20 \\
27 \\
24\end{array}$ & $\begin{array}{l}44 \\
42 \\
40\end{array}$ & $\begin{array}{l}18 \\
10 \\
12\end{array}$ & $\begin{array}{c}--d \\
4 \\
6\end{array}$ & $\begin{array}{r}-- \\
2 \\
1\end{array}$ & $\begin{array}{r}-- \\
0\end{array}$ \\
\hline$\frac{\text { Least harmful to }}{\text { environment }}$ & & & & & & \\
\hline $\begin{array}{l}(75 / 8) \\
(76 / 8) \\
(77 / 8)\end{array}$ & $\begin{array}{r}44 \\
3 \\
4\end{array}$ & $\begin{array}{r}16 \\
3 \\
4\end{array}$ & $\begin{array}{r}20 \\
2 \\
1\end{array}$ & $\begin{array}{r}-- \\
6 \\
6\end{array}$ & $\begin{array}{l}-- \\
30 \\
28\end{array}$ & $\begin{array}{l}-- \\
45 \\
48\end{array}$ \\
\hline Low air pollution ${ }^{b}$ & & & & & & \\
\hline $\begin{array}{l}(75 / 4) \\
(76 / 7) \\
(78 / 10) \\
(79 / 4)\end{array}$ & $\begin{array}{l}57 \\
60 \\
55 \\
61\end{array}$ & $\begin{array}{l}10 \\
14 \\
14 \\
19\end{array}$ & $\begin{array}{l}24 \\
25 \\
25 \\
38\end{array}$ & $\begin{array}{l}-- \\
-- \\
--\end{array}$ & $\begin{array}{l}-- \\
-- \\
--\end{array}$ & $\begin{array}{l}-- \\
-- \\
--\end{array}$ \\
\hline $\begin{array}{c}\text { Low water pollution } \\
(75 / 4) \\
(76 / 7) \\
(78 / 10)\end{array}$ & $\begin{array}{l}44 \\
46 \\
30\end{array}$ & $\begin{array}{l}24 \\
27 \\
30\end{array}$ & $\begin{array}{l}24 \\
24 \\
29\end{array}$ & $\begin{array}{l}-- \\
--\end{array}$ & $\begin{array}{l}-- \\
--\end{array}$ & $\begin{array}{l}-- \\
--\end{array}$ \\
\hline
\end{tabular}

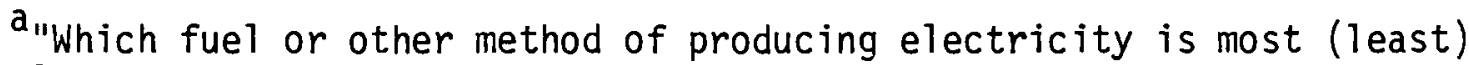
harmful to the environment in which we live?" $[\operatorname{RAC}(75 / 8 ; 76 / 8 ; 77 / 8)]$

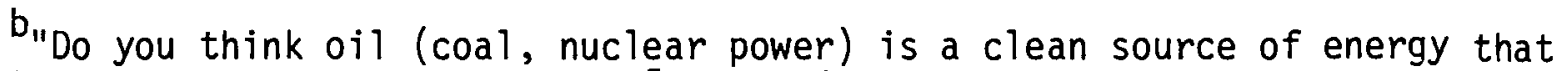
doesn't pollute the air so much?" [Harris $(75 / 4 ; 76 / 7 ; 78 / 10 ; 79 / 4)$ ]

$C$ "Do you think oil (coal, nuclear power) is a clean source of energy that doesn't pollute the water so much?" [Harris $(75 / 4 ; 76 / 7 ; 78 / 10)]$

${ }^{d}$ Not asked. 
to other sources including oil, natural gas, hydroelectric plants, and solar energy [RAC (77/8)]. When asked to name the major disadvantages of using coal power plants, over $60 \%$ of the public cited air pollution [ARB (79/7) and Cambridge (80/11)].

In 1975, nuclear power was selected most of ten as the least harmful energy source (44\%) when only coal, oil, and nuclear power were included as choices. However, when hydroelectric plants and solar energy were added to the list by $\operatorname{RAC}(75 / 8 ; 77 / 8)$, most of the public selected these two sources as least harmful. Seasonwein $(79 / 11)$ reported $50 \%$ of the public selected solar energy, and $30 \%$ selected "saving energy" as the one or two ways to improve the energy situation "with the least damage to the environment and health" from a list that also included oil and natural gas $(17 \%)$, synthetic energy (11\%), coal (10\%), and nuclear energy ( $8 \%)$. Harris $(78 / 10 ; 79 / 4)$ found that a majority of the public agreed that nuclear power is a clean source of energy in terms of air pollution, and this belief has remained stable from 1975 through the period of the TMI accident. There was a decrease in the percentage of the public who considered nuclear power a clean source of energy in terms of water pollution, from approximately $45 \%$ in 1975 and 1976 to $30 \%$ in 1978, which is similar to the results for both oil (29\%) and coal (30\%). There was little change in the public's belief that "nuclear power actually pollutes far less than electric power produced from oil or coal" before and after the TMI accident. A majority of the public believed this was a true statement both in 1978 (59\%) and in 1979 (55\%), although the percentage that believed this was not true increased from 16\% in 1978 to $24 \%$ following the TMI accident [Harris $(78 / 10 ; 79 / 4)]$. 
Specific trade-off questions on environmental risks associated with energy development provide some indication of the price the public may be willing to pay to protect the environment. In terms of increasing the energy supply, there appears to be greater willingness to take environmental risks for drilling for of fshore oil than for burning coal, except under emergency circumstances. For example, Cambridge (77/9) found that $56 \%$ of the public was favorable to offshore oil drilling "to get the energy we need" even if there was a significant risk that a major accidental leak would occur every four to five years. In addition, $49 \%$ favored speeding up offshore oil development on the East Coast despite concerns about environmental damage to beaches and fishing areas, while $30 \%$ of the public was opposed to such a speed up. Using a similar question, Gallup (77/3) found that $45 \%$ of the public favored offshore 011 drilling and $42 \%$ opposed it if there were a risk of polluting ocean water and beaches. Harris (79/12) reported that $56 \%$ of the public supported and $34 \%$ opposed oil exploration "despite the environmental risk."

In the past, a majority of the public rejected increased use of coal when the problem of air pollution was specifically mentioned except during 1 imited energy emergencies. For example, YS\&W (78/unk.) reported that approximately $50 \%$ of the public opposed the increased use of coal between 1974 through 1978, if it resulted in greater air pollution, except for only 38\% opposition in 1977--the year of a severe winter. Less than $10 \%$ of the public was willing to accept the increased pollution from expanded use of coal, except in 1977, when $23 \%$ was favorable. A Gallup (77/2) study during the period of natural gas shortages in the severe winter of 1977 found that $64 \%$ of the public approved the use of 
"the kind of coal that causes air pollution" if power plants could not obtain natural gas. It appears that public opposition to use of coal because of environmental risk generally has decreased since 1979. Harris (79/12) found a $69 \%$ level of support for increased use of coal in a question that specifically referred to risks to human life and the environment. Furthermore, Cambridge (80/11) reported on ly $15 \%$ very concerned and $23 \%$ somewhat concerned with carbon dioxide build-up from burning coal; the levels increased to $32 \%$ very concerned and $35 \%$ somewhat concerned after respondents were provided with a brief explanation of potential damage from this build-up.

In a series of questions concerning power plant construction at the cost of specific environmental loss, Cambridge $(78 / 6)$ reported that $48 \%$ of the public approved building a dam if the loss was the extinction of a rare plant, $44 \%$ approved building a dam if it resulted in extinction of a small fish, and 27\% approved building an electric power plant if it discharged heated water that might change the adjacent sea life. As shown in Figure 5.3, responses varied significantly by the respondent's attitude toward nuclear power. Pronuclear respondents were more supportive of construction in all cases than were those opposed to nuclear power. Note that the rank order of environmental concerns was the same for both the pro and antinuclear respondents; the possible damage related to heated water was considered more serious than the loss of a rare plant or a fish species.

In trade-offs involving increased energy costs to protect the environment, the public generally rejected direct price increases but was more accepting of indirect costs, e.g., via government taxation. 


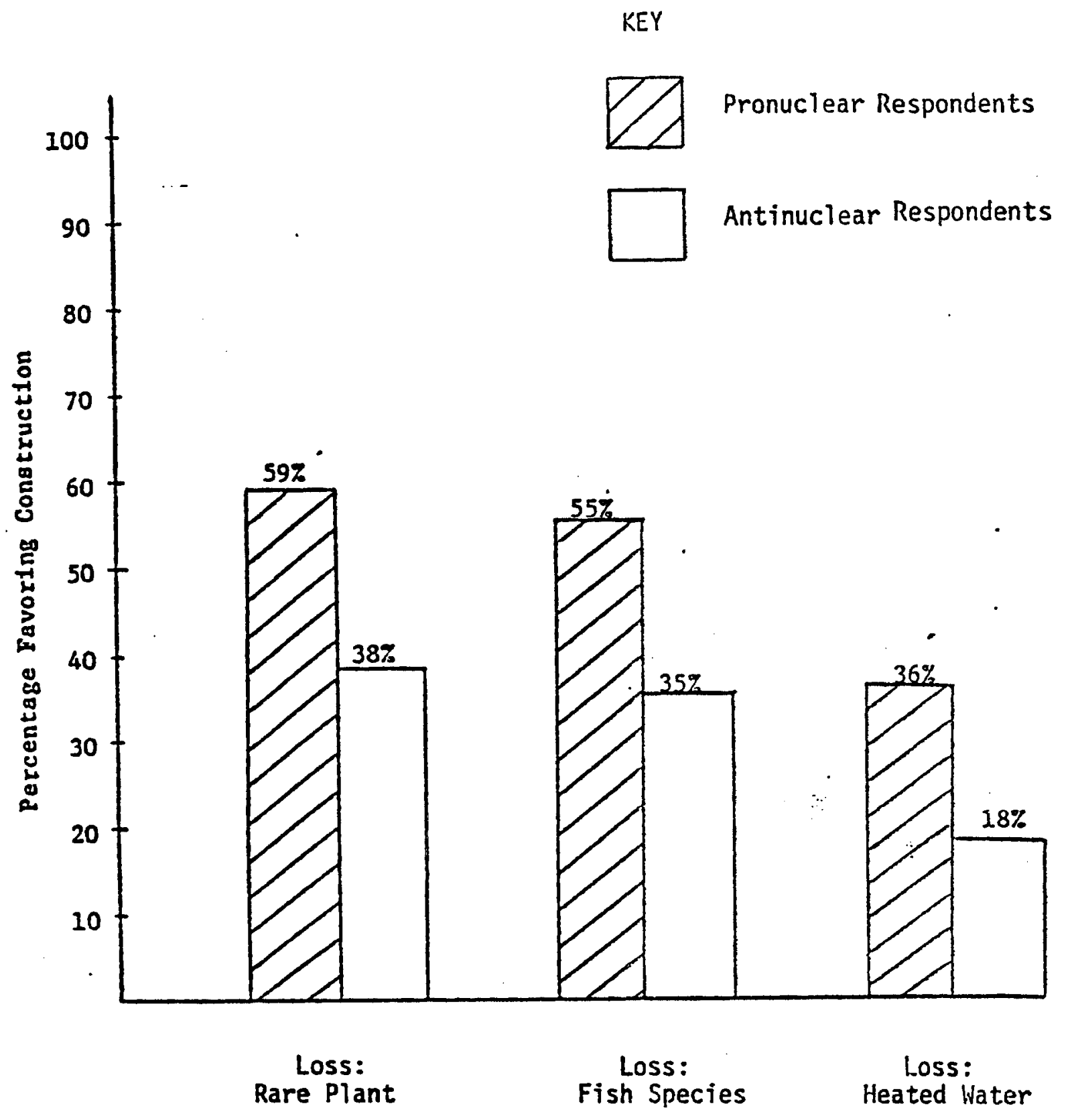

FIGURE 5.3 POWER PLANT CONSTRUCTION VERSUS ENVIRONMENTAL COST

NOTE: "I'd like you to tell me whether you would lean toward constructing each project and having some environmental damage or not building at all. Construction of an electric power dam, even if it would mean the extinction of a rare plant that grows only in the area that would be flooded by the dam. Construction of an electric power dam, even if it would mean the extinction of a small fish that lives only in the stream that would be dammed. Construction of a new electric power plant, even if the water flowing from it would be hotter than the sea water into which it flowed, and might cause some changes in the kind of sea life living off the plant." [Cambridge (78/5)] 
YS\&W (78/unk.) found very low acceptance levels of electricity price increases for strip mining protection (24\% favorable and $37 \%$ against) and for coal conversion with air pollution control devices (20\% favorable and $51 \%$ against). There generally has been greater support for government projects to reclaim strip-mined land, even though increased taxes to pay for these projects were specified as the cost.

In summary, coal is evaluated as the least desirable energy source in terms of environmental effects, primarily in terms of air pollution and to some extent water pollution. Also, there is little willingness to pay higher prices to reduce the environmental damage associated with coal use. There is evidence of a change in the late 1970s in the impact of the environmental risks associated with coal on public support for coal use. Support for expanded use of coal has increased, even though a majority of the public believes such use will result in environmental damage. A plurality of the public is willing to risk oil leaks in order to obtain more oil through offshore drilling. Nuclear power is generally believed to be a clean energy source in terms of air pollution but not in terms of water pollution. Solar energy and hydroelectric power are considered by the public the energy sources least harmful to the environment.

\subsubsection{Comparative Health and Safety Beliefs}

There are very limited data of a comparative nature that directly deal with questions of health and safety. Beliefs about environmental consequences are likely to encompass some concerns for both the health and safety impacts of various energy sources. In response to an ARB (79/7) open-ended question about advantages and disadvantages of nuclear 
energy, coal, and oil-fired plants, public safety was a significant concern primarily for nuclear energy. A majority of the public mentioned both possible accidents (53\%) and radiation hazards under normal conditions (52\%) as disadvantages of nuc lear power. In addition to the concern for air pollution caused by coal plants (63\%) reported earlier, $32 \%$ of respondents mentioned health and safety risks to coal miners as a disadvantage of coal. Health and safety generally were not seen as major problems with oil-fired power plants.

Harris $(75 / 4 ; 76 / 7 ; 78 / 10 ; 79 / 4)$ has used a structured question over a five-year period that compares public beliefs regarding health and safety issues for nuclear power, coal, and oil (see Table 5.5). Respondents were asked if they agreed that these sources raise "few health hazards and dangers" in their use. Thirty-one percent to $48 \%$ agreed that nuclear power raises few health hazards and dangers; $40 \%$ to $50 \%$ agreed that coal raises few hazards; and $45 \%$ to $52 \%$ agreed with this statement for oil. The greatest change was in the percentage of respondents who were unsure. For all sources there was a decline in the size of the unsure group, but this decline was most significant for nuclear power--from 33\% unsure in 1975 to $12 \%$ unsure in 1979 . Between 1975 and 1978 there was a significant increase (from 31\% to 48\%) in disagreement with the statement concerning nuclear power, but little change regarding coal and oil. There was increased agreement and a decline in percentage disagreeing for both coal and nuclear power in the 1979 survey, which was conducted during the first week of the TMI accident. While the more positive response to coal is consistent with findings presented earlier in this chapter, the increased agreement that 
TABLE 5.5

BELIEFS OF THE PUBLIC THAT ENERGY SOURCES

RAISE FEW HEALTH HAZARDS

\begin{tabular}{|c|c|c|c|c|c|c|c|c|c|c|c|c|}
\hline \multirow[b]{2}{*}{ Energy Source } & \multicolumn{4}{|c|}{ Agree } & \multicolumn{4}{|c|}{ Disagree } & \multicolumn{4}{|c|}{ Unsure } \\
\hline & $(75 / 4)$ & $(76 / 7)$ & $(78 / 10)$ & $(79 / 4)$ & $(75 / 4)$ & $(76 / 7)$ & $(78 / 10)$ & $(79 / 4)$ & $(75 / 4)$ & $(76 / 7)$ & $(78 / 10)$ & $(79 / 4)$ \\
\hline Nuclear power & 36 & 34 & 31 & 48 & 31 & $--a$ & 45 & 40 & 33 & -- & 22 & 12 \\
\hline Coal & 39 & 40 & 42 & 50 & 46 & -- & 48 & 44 & 15 & -- & 9 & 6 \\
\hline $0 i 1$ & 45 & 46 & 52 & 52 & 38 & -- & 38 & 40 & 17 & -- & 10 & 8 \\
\hline
\end{tabular}

$\tilde{N}$

adata not reported in Harr is $(76 / 7)$.

Note: "Do you think oil (coal, nuclear power) raises few health hazards and dangers in using it?" [Harris $(75 / 4 ; 76 / 7 ; 78 / 10 ; 79 / 4)]$ 
nuclear power raises few hazards is less expected. Harris (1979) suggests that:

. . . in the cases of coal and nuclear power, these are signs that people are prepared to lower their standards on acceptable health risks, simply because the number of alternatives to turn to for energy. . .are limited."

This interpretation does not appear to be based on empirical findings, but is rather a plausible post hoc explanation. Other explanations are also plausible. A more detailed discussion of the impact of the TMI accident on beliefs about nuclear power safety has been presented in Chapter 4.

\subsubsection{Comparative Beliefs about Cost}

Comparative beliefs regarding the costs of various electrical energy sources are presented in Table 5.6. It is difficult to assess any changes over time, since the list of energy alternatives has differed in the Cambridge (75/4), $\operatorname{RAC}(77 / 8)$, and Seasonwein $(79 / 11)$ surveys. Solar energy and conservation were most of ten selected $131 \%$ and $32 \%$, respectively) as the one or two sources that would cost least in the Seasonwein (79/11) survey. In 1977, solar ranked third (18\%) after hydroelectric plants (36\%) (not included in the Seasonwein list) and coal $(25 \%)$, and in 1975 solar ranked first (29\%) as the cheapest source. Coal has been considered one of the lowest cost sources. It ranked second in 1975 (24\%) (after solar energy) and 1977 (25\%) (after hydroelectric plants) and third (29\%) (after conservation and solar energy) in 1979. When respondents were asked in an open-ended question to list advantages of coal as an energy source in the Cambridge (80/11) and ARB (79/7) surveys, $30 \%-34 \%$ mentioned low cost. Nuclear energy has been selected by 
TABLE 5.6

BELIEFS OF THE PUBLIC CONCERNING COSTS OF ENERGY SOURCES

\begin{tabular}{lcccc}
\hline & \multicolumn{2}{c}{ One or Two Lowest Cost } & $\begin{array}{c}\text { One } \\
\text { Highest Cost }\end{array}$ \\
\cline { 2 - 5 } Energy Source & $(75 / 4)^{\mathrm{a}}$ & $(77 / 8)^{\mathrm{b}}$ & $(79 / 17)^{\mathrm{c}}$ & $(77 / 8)^{\mathrm{c}}$ \\
\hline Water/hydroelectric plant & 17 & 36 & 0 & 3 \\
Coal & 24 & 25 & 29 & 4 \\
Solar energy/the sun & 29 & 18 & 31 & 17 \\
Nuclear energy & 6 & 4 & 8 & 21 \\
Natural gas & 17 & 17 & $14^{\mathrm{d}}$ & 20 \\
Oil & 7 & 7 & $-{ }^{\mathrm{d}}$ & 30 \\
Saving energy & 0 & 0 & 32 & 0 \\
\hline
\end{tabular}

" "Which energy source is cheapest?" [Cambridge (75/4)]

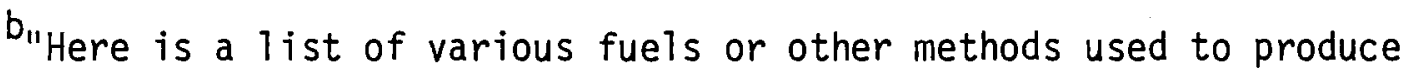
electricity. Of the ones on the list, which one would you say produces electricity for the lowest (highest) overall cost at the present time, taking into account all the different costs that might be involved?" [RAC $(77 / 8)]$

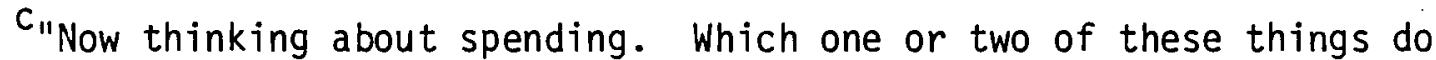
you feel could help to substantialiy improve this country's energy situation for the least money--oil and natural gas, or synthetic energy, or saving energy, or nuclear energy, or coal, or solar energy?" [Seasonwe in $(79 / 11)]$

${ }^{d} 0 i l$ and natural gas are combined in this survey. 
only $4 \%-8 \%$ of the public as one of the lowest cost energy sources; $21 \%$ considered it the highest cost energy technology in 1977. However, $23 \%$ of respondents mentioned low cost as an advantage of nuclear power in the ARB (79/7) survey. $0 i 1$ was considered the most expensive source by the largest percentage of respondents (30\%) in 1977, and very seldom has been selected as a low cost energy source $17 \%$ in 1975 , 3\% in $1977,14 \%$ for oil and natural gas combined in 1979). High cost was cited by $42 \%$ of respondents as a disadvantage of oil in the ARB (79/7) survey.

\subsubsection{Beliefs about Energy Source Availability}

Nuclear power is believed to be a readily available energy source. As shown in Table 5.7, approximately three-fourths of the public thinks that there is a good supply of nuclear energy for both the near and far term and that nuclear power is a domestically available source which reduces dependence on foreign energy supplies [Harris $(75 / 4 ; 76 / 7 ; 78 / 10$; 79/4)]. In addition, $26 \%$ of respondents mentioned energy independence and $19 \%$ referred to availability as major advantages of nuclear power in response to an open-ended question [ARB (79/7)]. While a majority of the public has considered nuclear power a readily available energy source from 1975 through 1979, the public's awareness of coal as such an energy resource for the United States increased during that period. Belief that there is an almost unlimited supply of coal increased from $44 \%$ in 1975 to $61 \%$ in 1979, belief that the U.S. will not run out of coal in the near term increased from $45 \%$ in 1975 to $67 \%$ in 1978, and belief that coal will reduce foreign energy dependence increased from $69 \%$ in 1975 to $82 \%$ in 1978 [Harris $(75 / 4 ; 76 / 7 ; 78 / 10 ; 79 / 4)]$. Furthermore, a majority of respondents referred to supply aspects of coal when listing advantages of 
TABLE 5.7

BELIEFS OF THE PUBLIC ABOUT ELECTRICAL ENERGY SUPPLY SOURCES

\begin{tabular}{|c|c|c|c|}
\hline \multirow[b]{2}{*}{ Response by Year } & \multicolumn{3}{|c|}{ Energy Source } \\
\hline & $\begin{array}{l}\text { Nuclear } \\
\text { Power }\end{array}$ & Coal & $0 i 1$ \\
\hline \multicolumn{4}{|c|}{ Almost unl imited supply } \\
\hline $\begin{array}{l}(75 / 4) \\
(76 / 7) \\
(78 / 10) \\
(79 / 4)\end{array}$ & $\begin{array}{l}65 \\
63 \\
69 \\
71\end{array}$ & $\begin{array}{l}44 \\
48 \\
58 \\
61\end{array}$ & $\begin{array}{l}28 \\
26 \\
32 \\
34\end{array}$ \\
\hline \multicolumn{4}{|l|}{ Wi11 not run out } \\
\hline $\begin{array}{c}\text { anytime soon } \\
(75 / 4) \\
(76 / 7) \\
(78 / 10)\end{array}$ & $\begin{array}{l}53 \\
51 \\
71\end{array}$ & $\begin{array}{l}45 \\
41 \\
67\end{array}$ & $\begin{array}{l}33 \\
33 \\
44\end{array}$ \\
\hline \multicolumn{4}{|l|}{$\frac{\text { Obtainable almost }}{\text { entirely in U.S. }}$} \\
\hline $\begin{array}{l}(75 / 4) \\
(76 / 7) \\
(78 / 10)\end{array}$ & $\begin{array}{l}73 \\
73 \\
78\end{array}$ & $\begin{array}{l}69 \\
70 \\
84\end{array}$ & $\begin{array}{l}38 \\
36 \\
37\end{array}$ \\
\hline \multicolumn{4}{|c|}{$\begin{array}{l}\text { Reduces dependence on } \\
\text { foreign sources }\end{array}$} \\
\hline $\begin{array}{l}(75 / 4) \\
(76 / 7) \\
(78 / 10)\end{array}$ & $\begin{array}{l}76 \\
73 \\
76\end{array}$ & $\begin{array}{l}69 \\
66 \\
82\end{array}$ & $\begin{array}{l}40 \\
37 \\
28\end{array}$ \\
\hline
\end{tabular}

NOTE: "Do you think oil, coal, nuclear power can be produced in almost unlimited quantities; will not run out of supply anytime soon in the future; can be obtained almost entirely within the U.S.; makes us less dependent on foreign sources?" [Harris $(75 / 4 ; 76 / 7 ; 78 / 10 ; 79 / 4)$ ] 
that source in the ARB (79/7) and Cambridge (80/11) surveys. ARB (79/7) reported $51 \%$ mentioned availability of coal and 30\% specifically referred to greater energy independence as advantages; Cambridge (80/11) found that $31 \%$ of respondents mentioned energy independence and $23 \%$ mentioned the large supply of coal in the United States as advantages. Approximately a third of the public has continued to believe that domestic oil is readily available. However, $51 \%$ of respondents referred to dependence on foreign countries as a disadvantage of oil [ARB (79/7)]. Survey questions regarding solar-generated electricity are primarily concerned with beliefs about technical feasibility. The supply of the fuel source, the sun, is not in question. The belief that the technology is currently available for solar energy to become a significant part of meeting national energy needs has been increasing over time. In 1975, $39 \%$ of the public thought the technology was available, but this percentage increased to $43 \%$ in $1976,52 \%$ in 1978 , and $56 \%$ in 1979 [Harris $(75 / 4,76 / 7,78 / 10,79 / 11)]$. When asked how long it would take to build enough solar facilities to provide $25 \%$ of electricity needs, the median time estimated by the public was 14 years [Harris $(78 / 10)$ ]. However, in $1979,42 \%$ of the public agreed and $36 \%$ disagreed that solar generated electricity could "solve the energy crisis in the next five years" [Gallup (79/4)]. This is a much more optimistic assessment of the short-term potential of solar energy than reported by Harris. The Harris question was specifically focused on time to build major facilities, while the Gallup question was quite vague. It is not clear what respondents have in mind in terms of cost and level of effort when saying that solar energy could solve the energy crisis. Public 
expectations of solar energy are much higher than expert predictions. The National Research Council (1980) projections of the potential contribution of solar energy in the year 2000 ranges from $1 \%$ to $10 \%$ of total energy demand (including all types of solar energy--heating and cooling as well as electricity production). The $10 \%$ figure is based on an "enhanced supply" assumption for solar energy and the lowest demand scenario for the year 2000 (58 quads of total energy demand, which is less than the 1975 level of actual energy consumption).

In summary, both nuclear power and coal are believed to be readily available energy sources. Solar electricity is seen as technically feasible, but as requiring a significant amount of time to bring on line. $0 i 1$ is the energy source perceived as having the most significant supply problem, primarily in terms of continued foreign dependence.

\subsubsection{Summary of Comparative Beliefs about Energy Technologies}

Beliefs about the specific characteristics of a number of energy sources indicate different types of advantages and disadvantages associated with each source. There is no one source that is rated best on all characteristics.

Beliefs about coal have been more positive in recent years, particularly in terms of supply assessments. This finding is consistent with the results reported earlier in this chapter of increasing public acceptance of coal. While coal also is believed by the public to be inexpensive, it is considered the most environmentally damaging energy source.

Nuclear power continues to be rated highly in terms of its domestic availability and air pollution impacts. However, nuclear power is 
believed to be one of the more expensive energy sources and the most hazardous in terms of health and safety risks.

Solar energy is considered the best source in terms of not producing negative environmental effects and is believed to be in the middle range in terms of costs relative to other sources. While the majority of the public thinks significant levels of electricity can be generated by solar power, bringing these facilities on line is expected to take over a decade.

\subsection{The Conservation Alternative}

\subsubsection{Introduction}

Conservation is the approach to energy needs that focuses on the demand side of the energy equation. Conservation can have two distinct meanings: (1) it can refer to increasing energy efficiency (e.g., developing appliances that operate on smaller amounts of energy), and (2) it can mean reducing energy consumption (e.g., using fewer appliances or using appliances less often). Surveys of public attitudes have focused primarily on the latter meaning of conservation. These surveys generally have been concerned with the public's willingness to change existing life styles that depend on high energy consumption habits.

\subsubsection{Preferences for Conservation Policy}

A majority of the public has been favorable to energy conservation. Trend data from $\operatorname{RAC}(77 / 8)$ show an increase in the percentage of the public who agreed that conservation of electricity is very important, from 55\% in 1975 and 1976 to $64 \%$ in 1977. Harris (79/2) reported that $61 \%$ of the public believed that Americans are highly wasteful in the use 
of energy. In another survey, Harris (79/11) found that wastefulness of most Americans was selected as a very important reason for the current energy problem by $54 \%$ of respondents, relative to $60 \%$ to $70 \%$ selecting reasons that referred to foreign oil dependence and the role of oil companies. Seasonwein $(79 / 11)$ reported that $48 \%$ of the public thought the United States should reduce energy use a great deal or a good deal, $35 \%$ a fair amount, and $15 \%$ not much or not at al1. When Seasonwein (79/11) asked respondents to list advantages and disadvantages of saving energy, $27 \%$ said there were no disadvantages, and another $41 \%$ said they did not know of any disadvantages; $2 \%$ said there were no advantages to saving energy, and $21 \%$ said they did not know of any advantages.

In terms of government policies, the majority of the public consistently has been opposed to higher prices as a mechanism to increase conservation, and has preferred regulations and rationing to across-the-board price increases. When asked to choose between gasoline rationing or reducing gasoline use by higher prices, $67 \%$ preferred rationing and 31\% preferred price increases [Seasonwein (79/11)]. Similarly, in a specific trade-off question by Cambridge $(77 / 11), 65 \%$ of the respondents said that they would prefer gasoline rationing (to three-quarters of current usage) compared to $15 \%$ who preferred to pay $\$ 2.00$ per gallon of gasoline. Data from YS\&W (78/unk.) indicated the same pattern. When questioned on former President Carter's statement that there must be price increases in order to achieve conservation, $65 \%$ of the public disagreed and $27 \%$ agreed. In terms of specific policy preferences, approximately $40 \%$ favored regulation (21\% supporting drastic restrictions on auto use and $20 \%$ favoring fuel rationing), while $10 \%$ 
supported price decontrol, $9 \%$ favored a fuel tax, and $35 \%$ favored no policy change. Cambridge (77/3) asked respondents if they would rather have price increases or rules governing energy use--61\% preferred rules and only $15 \%$ favored higher costs. Findings by Gallup (77/2) are similar: only $20 \%$ of the public supported price decontrol, while $70 \%$ were opposed.

There is greater support for efforts that would have indirect as opposed to direct price impacts. In response to a series of policy options presented by Gallup (77/3) during a natural gas shortage, a majority of the public opposed an extra tax on poor mileage automobile purchases, but approved of a tax rebate for good mileage automobile purchases. A majority also approved of tax rebates for installation of insulation, storm windows, or solar heaters. Similarly, Cambridge (77/3) found that $70 \%$ of the public supported government efforts to expand mass transit and that a majority of those approving such efforts would support higher taxes to pay the costs. In addition, $63 \%$ of the public favored using energy tax revenues for improving mass transit rather than returning them as consumer rebates. Seasonwein $(79 / 11 ; 80 / 2)$ reported $71 \%$ support for and $25 \%$ opposition to government financial assistance to homeowners for improving energy efficiency. Support for such assistance for businesses has increased from $48 \%$ in 1979 to $57 \%$ in 1980, though there is still substantial opposition (39\%) to that proposal.

There has been a change in public support for mandatory conservation requirements set by the government. There is now much greater support for mandatory conservation than during the mid-1970's. For example, Gallup (77/3) asked respondents during the natural gas shortage whether 
they thought legal requirements or encouragement of voluntary energy conservation would be more effective--over $70 \%$ said voluntary approaches would work better. A majority of the public (58\%) in 1979, however, said compulsory measures were needed to reduce usage of gasoline and fuel oil. Only $37 \%$ said voluntary measures would work [Harris (79/2; 79/12)]. Similarly, there has been an increase in support for restriction of both household and business and industry electricity usage. In 1977, government restriction of household energy use was favored by $8 \%$ of respondents, compared to $75 \%$ who preferred voluntary efforts; by $1980,29 \%$ said household electricity use should be restricted and $64 \%$ disagreed $[\operatorname{RAC}(77 / 8)$ and $A R B(80 / 6)]$. In response to the same question regarding business and industry, $24 \%$ approved of government restrictions on energy use, but 58\% preferred voluntary approaches in 1977, compared to $51 \%$ approval and $42 \%$ opposition to mandatory restrictions on business in $1980[\operatorname{RAC}(77 / 8)$ and $A R B(80 / 6)]$.

\subsubsection{Beliefs about Economic Impacts of Conservation}

The public's major concern with the economic consequences of conservation has been with regard to the effects on the standard of living. In response to an open-ended question by Seasonwein $(79 / 11), 29 \%$ of the public referred to negative economic or life-style impacts as the major disadvantage of conservation. However, $26 \%$ said that energy conservation would result in lower energy prices. The public was evenly split concerning whether or not conservation would lead to a reduction in the standard of living. While $48 \%$ of respondents thought such a reduction would be necessary, 50\% did not agree. Cambridge (78/9) has found this result to be quite stable since 1976 . For example, $54 \%$ of 
respondents in 1976, 46\% in 1977, and 50\% in 1978 agreed that

"conservation is not a realistic solution to the energy crisis unless we are all prepared to accept a much lower standard of living". Residents of the Northeast and the South were most likely to see conservation as reducing the standard of living, and residents from the Pacific states were least likely to agree with this position. Cambridge (77/9) also asked respondents to estimate whether their own standard of living would change under a conservation program. Most respondents (59\%) thought it would stay the same, with $17 \%$ expecting an improvement and $19 \%$ expecting a decline. In addition, $46 \%$ of the public said that it would be willing to accept a lower standard of living to help solve energy problems. Individuals with higher incomes and educational levels were most willing to reduce their own current standard of living. However, there were no differences between men and women or among age groups on this question.

\subsubsection{Reported Conservation Behavior}

Trend data. on self-reported conservation behavior by YS\&W (78/unk.) indicated little change in the types of daily energy use patterns over time, except for a return to greater gasoline usage between 1974 and 1978 (see Table 5.8). While most respondents (about $70 \%$ ) claimed they attempt to use less electricity, only two specific continuing energy conservation actions--lowering of thermostats and driving more slowly on highways--were reported by a majority of the public. Less than $15 \%$ were using mass transit more of ten or participating in a car pool. These results are quite similar to the findings of Cambridge (77/3), which reported that 13\% of respondents used mass transit and 19\% used a car pool. 
TABLE 5.8

PERCENTAGE OF THE PUBLIC WHO REPORTED

SPECIFIC CONSERVATION BEHAVIORS

\begin{tabular}{lccccc}
\hline \multicolumn{1}{c}{ Conservation Action } & $(74 / \mathrm{u})$ & $(75 / \mathrm{u})$ & $(76 / \mathrm{u})$ & $(77 / \mathrm{u})$ & $(78 / \mathrm{u})$ \\
\hline Trying to use less electricity & 71 & 71 & 69 & 74 & 74 \\
Maintaining a lower temperature at home & 70 & 69 & 63 & 73 & 73 \\
Driving more slowly on highways & 72 & 70 & 64 & 55 & 60 \\
Taking fewer nonessential car trips & 61 & 50 & 38 & 37 & 36 \\
Buying a smaller car & 20 & 22 & 22 & 22 & 29 \\
Installing new insulation & -- & -- & -- & 20 & 28 \\
Using mass transit more often & 13 & 13 & 9 & 7 & 15 \\
Canceling plans for major auto trips & 32 & 21 & 14 & 8 & 13 \\
Using a car pool more often & 18 & 14 & 16 & 14 & 13 \\
Trading in or selling a gas-guzzling car & 7 & 10 & 7 & 9 & 12 \\
\hline
\end{tabular}

NOTE: "Some people have told us that they have made changes in their way of 1 iving because of the energy problem. Which of these, if any, are changes you have made in your way of living because of the energy situation?" All data reported in YS\&W (78/unk). 
There does appear to be, however, an increase in investment in one-time energy efficiency improvements. For example, Cambridge (77/9) found $30 \%$ of respondents said they had added insulation to the ir homes and $12 \%$ said they had installed storm windows within the previous five years. In a Gallup (77/3) survey conducted during a severe winter, $42 \%$ had weather-stripped doors and windows, $36 \%$ had added storm windows or plastic sheeting, $13 \%$ had added attic insulation, and $9 \%$ had added wall insulation. Seasonwein $(79 / 11)$ found that $65 \%$ of the public reported having used caulking and weather stripping, $43 \%$ had installed or added insulation, and $38 \%$ had installed storm windows or doors since 1977. There was an increase from $20 \%$ in 1974 to $29 \%$ in 1978 of respondents who had purchased a smaller car to save energy (see Table 5.8)

\subsubsection{Summary of Conservation Belief Findings}

The majority of the public opposed direct market pricing mechanisms to achieve energy conservation, although indirect increases in costs via taxation received majority support. Compared to higher prices, most of the public would prefer regulations and rationing as a means to achieve energy conservation. There has also been an increase in support for mandatory as opposed to voluntary conservation requirements in recent years.

There is a substantial gap between support for the idea of conservation, such as using less gasoline, and actual reported energy conservation behavior. While most of the public reports some type of conservation activity, it is usually of a very limited nature. Only a very small proportion of the public has made major changes in daily 
energy consumption habits beyond turning off lights and lowering thermostat temperatures during winter months. There is little use of mass transit or car pooling, and through 1978 most individuals had not maintained reduced driving patterns that followed the 1973 oil embargo. The one area that has shown increased public conservation behavior is in capital investments (such as insulation, storm windows, smaller cars, etc.) to improve energy efficiency. These actions require a one-time investment, as opposed to a change in daily energy activities, such as driving less, which requires maintenance of a new behavior pattern over an extended time period. These findings suggest that emphasis on these types of one-time investments that result in continuous energy savings will be more successful than attempts to change daily consumption patterns. They also indicate more individual change in the area of energy efficiency than in reducing energy-consuming activities.

\subsection{Supply Versus Demand Energy Orientations}

\subsubsection{Introduction}

Since the development and expansion of nuclear power is an approach to meeting the energy needs of the American public by increasing the supply of energy, support versus opposition to nuclear power may reflect a broader perspective that emphasizes measures to increase the energy supply versus approaches to reduce energy demand. An energy production orientation would suggest favorability to all types of energy sources, while an energy consumption orientation would be associated with higher levels of opposition to the various energy sources. In this section recent data on trends in general public attitudes regarding increasing 
supply versus reducing demand are presented, and the relationship between attitudes toward nuclear power and toward energy production in general is examined.

\subsubsection{Public Attitudes and Beliefs about Consumption versus} Production Energy Measures

There have been various approaches used by survey organizations to elicit public attitudes regarding increasing the energy supply versus reducing energy demand. Table 5.9 presents data from Harris $(77 / 5 ; 78 / 4$; 78/12; 80/11) indicating respondents' preferred emphasis for an energy strategy. From 1977 to 1978, there was an increase from 41\% to 57\% in the proportion of respondents preferring a production emphasis, while preference for a conservation emphas is remained stable with approximately $30 \%$ of the public favoring reduced energy consumption. The Harris $(80 / 11)$ survey asked respondents to indicate which strategy was "more likely to improve the country's energy situation," and added a third approach--technological breakthrough to provide new sources--to the two former choices of a conservation or production emphasis. The response pattern showed an interesting change--a $47 \%$ plurality of the public selected the technological breakthrough option; only $17 \%$ believed an energy production emphasis (using current sources) would be more beneficial. There was no significant difference in the proportion (28\%) selecting a conservation emphasis. Since both the technological breakthrough and expanded production of current sources options emphasize the energy supply approach, it appears that there is majority support for a production emphasis. However, it is important to recognize that $47 \%$ of the public expects (or perhaps prefers) an energy solution from 
TABLE 5.9

PERCENTAGE OF THE PUBLIC WHO SELECT A SUPPLY VERSUS DEMAND ENERGY EMPHASIS

\begin{tabular}{lcccc}
\hline \multirow{2}{*}{ Strategy } & \multicolumn{4}{c}{ Harris (\%) } \\
\cline { 2 - 5 } & $(77 / 5)^{\mathrm{a}}$ & $(78 / 4)^{\mathrm{a}}$ & $(78 / 12)^{\mathrm{a}}$ & $(80 / 11)^{\mathrm{b}}$ \\
\hline Conserve energy & 32 & 26 & 30 & 28 \\
Increase production & 41 & 46 & 57 & 17 \\
Technological breakthrough & $-\mathrm{c}$ & - & - & 47 \\
Both/all (volunteered) & 23 & 24 & 10 & 5 \\
Don't know/no answer & 4 & 4 & 3 & 3 \\
\hline
\end{tabular}

a"If you had to choose, which do you think should have the primary emphasis in dealing with the energy problem in this country--going all out to cut back the use of energy in the United States, or going all out to increase the production of energy in the United States?" [Harr is $(77 / 5 ; 78 / 4 ; 78 / 12)]$

b"If you had to say, which is more likely to improve the country's energy situation--an all-out effort to increase current energy production, a technological breakthrough that would provide new sources of energy, or a tough program to conserve energy?" [Harris $(80 / 11)]$

CNot asked. 
unspecified new technological developments rather than expanded reliance on existing energy sources and production methods. These results suggest considerable support for government efforts for increased energy production and development.

RAC and Cambridge have asked questions phrased in an extreme fashion on the production versus consumption issue. Trend data from 1971 through 1978 from RAC indicate a sharp decrease in support for "building as many new power plants as needed to let everybody use all the electricity they want," from over 60\% favorable in 1971 to about $35 \%$ favorable in 1978; the corresponding increase in support for reduced electricity consumption was from about $25 \%$ in 1971 to over $50 \%$ in 1978 (Figure 5.4). In addition, the percentage of the public considering the doubling of electricity usage in a ten-year period a bad thing has increased sharply, from approximately $25 \%$ in 1971-1973 to over $60 \%$ in 1976 and 1977 $[\operatorname{RAC}(77 / 8)]$. While these findings show a dramatic shift in public attitude after 1973, the year of the oil embargo, they primarily indicate a concern with unlimited energy consumption and a preference for reducing new plant construction, rather than a complete change from energy production to energy conservation support. Energy use is no longer seen as a good in itself, but as a problem.

Cambridge (78/6) posed a question with the opposite emphasis. Respondents were asked to agree or disagree with the statement: "We don't need any more power plants of any kind." Most of the public (64\%) disagreed, and only $20 \%$ agreed with this statement. Respondents with higher income and higher education disagreed most of ten. Thus, there appears to be majority support for an emphasis on energy production 


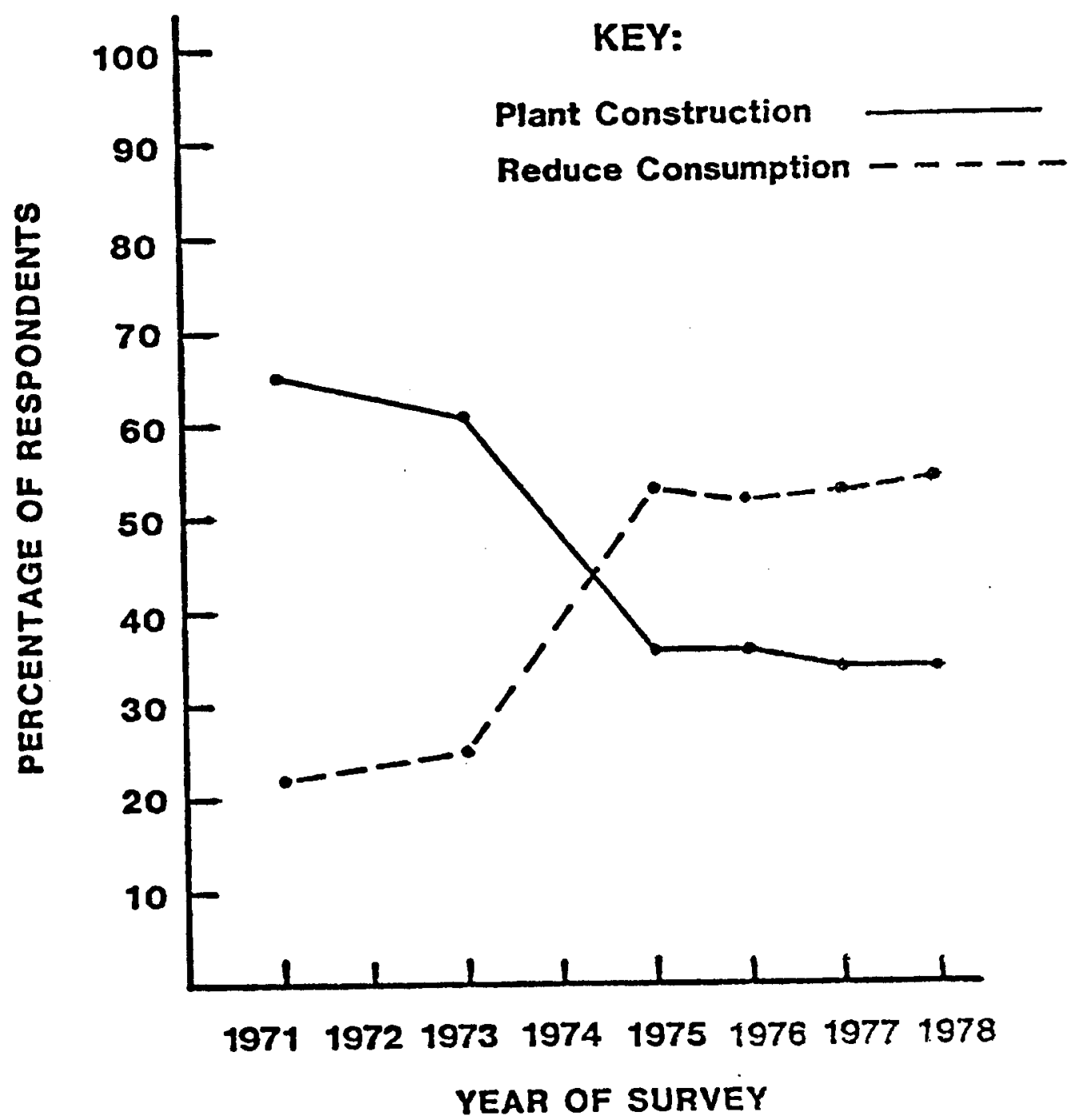

FIGURE 5.4 Construction Versus Conservation

NOTE: "Which of these two things do you think is better: to build as many new power plants as are needed to let everybody use all the electricity they want, or to try to limit or cut back the use of electricity so that fewer new power plants will have to be built?" [RAC (78/8)] 
approaches. There has been a dramatic shift, however, from a previous position of support for unlimited energy consumption to concern with limiting unnecessary energy use. Most of the public sees a need for construction of some new power plants. Public debate and controversy are likely to center on the extent of new energy development and the bases for determining what levels of energy consumption are necessary and desirable for American society.

\subsubsection{Energy Production Orientation and Nuclear Power Attitudes}

The examination of the relationship between energy production orientation and attitude toward nuclear power focuses on the extent to which support for any given energy production strategy is associated with support for development of other energy sources. Evidence that support for energy production measures in general is associated with favorability toward nuclear power is found in in surveys by Becker, Cambridge, and ARB. Becker $(74 / 5)$ found that almost $60 \%$ of nuclear power supporters approved of a local coal-fired power plant compared to only $33 \%$ of those opposed to nuclear power. As shown in Table 5.10, Cambridge (78/6) found that pronuclear respondents were significantly more supportive of all energy production approaches--including expansion of offshore oil drilling, conversion of utilities to coal, and increased strip mining--than were antinuclear respondents. Those unsure about nuclear power were generally least supportive of any of these other measures, primarily because they tended to be unsure about energy policy in general. Support for increased use of coal and favorability toward hydroelectric power plant construction were found to be significantly and positively related to favorability toward nuclear power, with correlation 
TABLE 5.10

ENERGY PRODUCTION FAVORABILITY BY GENERAL

ATTITUDE TOWARD NUCLEAR POWER

\begin{tabular}{|c|c|c|c|c|}
\hline \multirow{2}{*}{ Energy Production Measure } & \multirow[b]{2}{*}{ Total } & \multicolumn{3}{|c|}{ Nuclear Power Attitude (\%) } \\
\hline & & Favor & Oppose & Unsure \\
\hline Favor expansion of offshore oil drilling & 72 & 82 & 67 & 53 \\
\hline $\begin{array}{l}\text { Favor conversion of electric utilities } \\
\text { to coal }\end{array}$ & 27 & 37 & 19 & 13 \\
\hline Favor increased strip mining for coal & 25 & 34 & 17 & 12 \\
\hline
\end{tabular}

NOTE: "Do you favor or oppose each of the following measures? Expand off shore drilling for $0 i 1$; increase strip mining for coal even if it damages the environment; construction of more nuclear power plants; conversion of electric utilities to coal even if it means dirtier air." [Cambridge $(78 / 6)]$ 
coefficients of .22 and .24 respectively. Similar results were obtained in an analysis of survey data collected by ARB (80/11). Acceptance of construction of a local nuclear power plant was positively related to construction of other types of power plants (see Table 5.11). Correlation coefficients between attitude toward nuclear power and attitude toward other energy sources ranged between .22 and .26, and all were significant at the .001 level. While the correlation coefficients indicate a weak to moderate association, there is evidence that an energy production orientation is consistently and positively related to support for nuc lear power development.

\subsubsection{Summary}

There is considerable evidence that the majority of the public supports an energy production emphas is in Federal energy policy. Approximately one-third of the public prefers a conservation emphasis. There has been a dramatic shift in public assessment of high growth rates in energy consumption, from majority approval prior to the 1973 oil embargo to majority opposition since that time.

Orientation toward an energy production emphas is is related to attitude toward nuclear power. Respondents supportive of nuclear energy are also more favorable toward other energy production alternatives than respondents who disapprove of nuclear power. This finding suggests that concern for energy production is one element in understanding nuclear power attitudes. There is no evidence of a sharp division between supporters of nuclear power and supporters of other options, such as coal and solar energy. Proponents of nuclear power development also tend to be proponents of the development of alternative energy sources. 
TABLE 5.11

SUPPORT FOR ENERGY SOURCES BY ATTITUDE TOWARD LOCAL NUCLEAR POWER PLANT CONSTRUCTION

\begin{tabular}{|c|c|c|c|c|c|}
\hline \multirow{2}{*}{ Energy Source } & \multirow[b]{2}{*}{ Total } & \multicolumn{4}{|c|}{ Nuclear Power Attitude (\%) } \\
\hline & & Favor & Oppose & Unsure & $\begin{array}{l}\text { Correlation } \\
\text { Coeffic ient }\end{array}$ \\
\hline $\begin{array}{l}\text { Accept coal-fired plant } \\
\text { Accept hydroelectic }\end{array}$ & 60 & 79 & 53 & 53 & .25 \\
\hline power plant & 82 & 89 & 82 & 67 & .22 \\
\hline $\begin{array}{l}\text { Accept oil-fired plant } \\
\text { Accept natural gas-fired }\end{array}$ & 44 & 55 & 39 & 42 & .24 \\
\hline plant & 63 & 71 & 61 & 57 & .22 \\
\hline Accept solar energy plant & 86 & 91 & 87 & 67 & .26 \\
\hline
\end{tabular}

NOTE: "Suppose a new power plant had to be built in this area. For each of these ways of producing electricity, please tell me whether it would be all right with you if this method were used in this-area, or whether you would be against it in this area: nuclear power; coal; water or hydro power; 0i1; natural gas; solar energy." [ARB (80/11)] 


\subsection{Environmental Priorities}

\subsubsection{Introduction}

Because energy production of ten involves risks to the environment, we expect that attitudes toward environmental issues in general will influence public attitudes toward nuclear power. In addition to beliefs about environmental consequences of specific energy sources, which were discussed earlier in this chapter, the overall priority of environmentalism is likely to be associated with acceptance of nuclear power and other energy production strategies. In this section we examine general trends in public concern with environmental issues, consider public responses to trade-offs between environmental protection and economic concerns and energy supply, and then examine the relationship between environmental concern and evaluation of nuclear power.

\subsubsection{General Trends in Environmental Concern}

There continues to be a high level of support for protection of the environment. While there has been some decrease from the early 1970s in the level of public concern over water and air pollution in the late 1970s, less than $20 \%$ of the public favors relaxation of regulations for control of water and air pollution. Figure 5.5 shows trend data from Harris $(75 / 4 ; 76 / 7 ; 79 / 10)$, Potomac $(72 / 6 ; 74 / 4 ; 76 / 5)$, and RFF $(80 / 1)$, which indicate the extent to which respondents perceived air and water pollution to be serious problems. Concern over air pollution decreased from $57 \%$ considering such pollution very serious in 1975 to $43 \%$ selecting that response in 1979 [Harris $(75 / 4 ; 79 / 7)]$; the percentage of the public concerned a great deal over air pollution and over water pollution 


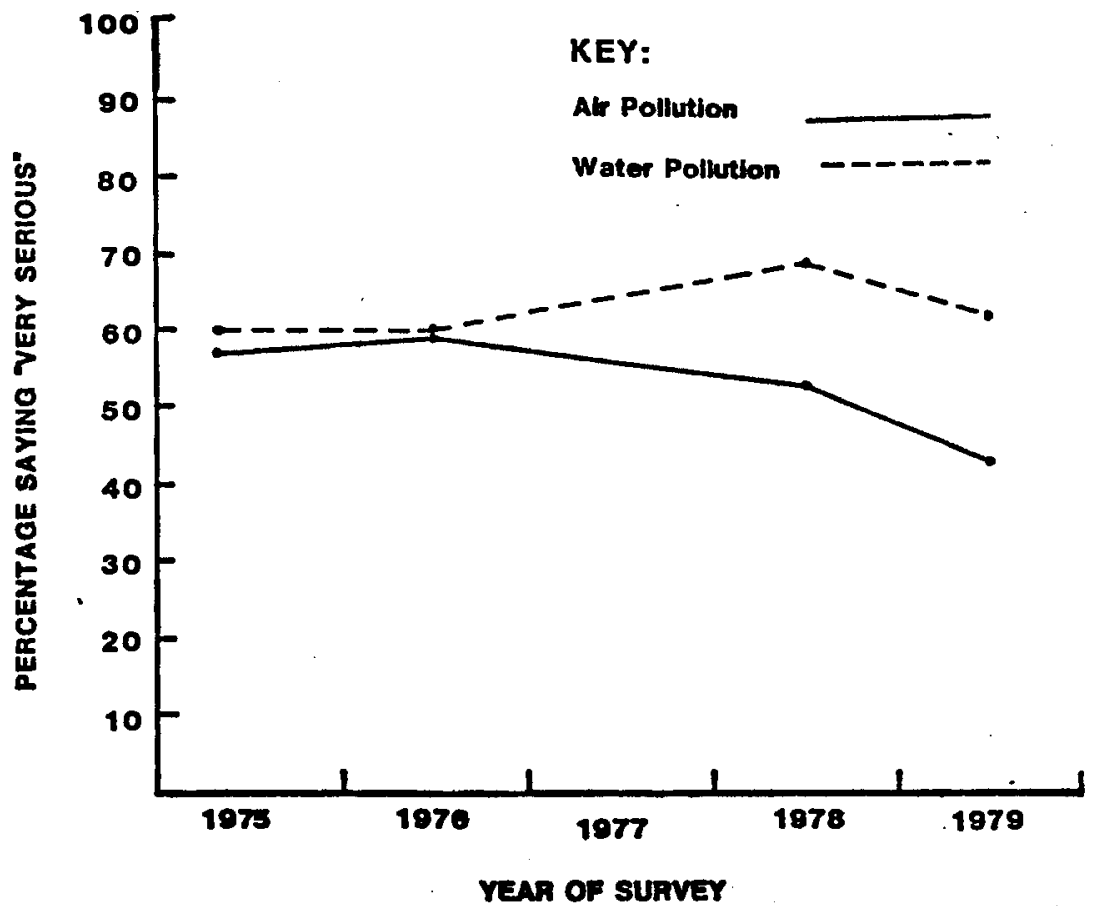

NOTE: "I'm going to read you some different kinds of environmental problems. For each, would you please tell me if it is a very serious problem, a somewhat serious problem, only a smal1 problem, or no problem at all in this country?" [Harris $(75 / 4 ; 76 / 7 ; 79 / 4)$ ]

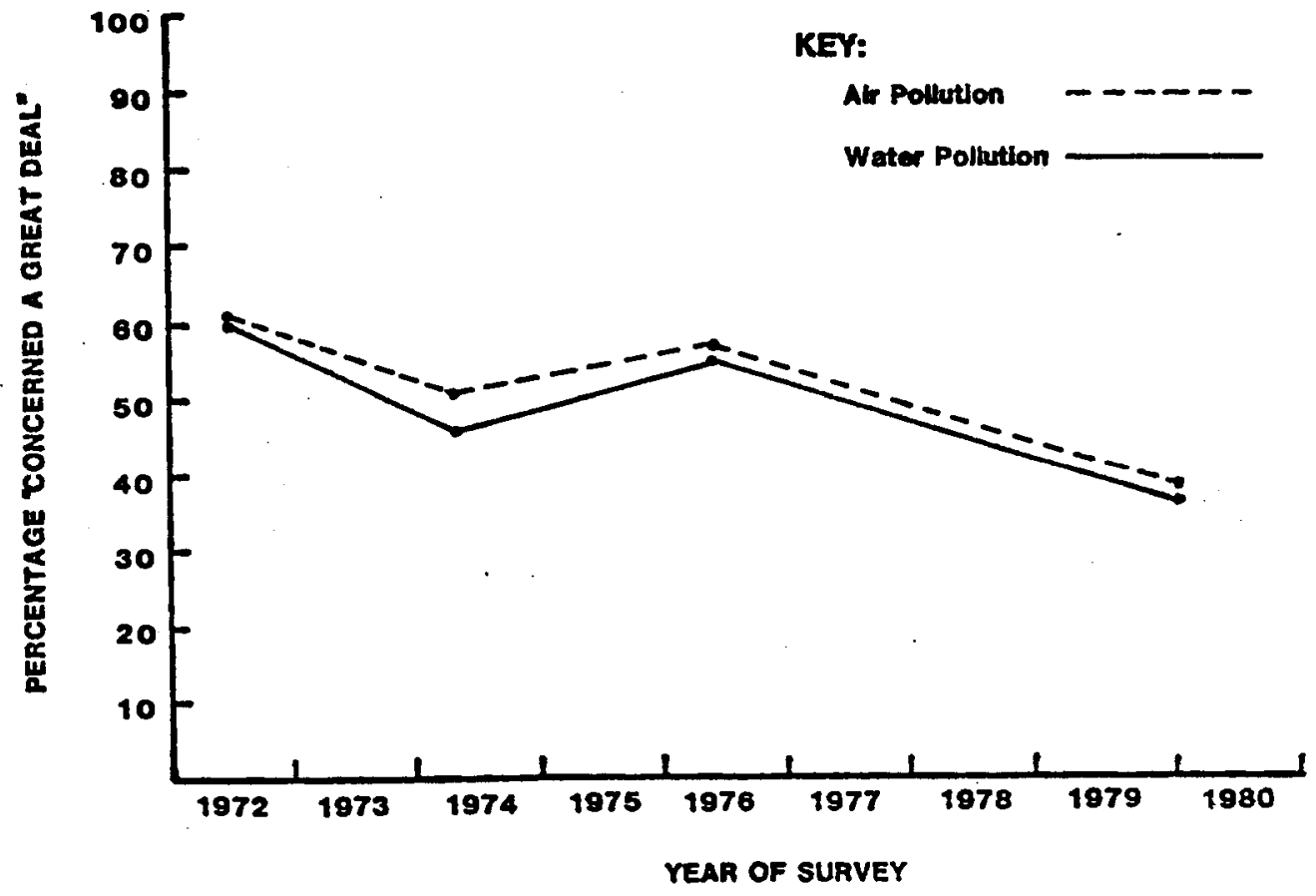

FGUPE 5.5 Trends in Public Concern About Air And Water Pollution

NOTE: "Now, I'd like to find out how worried or concerned you are about a number of problems I'm going to mention: a great deal, a fair amount, not very much, or not at all. If you aren't really concerned about some of these matters, don't hesitate to say so. Cleaning up our waterways and reducing pollution? Reducing air pollution?" [Potomac $(72 / 6 ; 74 / 4 ; 76 / 5)$ and $\operatorname{RFF}(80 / 1)]$ 
decreased from $61 \%$ and $60 \%$ in 1972 to $38 \%$ and $36 \%$, respectively, in 1980 [Potomac (72/6) and RFF (80/1)]. However, these results do not appear to indicate the public is ready to accept a reduction in the level of environmental protection effort by the government. Data from Seasonwein $(79 / 9)$ and harris $(81 / 5)$ show that $76 \%$ to $93 \%$ of the public consider current regulations sufficient or not strict enough, while between $4 \%$ to $18 \%$ of the public believe that these laws are overly protective (see Table 5.12).

\subsubsection{Conflicts between Environmental Protection}

The public's perceptions of the costs of maintaining and improving environmental quality have been investigated by a number of survey organizations during the past several years. Trend data from Cambridge $(78 / 6)$ indicate that close to half of the public $(50 \%$ in $1976,44 \%$ in 1977, and $47 \%$ in 1978) did not believe that economic growth necessarily conflicted with environmental quality. Between 1976 and 1978 there was a slight rise from $23 \%$ to $30 \%$ in the percentage of the public believing that economic growth and environmental quality conflicted and that one could only improve at the expense of the other. Seasonwein (79/9) found that $41 \%$ of respondents thought that environmental protection laws hold down economic growth; $25 \%$ thought they help such growth. Newsweek (81/6) reported $75 \%$ of the public agreed and $17 \%$ disagreed with a statement that , the United States could have strong economic growth and maintain high environmental standards.

When asked to choose between environmental quality and economic growth [Cambridge $(78 / 6)$ ] (see Table 5.13 ), 37\% chose environmental 
TABLE 5.12

ASSESSMENT OF NEED FOR CHANGE IN ENVIRONMENTAL PROTECTION REGULATIONS

\begin{tabular}{|c|c|c|c|c|}
\hline Environmental Regulation & More Strict & Just Right & Less Strict & Don't know \\
\hline \multicolumn{5}{|l|}{ Air Pollution } \\
\hline $\begin{array}{l}\text { Regulations in generala } \\
\text { Health standards } \\
\text { Clean Air ActC }\end{array}$ & $\begin{array}{l}52 \% \\
40 \\
38\end{array}$ & $\begin{array}{l}29 \% \\
38 \\
48\end{array}$ & $\begin{array}{l}15 \% \\
18 \\
12\end{array}$ & $\begin{array}{l}4 \% \\
4 \\
2\end{array}$ \\
\hline \multicolumn{5}{|l|}{ Water Pollution } \\
\hline $\begin{array}{l}\text { Regulations in generald } \\
\text { Health Standards }{ }^{\mathrm{a}} \\
\text { Clean Water ActC }\end{array}$ & $\begin{array}{l}60 \\
48 \\
52\end{array}$ & $\begin{array}{l}28 \\
43 \\
41\end{array}$ & $\begin{array}{l}8 \\
6 \\
4\end{array}$ & $\begin{array}{l}4 \\
3 \\
3\end{array}$ \\
\hline
\end{tabular}

a"Is it your feeling that the types of regulations of water pollution (air pollution) should be made more strict, made less strict, or kept about the way they are now?" [Seasonwe in (79/9)]

b"Do you think that federal air (water) pollution standards are overly protective of people's health, not protective enough, or just about right?" [Harris $(81 / 5)]$

C"Next year Congress will reconsider the Clean Air Act (Clean Water Act). Given the costs involved in cleaning up the environment, do you think Congress should make the Clean Air Act (Clean Water Act) stricter than it is now, keep it about the same, or make it less strict?" [Harris (81/5)] 
TABLE 5.13

ECONOMIC GROWTH VERSUS ENVIRONMENTAL QUALITY

\begin{tabular}{lccc}
\hline \multirow{2}{*}{$\begin{array}{c}\text { Belief in } \\
\text { Trade-off }\end{array}$} & \multicolumn{2}{c}{ Forced } & Choice Preference (\%) \\
\cline { 2 - 4 } & $\begin{array}{c}\text { Sacrifice } \\
\text { Environment }\end{array}$ & Unsure & $\begin{array}{c}\text { Sacrifice } \\
\text { Economic Growth }\end{array}$ \\
\hline Total (100\%) & 23 & 39 & 37 \\
$\begin{array}{l}\text { Can have both economic growth } \\
\text { environmental quality (47\%) }\end{array}$ & 30 & 37 & 33 \\
Unsure (23\%) & 11 & 77 & 12 \\
Must sacrifice one (30\%) & 22 & 17 & 60 \\
\hline
\end{tabular}

NOTE: "Which of these two statements is closest to your opinion: there is no relationship between economic growth and the quality of the environment--indeed, we can have more and more goods and services and also a clean world; or we cannot have both economic growth and a high level of environmental quality, we must sacrifice one or the other." "Which of these two statements is closer to your opinion: we must be prepared to sacrifice environmental quality for economic growth; we must sacrifice economic growth in order to preserve and protect the environment." [Cambridge (78/6)] 
quality, $23 \%$ chose economic growth, and $39 \%$ were unsure. The very large percentage of don't know responses is unusual; in these surveys, don't know responses usually range from $15 \%$ to $20 \%$. Even among the highly educated and high income groups (those most likely to take a position on issues), about one-third were unsure. These findings suggest that the trade-off is a very difficult one, and that there is considerable ambivalence on this issue. Those who thought that the United States could have both environmental quality and economic growth were evenly split when forced to choose between the two (30\% preferring economic growth, $33 \%$ preferring environmental protection, and $37 \%$ unsure), while there was a clear preference for environmental protection at the expense of economic growth among those who thought a trade-off was necessary $60 \%$ for protection, $22 \%$ for growth, $17 \%$ unsure).

RFF $(80 / 1)$, which asked respondents to choose between three viewpoints on this issue, reported $39 \%$ of the public thought that economic growth and environmental protection were not in conflict, $20 \%$ thought environmental standards should be lowered to achieve economic growth, and $27 \%$ thought there should be a slower rate of economic growth to protect the environment.

There is a wide split within the public over willingness to pay for environmental protection. Harris $(78 / 10)$ reported $45 \%$ of respondents favored enforcing the toughest environmental standards in spite of cost; $36 \%$ favored lowering standards to reduce costs. Support for relaxing standards increased with age, from $26 \%$ among 18-29 year olds, to $35 \%$ among 30-49 year olds, to $44 \%$ among those 50 years of age or older. RFF $(80 / 1)$ found $42 \%$ support for improving environmental protection 
regardless of cost; $47 \%$ were more concerned with holding down costs than increasing environmental standards. In response to specific proposals, YS\&W (78/unk.) found from 1974 through 1978 approximate $1 y 35 \%$ to $40 \%$ of the public unwilling to pay higher electricity prices for better pollution control of power plants; approximately $20 \%$ of the public approved of increased costs. A study of several communities across the country by SRL $(76 / 6)$ found that respondents who were younger (under age 30) and those who had higher income or educational levels were most willing to pay increased prices (an additional 10\% to $25 \%$ ) for pollution-free energy. Residents from the West (Washington and Wyoming) were also more supportive of price increases than those from the Midwest (Michigan and I1linois). Newsweek (81/6) found $42 \%$ support and $53 \%$ opposition to relaxing emission control standards on automobiles in order to reduce prices. Thus, there is no clear-cut public mandate either to accept higher costs to improve environmental quality or to reduce such protection in order to lower prices.

\subsubsection{Energy Supply Versus Environment Trade-offs}

As with the question of a potential conflict between economic growth and environmental protection, there has also been debate concerning whether a conflict necessarily exists between energy supply and the maintenance of strict environmental standards. Harris (79/4c) found that $25 \%$ of the public thought restrictive Environmental Protection Agency regulations were a very important reason for current energy problems. This was the lowest percentage selection among the eleven reasons for current energy problems provided to respondents.

Assuming a conflict does exist, Roper $(77 / 9 ; 79 / 9)$ data indicate 
that the public has been split over whether energy needs or environmental protection should receive higher priority, with preference for an energy supply emphasis ranging from $33 \%$ to $47 \%$ and for an environmental protection emphasis ranging from $34 \%$ to $44 \%$ (see Figure 5.6 ). Support for increasing the energy supply was the highest during the oil embargo of 1973 and following the severe winter of 1977.

Data concerning trends in public willingness to relax pollution control efforts because of energy problems are conflicting. Harris (78/10) reports increasing support for relaxing such standards. In 1975 and 1976 only about $25 \%$ of the public favored this approach and $65 \%$ to $70 \%$ were opposed, but in $1978,45 \%$ were supportive compared to $42 \%$ opposed. However, findings reported by RAC (78/8) and RFF (78/8) indicate greater support for environmental protection than found by Harris. RAC (78/8) reported $51 \%$ of the public preferred to keep current pollution laws in spite of electricity shortages; $40 \%$ preferred relaxing pollution laws to assure an adequate energy supply. RFF (78/8) found $47 \%$ of the public supportive of protecting the environment and $31 \%$ favorable to energy production in a similar direct trade-off question. Gallup (79/7) reported majority support (55\%) for relaxing environmental protection laws in order to increase energy production. Harris (79/3; 79/4) also found majority support for specific energy measures that would increase air pollution, though wording of the question does not specifically refer to any environmental consequences. Approximately $60 \%$ of the public favored relaxing environmental controls to allow cars to use less lead-free gasoline and to allow electric power plants to use more high-sulfur oil and coal. Harris (78/4) results concerning public 


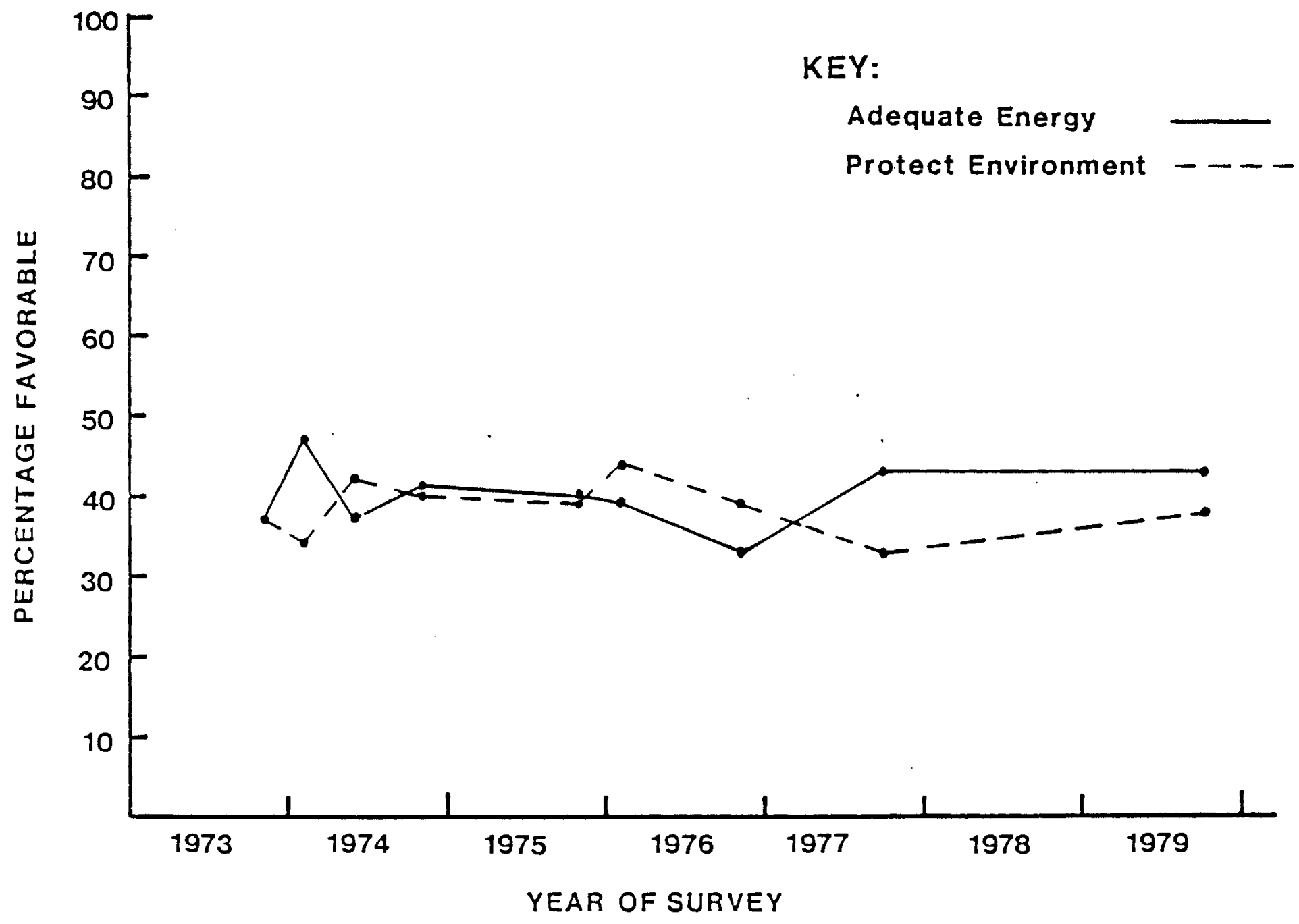

FIGURE 5.6 Energy Versus Environment

NOTE: "There is continuing talk about an energy crisis and the idea that there won't be enough electricity and other forms of energy to meet consumer demand in the coming years. Some people say that the progress of this nation depends on an adequate supply of energy and we have to have it even though it means taking some risks with the environment. Others say the important thing is the environment, and that it is better to risk not having enough energy than to risk spoiling our environment. Are you more on the side of adequate energy or more on the side of protecting the environment?" [Roper (76/10; $77 / 9)]$ 
approval of use of high-sulfur fuel ( $34 \%$ favorable and $52 \%$ opposed) were significantly different from the Harris $(79 / 3 ; 79 / 4)$ findings of $60 \%$ support. The question wording in Harris (78/4) specified "relax emission standards for power plants" rather than "allow power plants" to burn high-sulfur fuels, which may account for the discrepancy. UM $(80 / 1$; $80 / 4)$ found $39 \%$ and $45 \%$, respectively, of the public against relaxation of environmental regulations, even if it would hurt energy production. Approximately $15 \%$ of the public would approve of such relaxation with qualifications, and $35 \%$ and $27 \%$, respectively, would approve in general with this approach. The most recent data available, Newsweek (81/6), showed $55 \%$ disagreement and $36 \%$ agreement with a proposal to slow down environmental protection efforts to help solve energy problems.

In interpreting these various findings over the past several years, the evidence indicates the difficulty of choosing between the desire for a high level of environmental quality and the concern with sufficient energy supplies. Fluctuation in public preference appears to be related to specific energy situations, such as the $0 i 1$ embargo, natural gas shortage, and gasoline supply disruption. There does appear to be a recent shift toward support for energy production, and a greater willingness than in earlier years to relax some environmental controls. However, there is still a wide split within the public on this issue, and no clear trend has been established.

\subsubsection{Environmental Orientation and Nuclear Power Attitudes}

The examination of the relationship between attitude toward nuclear power and degree of environmental concern indicates a consistent pattern, with those most concerned with environmental protection less positive 
toward nuclear power. The positions of pro and antinuclear individuals within the general public on a range of environmental questions are presented in Table 5.14. Those who are opposed to further nuclear power plant construction generally are more supportive of efforts for air and water pollution control, less likely to believe that environmentalism is harmful to the economy, and less likely to agree that there has been an undue emphasis on ecological issues [Cambridge (78/6)]. Similarly, analysis of ARB $(80 / 11)$ data found antinuclear respondents more likely to select environmental pollution as a problem needing immediate action than pronuclear respondents ( $40 \%$ relative to $31 \%$ ).

Cambridge (78/6) found less difference between pro and antinuclear respondents regarding the issue of trade-offs between environmental protection and economic growth. A higher percentage of antinuclear individuals (45\%) relative to pronuclear individuals $(36 \%)$ favors sacrifices in economic growth in order to protect the environment, but over one-third of both groups is. unsure about which choice to make. This is in contrast to the findings concerning energy and environment trade-offs, where differences between pro and ant inuclear positions were much greater (see Figure 5.3). While the findings are consistent across a range of environmental issues, the differences are not great. This suggests a definite, but moderate, association between attitude toward nuclear power and environmental orientation.

\subsection{Beliefs about Growth and Scarcity}

\subsubsection{Introduction}

Concern over growth and availability of resources, particularly energy, have often been assumed to be related to attitude toward nuclear 
NUCLEAR ATTITUDES AND ENVIRONMENTAL CONCERNS

\begin{tabular}{|c|c|c|c|c|}
\hline \multirow{2}{*}{ Environmental Issue } & \multirow[b]{2}{*}{ Total } & \multicolumn{3}{|c|}{ Nuc lear Attitude (\%) } \\
\hline & & Pronuclear & Antinuclear & Unsure \\
\hline \multicolumn{5}{|l|}{ Economic Growth/Environment Tradeoff } \\
\hline Can have both & 46 & 52 & 46 & 34 \\
\hline Must sacrifice one & 30 & 30 & 31 & 26 \\
\hline \multicolumn{5}{|l|}{ Forced Choice } \\
\hline Favor economic growth & 23 & 29 & 20 & 14 \\
\hline Unsure & 40 & 35 & 35 & 59 \\
\hline Favor environment & 36 & 36 & 45 & 27 \\
\hline \multicolumn{5}{|l|}{ Pollution Control Efforts } \\
\hline Favor more air pollution control efforts & 64 & 61 & 74 & 58 \\
\hline Favor more water pollution control efforts & 72 & 72 & 79 & 61 \\
\hline \multicolumn{5}{|l|}{ Environmentalists Hurt the Economy } \\
\hline $\begin{array}{l}\text { Agree } \\
\text { Disagree }\end{array}$ & $\begin{array}{l}28 \\
51\end{array}$ & $\begin{array}{l}34 \\
50\end{array}$ & $\begin{array}{l}26 \\
62\end{array}$ & $\begin{array}{l}17 \\
41\end{array}$ \\
\hline \multicolumn{5}{|l|}{ Too Much has been Made of Ecology Issue } \\
\hline Disagree & 44 & 42 & 55 & 34 \\
\hline
\end{tabular}

NOTE: "Do you generally favor or oppose construction of more nuclear power plants? Which of these two statements is closest to your opinion: there is no relationship between economic growth and the quality of the environment--indeed, we can have more and more goods and services and also a clear world; or we cannot have both economic growth and a high level of environmental quality; we must sacrifice one or the other." "Which of these two statements is closer to your opinion: we must be prepared to sacrifice environmental quality for economic growth; don't know, we must sacrifice economic growth in order to preserve and protect the environment." Tell me... whether you would like to see more effort, less effort, or ... the same... effort directed to each area of concern: air pollution, water pollution." "Do you agree or disagree with the following statements: environmentalists are hurting the economy; I think too much has been made of the whole ecology issue and that the situation is not as bad as a lot of people believe."

$[$ Cambridge $(78 / 6)]$ 
power. Both beliefs--whether or not there is an energy shortage--and value positions--whether or not economic growth is positive--could influence support and opposition to nuclear power. Those who perceive a need for a larger energy supply have been expected to be more supportive of nuclear power development. It also has been argued that opponents of nuclear power are against continued growth and development in general, which is one basis for opposition to nuclear power.

In this section we examine general trends in beliefs and attitudes concerning energy shortages and economic growth and assess the relationship between positions on these issues and attitude toward nuclear power.

\subsubsection{Beliefs about Energy Shortages}

Trend data from 1973 through 1981 concerning the public's belief about the seriousness of "the energy shortage" are presented in Figure 5.7. Data from Harris and Cambridge surveys generally are similar for the period between 1976 through 1978, for which data points from both survey organizations are available. While there is a considerable amount of fluctuation in public concern, there appears to be an overall trend toward a gradual increase in the percentage of the public who considers the energy shortage as very serious [Harris (78/10) and Cambridge (80/11; 81/6)]. Concern peaked between fall, 1979, and winter, 1980, but the level of public concern throughout 1980 and 1981 has been similar to or higher than during the 1973 period of the $0 i 1$ embargo, averaging 60\% in 1980 and 52\% in 1981 compared to 50\% in November, 1973. Residents of the West (Pacific Coast, Rocky Mountain, Southwestern and Plains states) were most likely to be concerned about energy shortages [Cambridge $(80 / 11)$ and 


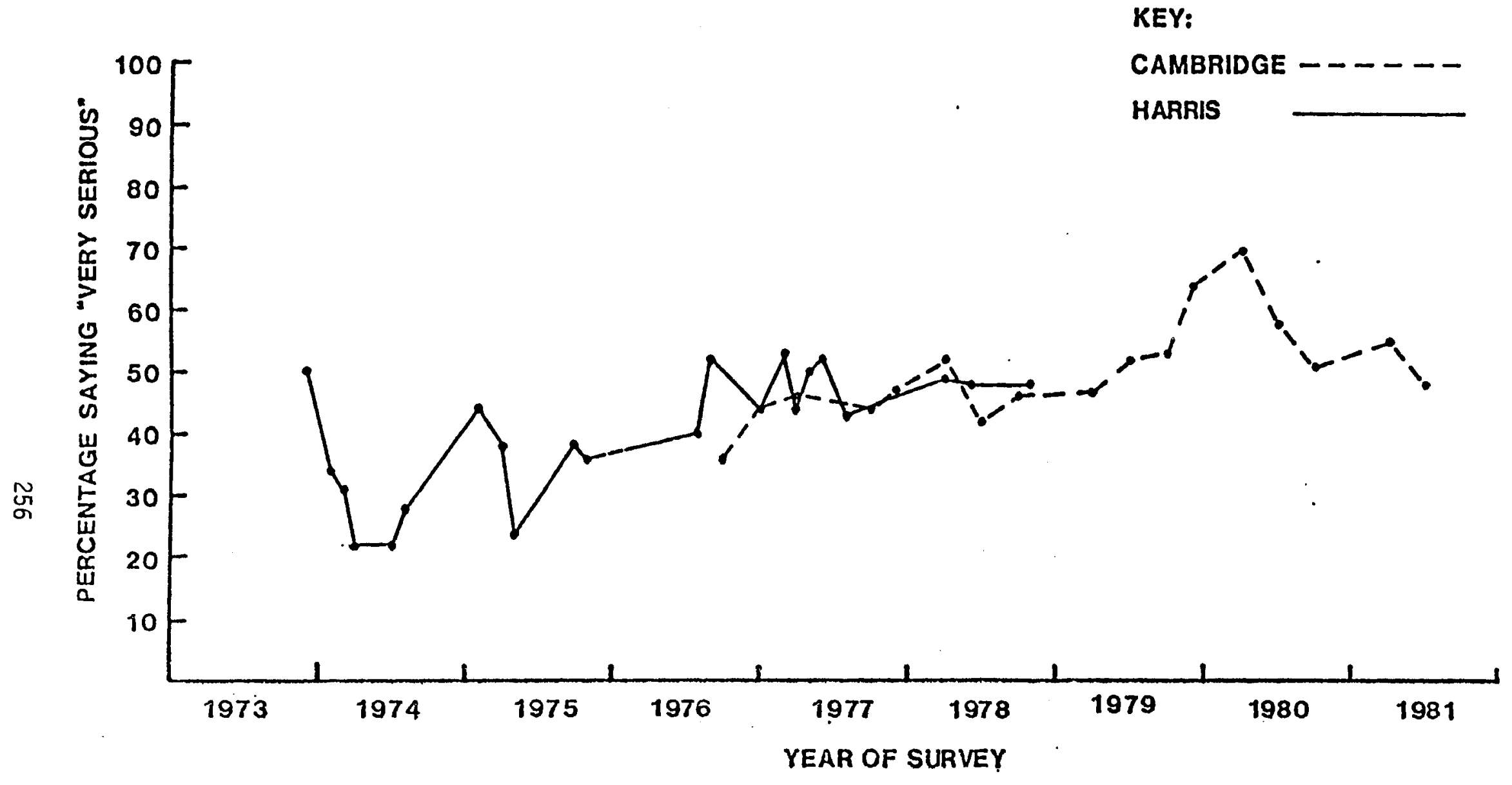

FIGURE 5.7 Serlousness Of The Energy Shortage

NOTE: "How serious do you feel the energy shortage is in this country--very serious, only somewhat serious, or hardly serious at all?" (Percentage selecting very serious.) [Harris (78/10)]

"How seriously do you view the energy problem: Not serious $1,2,3,4,5,6,7,8,9,10$ Very serious." (Percentage selecting $8,9,10$ on scale.) [Cambridge $(78 / 9 ; 79 / 9 ; 81 / 6)$ ] 
ARB $(79 / 7)]$. There also has been an increase in the percentage of the public who believes that shortages of energy and raw materials are a permanent and not a temporary situation. In $1975,28 \%$ of the public thought these shortages were permanent, while $60 \%$ felt they were temporary; by $1977,40 \%$ saw the shortages as permanent and $37 \%$ thought they were temporary [Cambridge $(77 / 6)]$. Residents of the Central region (Rocky Mountain, Southwestern, and Plains states) were most likely to consider this problem permanent; these are the states where national pressures for natural resource development and extraction may have a large impact on the regional population and environment.

The major concerns of the public in terms of energy problems are with higher prices and dependence on foreign countries, rather than with energy' supply shortages. Data from YS\&W (78/unk.) from 1976 through 1978 indicate increasing concern with both energy costs (from 63\% to 70\%) and foreign dependence (from 53\% to $63 \%$ ). Concern over shortages, both within the next two years and within 20 to 25 years, remained stable from 1976-1978, at about the $40 \%$ leve1. A further indication of the relative lack of concern over immediate shortage problems is seen in data spanning 1974 through 1978, which show that a substantial percentage of the public believed that the shortages of electricity (average of $57 \%$ ), gasoline (average of $60 \%$ ), heating $0 i 1$ (average of $50 \%$ ), and natural gas (average of $47 \%$ ) were exaggerated and were not serious. However, there is evidence of a significant increase in belief between 1978 and 1979 in the likelihood of an energy shortage in the next decade, while there was virtually no change in perceptions about the current energy situation in the United States. The percentage of respondents saying there was an 
energy crisis was $32 \%$ in 1978 and $37 \%$ in 1979. Belief that an electricity shortage was somewhat likely or very likely in the next ten years increased from $45 \%$ in 1978 to $65 \%$ in 1979 ; the percentage saying such a shortage was unlikely decreased from $48 \%$ to $29 \%$. In $1979,27 \%$ of the public believed a regional shortage of electricity was very likely in the next decade, and an additional $38 \%$ thought this was somewhat likely; again the highest levels of concern were found in the West (34\% very likely; $44 \%$ somewhat likely) $[\operatorname{RAC}(78 / 8)$ and $\operatorname{ARB}(79 / 7)]$.

\subsubsection{Relationship Between Belief about Energy Shortage and Nuclear Power Attitude}

Beliefs about the seriousness of the energy shortage have not been found to be related to attitudes toward nuclear power. Empirical evidence has not supported the hypothesis that greater concern about or belief in an energy crisis is positively related to support for nuclear power development. Secondary analys is of data tapes from Cambridge $(78 / 9)$ and ARB $(80 / 6)$ found no significant relationship between concern over the energy situation and attitude toward nuclear power; the correlation coefficients between positions on these two issues were .02 and .01 , respectively. Both pro and antinuclear respondents are equally likely to consider the energy shortage as very serious. Those who are unsure about nuclear power development are least likely to believe that the energy shortage is very serious. This finding is probably due to those who are unsure taking a middle ground as opposed to a strong position on most questions. 


\subsubsection{Beliefs and Attitudes about Economic Growth}

There is some indication of a recent decline in the belief that high levels of economic growth are necessary for the United States. However, there is considerable support in all segments of the American public for some level of continued economic growth. For example, $\operatorname{RAC}(78 / 8)$ found that one-quarter of the public favored the economy growing as fast as it can; about half of the respondents preferred reducing the rate of growth somewhat; and 10\% supported a very sharp decline or a no growth economy. In a series of questions assessing attitudes toward economic growth, Cambridge $(78 / 6)$ found similar results. Between $45 \%$ to $50 \%$ of respondents between 1975 and 1978 felt it would be better to stop the frantic pace of growth, but a majority of the public thought that economic growth is the only way ordinary people can get ahead in this society, and approximately $45 \%$ thought that there would be a negative personal impact if there was a slowdown in economic growth. Seasonwein (79/9) found that $41 \%$ of the public favored the economy growing a great deal or a good deal, 42\% a fair amount, and 13\% not too much or not at all.

There appears to be a great deal of indecision or ambivalence about the necessity of rapid economic growth. The high percentage of respondents unwilling to choose between environmental quality and economic growth was noted earlier. Those who believe there is not an inherent conflict between these two are evenly split when forced to choose; those who think a trade-off is necessary show a clear preference for environmental protection. When Cambridge (77/11) asked whether economic growth is necessary to improve the position of low income 
individuals or whether redistribution of current resources could be sufficient, about $45 \%$ of the public said growth is necessary and $33 \%$ said redistribution would work. Seasonwein (79/9) reported that $56 \%$ of the public believed that economic growth improves the average person's living standard, and $49 \%$ believed that such growth helps their own personal economic situation.

\subsubsection{Relationship Between Attitude Toward Economic Growth and Nuclear Power}

There is some evidence that individuals favorable to nuclear power are slightly more positive toward economic growth than those opposed to nuclear power plant construction, but the differences are small. An anlysis of the Cambridge (78/6) survey found that $39 \%$ of pronuclear respondents compared to $29 \%$ of ant inuclear respondents were very positive towards economic growth (agreed that economic growth is the only way ordinary people can get ahead, is the foundation of our social and political system, and that a slowdown of such growth would hurt their own personal chances for economic betterment.). The correlation coefficient between attitude toward economic growth and attitude toward nuclear power was .10 , indicating a significant but weak relationship.

\subsection{Summary}

Compared to other energy resources, solar energy continues to receive the greatest support from the general public. It is believed to be the safest and least environmentally damaging of all energy sources. While there is increasing awareness of high costs associated with solar development, it is not considered as expensive an energy source as 
nuclear power. Solar energy is considered the best source for the United States for the future by the largest segment of the public.

Nuclear power is believed to be a highly available energy source and is generally believed to be nonpolluting. However, it is considered the least safe energy source and one of the most expensive sources after oil.

Acceptance of coal has been increasing since the early 1970s. It is now generally at least as acceptable as nuclear power, while previously it was one of the least preferred energy sources. Public awareness of the domestic availability of coal has increased over the past few years, and coal is considered a good alternative in terms of cost. However, coal is believed to be one of the most environmentally damaging energy sources.

Public support for energy conservation has been very strong in recent years. Concern with the need for energy conservation has been growing, and there is considerable support for government programs in this area. There has been an increase in investments in energy efficiency, such as in the purchase of smaller cars and household insulation. However, there is little evidence of significant conservation behavior in terms of changes in daily energy use patterns beyond lowering household temperatures and turning off lights. While mandatory conservation programs are not widely supported, favorability toward such requirements has been increasing. In addition, a majority of the public definitely prefers rationing and distribution rules to pricing mechanisms to reduce energy demand.

There is considerable favorability toward increasing energy production, particularly during periods of acute energy shortages, such 
as gasoline and natural gas supply disruptions. However, there has been a definite shift from support for unlimited energy growth and consumption, which was the majority position as late as 1973, to a concern for reducing unnecessary energy growth. Thus, while energy production is considered important, the justification of the need for additional power plants is likely to be under greater scrutiny than in the past.

There is evidence of a gradual increase in the belief that there is a serious energy shortage, and an increase in the belief that such shortages will be a permanent problem. The greatest concern of the public, however, is with the price of energy rather than with supply availability.

Support for environmental protection has remained high over the past several years. The public generally is concerned with maintaining and improving environmental quality. Although there has been a slight decline in concern over pollution in recent years, there is minimal support for reduction of the government's role in maintaining strict environmental standards. In terms of trade-offs between environmental quality and energy supply, there is some evidence in recent years of a greater willingness to relax environmental controls to improve energy availability under certain circumstances. In addition, there is only limited support for increasing current energy prices in order to reduce pollution associated with energy production.

There is general broad support for economic growth in the United States, but there has been less support for high rates of growth over the past few years. There is considerable ambivalence over the priority 
economic growth should receive when in conflict with environmental protection.

A number of these broader issues are related to general attitudes toward nuclear power. Degree of environmental concern and emphasis on increasing supply versus reducing demand approaches to energy problems both have been found to be significantly related to general nuclear power attitudes. Individuals who place a high priority on environmental protection or who emphasize reducing energy consumption rather than increasing energy production are more likely to be opposed to cont inued nuc lear power expansion than individuals who are less environmentally. concerned or who emphasize the need for energy production. There is a positive, though very weak, relationship between support of economic growth and support of nuclear power. Belief about the seriousness of the energy shortage, on the other hand, generally has not been found to be significantly related to one's general attitude toward nuclear power. 


\section{CHAPTER 6}

\section{SUMMARY AND CONCLUSIONS}

This final chapter briefly summarizes the major survey findings from the three preceding substantive chapters. For more complete summaries, the reader is referred to the summaries that are contained in those chapters. The conclusions that we draw from these findings follow. From Chapter 3, several important findings are apparent. Public acceptance of a nuclear power plant built near one's residence has declined steadily since the early 1970s, so that there is majority opposition to the concept. Despite this gradual change in attitude, public acceptance of the continued construction of nuclear power plants at a more general level (in the United States) remained positive and quite steady during the mid- and late 1970s until the TMI accident in April, 1979. Immediately following the TMI accident support decreased, uncertainty about taking a stand on nuclear power decreased, and opposition toward nuclear power increased. Although there has been some attitude rebound toward pre-TMI support and opposition levels, the return has not been complete. At this time, however, the percentage of the public who supports the continued building of nuclear power plants in the United States averages $5 \%$ to $10 \%$ more than the percentage of the public who opposes such construction.

It is important to note that men's and women's attitudes toward nuclear power were differentially affected by the TMI accident. While the attitudes of both groups changed following the TMI accident, women's attitudes changed much more dramatically in the antinuclear direction 
than did men's. In addition, while men's attitudes returned almost to pre-TMI levels, women's attitudes have not returned to pre-TMI levels over the two years post-TMI. Thus, the plurality to majority support for continued nuclear power plant construction still enjoys is composed of strong majority support on the part of men and minority support (plurality to majority opposition) on the part of women.

While public support for nuclear power has decreased as a result of the TMI accident, the public is not favorable to foregoing the nuclear option. This has been demonstrated both by other attitudinal questions and by 1980 state initiative votes. A series of questions have been asked to determine exactly what measures the public would accept regarding nuclear power. While a slight majority of the public favors cutting back on operations until certain safety questions are answered, a majority of the public is against prohibiting the construction of any more plants, and a large majority of the public is against shutting down all nuclear plants forever.

In addition, state initiatives that would greatly restrict nuclear power were generally turned down. Maine residents voted down an initiative that would have closed down Maine Yankee and prevented other nuclear power plants from being built. Missouri voters turned down an initiative that would have prohibited the operation of nuclear plants until a waste management facility was available--an initiative that would have prohibited the start-up of the Calloway plants. Finally, South Dakota voters turned down an initiative that would have severely restricted nuclear operations--uranium mining, plant construction and operation, and waste management. However, Oregon residents did pass an 
initiative that requires voter approval of new plants and a moratorium on the construction of new plants until a federal waste disposal facility is available. The outcomes of these state initiative votes were predictable on the basis of survey data collected before the initiative votes.

Chapter 4 discussed beliefs and attitudes about specific nuclear power issues. The first type of data analyzed was from volunteered responses to open-ended questions about nuclear power. When respondents were asked why they opposed nuclear power, what harmful consequences might come from building more power plants, and disadvantages of nuclear power, the majority of the responses dealt with safety-related issues. The safety-related issue volunteered most often dealt specifically with reactor accidents. Second highest mention was given to radiation hazards from normal operation conditions, and waste management concerns were voiced third.

When asked why they supported nuclear power, what benefits would come from building more plants, and advantages of nuclear power, the majority of the responses dealt with energy supply issues. The public believes that there is a large supply of uranium within the United States and that this can fuel United States reactors for a long period of time. The related belief that these advantages help to free us from dependence upon other nations for our energy needs, especially for crude oil, is also believed to be a significant benefit of nuclear power. Finally, a small segment of the public volunteered the belief that nuclear power is cheaper than other types of energy.

When respondents volunteer concerns about nuclear power, reactor safety issues predominate the volunteered responses. However, when 
respondents are asked to make importance judgments regarding a list of nuclear issues, respondents show slightly more concern about nuclear waste management issues than reactor safety issues. Which is the most important issue? Regression analysis conducted on one of the national surveys found that reactor safety concerns were three to four times more important than nuclear waste concerns in affecting a respondent's attitude toward building a nuclear power plant within five miles of the respondent. Almost as strong a determinant of attitude as the safety belief was a respondent's belief about whether nuclear power is necessary to free us from Arab oil. Beliefs about government support of safety research and the regulation of safe operations also influenced local plant acceptance.

Numerous questions specifically about reactor safety have been asked by survey organizations. In general, the public is somewhat evenly split in its belief that reactors are safe or unsafe. However, the percentage of the public who were previously undecided about the reactor safety issue decreased in the late 1970s, while the percentage who believe that reactors are unsafe has increased. These changes were evident before TMI. A plurality to majority of the public still believes that a nuclear power plant can explode like an atomic bomb. Finally, the public believes that the government should help to ensure nuclear power plant safety.

Numerous survey questions were asked about the TMI accident, which is the largest nuclear safety-related accident ever to have occurred. Almost the total United States public was aware of the accident, and a majority were disturbed by the accident. The cause was believed to be 
mostly due to human error. A plurality of the public was satisfied with the way the accident was handled. A majority of the public believes that more such accidents are likely to happen. Despite concerns raised by the accident and by the ensuing Kemeny Commission report, a majority of the public believes that nuclear power plants are necessary and that operating plants should not be shut down, because these options would incur economic costs and increased risk.

Nuc lear waste management has been an important issue to survey researchers, so a large amount of survey data exist on this issue area. Public concern about nuclear waste management has increased during the late 1970s. On a general level a large majority of the public now says that it is concerned about waste management issues. On a comparative basis, however, the public believes that the disposal of toxic industrial chemicals is a more severe problem than the disposal of nuclear wastes. However, nuclear wastes are believed to be qualitatively different, and more risky, than typical industrial risks.

The public is about evenly divided in its belief as to whether an acceptable waste management disposal concept is or is not already available. However, a majority of the public believes that an acceptable solution will be found by the scientific and technical community. Public opposition to siting a high-level repository in one's state is much greater than public acceptance, although there is slight majority support for siting a small-scale demonstration facility in one's state. When asked to choose among different waste disposal techniques that had been certified as safe, the public showed greatest acceptance of above-ground storage at remote locations, followed closely by disposal in granite or 
in salt. United States leadership groups showed most favorability to granite disposal and salt disposal. Seabed disposal was uniformly the least popular disposal technique.

Other nuclear power issues have not received as much attention as reactor safety and nuclear waste management. Some data exist, however, regarding beliefs and/or attitudes about the uranium supply, reprocessing, the breeder reactor, the sale of reactors abroad and related proliferation considerations, and about the fairness and length of the process that utilities go through to plan, construct, and operate a nuclear facility.

As discussed earlier, nuclear fuel supply considerations are believed to be a major advantage of nuclear power. Before 1977, the public was uncertain about how large the United States uranium supply was. However, probably because of former President Carter's stand on proliferation and his remarks about the large United States uranium supply and on supplying nations with United States uranium to forego the need for reprocessing, by 1978 the public believed that an adequate supply of uranium existed for the near term. The public did not support the sale of United States uranium abroad, even to control proliferation.

A slight majority of the United States public favors reprocessing nuclear fuel rather than disposing of it, while a much larger majority of United States leadership groups favor reprocessing, except for enviromental leaders who oppose reprocessing. The main reasons found for supporting reprocessing are that it reduces the amount of nuclear wastes that need disposal and that it is economically attractive. Sabotage and 
terrorism concerns seem small enough so as not greatly to influence public attitudes toward reprocessing.

The public, at least through 1979, was largely unaware of the breeder reactor concept. There has been plurality public support for the concept, but there is a large amount of uncertainty about the breeder reactor. Many of the United States leadership groups support the breeder reactor--politicians, business leaders, regulators, labor leaders, and utility company leaders--while media leaders and environmental leaders strongly oppose the breeder concept.

The United States public generally does not favor the sale of United States reactors abroad, unless the foreign country is going to purchase a reactor from elsewhere regardless of the United States' position. About one-fifth of the public opposes reactor sales abroad because of specific concerns about nuclear weapons proliferation.

Planning and constructing a nuclear power plant in the United States has become a complex process. A majority of the public believes that the government should have some say as to the type of power plants that utilities build and where the plant can be sited. In the case of a siting conflict, the public believes that a specialized group of scientists and engineers is best qualified to settle the siting issue. A majority of the public believes that the United States is better off because of protest groups delaying nuclear power plant construction, and a plurality of the public believes that decisions to build nuclear power plants are done at about the right speed. However, a majority of the public greatly underestimates how long it takes to build a nuclear power plant and how much a delay eventually costs the consumer. When told that 
it takes over ten years to build a plant, a plurality of the public favored speeding up the process. However, the public was evenly divided as to whether the government should limit public participation to speed up the process or whether full public participation should be allowed. Chapter 5 placed public beliefs and attitudes about nuclear power within the contexts of public beliefs and attitudes about non-nuclear energy sources and about environment and growth issues. The public strongly supports the development of solar power. It is believed to be the safest and least environmentally damaging of the energy sources and is believed to be cheaper than nuclear power. However, public expectations regarding solar power are much more optimistic than are expert predictions. The public supports drilling for offshore oil more than it supports nuclear power plant construction. However, increased oil production is seen only as a short-term solution, while nuclear power is seen as a much better long-term energy supply.

Support for nuclear power has declined through the late 1970s relative to support for other energy options. Nuclear power is seen as a good long-term source that is relatively non-polluting, but compared to other energy sources, it is believed to be expensive and more risky. Support for coal, which was lower than support for nuclear power through most of the 1970s, is now equal to nuclear power in terms of general attitudes and is greater than support for nuclear power in terms of attitudes toward local power plant acceptance. Coal is seen as very polluting, but available and fairly inexpensive. However, the public does not believe that coal will play a long-term role in the United States energy future. 
The public is strongly behind energy conservation, in principle, as a means of reducing energy demand. However, the public does not strongly support energy conservation in practice. The public typically supports voluntary rather than involuntary conservation programs. However, compared to higher prices, the public would rather decrease energy use through regulations or even rationing.

Since the early 1970s there has been a gradual increase to a slight majority belief that there is a serious energy shortage. Even more of the public believes that there will be permanent, serious energy shortages in the future. The greatest public concern, however, has to do with the price of energy, not energy availability.

There is majority favorability toward increasing energy production, which is especially manifested during periods of energy shortages. However, there has been a shift from a majority belief in unlimited growth in energy production and consumption in the early 1970s to the present belief in reducing unnecessary energy production, especially for environmental reasons.

The public is generally concerned with maintaining and improving environmental quality. While support for environmental protection has remained somewhat stable over the past few years, there is some evidence that the public is more willing, as of late, to relax environmental controls to improve energy availability. While there is majority support for economic growth in the United States, there is general ambivalence over the priority that economic growth should receive when it conflicts with environmental protection. 
A number of these broad energy issues are related to one's attitude toward nuclear power. Those who indicate more concern about environmental issues and who emphasize conservation approaches over energy production approaches tend to be against nuclear power. Those who are less concerned about environmental issues and who believe in increasing the energy supply tend to favor nuclear power. Beliefs about the general energy shortage (as opposed to specific shortages caused by foreign energy suppliers) and attitudes toward economic growth, however, appear not to be related to attitudes toward nuclear power.

As we have shown, a lot of survey data are available that bear on the way that the public thinks about nuclear power and its continued development. Of importance now are the conclusions that can be drawn from these data that relate to the future of nuclear power development. First, we wish to draw the obvious, but very important conclusion that nuclear-related beliefs and attitudes can change. Attitudes toward local plant construction decreased gradually and significantly through the 1970s. Attitudes toward general nuclear power plant construction remained relatively stable, with minor fluctuations, until the TMI accident. At that time, especially women's attitudes toward nuclear power suddenly became, and have remained, significantly antinuclear. Thus, significant events have shown the ability to influence nuclear-related beliefs and attitudes.

This leads to a second, equally obvious conclusion that these beliefs and attitudes will likely change in the future if significant nuclear-related events occur. What might these events be and what effects would they likely have? Our research has shown that reactor 
safety concerns and energy supply concerns are the largest determinants of nuclear attitude. Thus, future reactor accidents could have further negative impact on public acceptance of nuclear power, especially if the accident were to occur within several years of the TMI accident. On the other hand, if no major reactor accidents occur over the next several years, the TMI accident may be gradually forgotten and belief in a history of safe reactor operation could increase. This change toward more positive attitudes would be even more likely to occur if two other events were to happen. One is that additional research be conducted on reactor safety, because the belief as to whether the government is acting to guarantee reactor safety is a secondary determinant of nuclear attitude. Second is that the government be perceived as strongly regulating the safe construction and operation of nuclear power plants, since this belief was also shown to be a secondary determinant of attitude toward nuclear power. With regard to safety-related beliefs and effects on nuclear attitude, we would have to conclude, however, that it would be much easier for nuclear attitudes suddenly to become significantly more antinuclear because of one large accident or a series of smaller accidents than it would be for nuclear attitudes to become significantly more pronuclear suddenly or as a longer-term result of safe operations coupled with strict regulation and safety-related research.

Sudden changes in a pronuclear direction are more likely to result from events related to energy supply, especially if the events are related to energy independence issues. Remember that one's nuclear attitude is not related to one's belief about whether a general energy shortage exists. However, one's nuclear attitude is related to energy 
shortage concerns if the shortages deal with a foreign country's manipulation of an energy supply to the United States' detriment. Thus, a United States coal miner's strike that shut down coal production would not likely change one's attitude toward nuclear power, but if another country withheld its usual supply of oil to the United States for political reasons or if oil prices were to take further large increases, then the public's attitude may become more pronuclear suddenly or gradually over a longer period of time.

Because of the way in which nuclear power is perceived relative to other energy sources, advances or lack thereof in the development of these sources could impact the relative favorability of nuclear power. If solar electricity production were to achieve technological breakthroughs with regard to cost, for example, so that it became cost-competitive with nuclear power, there appears to be little doubt that the solar option would be favored, unless other strongly negative conditions prevailed.

However, in the public's mind, coal plants and nuclear plants are most likely viewed as the two major power plant possibilities for present-day construction. In addition, public acceptance of coal plants has been increasing over the past several years while public acceptance of nuclear plants has been decreasing. Thus, events that would enhance public beliefs about coal plants would increase public acceptance of a local coal plant relative to acceptance of a local nuclear plant. Such enhancement could come through technological breakthroughs--for example, a low-cost desulphurization process--or through regulatory changes, such as lowering of air pollution standards that would make coal more 
economically attractive than nuclear power. On the other hand, technological discoveries or regulatory changes that would increase the safety or lower the cost of nuclear power relative to coal plants would increase nuclear power's relative attractiveness.

The preceding paragraph has speculated about future choices regarding the type of power plant acceptable to the public. What about the continued operation of existing nuclear power plants and the licensing and operation of plants already under construction? We conclude that the public has strongly indicated its attitude that operating plants should continue to operate. This attitude is likely held for two main reasons--that the energy is needed and that the economic investment is too important simply to discard. Thus, it is likely that the public holds almost the same attitude toward other nuclear plants that are well into the construction phase. This leads to the further conclusion that the larger the United States nuclear industry--both in terms of the relative amount of energy being produced and in terms of economic investment--the less likely that the public will be willing to forego totally the nuclear option.

What conclusions can be drawn about nuclear waste management? First, nuclear waste management issues seem to have little influence on one's attitude about allowing a nuclear plant to be built nearby. However, nuclear waste management issues have become very salient to the general public over the past several years as a general issue. This may be due to increased media coverage of waste issues during that time period. Regardless, it appears that nuclear waste management issues may be carefully followed by the public as an indicator of whether the 
government and the nuclear industry are capable of safely disposing of nuclear wastes. Since both nuclear supporters and opponents show strong concern about waste management issues, we conclude that it is more likely that nuclear supporters will become opponents if the waste management program is not implemented in a timely and safe fashion than it is likely that nuclear opponents will become supporters if the program is implemented in a timely and safe fashion.

Another conclusion that we can draw from our data is that the public still possesses little information or possesses misinformation about some areas of nuclear power. For example, not much is known by the public about the breeder reactor and reprocessing. If the government wishes to make publicly acceptable policy decisions in these areas, the public needs to be provided with information about the issues. Important misinformation exists about nuclear power, as is exemplified by plurality to majority public belief that a nuclear power plant can explode like an atomic bomb. Similar misinformation has been shown to exist with regard to the risks from nuclear waste management. Thus, we conclude that the public has not yet been adequately informed about nuclear power issues. 


\section{REFERENCES}

Dillman, D. Mail and telephone surveys: The total design method. Somerset, NJ: Wiley-Interscience, 1978.

Harris, L. Sharp increase seen in number of Americans who consider energy problem in U.S. very serious. ABC News-Harris Survey, 1(52) Apri1 30, 1979.

Insko, C. A. Theories of attitude change. Englewood Cliffs, NJ: PrenticeHal1, Inc., 1967.

Melber, B. D., Nealey, S. M., Hammersla, J., and Rankin, W. L. Nuclear power and the public: Analys is of collected survey research (PNL-2430). Battelle Human Affairs Research Centers, Seattle, WA 98105, November, 1977.

National Research Council (Council on Nuclear and Alternative Systems). Energy in transition 1985-2010. San Francisco: W. H. Freeman and Co., 1980.

Nealey, S. M. and Rankin, W. L. Nuclear knowledge and nuclear attitudes: Is ignorance bliss? (B-HARC-417-002). Battelle Human Affairs Research Centers, Seattle, WA 98105, October, 1978.

Rankin, W. L. and Nealey, S. M. The relationship of human values and energy beliefs to nuclear power attitudes (B-HARC-411-007). Battelle Human Affairs Research Centers, Seattle, WA 98105, November, 1978.

Rokeach, M. The nature of human values. New York: The Free Press, 1973.

Schulman, M. A. The impact of Three Mile Island. Public Opinion, June/July, 1979, pp. 7-9. 


\section{APPENDIX A}

DESCRIPTION OF SURVEYS BY IDENTIFICATION CODE, SAMPLE SIZE, AND RESPONSE MODE

\begin{tabular}{|c|c|c|c|}
\hline SURVEY IDENTIF ICATION & SURVEY ORGANIZATION & $\begin{array}{l}\text { APPROXIMATE } \\
\text { SAMPLE SIZE }\end{array}$ & $\begin{array}{l}\text { RESPONSE } \\
\text { MODE }\end{array}$ \\
\hline \multicolumn{4}{|c|}{ NATIONAL SURVEYS } \\
\hline $\begin{array}{l}\text { ARB (77/unk; 78/unk; 79/7; } \\
\quad 80 / 6 ; 80 / 11)\end{array}$ & $\begin{array}{l}\text { Associates for Research } \\
\text { in Behavior, Inc. }\end{array}$ & $900-1624$ & personal \\
\hline Becker $(73 / 6 ; 74 / 5 ; 74 / 6)$ & Becker Research Corporation & 1500 & personal \\
\hline $\begin{array}{l}\text { Cambridge }(1975 ; 75 / 4 ; 75 / 5 ; 75 / 8 ; \\
75 / 1 ; 75 / 12 ; 1976 ; 76 / 3 ; 76 / 4 ; \\
76 / 5 ; 76 / 7 ; 76 / 8 ; 76 / 10 ; 76 / 11 ; \\
76 / 12 ; 1977 ; 77 / 2 ; 77 / 3 ; 77 / 5 ; \\
77 / 6 ; 77 / 9 ; 77 / 11 ; 1978 ; 78 / 3 ; \\
78 / 5 ; 78 / 6 ; 78 / 7 ; 78 / 9 ; 78 / 10 ; \\
78 / 11 ; 79 / 3 ; 79 / 6 ; 79 / 5 ; 79 / 9 ; \\
79 / 11 ; 79 / 12 ; 80 / 3 ; 80 / 5 ; 80 / 8 ; \\
80 / 11 ; 81 / 3 ; 81 / 5 ; 81 / 6)\end{array}$ & Cambridge Reports, Inc. & $1500-2000$ & personal \\
\hline $\operatorname{CBS}(79 / 4 ; 79 / 5)$ & CBS News/New York Times & 1158 & telephone \\
\hline $\begin{array}{l}\text { Gallup }(76 / 6 ; 76 / 7 ; 77 / 2 ; 77 / 3 ; 79 / 4 ; \\
\quad 79 / 4 a ; 79 / 4 b ; 79 / 6 ; 79 / 7 ; 80 / 1)\end{array}$ & $\begin{array}{l}\text { Gallup Opinion Index; Gallup } \\
\text { Poll }\end{array}$ & 1500 & personal \\
\hline $\begin{array}{l}\text { Harr is }(73 / 9 ; 74 / 7 ; 74 / 11 ; 75 / 4 ; \\
75 / 5 ; 75 / 6 ; 75 / 8 ; 75 / 11 ; 76 / 4 ; \\
76 / 6 ; 76 / 7 ; 76 / 10 ; 76 / 12 ; 1977 ; \\
\text { 77/4;77/5;77/11;78/3;78/4; } \\
\text { 78/5;78/7;78/9;78/10;78/12; } \\
\text { 1979;79/2;79/3;79/4;79/4b; } \\
\text { 79/4c;79/5;79/6;79/7;79/10; } \\
\text { 79/11;79/12;80/1;80/11; } \\
\text { 80/12;81/5) }\end{array}$ & $\begin{array}{l}\text { Louis Harris and Associates, } \\
\text { Inc. }\end{array}$ & $1000-2088$ & $\begin{array}{l}\text { personal } \\
\text { and } \\
\text { telephone }\end{array}$ \\
\hline
\end{tabular}


APPENDIX A (cont.)

\begin{tabular}{|c|c|c|c|}
\hline SURVEY IDENTIF ICATION & SURVEY ORGANIZATION & $\begin{array}{l}\text { APPROXIMATE } \\
\text { SAMPLE SIZE }\end{array}$ & $\begin{array}{l}\text { RESPONSE } \\
\text { MODE }\end{array}$ \\
\hline \multicolumn{4}{|c|}{ NATIONAL SURVEYS (cont.) } \\
\hline NSF $(79 / 10)$ & National Science Foundation & 1635 & personal \\
\hline $\operatorname{NBC}(79 / 4)$ & NBC News/Associated Press & 1600 & telephone \\
\hline Newsweek $(81 / 6 ; 81 / 10)$ & Newsweek Magazine Poll & 745 & te lephone \\
\hline ORC $(74 / 11 ; 75 / 2 ; 75 / 4 ; 79 / 3)$ & Opinion Research Corporation & $600-2100$ & telephone \\
\hline Potomac $(72 / 6 ; 74 / 4 ; 76 / 5)$ & Potomac Institute & $\begin{array}{l}1806 ; 1865 ; \\
1071\end{array}$ & personal \\
\hline $\operatorname{RAC}(75 / 8 ; 76 / 8 ; 77 / 8 ; 78 / 8)$ & Response Analysis Corporation & 1000 & personal \\
\hline $\operatorname{RFF}(78 / 8 ; 80 / 1)$ & Resources for the Future & $1000 ; 1576$ & $\begin{array}{l}\text { telephone; } \\
\text { personal/ } \\
\text { telephone }\end{array}$ \\
\hline $\begin{array}{l}\text { Roper }(75 / 4 ; 75 / 8 ; 76 / 10 ; 76 / 11 \\
\quad 77 / 3 ; 77 / 9 ; 79 / 9)\end{array}$ & Roper Organization & 2000 & personal \\
\hline Seasonwe in $(79 / 9 ; 79 / 11 ; 80 / 2)$ & Roger Seasonwe in Associates & 1000 & telephone \\
\hline SERI $(80 / 11)$ & Solar Energy Research Institute & 2023 & personal \\
\hline SRL $(76 / 6)$ & $\begin{array}{l}\text { Survey Research Laboratory, } \\
\text { University of Illinois }\end{array}$ & 1400 & personal \\
\hline UM $(80 / 1 ; 80 / 4 ; 80 / 6 ; 80 / 9 ; 80 / 11)$ & $\begin{array}{l}\text { University of Michigan, } \\
\text { Institute for Social Research }\end{array}$ & 1008 & questionnaire \\
\hline YS\&W $(76 ; 77 ; 78)$ & $\begin{array}{l}\text { Yankelovich, Skelly, and } \\
\text { White, Inc. }\end{array}$ & 2500 & personal \\
\hline
\end{tabular}


APPENDIX A (cont.)

\begin{tabular}{|c|c|c|c|}
\hline SURVEY IDENTIF ICATION & SURVEY ORGANIZATION & $\begin{array}{l}\text { APPROXIMATE } \\
\text { SAMPLE SIZE }\end{array}$ & $\begin{array}{l}\text { RESPONSE } \\
\text { MODE }\end{array}$ \\
\hline \multicolumn{4}{|c|}{ STATE SURVEYS } \\
\hline \multicolumn{4}{|l|}{$\frac{\text { California }}{\text { State }}$} \\
\hline$\frac{\text { State }}{\text { Field }}($ CA 78/8) & The Field Institute & 1000 & personal \\
\hline \multicolumn{4}{|l|}{ Maine } \\
\hline$\frac{\text { State }}{\text { U. Maine (ME } 79 / 1 \text { ) }}$ & University of Maine Social Science & 600 & telephone \\
\hline Weekly (ME 80/5) & The Weekly & 63 & telephone \\
\hline \multicolumn{4}{|l|}{$\frac{\text { Massachusetts }}{\text { State }}$} \\
\hline Becker (MA 80/4;80/12;81/2) & Becker Research Corporation & 300 & telephone \\
\hline PARC (MA $79 / 2 ; 79 / 5)$ & $\begin{array}{l}\text { Public Affairs Research Center, } \\
\text { Clark University }\end{array}$ & 1000 & telephone \\
\hline WPI (MA 79/unk; 80/3) & Worcester Polytechnic Institute & 1004 & telephone \\
\hline $\begin{array}{l}\frac{\text { Site }}{\text { Becker }(P 1 \text { ymouth } 74 / 6 ; 76 / 3} \text {; } \\
\quad 77 / \text { unk; 79/6;80/4;80/8; } \\
\quad 80 / 11)\end{array}$ & Becker Research Corporation & 300 & telephone \\
\hline$\frac{\text { Missour i }}{\frac{\text { State }}{\text { FH }}(\text { Mo } 79 / 3 ; 79 / 8)}$ & Fleishman-Hillard, Inc. & 500 & telephone \\
\hline$\frac{\text { Site }}{F H}$ (Calloway $\left.79 / 11\right)$ & Fleishman-Hillard, Inc. & 400 & telephone \\
\hline
\end{tabular}


APPENDIX A (cont.)

\begin{tabular}{|c|c|c|c|}
\hline SURVEY IDENTIF ICATION & SURVEY ORGANIZATION & $\begin{array}{l}\text { APPROXIMATE } \\
\text { SAMPLE SIZE }\end{array}$ & $\begin{array}{l}\text { RESPONSE } \\
\text { MODE }\end{array}$ \\
\hline \multicolumn{4}{|c|}{ STATE SURVEYS (cont.) } \\
\hline \multicolumn{4}{|l|}{ New York } \\
\hline Harris (NY 78/2) & Louis Harris and Associates & 1000 & telephone \\
\hline \multicolumn{4}{|l|}{ Oregon } \\
\hline$\overline{B H}($ Trojan 79/4) & Bardsley and Haslacher & 609 & interview \\
\hline \multicolumn{4}{|l|}{ Pennsylvania } \\
\hline RAC (PA 78/8) & Response Analysis Corporation & 565 & personal \\
\hline$\frac{\text { Site }}{\text { TMI }}$ (Harrisburg 79/7) & Mountain West Research & 1500 & te lephone \\
\hline$\frac{\text { Rhode I sland }}{\frac{\text { State }}{\text { Becker (RI 78/6) }}}$ & Becker Research Corporation & - & - \\
\hline$\frac{\text { South Dakota }}{\frac{\text { State }}{\text { ambridae }}}$ & Cambridae Renorts Inc & 600 & telenhone \\
\hline \multicolumn{4}{|l|}{ Washington } \\
\hline$\frac{\text { State }}{\text { WASHPIRG (WA 78/12) }}$ & $\begin{array}{l}\text { Washington Public Interest } \\
\text { Research Group }\end{array}$ & 1002 & telephone \\
\hline \multicolumn{4}{|l|}{ Wiscons in } \\
\hline WSRL (WI 78/5;79/5) & $\begin{array}{l}\text { Wisconsin Survey Research } \\
\text { Laboratory }\end{array}$ & 650 & telephone \\
\hline
\end{tabular}




\section{APPENDIX B}

TABLE 1

CAMBRIDGE SURVEY DATA ON THE PERCENTAGE OF RESPONDENTS

WHO FAVORED, OPPOSED, OR WERE UNCERTAIN ABOUT

NUCLEAR POWER PLANT CONSTRUCTION

AND ON THE INDEX OF ACCEPTABILITY

\begin{tabular}{|c|c|c|c|c|}
\hline \multirow[b]{2}{*}{ Survey Date } & \multicolumn{3}{|c|}{ Attitude } & \multirow{2}{*}{$\begin{array}{c}\text { Index of } \\
\text { Acceptability }\end{array}$} \\
\hline & Favor & Oppose & Uncertain & \\
\hline $\begin{array}{l}(74 / 10) \\
(75 / 1) \\
(75 / 5) \\
(75 / 8) \\
(75 / 12) \\
(76 / 4) \\
(76 / 7) \\
(76 / 10) \\
(76 / 12) \\
(77 / 3) \\
(77 / 6) \\
(77 / 9) \\
(77 / 12) \\
(78 / 3) \\
(78 / 6) \\
(78 / 9) \\
(78 / 12) \\
(79 / 3)\end{array}$ & $\begin{array}{l}59 \\
54 \\
45 \\
48 \\
46 \\
47 \\
49 \\
48 \\
52 \\
51 \\
55 \\
58 \\
54 \\
49 \\
53 \\
52 \\
53 \\
50\end{array}$ & $\begin{array}{l}27 \\
30 \\
35 \\
30 \\
31 \\
34 \\
33 \\
31 \\
28 \\
30 \\
27 \\
27 \\
28 \\
30 \\
26 \\
29 \\
29 \\
32\end{array}$ & $\begin{array}{l}14 \\
16 \\
21 \\
22 \\
23 \\
19 \\
18 \\
21 \\
20 \\
19 \\
18 \\
16 \\
19 \\
21 \\
21 \\
20 \\
19 \\
18\end{array}$ & $\begin{array}{l}69 \\
64 \\
56 \\
62 \\
57 \\
58 \\
60 \\
61 \\
65 \\
63 \\
67 \\
68 \\
66 \\
62 \\
67 \\
64 \\
65 \\
61\end{array}$ \\
\hline \multicolumn{5}{|c|}{ Three Mile Island } \\
\hline $\begin{array}{l}(79 / 6) \\
(79 / 9) \\
(79 / 12) \\
(80 / 3) \\
(80 / 6) \\
(80 / 9) \\
(80 / 12) \\
(81 / 3) \\
(81 / 6)\end{array}$ & $\begin{array}{l}39 \\
46 \\
45 \\
41 \\
45 \\
49 \\
47 \\
46 \\
44\end{array}$ & $\begin{array}{l}44 \\
38 \\
40 \\
42 \\
39 \\
35 \\
37 \\
39 \\
42\end{array}$ & $\begin{array}{l}16 \\
16 \\
16 \\
17 \\
16 \\
16 \\
16 \\
16 \\
14\end{array}$ & $\begin{array}{l}47 \\
55 \\
53 \\
49 \\
54 \\
58 \\
56 \\
54 \\
51\end{array}$ \\
\hline
\end{tabular}

$a_{\text {Index of Acceptability }}=\frac{\text { favor }}{\text { favor }+ \text { oppose }} \times 100$

NOTE: "Do you favor or oppose the construction of more nuclear power plants?" (Cambridge) 
TABLE 2

HARRIS SURVEY DATA ON THE PERCENTAGE OF RESPONDENTS

WHO FAVORED, OPPOSED, OR WERE UNCERTAIN ABOUT

NUCLEAR POWER PLANT CONSTRUCTION AND

ON THE INDEX OF ACCEPTABILITY

\begin{tabular}{|c|c|c|c|c|}
\hline \multirow[b]{2}{*}{ Survey Date } & \multicolumn{3}{|c|}{ Attitude } & \multirow{2}{*}{$\begin{array}{c}\text { Index of } \\
\text { Acceptability }\end{array}$} \\
\hline & Favor & Oppose & Uncertain & \\
\hline $\begin{array}{l}(75 / 3) \\
(76 / 4) \\
(76 / 7) \\
(77 / 5) \\
(78 / 3) \\
(78 / 8)\end{array}$ & $\begin{array}{l}63 \\
44 \\
61 \\
59 \\
55 \\
57\end{array}$ & $\begin{array}{l}19 \\
35 \\
22 \\
25 \\
25 \\
31\end{array}$ & $\begin{array}{l}18 \\
21 \\
17 \\
16 \\
20 \\
12\end{array}$ & $\begin{array}{l}79 \\
56 \\
73 \\
70 \\
69 \\
65\end{array}$ \\
\hline \multicolumn{5}{|c|}{ Three Mile Island Accident } \\
\hline $\begin{array}{l}(79 / 4 a) \\
(79 / 4 b) \\
(79 / 4 c) \\
(79 / 5) \\
(79 / 8) \\
(79 / 9) \\
(79 / 11) \\
(79 / 12) \\
(80 / 1) \\
(80 / 4) \\
(80 / 6) \\
(80 / 9) \\
(80 / 71) \\
(81 / 1) \\
(81 / 3)\end{array}$ & $\begin{array}{l}52 \\
47 \\
44 \\
52 \\
56 \\
50 \\
42 \\
48 \\
57 \\
47 \\
50 \\
57 \\
47 \\
52 \\
47\end{array}$ & $\begin{array}{l}42 \\
45 \\
43 \\
42 \\
37 \\
40 \\
47 \\
40 \\
37 \\
46 \\
40 \\
40 \\
47 \\
39 \\
42\end{array}$ & $\begin{array}{r}6 \\
8 \\
13 \\
6 \\
8 \\
10 \\
11 \\
12 \\
12 \\
7 \\
10 \\
9 \\
6 \\
9 \\
12\end{array}$ & $\begin{array}{l}55 \\
51 \\
51 \\
55 \\
60 \\
56 \\
47 \\
55 \\
58 \\
51 \\
56 \\
56 \\
50 \\
57 \\
53\end{array}$ \\
\hline
\end{tabular}

$a_{\text {Index of Acceptability }}=\frac{\text { favor }}{\text { favor }+ \text { oppose }} \times 100$

Note: "In general, do you favor or oppose the building of more nuclear power plants in the United States?" (Harris) 
No. of

Copies

E. E. Anschutz, Director

DOE External Nuclear Affairs

Washington, D.C. 20585

W. Ballard, Jr.

DOE Office of Energy Programs

Washington, D.C. 20545

D. L. Bodde

Congressional Budget Office

Room 410-HA\#2

2nd \& D Streets, S.W.

Washington, D.C. 20515

A. A. Churm

DOE Chicago Patent Group

9880 South Cass Avenue

Argonne, IL 60439

W. K. Davis, Deputy Secretary

DOE

Washington, D.C. 20585

DOE Technical Information Center

P.0. Box 62

Oak Ridge, TN 37830

C. H. George

DOE Office of Waste Isolation

Washington, D.C. 20545

G. Graves

Los Alamos Scientific Laboratory

Los Alamos, NM 87544

J. P. Hamric

DOE Idaho Operations Office

550 Second Street

Idaho Falls, ID 83401

C. A. Heath

NUS

910 Clopper Road

Gaithersburg, MD 20878

D. Jackson

DOE Office of Public Affairs

Albuquerque Operations Office

Albuquerque, NM 87115
No. of

Copies

J. Jackson

Argonne Nationa 1 Laboratory

Argonne, IL 60439

R. Jefferson

Transportation Technology Center

Sandia National Laboratories

A1buquerque, NM 87102

E. A. Jordan

DOE Office of Waste Isolation

Washington, D.C. 20545

R. Laskiewicz

Argonne National Laboratory

Argonne, IL 60439

M. J. Lawrence

DOE Office of Transportation and Fuel Storage

Washington, D.C. 20545

R. L: Lowrey

Albuquerque Operations Office

A1buquerque, NM 87115

J. B. Martin

NRC Division of Fuel Cycle and Material Safety

Washington, D.C. 20555

E. F. Mastal

DOE Office of Resource Management and Planning

Washington, D.C. 20545

D. F. Miller

DOE Office of Public Affairs

Nevada Operations Office

Las Vegas, NV 89114

A. H. Morgan, Director

DOE Office of Public Affairs

Washington, D.C. 20585

R. L. Murray

Nuclear Engineering Department

North Carolina State University

Raleigh, NC 27650 
No. of

Copies

J. 0. Neff

DOE National Waste Terminal Storage Program Office

Columbus, $\mathrm{OH} 43201$

G. K. Oertel

DOE Office of Waste Operations and Technology

Washington, D.C. 20545

A. F. Perge

DOE Office of the Deputy Assistant Secretary for Nuclear Waste Management Washington, D.C. 20545

R. Pierre

Argonne National Laboratory

Argonne, IL 60439

J. Pomeroy

National Academy of Sciences

Washington, D.C. 20518

R. W. Ramsey, Jr. DOE Projects Staff

Washington, D.C. 20545

G. K. Shriver

DOE Office of Public Affairs

Washington, D.C. 20585

L. J. Smith

TRU Waste Systems Office

Rockey Flats Plant

Golden, CO 80401

J. P. Thereault, Director

DOE Plans and Evaluation Staff

Washington, D.C. 20585

S. L. Topp

Savannah River Laboratory

Aiken, SC 29801

V. G. Trice

DOE Office of Resource

Management and Planning

Washington, D.C. 20545
No. of

Copies

E. J. Wahlquist

DOE Office of Resource

Management and Planning

Washington, D.C. 20545

Office of Nuclear Waste Isolation

N. E. Carter

J. Finley

M. Kehnemuyi

D. L. Keller

J. M. Mounta in

B. A. Rawles

Richland Operations Office

3 Contract office

T. A. Bauman

P. A. Craig

R. B. Goranson

R. W. Newl in

H. E. Ransom

J. J. Schreiber

M. W. Shupe

F. R. Standerfer

Pacific Northwest Laboratory

5 Technical Files

2 Publishing Coordination

J. B. Burnham

T. D. Chikalla

D. E. Deonigi

M. R. Kreiter

J. M. Latkovich

R. C. Liikala

R. P. Marshall

D. E. Olesen

A. M. Platt

5 J. V. Robinson 